Sarah Dessì Schmid

Aspectuality 



\section{Sarah Dessì Schmid}

\section{Aspectuality}

An Onomasiological Model Applied to the Romance Languages

\section{DE GRUYTER}


ISBN 978-3-11-056207-1

e-ISBN (PDF) 978-3-11-056208-8

e-ISBN (EPUB) 978-3-11-056410-5

\section{(cc) BY-NC-ND}

This work is licensed under a Creative Commons Attribution-NonCommercial-NoDerivatives 4.0 International License. For details go to http://creativecommons.org/licenses/by-nc-nd/4.0/.

\section{Library of Congress Control Number: 2019947559}

\section{Bibliographic information published by the Deutsche Nationalbibliothek}

The Deutsche Nationalbibliothek lists this publication in the Deutsche Nationalbibliografie; detailed bibliographic data are available on the Internet at http://dnb.dnb.de.

(c) 2019 Sarah Dessì Schmid, published by Walter de Gruyter GmbH, Berlin/Boston This book is published with open access at www.degruyter.com

Cover image: Andyworks/iStock/gettyimages Typesetting: Integra Software Services Pvt. Ltd. Printing and binding: $\mathrm{CPI}$ books $\mathrm{GmbH}$, Leck

www.degruyter.com 


\section{Preface to English Edition}

This is the English translation of the book Aspektualität, which was published in 2014 in the Journal of Romance Philology's series of supplements (Beihefte zur Zeitschrift für romanische Philologie) by De Gruyter publishers. Except for minor corrections, the German text has been retained unchanged.

I would like to take this opportunity to thank all the people who contributed in many ways to the English version of this book and without whose support it would not have been possible.

The idea for an English translation came from Lia and Daniel, when I hadn't even thought of it. Daniel encouraged me in this undertaking in every possible way. My heartfelt thanks to both of them. I would like to thank Sam Featherston, Neil Huggett, Andrew Duane and - especially - Tessa Say very warmly for their mother-tongue competence, as well as the long phone calls, rich in linguistic content and empathic laughter. My deepest gratitude goes to Reinhild Steinberg - who loves language games as much as I do - for her generous and highly competent help as well as for her precious friendship in preparing the English manuscript in all its phases up to its publication. I am greatly indebted to De Gruyter publishers - especially to Ulrike Krauss, Christine Henschel and Gabrielle Cornefert - for their unfailing kindness and patience and their experienced support throughout this project.

Tübingen, July 2019 



\section{Preface}

This book is a slightly revised version of my Habilitation (post-doctoral) thesis which was successfully presented in June 2012 to the Faculty of Humanities of the University of Tübingen, and then to the University of Stuttgart in February 2013.

The core of the research is the presentation of a new theoretical model for classifying and interpreting the aspectual contents of states of affairs. In this book, I develop a set of descriptive and analytical tools at the conceptual level, which may be applied crosslinguistically and are therefore suitable for language comparison, but nevertheless may also be used for detailed analyses of specific phenomena in individual languages. In retrospect, I recognise in this a recurring - more or less conscious - motivation in my research, namely, the wish to combine the different thematic domains in which I work and the passions that drive me: grammar and semantics, linguistics and language philosophy.

As with any work of this sort, I have travelled a long way, but not alone. I would like to take this opportunity to thank all those who have accompanied me on this journey and have contributed in many ways to the making of this book.

First of all, I would like to thank Peter Koch with all my heart. Always with the right questions at the right time, he has accompanied the process from conception to completion of the book with tireless enthusiasm and his typically respectful and constructively critical nature. I am especially grateful to him for sharing his human and intellectual greatness with me and for his generosity in past years and now once again on a daily basis. I would also like to affectionately thank Achim Stein, who gave me wonderful years in Stuttgart and opened up new horizons. He not only showed me new ways and perspectives in research as well as in the university realm, but also continuously supported my project with many helpful suggestions, not least by granting me the freedom needed to pursue it. I cannot be grateful enough for that. My sincere thanks also go to Johannes Kabatek and Tilman Berger not just for their willingness to take on additional reviews of my work, but also for important advice, remarks and helpful criticism, which have unquestionably contributed to the development of this book. I would also like to thank them for their special sense of humour that often filled our discussions with gaiety.

For valuable suggestions, bibliographic references, attentive and constructively critical reading of the text, and last but not least encouraging words of friendship, I owe thanks to those dear friends who are an example and a help to me every day: Heidi Aschenberg, Andrea Fausel and Daniela Marzo. 
Many colleagues and friends, not only of the institutes of Romance and Slavic languages and literature in Tübingen, Stuttgart and all of Germany, with whom I was able to discuss aspectuality on numerous occasions, have substantially contributed to the development of this book in its various phases. They have listened, commented and shared fruitful discussions with me, provided valuable bibliographical references, offered to present and discuss my project in front of an audience while it was still in the making, offered their expertise as native speakers, helped me deal with the flood of work from other areas and given me much-needed support with their friendship and affection. I can acknowledge here only a few of these people, but those who are not mentioned are by no means forgotten - my sincere gratitude goes to them all: Tanja Anstatt, Vahram Atayan, Asencion Bailen, Gabriele Beck-Busse, Martin Becker, Christine Blauth-Henke and her daughter Julia, Klaus Böckle, Daniel Bunčić, Giuseppe Burgio, Eva Erdmann-Schwarze, Ljudmila Geist, Paul Gévaudan, Jochen Hafner, Antonio Junco, Wiltrud Mihatsch, Carla Miotto, Rosina Nogales, Daniela Pirazzini, Nicoletta Rivetto, Marie-Rose Schoppmann, Stefan Schreckenberg, Maria Selig, Reinhild Steinberg, Liane Ströbel, Carola Trips, Eva Varga, Chrisoula Vernarli, Valentina Vincis, Richard Waltereit and all the other participants in the Tübingen colloquia on Wednesday evenings, as well as all the other colleagues and friends at the Institute of Linguistics/ Romance Studies of the University of Stuttgart and the Institute of Romance Languages and Literature of the University of Tübingen.

I would like to thank Andrea Fausel, Annika Franz, Jürgen Freudl, Lara Schleyer, Daniel Schmid and Martin Sinn for their efficiency, precision and patience in proofreading, even under great pressure of time at various stages of the work. Additional thanks go to Daniel Schmid for drawing the figures and images.

I am especially indebted to Claudia Polzin-Haumann, Günter Holtus and Wolfgang Schweickard for including my work in the Journal of Romance Philology's series of supplements (Beihefte zur Zeitschrift für romanische Philologie), as well as to the publishers De Gruyter - especially to Ulrike Krauss and Christine Henschel - for their always exceptionally friendly and competent support through the various difficulties which tend to arise on the path to publication of a long project.

The privilege of working in a discipline where the boundaries between work and private life are not necessarily clear-cut means that many of the friends I would like to thank have already been mentioned above. Once again, and a little more privately, I would like to extend special thanks to them and to all my other friends and my family for their patience and their readiness to 
support me - especially my dear parents, as well as my siblings, whether by birth or by affection: Alessandra and Alessandro, Luca and Daniela.

To my husband Daniel - without whom this book would not have been possible - and to my son Leonhard I owe thanks for unlimited support and constant encouragement, and for loving distraction and cheeky laughter at work-intensive moments. Certainly, this was not always easy for them, but they have shared the load and accompanied me with rarely finite patience, even as far as the examples that appear in this book. I owe all this and much more to them - the sounds and images of my verbal and nonverbal world.

Tübingen, June 2014

A few days after this preface was written my dear and beloved teacher and friend Peter Koch died unexpectedly. He had been looking forward to the publication of this book with joy and pride, as he always enjoyed the successes of people who were close to him as if they were his own. We had forged many plans for the next few years and were very happy about our cherished academic exchanges and close personal contact which we re-established in October last year. I painfully miss his laughter and his wisdom, and our many conversations, which neither of us could ever keep short, every day - and every day more.

Tübingen, July 2014 



\section{Contents}

\section{Preface to English Edition — V}

Preface - VII

Introduction -1

1 The Temporal Structuring of States of Affairs - Tense, Aspect and Aktionsart - 9

1.1 Introductory remarks - 9

1.2 Tense, aspect and Aktionsart - traditional definitions - $\mathbf{1 0}$

1.2.1 Tense - a grammatical, deictic category - 10

1.2.2 Aspect - a grammatical, non-deictic category - 14

1.2.3 A terminological-definitional remark -19

1.2.4 Aktionsart - a lexical category - 21

1.3 On the relation between tense, aspect and Aktionsart - three theoretical approaches - $\mathbf{2 6}$

1.3.1 Bertinetto's interpretation of tense, aspect and Aktionsart - 27

1.3.2 Temporal relations and tenses according to Rojo and Veiga - 31

1.3.3 The Romance verbal system according to Coseriu - 33

1.4 Delimitation problems with the traditional verbal categories aspect vs. tense vs. Aktionsart - 36

2 The Aspectual Domain - 39

2.1 Introductory remarks - 39

2.2 Aspectuality - onomasiology and content categories - 39

2.3 Onomasiological approaches to aspectuality - $\mathbf{4 5}$

2.3.1 Aspectuality in Romance linguistics - De Miguel's concept -45

2.3.2 The two components of the aspectual domain - Smith's approach -48

$2.4 \quad$ Bidimensional vs. unidimensional approaches to aspectuality -49

2.4.1 Aspect and Aktionsart - two categories? - $\mathbf{5 0}$

2.4.2 Grammaticality vs. Lexicality, Obligatoriness vs. Optionality, Subjectivity vs. Objectivity $-\mathbf{5 3}$

$2.5 \quad$ Limits of unidimensional approaches? -62 
3 Aspectuality as a Complex, Semantic, Universal Category. Theoretical and Methodological Foundations - 65

$3.1 \quad$ Introductory remarks -65

3.2 Aspectuality and frames - 69

3.2.1 Aspectuality and the levels of language -69

3.2.2 Frames as basic structures of the categorisation of reality -72

3.2.3 Contiguity and the figure-ground effect -74

3.2.4 Areas where the notion of frame can be applied -78

3.2.5 Aspectuality and situation frames - a first definition - $\mathbf{8 0}$

3.3 Semanticity - abolishing the semantic distinction between aspect and Aktionsart $-\mathbf{8 2}$

3.4 Universality - cognition and the crosslinguistic perspective $-\mathbf{8 5}$

3.5 Complexity - the structuredness of the category and the interplay in the sentence - $\mathbf{8 8}$

3.6 Summary and a first interim conclusion $-\mathbf{1 0 0}$

4 The Model of Aspectuality as an Internal Temporal Structuring of States of Affairs - 103

4.1 Introductory remarks - 103

4.2 Aspectual situation frames -104

4.3 The delimitation principle - 106

4.4 The three dimensions of aspectuality — 111

4.4.1 External, adjacency-related and internal aspectuality - 111

4.4.2 Realisations of the three dimensions of aspectuality - 115

4.4.3 External aspectuality - delimitation of a state of affairs - 117

4.4.4 Adjacency-related aspectuality - adjacency relevance of the state of affairs -127

4.4.5 Internal aspectuality - subdivision of the state of affairs - 134

4.5 A second interim conclusion -139

5 Combinations of the Dimensions of Aspectuality in the Situation

Frame: the First Level of the Model Applied — 141

$5.1 \quad$ Introductory remarks - 141

5.2 Aspectual delimitation schemas - 141

5.2.1 A comprehensive inventory of delimitation schemas -141

5.2.2 Presentation of the individual delimitation schemas $-\mathbf{1 4 5}$

5.3 A third interim conclusion -166 
6 The Second Level of the Aspectuality Model Applied - 169

6.1 Introductory remarks -169

6.2 Aspectual delimitation schemas of the second level of the model 170

6.2.1 An inventory of the delimitation schemas of the second level -170

6.2.2 Presentation of the individual delimitation schemas -173

6.3 (Aspectual) periphrastic verbal constructions - 202

6.3.1 The relevance of the phenomenon and problems of definition 203

6.3.2 A flexible definition $-\mathbf{2 1 2}$

6.3.3 STARE + gerund - a semasiological parenthesis - 215

6.3.4 "Aspectual-grammatical" and "actional" verbal periphrases? - $\mathbf{2 2 7}$

6.4 Verbal periphrases - a last interim conclusion $-\mathbf{2 2 9}$

$7 \quad$ Closing Remarks -231

Abbreviations -237

References — 241

Author Index -267 



\section{Introduction}

Is it really possible to speak of aspect in the Romance languages? Is the Romance verbal system not to be interpreted as fundamentally temporal?

These questions - which can still be heard occasionally - arise, on the one hand, from the history of the definition of the category of aspect itself, and, on the other hand, from an old misconception connected with it, which has not yet been conclusively overcome, as the category was based on studies of Slavic languages, which have a complex, grammatically expressed aspect system that is manifested on various temporal levels. ${ }^{1}$ This determined the general direction of traditional research on verbal aspect, which then went on to look at other languages, mainly individually (considering only one language in each case) and from a semasiological point of view.

If it is therefore not surprising that research on aspect par excellence is localised in Slavic linguistics, we must correct the misconception that has arisen from it, which is that, in principle, if the category "aspect" exists in the Romance languages it can only be in the exact same form in which it appears in the Slavic languages. It follows from this that, in this very special form as a language-particular verbal category, aspect is not actually present in the Romance languages, but instead aspectual oppositions are found in grammaticalised form only on the past temporal level. However, what the Romance languages do indeed have is a multitude of other possibilities for communicating the aspectual contents that are grammatically expressed in the Slavic languages.

In Romance linguistics, the Romance verbal system has mainly been conceived of as being temporally based ${ }^{2}$ so that little attention has been paid to the exploration of aspect. ${ }^{3}$ When it has been explored, it has often been only indirectly: aspect has not been given its own definition but has instead been defined in opposition to "Aktionsart" or "tense". A better demarcation should be provided, but the implication is that the boundaries of the category thus defined cannot be drawn sufficiently clearly.

Over the past thirty years, there has been growing interest in aspect, not so much in traditional Romance research but rather in typological studies. Here, there has been intensive and increasing concern with the combination of those

1 On the history of "aspect" and “Aktionsart" and determination of the terminology see §1.2.3.

2 See, among others, the interpretation of the Spanish verbal system by Rojo/Veiga (1999) and that of Weinrich (1964) (which is valid not only for the Romance languages); on this topic in general see $§ 1.3$.

3 See, e.g., Bertinetto (1986).

Ә Open Access. (C) 2019 Sarah Dessì Schmid, published by De Gruyter. (cc) BY-NC-ND This work is licensed under a Creative Commons Attribution-NonCommercial-NoDerivatives 4.0 International License.

https://doi.org/10.1515/9783110562088-001 
grammatical verbal categories that are often realised by morphological syncretism in many of the world's languages, the so-called TMA categories: tense, mode and aspect. Emphasis has repeatedly been laid on tense and aspect as systems complementary to the temporal categorisation and structuring of states of affairs, stressing their close connection. ${ }^{4}$ Meanwhile, studies of the lexically expressed category of Aktionsart, related to aspect in terms of content, became more frequent and more precise. The question, in particular, of the semantic similarity between these two categories has been repeatedly discussed and investigated. In research on aspect, this has raised various questions that have opened up new avenues of investigation.

An important point here is that the verb shouldn't be considered in isolation: it has proved difficult to maintain "simple" verbal classifications - such as, for example, Vendler's (1957) classic classification - in the study of aspectual categories, ${ }^{5}$ i.e., to treat verbs independently of their argument structure. In pointing to the role of the valency of the verb, the aspectual interpretation of a state of affairs has been attributed to the lexical-grammatical level, that is, the morphosyntactic complex formed by the verb and its arguments. ${ }^{6}$

A second important point concerns the now widespread opinion that the information related to aspect has clear semantic similarities and connections among the world's languages, and exhibits more or less evident regularities, even though it is formally expressed very differently and concerns different linguistic levels. ${ }^{7}$ Increasing emphasis has, therefore, been placed on the fact that several meanings of aspect are to be distinguished, of which the grammatical verbal category represents only one. ${ }^{8}$ The limits of semasiological approaches have become

4 Often they are referred to as "temporal-aspectual” systems; see, e.g., Bertinetto (1997).

5 From this perspective, this also includes Aktionsart, as its semantic contents are similar to those of aspect.

6 Verkuyl (1972) was one of the first to indicate the relevance of the interdependence of the verb and its arguments in analysing aspectual information.

7 See, among others, the works (differing substantially in their approaches) by Alturo (1997 and 1999), Bache (1982, 1995a and 1995b), Beck (1987), Bertinetto (1996), Binnick (1991 and 2012), Bybee (1985), Bybee/Dahl (1989), Bybee/Perkins/Pagliuca (1994), Comrie (1976), Croft (2012), Dahl (1985, 1989 and 2000), De Miguel (1999), de Swart (1998 and 2000), Fauconnier (1984 and 1999), Giorgi/Pianesi (1997), Goldberg (1995 and 2006), Guillaume (1929), Herweg (1990), Hopper (1979 and 1982a), Jackendoff (1991a and 1991b), Kamp/Reyle (1993), Krifka (1989a and 1989b), Langacker (1987, 1990 and 1991), Leiss (2000), Mitko (2000), Smith (1991), Tenny (1989 and 1994), Thieroff/Ballweg (1994-1995), Verkuyl (1972 and 1993), Vet/Vetters (1994).

8 On the polysemy of the term “aspect” see Comrie (1976) and especially Sasse (1991 and 2002). 
clear, particularly in typological research, which takes a crosslinguistic perspective, and the absence of a suitable basis for language comparison, a tertium comparationis, has been painfully felt. More attention has been given - also in Cognitive Linguistics - to the possible existence of a functional category comprising both aspect and Aktionsart: aspectuality, ${ }^{9}$ which is now being approached onomasiologically. This is an abstract content category, which is considered to have crosslinguistic or even universal validity and which subsumes the various not only grammatical - possibilities of reproducing contents related to the traditional notion of aspect in the individual languages. In this sense, "aspectuality" is defined as a general aspectual domain, as the content category by which speakers linguistically structure the nature of the development and distribution of a state of affairs in time. ${ }^{10}$

A delicate problem, however, which has not yet been solved, divides aspectologists into two camps. ${ }^{11}$ Being discussed here is the homogeneity or heterogeneity of the semantics of the aspectual area. Bidimensional approaches conceive aspect and Aktionsart as strictly separate categories, as semantically different components of the general aspectual domain within which a substantial division is asserted. Unidimensional approaches, on the other hand, assume no semantic distinction on the cognitive level between the two categories and therefore also no division within aspectuality. In this sense, aspect and Aktionsart represent only different formal realisations of one and the same content category. The majority of approaches adopt the bidimensionalist premise, especially in the majority of Romance investigations, although various important contributions to the research also build on the unidimensionalist postulate.

Regardless of the positions presented in this discussion, however, one thing remains indisputable: if we ask by which linguistic means aspectual contents are expressed, and if we do not proceed from a comparison of similar forms of expression in the different languages, we can adopt a perspective that defines a suitable tertium comparationis on a conceptual level and thus allows for a comparative approach.

9 On the history of the term "aspectuality" see §2.2.

10 In the German version of this book, the adjective "aspektual" is used in reference to aspectuality as a (crosslinguistic) content category and the adjective "aspektuell" with regards to aspect as a grammatical category (inflection). In the English version, I use "aspectual" with reference to aspectuality and "aspectual-grammatical" with regards to the grammatical category.

11 See Sasse (2002) and Squartini (1990). 
In cognitive-linguistic research this onomasiological perspective is flanked by a new conception of lexicon and grammar: lexical and grammatical linguistic elements represent poles with the space between them conceived as a continuum.

The present work continues the current discussion. From an onomasiological point of view, it will deal specifically with the pieces of information which, in their interplay, constitute the aspectual value of states of affairs. The object of this study is therefore the identification, delimitation and theoretical analysis of the content category of aspectuality as such, as well as its manifestations in different Romance languages.

Given the above, in this book I develop a unidimensional model for the description and classification of aspectual information, which, in accordance with the chosen onomasiological perspective, is situated on a very general linguistic level and is structured by a principle based on a fundamental human cognitive ability: the delimitation principle. The resulting crosslinguistic model of aspectuality - hence also called "aspectual delimitation" - is then applied to specific examples from Catalan, French, Italian and Spanish and its efficiency tested in the individual languages.

Like other content categories - modality or temporality - aspectuality is based on universal cognitive abilities, with the help of which humans perceive and constitute their world. These basic human abilities include primary mental operations, such as the recognition of recurring features, the grouping of contents that are similar or opposing or contiguous into larger relationship patterns, or the division of complex scenarios into simpler, clearly delineated, smaller units, the creation of figure-ground schemas, and the production of hierarchical conceptual relations and structures. ${ }^{12}$ Some of these operations are explained on these pages, for which a frame-theoretical interpretation is also chosen from the various available frameworks. ${ }^{13}$ This choice is motivated in the first place by a very general decision: it is assumed that our perception and categorisation capacity perceives concepts, subconcepts and categories in relation to each other and stores them as such in memory. Frames represent such perceptual or conceptual gestalts, such structures of the human conceptual organisation of reality. ${ }^{14}$ If a case is then made in detail for a frame-based interpretation of aspectuality, this is done in a particular way, since aspectuality frames are very abstract and stand

12 In general, on Gestalt laws and association principles see Herrmann (1976) and Metzger (1986); see also Blank (2001, 43), Croft/Cruse (2004) and Koch (1999a), among others.

13 See, among others, Fillmore (1975, 1977 and 1985), Minsky (1975) and Schank/Abelson (1977).

14 This is based on the models of description and interpretation developed in Gestalt theory; see the following section. 
for whole classes of frames. ${ }^{15}$ But the investigation also builds a bridge to a more classical theoretical linguistic line whose theoretical proximity to some of the most modern reflections of cognitive orientation is rarely emphasised: the theories of Humboldt, Cassirer, Wittgenstein, etc.

Aspectuality is understood here as a complex category because its complete realisation, its "definitive" form, results from the combination of its three perspectives: it is thus complex at the level of the onomasiological foundation, the structuring of the category as such. On the other hand, this content category is complexly expressed in different languages by the interplay of the various elements which represent the respective states of affairs in actual sentences. These elements can be found on all organisational levels of language, from the typically lexical to the typically grammatical: components of verb meanings, verb arguments, tenses, adverbs, negations, word order, etc.

The various realisations of aspectuality in all their language-particular forms in the Romance languages show an enormous diversity. Since neither a complete presentation is attempted here nor are examples to be cited indiscriminately, a clear focus is set. The core of the work - which is to be understood as a synchronic Romance investigation - is the representation of a new unidimensional theoretical model based on the principle of delimitation, which can be applied in principle to any language. On the basis of the model, which also allows for a differentiated view of complex problems that have so far been difficult to classify, such as that of verbal periphrases, the aspectual systems of Catalan, French, Italian and Spanish are studied comparatively. Some insights into the diachrony of the Romance languages and possible fields of application of the model round off the investigation.

The structure of the book is as follows:

Chapter 1 is devoted to the presentation of the categories of tense, aspect and Aktionsart by means of approaches that can be considered classic. By way of example, various works that are representative of the Romance tradition are then presented and discussed: Bertinetto (1986), Rojo and Veiga (1999) and Coseriu (1976). This paves the way for discussion of the problems regarding demarcation of the traditionally conceived categories of tense, aspect and Aktionsart.

Chapter 2 deals with aspectuality from an onomasiological perspective as a universal semantic category. The comparison of aspectuality with modality, the latter being more frequently discussed in the Romance tradition, is intended to further clarify what precisely is meant by "content category". A selection of various onomasiologically oriented studies is then presented, two of which will be

15 For a similar approach see Talmy (2000). 
discussed in more detail, namely Smith (1991) and De Miguel (1999). The focus will be on the question of how aspectuality (or the aspectual domain) is conceived. For, as already pointed out, two main lines constitute the field of aspect research, divided according to whether a substantial separation of aspect and Aktionsart within the general aspectual domain is advocated or is rejected: the bidimensional and the unidimensional approaches. In the last part of the chapter, the arguments put forward by the two camps in support of their theses are critically examined. Subsequently, the position adopted in this work - a unidimensional approach - is situated with reference to this critical discussion.

In Chapter 3, a further theoretical premise for the model of aspectuality developed here is presented, which explains in what sense and for what reason a frame-based approach is advocated. Frames are defined as basic structures of the human categorisation of reality, while states of affairs are described as situation frames. In particular, the relationship between states of affairs conceived as situation frames and aspectuality is examined in greater detail. An explanation of the definition of aspectuality as a semantic, universal and complex category concludes the chapter.

In Chapter 4, the model developed here is described. Presented first is the principle underlying the description and classification of the aspectual content used in this study: the delimitation principle, which is based on universal human cognitive abilities. On this basis, aspectuality is defined as aspectual delimitation, the setting of temporal boundaries in the structuring of states of affairs, and has three dimensions - the external, the adjacency-related and the internal delimitation. All "aspectual basic conceptualisations", i.e., all possible realisations of the three perspectives of aspectuality, are presented in detail. Within a given state of affairs they necessarily occur in combination with one another.

Chapters 5 and 6 present a complete inventory of the possible combinations of aspectual basic conceptualisations in states of affairs and a further explanation of the model's system. The possible combinations are represented by delimitation schemas, which also visually represent the composition of the various realisations of aspectuality. With a multitude of examples, these chapters also illustrate the application of the model to the Romance languages (here Catalan, French, Italian and Spanish) and reveal the similarities and differences in their aspect systems. Chapter 5 analyses a first level of the model, the combination of the basic conceptualisations, while Chapter 6 deals with a second level, which is also concerned with the study of a classical phenomenon that is central to the Romance languages and downright classical in Romance linguistics, i.e., that of aspectual verbal periphrases. This allows for a new analysis of the phenomenon and provides a possible answer to the question as to which 
common denominator connects all the aspectual verbal periphrases and which aspectual categories they are to be assigned to.

In some concluding remarks, the central findings are summarised, an outlook on some possible areas of application of the model is given, and the question of its relevance and usefulness for current research on aspectuality is discussed. 



\title{
1 The Temporal Structuring of States of Affairs - Tense, Aspect and Aktionsart
}

\subsection{Introductory remarks}

\begin{abstract}
It has become commonplace to introduce works on aspect with the remark that there is hardly another field in linguistics so much plagued by terminological and notional confusion. The semantics of time has served as a playground for mental exercise to many generations of philologists, linguists, philosophers, and logicians, resulting in an impenetrable thicket of definitions, theories, and models. (Sasse 2002, 199)
\end{abstract}

It is not easy to resist the temptation to deal with time, which is one of the fundamental categories of human cognition and one of the most important structuring principles of our individual as well as social life. It is therefore not surprising that generations of physicists, philosophers, historians, logicians, literati and linguists have yielded to this urge. It is in concession to this fact, indicated in the quote above, that I begin this work and enter the fascinating "impenetrable" terminological thicket.

A distinction is to be made between, on the one hand, physically or publicly and psychically or personally constructed time, which can be conceived of as objectively measurable and subjectively perceivable, and, on the other hand, time in language, in other words, the linguistic representation of temporal conditions. These conditions are represented by various means - both lexical and grammatical - in every language at different organisational levels, both morphological and syntactic. This includes the verbal categories "tense", "aspect" and "Aktionsart".

In this chapter, the traditional definitions of tense, aspect and Aktionsart are given as verbal categories by which individual languages provide information about the temporal structuring of states of affairs. Each of these categories is presented by means of various hermeneutic models, which are important not just for the Romance languages. The brief overview of the current state of research that I give here is - for a number of reasons - only very selective and regards the specific topics of this book. On the one hand, a more detailed historiographical account of these models is beyond the scope of this study and contradicts its approach. On the other hand, an exhaustive treatment of the literature devoted to the categories of the verbal system in recent decades would in itself constitute an endeavour doomed to failure: in his bibliographical project, The Project on Annotated Bibliography of Contemporary Research in Tense, Grammatical Aspect, Aktionsart, and Related Areas, Binnick counts no less than 9,000 titles - and the 
last update of the bibliography was in 2006. The chapter will close with a brief discussion of the delimitation problems of the traditionally perceived categories of tense, aspect and Aktionsart, which will form a bridge to the following chapter.

\subsection{Tense, aspect and Aktionsart - traditional definitions}

\subsubsection{Tense - a grammatical, deictic category}

Let us consider the following examples: ${ }^{1}$
(1a) It.
Leo mangia [Pres.] un cornetto al cioccolato.
(1b) Fr.
Léo mange [Prés.] un croissant au chocolat.
(1c) Sp.
Leo come [Pres.] un cruasán con chocolate.
(1d) Ger.
Leo isst [Präs.] ein Schokocroissant.
'Leo eats a chocolate croissant.'

(2a) It.
(2b) Fr.
(2c) Sp.
(2d) Ger.

Leo mangiò [Perf. Sem.] un cornetto al cioccolato.

Léo mangea [Pass. Sim.] un croissant au chocolat.

Leo comió [Perf. Sim.] un cruasán con chocolate.

Leo aß [Prät.] ein Schokocroissant.

'Leo ate a chocolate croissant.'

(3a) It. Leo mangiava [Imp.] un cornetto al cioccolato.

(3b) Fr. Léo mangeait [Imp.] un croissant au chocolat.

(3c) Sp. Leo comía [Imp.] un cruasán con chocolate.

(3d) Ger. (= 2d) Leo aß [Prät.] ein Schokocroissant.

'Leo was eating a chocolate croissant.'

(4a) It. Leo mangerà [Fut.] un cornetto al cioccolato.

(4b) Fr. Léo mangera [Fut.] un croissant au chocolat.

(4c) Sp. Leo comerá [Fut.] un cruasán con chocolate.

(4d) Ger. $\quad$ Leo wird [Fut.] ein Schokocroissant essen.

'Leo will eat a chocolate croissant.'

1 Here, examples from the Romance languages analysed (and, where useful, also from German and English) are usually cited in parallel to allow for a first-glance comparison of the languages. The tense markings are indicated in square brackets within the examples themselves; special periphrastic constructions are also noted in square brackets at the end of the respective examples. A list of abbreviations can be found at the end of the book. 
The verbal inflectional forms in sentences (1a-d), (2a-d) and (4a-d), It. mangia/ mangiò/mangerà, Fr. mange/mangea/mangera, Sp. come/comió/comerá and Ger. isst/aß/wird essen, express grammatically information conveying the present, past or future determination of the states of affairs, in other words, information that presents the states of affairs as simultaneous with, or previous or subsequent to the moment of the utterance. We are therefore dealing with forms which, via morphemes (or an alternation in the root vowel, such as in Ger. $a \beta$, or periphrastic solutions, such as wird essen from werden + infinitive), express the temporal determination of the states of affairs.

Since Reichenbach (1947) - as well as in large parts of the current research on time and tense $\mathrm{e}^{2}$ - tense has been defined as the grammaticalised location of states of affairs in time, ${ }^{3}$ hence as a deictic grammatical category which expresses the system of temporal relations of states of affairs on the verb by morphological means, i.e., by inflection:

Tense is a deictic category, i.e. it locates situations in time, usually with reference to the present moment, though also with reference to other situations. (Comrie 1976, 3)

It owes its classic representation to Reichenbach's model, that is, as an ideal time line moving from left to right $(\mathrm{t}=$ time), on which states of affairs can be located via the relation between three points of reference: the point of speech $(\mathrm{S})$, the point of the event $(\mathrm{E})$ and the point of reference $(\mathrm{R})$, the latter only becoming necessary in the location of more complex states of affairs, which are usually expressed via compound tenses. ${ }^{4}$ Thus, through the relations of simultaneity,

2 An exception is the work of Weinrich (1964), who advocates an interpretation of tense as an expression of the "language stances" (Sprachhaltungen) "tension" and "relaxation" (Gespanntheit and Entspanntheit). He links "tension" to "discussing tenses", and "relaxation" to "narrative tenses" (besprechende and erzählende Tempora). The former, according to Weinrich, include Present, Perfect, Future I and Future II, the latter Past, Past Perfect, Conditional I and Conditional II. As a general introduction to time linguistics see, among others, Vater (1994) and Bonomi/Zucchi (2001).

3 Of course, languages also have other - lexical and non-grammatical - means to express temporal-deictic (i.e., speech- and event-related) content, such as temporal adverbs. However, Reichenbach focusses his investigation on tense: "The tenses determine time with reference to the time point of the act of speech, i.e., of the token uttered." (1947, 287f.).

4 Examples (1a-d), (2a-d), (3a-d) and (4a-d) illustrate the "absolute tenses" (see Reichenbach 1947, Comrie 1976), which require only two of the above-mentioned reference points for their definition, i.e., $\mathrm{S}$ and $\mathrm{E}$. R only becomes relevant for the definition of "relative tenses". For criticism of Reichenbach's conception of R, see, among others, Comrie (1981) and Bertinetto (1986); the latter modifies Reichenbach's model with the introduction of a momento d'ancoraggio temporale (moment of temporal anchorage) and a localizzatore temporale (temporal localiser) as a replacement and a further specification of R (see §1.3.1). See also the more radical critique by Klein (1994), who sees the 
anteriority and posteriority a state of affairs is located as simultaneous with, or previous or subsequent to the point of speech. Examples (1b), (2c) and (4d) can be illustrated as follows: ${ }^{5}$

(1b) Fr.

Léo mange [Prés.] un croissant au chocolat.

'Leo eats a chocolate croissant.'

E, S

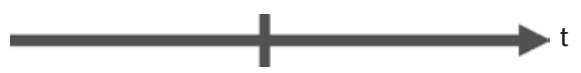

Fig. 1: Temporal relation of the present.

(2c) Sp. Leo comió [Perf. Sim.] un cruasán con chocolate.

'Leo ate a chocolate croissant.'

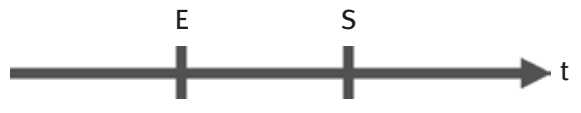

Fig. 2: Temporal relation of the past.

(4d) Ger. Leo wird ein Schokocroissant essen [Fut.]. [werden + Inf.] 'Leo will eat a chocolate croissant.'

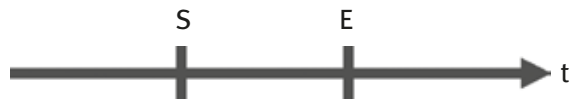

Fig. 3: Temporal relation of the future.

big problem as being that $\mathrm{R}$ does not serve to deictically locate $\mathrm{E}$, but mainly to anaphorically locate it in relation to other states of affairs. In Klein's opinion, this problem is typical of the punctual interpretation of time and can be better solved with the introduction of another parameter, Topic Time (TT), which does not refer to the temporal location of the event, as such, but to "the time span to which the speaker's claim on this occasion is confined" (Klein 1994, 4).

The problem of $\mathrm{R}$ also involves the need to distinguish the deictic location of a state of affairs relative to $\mathrm{S}$ from the anaphoric location of that moment in relation to other events (cf. absolute temporal location (present, past, future) vs. relative temporal location (simultaneity, anteriority, posteriority)).

5 See Reichenbach (1947), especially 296ff., for a schematic representation of the possible combinations using the verb forms of English. 
The simple or compound ${ }^{6}$ tenses are language-particular forms of the grammatical category tense, in other words, concrete realisations of it, which are subdivided and referred to differently in each language. Some from the Romance languages analysed here are presented in examples (1a-d)-(4a-d). Table (1) presents an overview of the tenses in the indicative mode (the left column shows the various temporal levels, the middle and the right columns, respectively, the simple and compound tense forms that express the different temporal dimensions). ${ }^{7}$

Tab. 1: Indicative tenses in Italian, French, Spanish and Catalan.

\begin{tabular}{|c|c|c|}
\hline & Simple tenses & Compound tenses \\
\hline \multirow[t]{4}{*}{ Present } & It. Presente (mangia) & It. Perfetto Semplice (ha mangiato) \\
\hline & Fr. Présent (il mange) & Fr. Passé Composé (il a mangé) \\
\hline & Sp. Presente (come) & Sp. Pretérito Perfecto Compuesto (ha comido) \\
\hline & Cat. Present (menja) & Cat. Pretérit Indefinit (ha menjat) \\
\hline \multirow[t]{8}{*}{ Past } & It. Perfetto Semplice (mangiò) & It. Trapassato/Piucheperfetto II (ebbe mangiato) \\
\hline & Fr. Passé Simple (elle mangea) & Fr. Passé Antérieur (elle eut mangé) \\
\hline & $\begin{array}{l}\text { Sp. Pretérito Perfecto Simple } \\
\text { (comió) }\end{array}$ & Sp. Pretérito Anterior (hubo comido) \\
\hline & $\begin{array}{l}\text { Cat. Pretèrit Perfet Simple } \\
\text { (menjà), Pretèrit Perfet } \\
\text { Perifràstic (va menjar) }^{8}\end{array}$ & Cat. Pretèrit Anterior (hagué menjat) \\
\hline & It. Imperfetto (mangiava) & It. Piucheperfetto (aveva mangiato) \\
\hline & Fr. Imparfait (il mangeait) & Fr. Plus-que-parfait (il avait mangé) \\
\hline & Sp. Pretérito Imperfecto (comía) & Sp. Pretérito Pluscuamperfecto (había comido) \\
\hline & Cat. Pretèrit Imperfet (menjava) & Cat. Pretèrit Imperfet (havia menjat) \\
\hline \multirow[t]{4}{*}{ Future } & It. Futuro Semplice (mangerà) & It. Futuro Composto (avrà mangiato) \\
\hline & Fr. Futur Simple (elle mangera) & Fr. Futur Antérieur (elle aura mangé) \\
\hline & Sp. Futuro Simple (comerá) & Sp. Futuro Perfecto (habrá comido) \\
\hline & Cat. Futur Simple (menjarà) & Cat. Futur Compost (haurà menjat) \\
\hline
\end{tabular}

6 Whether - and at what degree of grammaticalisation - compound tenses (which are periphrastic, analytical constructions) can be counted among the constituents of a verbal system in the narrower sense is a much-debated question. See among others Rojo/Veiga (1999, 2869-2871).

7 The terms used here for the individual forms (for which some alternatives also exist) are from various sources: Bertinetto (1986 and 2001) for Italian, Grevisse/Goosse (2008) for French, RAE (2009) for Spanish, Badia i Margarit (1994) for Catalan.

8 In addition to the analytical form, Catalan also knows a periphrastic form of the perfect, the Pretèrit Perfet Perifràstic. This is formed from the combination of the verb anar as an auxiliary verb and the infinitive of the respective main verb. 
However, this classification - which follows traditional grammars - is only meant to provide a rough overview, for it exhibits a number of limitations and difficulties. For example, the forms of the conditional are not included in Table (1), as these are not dealt with consistently in the grammaticographical tradition of the Romance languages. The conditional may be viewed as a tense form within the indicative ${ }^{9}$ or as a mode (see, e.g., Bertinetto 1986), and which in itself has two tense forms (one for the present, one for the past). Moreover, not listed here are those periphrastic constructions whose use as tenses has become very common, such as the French and Spanish periphrastic future constructions aller + infinitive and ir $a+$ infinitive, respectively, or the French formes surcomposées (elle a eu mangé, il avait eu mangé).

\subsubsection{Aspect - a grammatical, non-deictic category}

The morphological markers in examples $(1 a-d)-(4 a-d)$ are cumulative morphemes in that they convey an array of grammatical information simultaneously. If we compare $(1 a-d)$ with $(5 a-d)$ and $(6 a-d)$, we can see there are no differences in the temporal information expressed by the verb morphemes (all the verb forms are in the present tense), but there are differences concerning mode: the morphemes in examples $(1 \mathrm{a}-\mathrm{d})$ express the indicative mode, those in $(5 \mathrm{a}-\mathrm{d})$ the imperative and those in $(6 \mathrm{a}-\mathrm{d})$ the subjunctive: ${ }^{10}$

(5a) It. Leo, prendi [Pres. Imp.] un cornetto al cioccolato!

(5b) Fr. Léo, prends [Prés. Imp.] un croissant au chocolat!

(5c) Sp. ¡Leo, toma [Pres. Imp.] un cruasán con chocolate!

(5d) Ger. Leo, nimm [Präs. Imp.] ein Schokocroissant!

'Leo, have a chocolate croissant!'

(6a) It. Che Leo ora prenda [Pres. Cong.] un cornetto al cioccolato, lo vedo.

'I can see that Leo is now taking a chocolate croissant.'

(6b) Fr. Il faut que Léo prenne [Prés. Subj.] un croissant au chocolat.

'Leo needs to have a chocolate croissant.'

9 See, e.g., Grevisse/Goosse (2008) for French, RAE (2009) and Rojo/Veiga (1999) for Spanish, Perea (2002) and Badia i Margarit (1994) for Catalan.

10 This is therefore information that relates to the speaker's statement on the validity of the state of affairs (in the current world) expressed by an utterance, and that, in this case, is also expressed grammatically via modes. 
(6c) Sp. Es necesario que Leo coma [Pres. Subj.] un cruasán con chocolate. 'Leo needs to have a chocolate croissant.'

(6d) Ger. Leo meint, Julia nehme [Präs. Konj.] gerne ein Schokocroissant zum Frühstück.

'Leo says Julia likes a chocolate croissant for breakfast.'

If we now compare examples $(2 a-d)$ with examples $(3 a-d)$, we can see that here again there are no differences on either the temporal-deictic or modal levels: both forms are in the past tense and indicative mode. It is also evident that the German verbal system has no appropriate equivalent here, ${ }^{11}$ instead solutions to the opposition pairs mangiò/mangiava, mangea/mangeait or comió/ comía have to be sought in lexical devices such as in (7a), periphrastic constructions such as in (7b), in which case the lexical component also plays a central role, or other syntactic alternatives, i.e., the addition of further information in the sentence, as in example (7c):

(7a) Ger. Leo aß [Prät.] ein Schokocroissant auf. 'Leo ate a chocolate croissant.'

(7b) Ger. Leo war [Prät.] dabei, ein Schokocroissant zu essen. 'Leo was eating a chocolate croissant.'

(7c) Ger. Leo aß [Prät.] ein Schokocroissant, als Julia ihn anlächelte. 'Leo was eating a chocolate croissant when Julia smiled at him.'

The difference between $(2 a-c)$ and $(3 a-c)$ is usually defined in literature as aspectual-grammatical ("aspektuell") ${ }^{12}$ and is as such attributed to a different verbal category, which is that of aspect. When we talk about aspect, we traditionally refer to the morphological possibility (especially with regards to inflection) to express the internal or particular temporal structure of states of affairs as well as the perspective from which they are seen. ${ }^{13}$ This definition stems historically

11 The verb form $a \beta$ in (2d) is identical to the form in (3d), which should clarify the fact that the categorial opposition expressed here - in this grammaticalised form - does not exist in German.

12 I would like to reiterate that the adjective "aspectual-grammatical" (aspektuell) is used here in terms of aspect, whereas "aspectual" (aspektual) is used in relation to the general semantic field of aspectuality.

13 "In traditional grammar, the difference between (1) and (3) [Leo picked up leaves in the garden and Leo was picking up leaves in the garden] is reconstructed by attributing different factual values to the verbal syntagms: the perfective and the imperfective, respectively. The idea is that verbal inflection is not limited to providing information of a strictly temporal nature, but also includes a reference to the internal structure of events (or sequences of events) and to the point of view from which they are considered.” (Bonomi/Zucchi 2001, 49, orig. It.). 
from the observation and study of the structure and behaviour of the verbal system of the Slavic languages, which - especially Russian - to a large extent express aspectual contents grammatically. Furthermore, it is a definition that is often given ex negativo, as can be seen in Comrie's (1976) explanation, based on Holt (1943):

However, although both aspect and tense are concerned with time, they are concerned with time in very different ways. As noted above, tense is a deictic category, i.e. locates situations in time, usually with reference to the present moment, though also with reference to other situations. Aspect is not concerned with relating the time of the situation to any other time-point, but rather with the internal temporal constituency of the one situation; one could state the difference as one between situation-internal time (aspect) and situation-external time (tense). (Comrie 1976, 5)

Aspect shares with tense the grammaticality - in other words, the form and the formal organisational principle by which temporal contents are expressed - hence also the characteristics which are traditionally considered to be connected with it (such as, e.g., the obligatoriness and the morphological boundedness). But, unlike tense, aspect is not a deictic category, as it does not need any further reference points to express the temporal contents conveyed. ${ }^{14}$

The perfective and the imperfective, the two most important realisations and the central aspectual-grammatical opposition, can be defined, respectively, as a) the consideration of a state of affairs in its entirety - without paying attention to its internal structure - and b) the consideration of the internal structuring of a state of affairs, independently of its view as a whole (see in this context Comrie 1976, 16). A common classification of the realisations of aspect is given in the following Table (2):

14 According to Heger (1963, 16f., based on Bühler 1934), two types of notion (and therefore of category) can be distinguished: "definitional” and "deictic". Bühler differentiates between a "symbolic field" (Symbolfeld), which is assigned a "naming function" (Nennfunktion), and a "deictic field" (Zeigfeld), which is assigned a "deictic, pointing function" (Zeigfunktion). The naming function designates linguistic categories independently of the particular concrete speech context, i.e., it shows a meaning that is equivalent to a definition. With the deictic function, on the other hand, the terms are not defined in the sense just given, but instead represent "anchor points" within a system of reference in which every definitional term can occur. They are therefore variables that can be assigned differently in the concrete speech context. In this sense, tense could be described as a deictic, and aspect (and Aktionsart, see below) as a definitional category. However, it is precisely with regard to the deicticity of aspect, that Heger (1963) comes to a different conclusion. 
Tab. 2: Aspectual-grammatical oppositions following Comrie (1976, 25).

\begin{tabular}{lll}
\hline Aspect & perfective & \\
\cline { 2 - 3 } imperfective & habitual \\
\cline { 2 - 3 } continuous & $\frac{\text { nonprogressive }}{\text { progressive }}$ \\
\hline
\end{tabular}

In the Romance languages, the grammaticalised basic aspectual-grammatical opposition perfective vs. imperfective can only be found with the past tense, as shown in $(8 \mathrm{a}-\mathrm{b})-(11 \mathrm{a}-\mathrm{b}):^{15}$

(8a) It. Leo mangiava [Imp.] un cornetto al cioccolato molto soddisfatto. 'Leo was eating a chocolate croissant with great satisfaction.'

(8b) It. Leo mangiò [Perf. Sem.] un cornetto al cioccolato molto soddisfatto. 'Leo ate a chocolate croissant with great satisfaction.'

(9a) Fr. Léo ne savait [Imp.] pas prononcer le ' $r$ ' italien. 'Leo couldn't pronounce the Italian ' $r$ '.'

(9b) Fr. Léo ne sut [Pass. Sim.] pas prononcer le ' $r$ ' italien. 'Leo couldn't pronounce the Italian 'r'.'

(10a) Sp. Leo comía [Imp.] triste un osito de gominola, cuando Julia salió. 'Leo was eating a jelly baby sadly when Julia came out.'

(10b) Sp. Leo comió [Perf. Sim.] triste un osito de gominola. 'Leo ate a jelly baby sadly.'

(11a) Cat. Leo parlava [Imp.] amb la Júlia, quan la Maria va venir. 'Leo was talking to Julia when Maria came.'

(11b) Cat. Leo parlà/va parlar [Pret. Perf. Sim./Per.] amb la Júlia. 'Leo talked to Julia.'

The temporal structure of the states of affairs expressed in (8a)-(11a) displays traits of indeterminacy and incompleteness, as the states of affairs are not seen as whole and in their entirety; rather, they are presented in their process and the focus is on

15 In the following, only (8a)-(8b) are analysed in more detail, as they are also representative of the other example pairs. 
a part or one of their constitutive moments $\left(t_{1}, t_{2}, t_{3}, \ldots t_{n}\right)$. With mangiava in (8a), for instance, the state of affairs MANGIARE UN CORNETTO is shown in its process, as no beginning nor end of the state of affairs can be identified (due to which we cannot know whether Leo, at the time of speaking, is still eating or if he has already finished his chocolate croissant). The following graphic representation (Figure (4)), in which the state of affairs is shown in dark grey and the area of its process in light grey, illustrates the temporal structure of the imperfective aspect:

(8a) It. Leo mangiava [Imp.] un cornetto al cioccolato molto soddisfatto. 'Leo was eating a chocolate croissant with great satisfaction.'

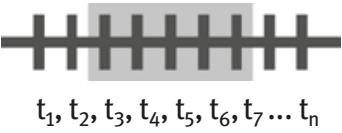

Fig. 4: Imperfective aspect.

In contrast, the temporal structure of the states of affairs shown in (8b)-(11b) expresses completeness, as none of its constitutive moments $\left(t_{1}, t_{2}, t_{3}, \ldots t_{n}\right)$ is especially focussed but presented as a whole. With mangiò in (8b) the state of affairs MANGIARE UN CORNETTO is presented as a complete, clearly delimited whole with a starting and an endpoint, as it comprises all constitutive moments $\left(t_{1}, t_{2}, t_{3}, \ldots t_{n}\right)$ of the state of affairs - and thus includes also $t_{1}$ and $t_{n}$ (even though they are not given special attention): Leo started to eat a chocolate croissant, continued to do so and finished it. ${ }^{16}$ At the time of speaking the croissant has completely disappeared. ${ }^{17}$ The temporal structure of the perfective aspect may be illustrated as in Figure (5):

16 Progress beyond the interval to which the statement refers is excluded, since this interval also represents the state of affairs as a single whole. This becomes even clearer when comparing examples such as (8a) and (8b) with the following pair, the second of which is unacceptable (and ungrammatical): (a) Leo mangiava il cornetto al cioccolato, quando gli cadde a terra e non lo poté finire di mangiare. vs. (b) ${ }^{*}$ Leo mangiò il cornetto al cioccolato, quando gli cadde a terra e non lo poté finire di mangiare ('Leo was eating a chocolate croissant when he dropped it on the floor and [so] couldn’t finish eating it' vs. '`Leo ate a chocolate croissant when he dropped it on the floor and [so] couldn't finish eating it').

17 In Spanish, the opposition between comió/ha comido (un osito de gominola) and se comió/se ha comido (un osito de gominola) is equivalent to the German opposition er hat ein Gummibärchen gegessen ('he has eaten a jelly baby') and er hat ein Gummibärchen aufgegessen ('he ate a jelly baby'). In both languages, each case represents a completed state of affairs (at the moment of the speech the jelly baby is completely gone), but the focus of the presentation of these states of affairs is different: in se comió/se ha comido (un osito de gominola) and er hat ein Gummibärchen 
(8b) It. Leo mangiò [Perf. Sem.] un cornetto al cioccolato molto soddisfatto. 'Leo ate a chocolate croissant with great satisfaction.'

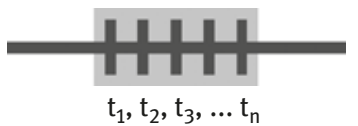

Fig. 5: Perfective aspect.

In the classic definition of aspect (such as Bertinetto's (1986), see §1.3.1), different criteria are used, both formal (the first two items in the following list) and semantic (the third item), which are to be identified absolutely separately from each other for a precise analysis of aspectual categories. ${ }^{18}$ Hence, aspect is a category that is:

- grammatical, inflectional, but non-deictic;

- obligatory, because it is grammatical, i.e., because it is expressed by means of verbal inflection (or grammaticalised verbal periphrases) and is therefore required by the syntax of the sentence;

- subjective, because it expresses the perspective freely chosen by the speaker, through which s/he presents the internal temporal structuring of the state of affairs (for example, in a phase of its process, as imperfective, or in its entirety, as perfective).

The fact that German, for example, does not have a comparable aspectual opposition marked grammatically by inflection, means that, from this traditional perspective - conceived mostly semasiologically and concerning a particular language - we are dealing with a language without aspect. This approach makes comparison with the Romance languages very difficult, as German uses a different verbal category to express aspectual contents, namely that of Aktionsart, which will be looked at in more detail on the following pages.

\subsubsection{A terminological-definitional remark}

Before dealing with the question of what exactly Aktionsart is, a brief history of the terms aspect and Aktionsart is sketched out here, as the history of the creation,

aufgegessen the result of the state of affairs is given relevance and not just its completion as in comió/ha comido (un osito de gominola) and er hat ein Gummibärchen gegessen. We will see how this difference is explained and presented in the model given here by different realisations of one of the perspectives of aspectuality (adjacency-related reference; see in particular \$4.4.4.1).

18 See Chapter 2 for a critical discussion of this issue. 
adoption and use of these two terms also provides information about the discovery or rediscovery of both categories and about their definition and distinction.

The origin of the term aspect can be found in various works of the Czech humanists. ${ }^{19}$ It seems to have arisen as a specialised form of the sense of the Greek term عĩסos ('external form'), which was used by the grammarians of antiquity to describe a class derived from a larger lexical category. The Greek grammarians used it in particular to denote the "formal categories within the verbal and nominal derivation system in their formal opposition to the nonderived root words” (Pollak 1988, 22, orig. Ger.). The Russian loan translation vid took over this new, more specific meaning. In the sense that is relevant here, in 1829 Reiff introduced the term "aspect” to Western European linguistic research (borrowed in the 15th century from Latin aspicere, 'to see' or 'to look at') as a translation of the Russian term vid into French. However, a terminological competitor for describing this category soon emerged, as Curtius (1846) prefered the term Zeitart ('type of time'), which he differentiated from the term Zeitstufe ('time stage'). ${ }^{20}$ Some years later, in 1885, Brugmann replaced Zeitart with Aktionsart, a term which is also found in Meyer-Lübke's Grammatik der romanischen Sprachen. Finally, we have Agrell's monograph Aspektänderung und Aktionsartbildung beim polnischen Zeitwort (1908), which marked a breakthrough for the term Aspekt ${ }^{21}$ over Zeitart: here Agrell used the "terminological duality of Aspekt - Aktionsart, which were synonymous until then, for a fundamental terminological differentiation" (Pollak 1988, 23, orig. Ger.). ${ }^{22}$

At this point, it may be necessary to draw attention to an additional distinction in order to offer further insight into the tricky terminology of the various philological traditions. The term "Aktionsart" is used nowadays in the Slavic tradition ${ }^{23}$

19 See Bertinetto $(1986,81)$ who in turn refers to Piva (1979). Pollak (1988, 20ff.) mentions, in particular, as a first example of dealing with this category the pioneering work of the Prague scholar Benedikt Vavř̀nec of Nudožer, who in 1603 described the fundamental features of the Slavic system. 20 Incidentally, with this work Curtius was the first to raise the question of the fundamental homogeneity of the Greek and Slavic verbal systems.

21 For a more detailed history of the term see Pollak (1988), Bertinetto (1986) and Piva (1979).

22 According to Agrell, aspect is a category that, in the Slavic verbal system, expresses the two main verbal categories, the uncompleted and the completed action (the imperfective and the perfective). Aktionsarten (plural of the German term Aktionsart), on the other hand, are semantic functions of verbal compounds that express more precisely how the action is accomplished (see Agrell 1908, 78ff.). The term "aspect" developed into an international technical term, first in Romance and the Northern Germanic languages (but also in English and Dutch) and later in the German and Slavic academic literature (see Pollak 1988, 23).

23 On Russian and Slavic aspect in general, see, among others, V. Lehmann (1993, 1997 and 1999), Breu (2000), Dickey (2000) and Anstatt (2003). 
in the sense of Isačenko (1962), who used it to denote various lexical classes of deverbal verbs derived by prefixation or suffixation (see Schwall 1991, Breu 2000 and Anstatt 2003). On the other hand, "Aktionsart" is understood in the Romance - as well as German and English - literature as the way by which the verb lexeme expresses the temporal structure of the state of affairs, i.e., as the time-related semantic content that is provided by the lexical component of the verb. ${ }^{24}$

\subsubsection{Aktionsart - a lexical category}

Aktionsart is usually defined as a category related to the "constant" semantic content, which is anchored in the lexically coded and fixed component of the verbal predicate. This is considered to be the expression of the type of temporal development (structure and articulation) of the state of affairs that is "objectively" expressed by the verb, i.e., as the expression of the nature of the temporal information, which is part of this content and thus intended to interact with the semantics of tense and aspect (see Bonomi/Zucchi 2001, 50). This type of temporal development of states of affairs can vary significantly, which is why the plural form "Aktionsarten" is often used, or the term "actional (verb) classes". Even though Aristotle had already stressed the difference between what are nowadays known as "telic" and "atelic" predicates, ${ }^{25}$ the actional classes became the subject of linguistic study, particularly since their classification by Zeno Vendler (1957 and 1967), ${ }^{26}$ who distinguished four types - "activities, accomplishments, achievements and states", a kind of cross-classification of the criteria "duration", "telicity" and "dynamicity". With regard to duration, a difference is made here between "durative" - states of affairs constituted by various subsequent points in time $\left(t_{1}, t_{2}, t_{3}, \ldots t_{n}\right)$ or various phases - and "nondurative" - states of affairs which take place at only one point in time $t_{x}$. Concerning telicity, a distinction is made between "telic" states of affairs -

24 "Aktionsarten" are understood and defined in this sense as "actional classes", and as such correspond to the "lexical action functions" (LAFs) of the more recent Slavic literature; see V. Lehmann (1992 and 1999) and Anstatt (2003), who describe the verb classes which result from the various combinations of lexical actional properties.

25 Aristotle distinguishes between kineseis and energeiai (see, e.g., Aristotle, Metaphysik 1048a, 25-1048b, 18-35). On Aristotle's definition and differentiation of actional classes see Dowty (1979), Kenny (1963), Verkuyl (1993) and Haug (2004).

26 Even before and independently of Vendler, Maslov (1984 [1948]) emphasised the connection between the aspectual-grammatical behaviour of verb lexemes and their lexical meaning (i.e., the Aktionsarten) in a now central work of Slavic aspectological research (The aspect and the lexical meaning of the verb in the modern Russian standard language; on this topic see Anstatt 2003, $7 \mathrm{ff}$.). 
which lean towards a goal inherent to the particular state of affairs, beyond which they are definitely completed - and "atelic" ones, which do not have such a goal. With regard to dynamicity, "dynamic" and "static" states of affairs are differentiated, exhibiting qualitatively different phases (or moments) or none of these. This gives us the four types of verb classes described in Table (3) according to the respective combinations of the criteria mentioned here (the left-hand column) and explained with examples (in the other four columns). ${ }^{27}$

Tab. 3: Actional classes, following Vendler (1957 and 1967).

\begin{tabular}{lllll}
\hline & Italian & French & Spanish & German \\
\hline $\begin{array}{l}\text { achievements } \\
+ \text { telic, - durative, + dynamic }\end{array}$ & $\begin{array}{l}\text { tagliare } i l \\
\text { traguardo }\end{array}$ & trouver & arribar & ankommen \\
\hline $\begin{array}{l}\text { accomplishments } \\
+ \text { telic, + durative, + dynamic }\end{array}$ & $\begin{array}{l}\text { mangiare } \\
\text { una mela }\end{array}$ & traverser la rue & envejecer & $\begin{array}{l}\text { von Rom nach } \\
\text { Paris fahren }\end{array}$ \\
\hline $\begin{array}{l}\text { activities } \\
\text { - telic, + durative, + dynamic }\end{array}$ & camminare & fumer & correr & schlafen \\
\hline $\begin{array}{l}\text { states } \\
\text { - telic, + durative, }{ }^{28}\end{array}$ & sapere & être grand(e) & habitar & wissen \\
- dynamic & & & & \\
\hline
\end{tabular}

As can be seen, states of affairs such as TAGLIARE IL TRAGUARDO ('to cross the finishing line') and ANKOMMEN ('to arrive') occur only at one point in time $\left(\mathrm{t}_{1}\right)$, while in TRAVERSER LA RUE ('to cross the street'), CORRER ('to run') and VON ROM NACH PARIS FAHREN ('to travel from Rome to Paris') various successive points in time $\left(t_{1}, t_{2}, t_{3}, \ldots t_{n}\right)$ or various phases can be identified. States of affairs such as MANGIARE UNA MELA ('to eat an apple'), TROUVER ('to find') and ENVEJECER ('to grow old') cannot be continued once they have reached their natural or internal goal (after I have eaten an apple I cannot continue eating it, it is not there anymore; after I have found something I cannot continue finding it, as I now

27 One of the severest critics of Vendler's classification is Mourelatos (1978). In his opinion, Vendler overlooks the very close relationship that exists between the various types of predicates and aspect (in its traditional understanding as a grammatical category).

28 Interpretation of the criterion of duration in states is not uniform: either they are taken to be durative states of affairs (that of someone being small cannot be described as punctual), or, since they represent properties, they are taken to be atemporal and therefore beyond duration (permanent). 
have it). ${ }^{29}$ Finally, states of affairs such as CAMMINARE, CORRER and SCHLAFEN contain qualitatively different points in time $\left(t_{1}, t_{2}, t_{3}, \ldots t_{n}\right)$ or phases (e.g., I can sleep more deeply or more restlessly in $t_{2}$ than in $t_{3}$ ), while no such qualitatively distinct points in time or phases can be differentiated in states of affairs such as ÊTRE GRAND(E) or WISSEN, where every moment is the same as every other moment.

Concerning stative predicates, a short parenthesis is necessary, which will also be important in the following chapters when dealing with states of affairs that contain these predicates. It has often been suggested that differences in the behaviour of (perfective) tenses in combination with states are to be traced back to the fact that these divide into two subgroups. Since Carlson (1977), a division between "stage level predicates" and "individual level predicates" has become increasingly common in formally oriented approaches: stage level predicates designate temporary or accidental features, individual level predicates permanent or essential features. ${ }^{30}$ However, not even such a detailed differentiation is helpful when it comes to final clarification of the question with which we are concerned here, because the acceptability of the combinability with perfective tenses, such as the Passé Simple, also varies within the class of individual level predicates, as the following examples show:

(12a) Fr. Julie détesta [Pass. Sim.] Jean.

'Julie hated Jean.'

(12b) Fr. Julie fut [Pass. Sim.] fâchée.

'Julie was angry.'

(12c) Fr. Julie fut [Pass. Sim.] intelligente/belle.

'Julie was intelligent/beautiful.'

(12d) Fr. 'Julie fut [Pass. Sim.] blonde.

'Julie was blonde.'

29 However, cases such as envejecer ('to grow old'), which exhibit a kind of "incremental telos", make such interpretations difficult. In the following, this issue will be discussed repeatedly and an alternative solution for analysing such cases will be given.

30 A test for differentiating them is their compatibility - among other things - with situationbased (frame setting) local modifiers: they can only be combined with stage level predicates, not with individual level predicates. Examples of this are: (a) Julie détesta Jean - (a") *Julie déteste Jean dans la cuisine; (b) Julie fut fâchée - (b") Julie est fâchée dans la cuisine; (c) Julie fut intelligente/belle - (c") *Julie est intelligente/belle dans le bus; (d) ?Julie fut blonde - (d") *Julie est blonde à l'université; (e) ?Le soleil fut lumineux - (e") *Le soleil est lumineux dans le grenier. Interesting also for the topic in general is the discussion of the so-called stupid predicates, see Meunier (1999) and Oshima (2009). 
(12e) Fr. 'Le soleil fut [Pass. Sim.] lumineux. 'The sun was bright.'

Examples (12a), (12b) and (12c) are well-formed, acceptable sentences. (12d) and (12e) are also grammatically well-formed sentences, but are pragmatically anomalous. In my view, differences in the combinability of the Passé Simple with different stative expressions cannot be found on the aspectual-semantic level expressed in the grammar and the lexicon. Rather, the explanation lies at the pragmatic level: based on their world knowledge, speakers and hearers apparently perceive the various permanent or essential qualities as differently permanent (allowing some predicates to be interpreted as temporary, others not). In Julie fut fâchée, her anger can be linked to a delimited period of time, which makes combination with the Passé Simple (characterised as externally delimited) acceptable. The same holds true for Julie fut intelligente/belle, where a delimited time frame is equally implied, the duration of her life or of a part of it: the fact that Julie was beautiful either means that she was beautiful in her youth and this is not the case anymore, or that she is no longer alive. ${ }^{31}$ Difficulties arise where the properties are perceived as innate and valid (such as red hair or brown eyes) in a way that makes it impossible to define a time frame that contains these features, which also seem to be perceived as independent of the individual person's life span. Only very special contexts, which, unlike the above, cannot be implied on a communication level based on cooperation and economy, allow for a solution and thus make a sentence such as Marie eut les yeux bleus jusqu'à l'opération acceptable. ${ }^{32}$

But let's return to Aktionsart. Regarding the classifications of types of predicates in the Romance languages and in German, the subcategorisations of Aktionsarten approximately follow the criteria of Vendler's (1957/67) classic verb typology. Different variants of this classification can, however, be found in the literature (see,

31 I will use similar arguments in Chapters 4, 5 and 6 to illustrate the interplay between the various elements and the context in expressing the various forms of aspectuality.

32 I base this interpretation on Maienborn's work on copula sentences (2003). Although she does not focus on the combinability of stage/individual phenomena with tenses, she opposes their being treated as part of the grammar and proposes instead a purely pragmatic solution. She speaks of a "temporarity effect" (Temporaritätseffekt), i.e., of the preferential interpretation of some predicates as having temporary properties. For predicates that do not allow temporary interpretation, the temporarity effect leads to pragmatic anomaly (Maienborn 2003, 178ff.). According to Vendler, states (as well as copula-predicate constructions, whether they are stage level predicates or individual level predicates) a) are excluded as indefinite complements of perception verbs ( ${ }^{\star}$ Leo vede Julia sapere l'inglese; ${ }^{\star}$ Leo vede Julia essere bionda/ ubriaca); b) cannot be combined with local situational modifiers ( ${ }^{\star}$ Leo è spiritoso/bello/alto all'università; * Leo ha i capelli rossi sull'autobus). 
among others, Maslov 1984 [1948], Mourelatos 1978, Bertinetto 1986 and Smith 1991)..$^{33}$ All these authors, however, take account of an important issue, which Verkuyl (1972) as one of the first aspectologists pointed out, namely, the problems that arise in using simple verb classifications - like Vendler's original one - to deal with verbs regardless of their argument structure. For while, for instance, MANGIARE is classified as an activity and thus as an atelic verb, MANGIARE UNA MELA would be considered, as shown above, an accomplishment, thus a telic verb. Verkuyl thus points out the role of the valency of the verb and suggests ascribing the aspectual interpretation of a state of affairs to the lexical-grammatical (morphosyntactic) complex constituted by the verb and its arguments. ${ }^{34}$

Looking more closely at the typical definition of Aktionsart in Romance linguistics, such as that given by Pérez Saldanya, some interesting observations can be made.

Si l'aspecte és una categoria gramatical associada a la flexió del verb (o a perífrasis molt gramaticalitzades), la modalitat de l'acció és una categoria eminentment lèxica, una categoria associada bàsicament al significat del predicat verbal. Si l'aspecte és una categoria subjectiva (una categoria del punt de vista), la modalitat de l'acció és una categoria objectiva, referida al tipus de situació designada. D'una forma come escurava, per exemple, es pot dir que té un'aspecte imperfectiu (o no delimitat); d'un predicat com escurar o d'una oració com En Lluís escurava es dirà que, des del punt de vista de la modalitat de l'acció, designa una situació dinàmica i durativa. (Pérez Saldanya 2002, 2602)

If aspect is a grammatical category associated with the inflection of the verb (or with highly grammaticalised periphrases), Aktionsart is an eminently lexical category, a category basically associated with the meaning of the verbal predicate. If aspect is a subjective category (a category of point of view), Aktionsart is an objective category, referring to the type of situation designated. It can be said that a form such as escurava, for example, has an imperfective (or non-delimited) aspect; a predicate such as escurar or a sentence such as En Lluís escurava can be said, from the point of view of Aktionsart, to designate a dynamic and durative situation.

The particularity of this definition lies in the fact that it combines the definitional criteria that, not by chance, are put forward as classic arguments for

33 For example, for Bertinetto (1986), achievements (trasformativi) and accomplishments (risultativi) are subtypes of telic verbs (see §1.3.1); for Mourelatos (1978), achievements (Bertinetto's trasformativi), accomplishments (Bertinetto's risultativi) and activities (Bertinetto's continuativi) are subcategorisations of the type occurrence, which is itself subdivided into events and processes. Processes are equivalent to activities, while events are further divided into punctual occurrences (=achievements) and developments (=accomplishments).

34 Verkuyl (1972) was one of the first to point out the relevance of the interdependence of the verb and its arguments for the analysis of aspectual information. 
justifying the separation of aspect and Aktionsart (referred to in the quote above as modalitat de l'acció). It is also an example of a definition by delimitation, already seen in the case of the differentiation between tense and aspect, which is litotic. Here again, Aktionsart is defined - as was aspect above, by combining formal criteria (the first two in the following list) and semantic criteria (the third) - as a category with the following features:

- It is lexical, not grammatical (like aspect), but (like aspect and unlike tense) non-deictic.

- It is optional, thus not obligatory (in contrast to grammatical categories). The argumentation here is the following: the speaker can choose which verb s/he uses in an utterance and which not (while s/he cannot choose not to use the inflectional markers required by the syntax).

- It is objective and inseparably connected to the described states of affairs: following this interpretation the temporal structuring of the states of affairs is given by the meaning of the verb and is not subject to the freely chosen point of view of the speaker in its (re)presentation.

In the various definitional efforts it has often been emphasised that we are dealing with a category which is objective in the sense explained above, as Aktionsart can be defined as an universal lexical category. However, there are a number of reasons (not least the fact that in the different languages of the world the actional classes are not distributed identically), which, with Sasse (1991, 32), support the claim that this is very problematic in terms of methodology. We will also look at this issue in more detail in Chapter 2 when dealing with aspectuality as a content category from an onomasiological perspective.

\subsection{On the relation between tense, aspect and Aktionsart - three theoretical approaches}

In the following, I present three particular approaches to the interpretation of tense, aspect and Aktionsart that belong to Romance linguistic research and which represent three extremes in their understanding of the relations between tense and aspect. While Bertinetto (1986) accords a substantial role to aspect and Aktionsart in the Italian verbal system, Rojo and Veiga (1999) exclude aspect from the Spanish verbal system, which they consider to be purely temporal. Both espouse a deictic interpretation and a linear, uniaxial representation of temporal relations. On the other hand, in his comparative model for Romance languages Coseriu (1976) proposes doubling the temporal axis and reinterpreting temporality as a relation between foreground and background ("actuality" and "inactuality"). 


\subsubsection{Bertinetto's interpretation of tense, aspect and Aktionsart}

In his monograph on the indicative verbal system, Bertinetto (1986) adopts (albeit critically) Reichenbach's model for Italian in his conception of the category of tense:

In sostanza, si può asserire che il tempo linguistico ${ }^{35}$ funziona in senso topologico, non metrico; esso non misura intervalli, ma si limita a situare relazionalmente gli eventi, secondo l'idea di un prima, un durante, un dopo. E se misura la durata degli intervalli, lo fa soltanto inglobando in sé, verbalizzandoli, gli strumenti che adoperiamo per la misurazione del tempo fisico. (Bertinetto 1986, 23f.)

In essence, it can be said that tense functions in a topological sense, not in a metric sense; it does not measure intervals, but simply situates events relationally according to an idea of a before, a during, an after. And if it measures the duration of intervals, it does so only by incorporating, through their verbalisation, the instruments we use to measure physical time.

Here, the tenses represent - together with the temporal adverbs - one of the most important means available to speakers for expressing the progression of time, and they are nothing other than: ${ }^{36}$

[...] la cristallizzazione, entro un preciso paradigma morfologico, di alcune opzioni fondamentali concernenti la possibile concettualizzazione dello svolgimento cronologico degli eventi. (Bertinetto 1986, 25)

[...] the crystallisation, within a precise morphological paradigm, of a few fundamental options concerning the possible conceptualisation of the chronological unfolding of events.

The fundamental change which Bertinetto makes is connected to his critique of Reichenbach's unspecific conception of the point of reference (R). He particularly criticises Reichenbach's assumption that temporal adverbs always represent $\mathrm{R}$ in a sentence as being not necessarily correct (especially in the case of simple tenses), ${ }^{37}$ and suggests giving the temporal adverb the status of $\mathrm{R}$

35 What Bertinetto defines as "tempo linguistico" ('time in language') is referred to here as the content category "temporality" (on the definition of so-called "content categories" see Chapter 2). 36 Bertinetto (1986, 24), referring to Kiparsky (1968), emphasises the similarity between the semantics of temporal adverbs and tenses, also because tenses diachronically originate from temporal adverbs. For a more recent investigation of temporal adverbs from a typological perspective, see Haspelmath (1997).

37 " [. . .] by MR [=R sds] we mean a time interval in which the result of an event is evaluated in its 'completeness' [...], the TL instead serves to place the MA [=E sds] in the time domain, but its emergence at the surface of the utterance [. . .] depends on strictly pragmatic reasons [...] it is wrong to associate the MR, in the sense defined here, with simple tenses [...] the MR is instead normally postulated by compound tenses (the Romance compound perfect in many of 
only when it follows the point of event (E), and defining it, when it occurs simultaneously with E, as a "localizzatore temporale (dell'avvenimento), LT" ['temporal localiser (of the event) TL']. After emphasising how closely related to the context of an utterance any decision to interpret the utterance is, he proposes to also add the notion of "ancoraggio temporale" ("temporal anchoring'), which would, on the basis of the criteria of anteriority, simultaneity and posteriority, allow for a more precise reconstruction of the relations between the different states of affairs in an utterance. ${ }^{38}$

Concerning aspect, Bertinetto also seems to give a definition in litotic terms, as it is mainly conceived as separate from tense and - particularly - from Aktionsart. $^{39}$ Table (4) shows the aspect oppositions he identifies in the Italian verbal system, which are more precisely illustrated in examples (13)-(17):

Tab. 4: Diagram of aspect in Italian, adapted from Bertinetto $(1986,119)$.

\begin{tabular}{lll}
\hline Aspetto & imperfettivo & abituale \\
\cline { 2 - 2 } progressivo & continuo \\
\hline perfettivo & compiuto & ingressivo $^{40}$ \\
\hline
\end{tabular}

its uses is a typical exception), and must always be inferable, at least, on the basis of the linguistic and situational context.” (Bertinetto 1986, 73, orig. It.).

38 "[...] it is possible to reconstruct the exact sequence of events in terms of relations of anteriority, simultaneity and posteriority (i) through the deciphering of temporal connections [...]; (ii) through the interaction of verbal tenses within the same text, from which it is possible to obtain the temporal anchors (TA) indispensable for a correct reconstruction of the chronological map of the text itself." (Bertinetto 1986, 69, orig. It.). He himself refers to Kamp/Rohrer (1983) for further corroboration of this idea.

39 "If we consider a given process from an immanent point of view, i.e., by targeting its intimate constitution and its specific modes of development (rather than its location in time and the network of temporal relationships of which it forms a part), then what is brought to the foreground are not the specifically temporal properties of the verb, but rather its aspectual properties. For example, we can consider a situation as a whole, as a single process that cannot be further analysed, or we can grasp it in a certain phase of its development [...]. The simplest and most immediate example that can be given, in terms of aspectual characterisations, is that concerning the distinction between the Imperfetto and the Perfetto in Italian." (Bertinetto 1986, 76, orig. It.).

40 Following Bertinetto, ingressivo is a subtype of aoristico. 
Some of the differences with regards to the classification proposed by Comrie (1976) (see \$1.2.2 above) are remarkable. On the one hand, the perfective is divided into two subtypes (compiuto and aoristico), as illustrated in examples (16) and (17), respectively, ${ }^{41}$ while on the other hand, the imperfective is divided into three subtypes which belong to the same level (abituale, progressivo and continuo), as shown in examples (13)-(15):

(13) It. Di solito Leo a colazione mangiava [Imp. v. abit.] un cornetto al cioccolato. 'Leo usually ate a chocolate croissant for breakfast.'

(14) It. Leo mangiava [Imp. v. prog.] il suo cornetto al cioccolato in cucina, quando Julia entrò.

'Leo was eating his chocolate croissant in the kitchen when Julia came in.'

(15) It. Mentre Leo mangiava [Imp. v. cont.] il suo cornetto al cioccolato, Julia lo guardava [Imp. v. cont.] interessata.

'While Leo was eating his chocolate croissant, Julia was watching him with interest.'

(16) It. Avrei voluto un morso di quel bel cornetto al cioccolato che aveva comprato Daniel, ma l'ha mangiato [Perf. Com. v. comp.] Leo.

'I would have liked a bite of that nice chocolate croissant that Daniel bought, but Leo has eaten it.'

(17) It. Leo mangiò [Perf. Sem. v. aor.] il cornetto al cioccolato sporcandosi tutta la faccia.

'Leo ate the chocolate croissant making a mess of his whole face.'

What makes Bertinetto's definition of the imperfective special is the fact that he sees the common denominator of the three subtypes (continuative, progressive,

41 According to Bertinetto, the temporal structuring of the states of affairs in (16) and (17) is precisely determined: in both examples, MANGIARE IL CORNETTO is represented in its entirety (i.e., in all its constitutive moments $\left(t_{1}, t_{2}, t_{3}, \ldots t_{n}\right)$ ), thus also the respective initial and final moments: Leo started to eat and continued to do so until he finished eating the croissant. The difference between the examples is that while in (16) the result following the state of affairs (that the croissant has been eaten) continues, i.e., there is in the given point of reference (when the subject of the sentence (I) wants to bite the croissant) a particularly emphasised aspect, in (17) the state of affairs is simply presented as completed (its endpoint is particularly focalised) and its eventual result (that the croissant is no longer there) is irrelevant in the structuring of the state of affairs and is not focussed on. 
habitual) as being indeterminacy (indeterminatezza) or non-delimitation (nondelimitazione) (see, e.g., Bertinetto 1986, 345ff.). The indeterminacy in the habitual value of the imperfective (see (13)) thus lies, according to Bertinetto, in the indeterminacy of the frequency of its occurrence (for, naturally, a state of affairs has to be completed in order to be repeated and then to become habitual via this repetition and the contribution of further semantic components). ${ }^{42}$ On the other hand, the progressive value of the imperfective (see (14)) exhibits traits of indeterminacy in the incompleteness of the state of affairs, as it is presented in its progression and from the perspective of a particular point in this progression. The indeterminacy of the continuous value of the imperfective (see (15)) can also be seen, following Bertinetto, in the incompleteness of the state of affairs, while the latter is neither seen from a particular point in its progression nor represents a habit (see Bertinetto 1986, 120-190).

Two things seem to be problematic here. On the one hand, a) very different types of indeterminacy are included here, even though this is particularly meant to represent the common denominator of the aspect type imperfective; on the other hand, b) the prototypical use of the imperfective, i.e., the continuous, is only defined ex negativo, because everything which cannot be defined as habitual or progressive is classified as continuous (see Bertinetto 1986, 162-190).

Except for a few changes in terminology and classification, Bertinetto's classification of Aktionsarten is essentially based on Vendler's, as Table (5) shows:

Tab. 5: Diagram of verbal action, adapted from Bertinetto $(1986,98)$.

\begin{tabular}{|c|c|c|c|c|c|}
\hline \multirow[t]{7}{*}{$\begin{array}{l}\text { Azione } \\
\text { verbale }\end{array}$} & $\begin{array}{l}\text { non- } \\
\text { durativo }\end{array}$ & $\begin{array}{l}\text { non- } \\
\text { telico }\end{array}$ & $\begin{array}{l}\text { non-trasformativo } \\
\text { puntuale }\end{array}$ & & \\
\hline & & telico & trasformativo & reversibile & \\
\hline & & & & non-reversibile & \\
\hline & durativo & & risultativo & & \\
\hline & & $\begin{array}{l}\text { non- } \\
\text { telico }\end{array}$ & non-risultativo & stativo & permanente \\
\hline & & & & & $\begin{array}{l}\text { non- } \\
\text { permanente }\end{array}$ \\
\hline & & & & $\begin{array}{l}\text { non-stativo } \\
\text { continuativo }\end{array}$ & \\
\hline
\end{tabular}

42 For more recent work on the topic and an analysis of the differences between "multiplicity", "reiterativity" and "habituality" see Bertinetto/Lenci (2012). 
Bertinetto's conception is notable for the vehemence with which he claims that aspect and Aktionsart should not be merged or confused (for more details see §1.4), an emphasis that remained unchanged in his later work (see, e.g., Bertinetto 1997).

\subsubsection{Temporal relations and tenses according to Rojo and Veiga}

Rojo and Veiga (1999) - inspired, on the one hand, by the tradition of Bello (1981 [1847]) and, on the other, by Bull's (1960) and Klum's (1961) interpretations - developed a vectorial model of the temporal relations in the Spanish verbal system, which distinguishes, in relation to a punto cero (the origo, which usually coincides with the moment of speaking) ${ }^{43}$ and on the basis of three temporal relations (anterioridad, simultaneidad and posterioridad), primary, secondary and tertiary tense forms:

[...] hemos venido hablando de un origen (0) respecto del cual se orientan temporalmente los procesos verbalmente expresados. Las orientaciones pueden ser directas, como en las relaciones del pretérito, presente y futuro, o indirectas, cuando entre el proceso verbal y el origen se interpone algún punto de referencia, cuya relación con el origen puede ser, igualmente, directa o indirecta; es este el caso de cualquier relación temporal como las de pospretérito, ante-presente y ante-pos-pretérito, etc. El origen, por tanto, constituye el centro deíctico de orientaciones temporales del sistema verbal, el punto desde el cual se enfoca, directa o indirectamente, todo proceso expresado por una forma verbal. (Rojo/Veiga 1999, 2889)

[...] we have been speaking of an origin (0) with respect to which the verballyexpressed processes are temporally oriented. Orientations can be direct, as in the relations with the past, present and future, or indirect, when interposed between the verbal process and the origin is some point of reference, whose relation with the origin can be equally direct or indirect; this is the case with any temporal relations, such as those of pos-pretérito, ante-presente and ante-pos-pretérito, etc. The origin, therefore, constitutes the deictic centre of the temporal orientations of the verbal system, the point from which any process expressed by a verbal form is focussed, directly or indirectly.

"Direct" or "indirect orientation" in relation to the origo can be compared with the known distinction between "absolute", "relative" and "absoluterelative tenses" (see Comrie 1985, 36-82 and 1993, 9-12). ${ }^{44}$ The temporal

43 For a discussion of this question see Rojo/Veiga (1999, 2889ff.).

44 This comparison is also accepted by the authors themselves, although they consider their own subdivision to be clearer (see Rojo/Veiga 1999, 2879). 
relations in the Spanish verbal system may be schematically represented as in Figure (6) and are illustrated by examples (18)-(26) ("O" refers to the origo and "O-V", "OoV" and "O+V" (noted in square brackets after each example) refer, respectively, to the relations of anteriority (A), simultaneity (S) and posteriority (P))..$^{45}$

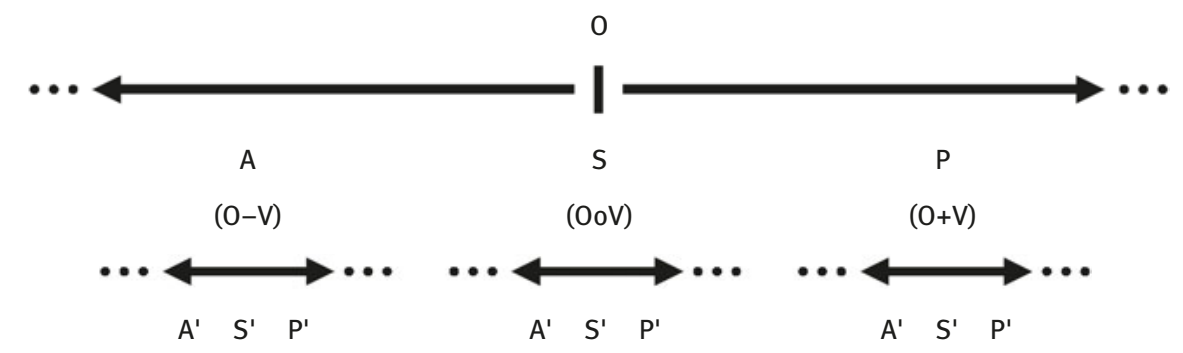

Fig. 6: Temporal relations according to Rojo/Veiga (1999).

(18) Sp. Eduardo llegó ayer. [O-V]

'Eduardo arrived yesterday.'

(19) Sp. Eduardo está hoy en Vigo. [OoV]

'Eduardo is in Vigo today.'

(20) Sp. Eduardo saldrá mañana de viaje. [O+V]

'Eduardo will leave tomorrow.'

(21) Sp. El jueves me enteré de que Eduardo había llegado el día anterior. $[(\mathrm{O}-\mathrm{V})-\mathrm{V}]$

'On Thursday I learned that Eduardo had arrived the day before.'

(22) Sp. El jueves me enteré de que Eduardo estaba ese mismo día en Vigo. $[(\mathrm{O}-\mathrm{V}) \mathrm{oV}]$

'On Thursday I learned that Eduardo was in Vigo that same day.'

(23) $\mathrm{Sp}$. El jueves me enteré de que Eduardo llegaría al día siguiente. [(O-V)+V]

'On Thursday I learned that Eduardo would arrive the next day.'

45 The examples are taken from Rojo/Veiga (1999). 
(24) Sp. Eduardo ha llegado hoy. [(OoV)-V]

'Eduardo arrived today.'

(25) Sp. Cuando llegue Eduardo, habremos terminado el trabajo. [(O+V)-V]

'When Eduardo arrives, we'll have finished the job.'

(26) Sp. Estaba seguro de que habríamos terminado el trabajo cuando llegara Eduardo. [((O-V)+V)-V]

'I was sure we would have finished the job by the time Eduardo arrived.'

Primary tense forms are represented in (18)-(20), secondary ones in (21)-(25), and tertiary forms in (26).

The particularity of this approach is the fact that the verbal category aspect is not included in the system, ${ }^{46}$ for Rojo and Veiga (1999, 2919ff.) claim that the verbal system of Spanish is solely temporal and modal, and that it would be much less efficient to explain it by postulating a category such as aspect, compared with a general temporal-vectorial (and thus "aspect-less") model, such as theirs. Nor do the authors deal with the category Aktionsart in the text analysed, although this is merely due to technical reasons, ${ }^{47}$ as otherwise Rojo and Veiga consider that Aktionsart, unlike aspect, plays a very important role in the Spanish verbal system.

\subsubsection{The Romance verbal system according to Coseriu}

Coseriu (1976) also understands the verbal system of the Romance languages as being mainly temporal. The functions which are normally ascribed to the categories of tense and aspect, ${ }^{48}$ however, are not integrated into a purely vectorial structuring of temporal relations, instead they are included and remodelled in a new, complex categorial system.

46 Cf. also Weinrich (1964), who in a different way also denies aspect a place in the verbal system. 47 In the Gramática, a separate article by De Miguel (1999) is dedicated to the "aspecto léxico"; however, given that this special approach diverges substantially from the concept proposed by Rojo and Veiga, it is looked at more closely in Chapter 2 on aspectuality.

48 Here, the purely temporal determination, the tense, is defined in terms of the "position" (Stellung) of the verbal action in time, and the aspectual determination in terms of the "view" (Betrachtungsweise) of the verbal action in time (see Coseriu 1976, 92). 
The Romance verb - the system is considered to be applicable to all Romance languages - is defined by Coseriu $(1976,115)$ as having "three storeys" (dreistöckig). More specifically, it contains three subsystems:

- the organisation of the periods of time;

- the definition of points of time within these periods;

- the definition of particular "aspective" ${ }^{49}$ values for every point of time.

The first subsystem contains the categories of the temporal level and the primary perspective, which are formally expressed via the simple tense forms; the second correlates with the secondary perspective (formally expressed via the compound tense forms); the third pertains to the categories of duration, repetition, completion, result and, particularly, Schau ('view') and Phase ('stage') (formally expressed through various verbal periphrases).

The category of the temporal level in the Romance languages is, according to Coseriu and unlike the interpretations previously presented, a double one: it contains an "actual level" (with the present tense at its centre) and an "inactual level" (with the imperfect at its centre), which are connected to each other by a foreground/background relation. Since the temporal level conceived as such represents the basis of Coseriu's interpretation of the Romance verbal system, it will be dealt with in greater detail than the other categories. It involves a new interpretation of the imperfect: Coseriu makes various criticisms of previous interpretations of the imperfect, such as, e.g., its conception as a past form (defined in direct opposition to the "perfektum simplex"), the underestimation of the formal analogy between the imperfect, the past perfect and the present conditional, and the disregard of its special (for example, modal) uses.

On the other hand, according to Coseriu the category of perspective subdivided into parallel, retrospective and prospective - communicates the attitude of the speaker with regards to the verbal action. This category, therefore determines periods of time on every temporal level and not tense, and does so from two perspectives, as every period of time delimited by the primary perspective can be further subdivided following the same principle (i.e., the secondary perspective). The system is illustrated in Table (6).

Various objections have been levelled against this system. It has been asked (Bertinetto 1986, 36f.) why, when doubling the temporal level, there should not also be a third axis, with the past perfect, for instance, at its centre.

49 Coseriu uses this rather uncommon adjective instead of "aspectual". 
Tab. 6: Temporal levels and perspectives in the Romance verbal system, according to Coseriu $(1976,94 f f$.$) with modifications.$

\begin{tabular}{|c|c|c|c|c|}
\hline & & $\begin{array}{l}\text { Past } \\
\text { retrospective }\end{array}$ & $\begin{array}{l}\text { Present } \\
\text { parallel }\end{array}$ & $\begin{array}{l}\text { Future } \\
\text { prospective }\end{array}$ \\
\hline \multirow[t]{6}{*}{ Actual } & primary & It. feci & It. faccio & It. farò \\
\hline & & Fr. je fis & Fr. je fais & Fr. je ferai \\
\hline & & Sp. hice & Sp. hago & Sp. haré \\
\hline & secondary & It. ho fatto & & Fr. je vais faire \\
\hline & & Fr. j'ai fait & & Sp. voy a hacer \\
\hline & & Sp. he hecho & & \\
\hline \multirow[t]{6}{*}{ Inactual } & primary & (Sp. hiciera) & It. facevo & It. farei \\
\hline & & & Fr. je faisais & Fr. je ferais \\
\hline & & & Sp. hacía & Sp. haría \\
\hline & secondary & It. avevo fatto & & It. avrò fatto \\
\hline & & Fr. j'avais fait & & Fr. j'allais faire \\
\hline & & Sp. había hecho & & Sp. habré hecho \\
\hline
\end{tabular}

Moreover - and here the objections seem to be more radical, touching the core of Coseriu's system - what he defines as a double temporal level is not really temporal (Detges 2001), because the classification of the imperfect as the present tense of the inactual level is based on the modal uses of this tense form (a case of grammatical polysemy).

The fact that Coseriu's interpretation of the Romance verbal system is based on a consideration and new classification of the imperfect, a concrete form of the verbal system, entails another problem. The analysis is essentially carried out on a semasiological basis and postulates an ideal Romance type, which, however, originates from observations of the Ibero-Romance system, particularly Portuguese (and which is only more or less completely realised in the other Romance languages). It is then used crosslinguistically as an onomasiological grid, even though applying semasiologically developed models onomasiologically often proves to be a theoretically difficult undertaking. Despite the genetic affilation (all the Romance languages inherited their verbal system from Latin), it appears, in part, that the interpretation grid, which is based on the Portuguese imperfect, is much more suitable for the description of Portuguese than for the other Romance languages. 


\subsection{Delimitation problems with the traditional verbal categories - aspect vs. tense vs. Aktionsart}

The very different definitions of tense, aspect and Aktionsart presented so far include not only all the criteria of their determination, but also all the classic arguments which have been used to justify distinguishing them. The need to distinguish aspect and Aktionsart has been emphasised often and vehemently:

Così come le nozioni di Tempo e di Aspetto non vanno in alcun modo confuse tra loro, allo stesso modo si dovrà fare attenzione a non confondere il concetto di Aspetto con quello di Azione. [...] Non di rado capita tuttora di vedere, pericolosamente mescolate queste due nozioni, a tutto scapito della validità teorica ed empirica delle indagini esperite. (Bertinetto 1986, 84)

Just as the notions of Tense and Aspect should in no way be confused with each other, so care should be taken not to confuse the concept of Aspect with that of Aktionsart. [...] It is not uncommon to see these two notions dangerously mixed up, to the detriment of the theoretical and empirical validity of the investigations undertaken.

But the fact that these definitions are full of metaphors and hedges, and that they often work only by virtue of their mutual demarcation, or that even the advocates of their strict differentiation must constantly insist on the semantic affinity between the two categories, suggests that the very boundaries of aspect and Aktionsart are not drawn clearly enough, which is a problem in a traditional conception of grammar and the associated Aristotelian conception of the notion of category. The tranquillity that the classic grammatical categorisation seeks to communicate to the Romance verbal system undoubtedly conceals problematic intersections, overlaps and interferences that are difficult to explain. If, on the one hand, the interaction between aspect and Aktionsart cannot be denied, it seems to be very important, on the other hand, to specify the particular characteristics of these two categories. Naturally, opponents of the "pericolosa mescolanza" are also aware of this when they allude to the "indubbie connessioni che esistono fra queste due fondamentali caratterizzazioni semantiche delle forme verbali" ("undoubted connections between these two [aspect and Aktionsart sds] fundamental semantic characterisations of verb forms') (Bertinetto 1986, 84), or when they discuss openly the problems of demarcation:

Aquesta categoria [la modalitat de l'acció sds], també anomenada aspecte lèxic o Aktionsart, presenta una clara proximitat amb la categoria gramatical de l'aspecte i la distinció entre l'una i l'altra no sempre és nítida en els estudis tradicionals, com ho 
mostra el fet que la mateixa terminologia que s'utilitza en un cas reaparegui sovint en l'altre. (Pérez Saldanya 2002, 2602)

This category [Aktionsart - in the original modalitat de l'acció sds], also called lexical aspect or Aktionsart, has a clear proximity to the grammatical category aspect and the distinction between one and the other is not always clear in traditional studies, as demonstrated by the fact that the same terminology used in one case often reappears in the other.

Despite this, the problem is often not tackled at the root, but shifted to the level of the grammatical vs. lexical distinction, which is a distinction of the statusrelational level and not of semantics (see Coseriu 1987, 125). Already in the 1980s Coseriu opposed this argument, which is often accompanied by a confusion of the universal category with that occurring and functioning in a particular language:

Seit S. Agrell unterscheidet man für die slawischen Sprachen den Aspekt, der die Art und Weise betrifft, eine Verbalhandlung in Betracht zu ziehen, und zur Grammatik gehört, und die Aktionsarten, welche die 'objektive' Art und Weise betreffen, in der die Verbalhandlung abläuft oder sich verwirklicht, und die zum Wortschatz gehören (z. B. 'effektiv', 'perdurativ', 'kursiv', 'terminativ', 'inchoativ'). Man hat auch versucht, diese Unterscheidung in genau demselben Sinne auf andere Sprachen zu verwenden. Das aber beruht auf einer doppelten Verwechselung: zunächst auf der von inhaltlichem Wert und relationellem Status ('lexikalisch' bzw. 'grammatikalisch') und danach auf der von universellem und 'historischem' (d. h. in einer Einzelsprache vorkommendem und funktionierendem) Aspekt. (Coseriu 1987, 125)

Since S. Agrell, a distinction has been made in the Slavic languages between aspect relating to the way in which verbal action is taken into consideration and which belongs to grammar, and Aktionsarten relating to the 'objective' way in which the verbal action takes place or is realised and which belong to vocabulary (e.g., 'effective', 'perdurative', 'recursive', 'terminative', 'inchoative'). Attempts have also been made to use this distinction in exactly the same way in other languages. This, however, is based on a double confusion: first, on that of content value and relational status ('lexical' or 'grammatical') and then on that of universal and 'historical' (i.e., occurring and functioning in a single language) aspect.

If a formal (or, as Coseriu calls it, "status-relational") distinction between aspect and Aktionsart seems to make sense in order to categorise and classify linguistic phenomena, it certainly is not enough to assert its semantic distinction. It is also important to clarify which semantic level is being referred to, the language-particular or the universal, when speaking of aspect and Aktionsart, because it is not possible simply to transfer categories that are defined, structured and subdivided according to their occurrence in one particular language (Russian in this case) to other individual languages. 
However, if we now take a closer look at the definitions of aspect and Aktionsart presented in this chapter - and above all their universal semantic function - the following question clearly arises: to what extent and in what sense are these categories actually different? For both serve to express the internal temporal structuring of states of affairs, i.e., their delimitation in their temporal development. 


\section{The Aspectual Domain}

\subsection{Introductory remarks}

In Chapter 1, tense, aspect and Aktionsart were defined as verbal categories by which individual languages provide information on the temporal structuring of states of affairs, the first as deictic, the other two as definitional, the first two grammatically, the last lexically. In the following, this information will be considered from an onomasiological perspective, and the more general aspectual domain will be described and analysed in more detail, as this chapter will deal with the crosslinguistic content category aspectuality, of which the verbal categories aspect and Aktionsart can be considered components.

Depending on the position taken in assessing the semantic or formal distinction between aspect and Aktionsart within the general aspectual domain i.e., their autonomy, their semantic homogeneity or heterogeneity - two main lines representing opposing positions can be distinguished in aspectological research. This difficult question will be dealt with following a general presentation of aspectuality.

The arguments of both these main lines will be subjected to a critical review. On the one hand, we have the bidimensional approaches, supported for the most part in Romance linguistics, in which aspect and Aktionsart are treated as clearly separate categories, i.e., substantially distinct within the general aspectual domain. On the other hand, there are the unidimensional approaches, which assume no semantic difference between the two categories.

Finally, the position I take in this book, which is to advocate a unidimensional approach, is put into this context. This choice is then justified in more detail in the description of the model in the following chapters.

\subsection{Aspectuality - onomasiology and content categories}

In order to reconstruct the history of the term "aspectuality" and to grasp its meaning precisely - as in the case of the aspectual verbal categories aspect and Aktionsart -, reference has to be made to Russian aspectology. Bondarko (1967) introduces the term to name the category which characterises the way an action proceeds, ${ }^{1}$ and which can be determined by various means - morphological (inflectional and word-formation), lexical and contextual. Two main points can be

1 The term is also used by Maslov (1978) to describe the semantic field of aspectual meanings.

Ә Open Access. (C) 2019 Sarah Dessì Schmid, published by De Gruyter. (cc) BY-NC-ND This work is licensed under a Creative Commons Attribution-NonCommercial-NoDerivatives 4.0 International License. 
seen in Bondarko's definition: on the one hand, aspect and Aktionsart, as defined above, are considered subordinate categories, just two of the possible ways by which aspectuality can be expressed. ${ }^{2}$ On the other hand, aspectuality is considered exclusively a content category and is thus no longer classified in languageparticular but rather in universal semantics (see Raible 1983 and §3.3 in the next chapter). This onomasiologically-derived and conceptually-perceived content category cannot therefore be compared with aspect and Aktionsart, since it is not a category realised in a particular language but more generally represents the cognitive domain that concerns the temporal structuring of states of affairs. ${ }^{3}$ Now, we have to consider that:

Categories which cannot be semantically defined are extremely difficult to compare across languages. (Haspelmath 2007, 126)

A category defined in this way should therefore be much better suited than aspect or Aktionsart as a basis for comparative analysis. It can function as a conceptual tertium comparationis since it is not derived from a formal pattern in an individual language, for which, of course, there would be no perfect equivalent in another individual language.

It is therefore astonishing that aspectuality is not a very popular topic in Romance linguistics, especially when we consider that Romance - as well as Slavic - linguistics is by definition a comparative linguistic discipline. In fact, there are few studies on Romance languages dealing with aspectuality from an onomasiological perspective. These include, in particular, the work of Heger $(1963)^{4}$ in the

2 These are "parts" of aspectuality, e.g., in addition to another category such as that of Aktionsart according to Isačenko (1962), who understands this as various lexical classes of deverbal verbs derived by prefixation or suffixation.

3 "Aspectuality" is also defined and applied in this way in more recent aspectological research in Slavic studies (see, among others, V. Lehmann 1992 and 1999).

4 'Understood as such, 'onomasiological' works can also be found among the efforts to clarify what verbal aspect actually is. They are not concerned with the content of a particular formal category, but in the terms by which aspects are expressed. But what aspects are, is first determined by semasiological interpretations of existing forms, and thus the results of the subsequent onomasiological investigations are condemned to remain mere tautologies. On the other hand, there is hardly ever an attempt to define aspects and time stages (Zeitstufen) as conceptual categories independent of linguistic conditions and thus to anchor them in a system in such a way that they cannot be accused of mere randomness.” (Heger 1963, 11, orig. Ger.). Heger is certainly one of the first important advocates of applying the onomasiological approach not only in the domain of lexicology but also in that of grammatical investigation. However, in his work on the conjugation systems of French and Spanish he makes a distinction between aspect, regarded (along with tense) as a deictic category, and Aktionsart, regarded as a definitional category (see Heger 1963, esp. 16ff.). 
1960s, the work of Schwall (1991), ${ }^{5}$ who is also well informed about the Slavic tradition, and the outline by De Miguel (1999) contained in an article on "aspecto léxico" in Bosque and Demonte's Gramática descriptiva de la lengua española (De Miguel's view is dealt with in more detail in §2.3.1). Moreover, some onomasiological hints can be found in the grammars of Serianni (1991) and of Grevisse and Goosse (2008), ${ }^{6}$ which become clear in the following quotes:

La nozione di aspetto verbale è alquanto controversa. [. . .] possiamo affermare che l'aspetto contrassegna l'atto verbale secondo la prospettiva della durata, della momentaneità, della ripetitività, dell'inizio o della conclusione di un processo, della compiutezza o dell'incompiutezza dell'azione. [...] Nella grammatica italiana l'aspetto ha un'importanza secondaria. [...] Accanto a mezzi morfologici (come l'opposizione tra imperfetto e passato remoto, cfr. xi. 377) o sintattici (come la perifrasi di stare + gerundio, cfr. xi. 48c), per esprimere l'aspetto verbale l'italiano può ricorrere a mezzi lessicali (addormentarsi, ad esempio, ha valore ingressivo, indica l'inizio dell'azione; dormire ha valore durativo, indica l'azione in sé) o derivativi (mediante il suffisso -icchiare un verbo può designare un'azione ripetuta e attenuata, cfr. xv. 61: cantare $\rightarrow$ canticchiare [...]). (Serianni 1991, 390f.)

The notion of aspect is quite controversial. [...] we can affirm that aspect marks the verbal act according to perspectives of durativity, momentaneity, reiteration, the beginning or conclusion of a process, the completeness or incompleteness of the action. Aspect has secondary importance in Italian grammar. Aside from expressing aspect by morphological means (such as the opposition between the imperfect and remote past, see xi. 377) and syntactic means (such as the periphrasis stare + gerund, see xi. 48c), Italian can also resort to lexical means (for example, addormentarsi 'to fall asleep' has an ingressive value and indicates the beginning of the action; dormire 'to sleep' has a durative value and indicates the action in itself) or derivational means (the suffix -icchiare on a verb can designate a repeated, attenuated action, see xv. 61: cantare $\rightarrow$ canticchiare 'to sing' $\rightarrow$ 'to sing softly', 'to hum' [...]).

L'aspect est la manière dont s'expriment le déroulement, la progression, l'accomplissement de l'action. [.. .] L'aspect se manifeste en outre par les semi-auxiliaires (§§ 789-791), ou encore par des suffixes (buvoter opposé à boire) ou des préfixes (retravailler) ou par le sens même des verbes (éclater présente l'aspect instantané) [cf. § 744, e]. - Il y a aussi des adverbes d'aspect: cf. $\S$ 965. Remarque. - La notion d'aspect n'a pris qu'assez récemment une grande place dans les études sur le français. Les linguistes présentent à ce sujet des vues souvent divergentes. (Grevisse/Goosse 2008, 1121)

5 Schwall's work is in many ways an interesting piece of research, not only for Slavic but also for Romance aspectology, as the author calls for a terminological (and perspective) turn in research based on the notion of aspectuality. Since this work focusses, in particular, on terminological clarifications (and a description of the relations between aspect, tense and mode in the Romance languages, especially in the forms of the indicative), without elaborating a model of aspectuality, it is not dealt with in depth here.

6 A similar position is also taken in Riegel/Pellat/Rioul (2004). 
Aspect is the way in which the unfolding, progression and accomplishment of the action are expressed. [.. .] Aspect is also manifested by semi-auxiliaries (§§ 789-791), by suffixes (buvoter 'to drink a little' vs. boire 'to drink'), by prefixes (retravailler 'to rework') or by the meaning of the verb itself (éclater 'to burst' has a punctual aspect) [cf. § 744, e]. That there are also aspectual adverbs: cf. § 965. Note. - The notion of aspect has only recently taken a prominent place in studies on French. Linguists often present divergent views on this subject.

On the one hand, these lines give indications of an onomasiological perspective: both ignore the usual distinction between grammatical and lexical means of expression, i.e., between aspect and Aktionsart. Instead, aspect ${ }^{7}$ is defined with reference to an abstract content, and the various individual language options which Italian and French have to express this content are mentioned. But the fact that these are only indications and that no real consequences are drawn concerning the general perspective of the work is just as evident. The passages cited are the only ones on the subject that can be found in these grammars. The reason for this lies not least in the supposedly lesser importance of the topic or the novelty of aspect research in Italian and French linguistics and grammaticography, which is suggested by both authors.

However, the neglect of aspectuality in Romance linguistics seems all the more surprising as there are clear parallels between this and other content categories, no doubt dealt with more successfully in the Romance research tradition. Onomasiological treatments of temporality and modality, albeit not very numerous, can indeed be found there. Consider, for example, the analysis of temporality and, in particular, modality in Schwarze's (1988) grammar $^{8}$ or Böckle's (1983a, 1983b, 1984) investigations, which were also carried out in the 1980s. In the meantime, linguistic research in general has taken it for granted that any (also semasiological and language-particular) treatment of the category mode, modal verbs or modal adverbs has to proceed from clarification of the relationships - and thus the distinction - between these grammatical and lexical elements on the one hand, and modality on the other (see, for example, Ridruejo 1999, Wandruszka 2001, Quer 2002 and Becker 2014). ${ }^{9}$ This is similarly

7 Here, aspetto or aspect also refer to what in this work is called "aspectuality". The polysemy of the term aspect (language-particular grammatical verbal category and crosslinguistic content category) and the problems associated with it have already been pointed out in the introduction; see, especially, Sasse (1991 and 2002).

8 Schwarze's grammar was recently translated into Italian, revised and reissued; see Schwarze (2010).

9 In non-Romance research see, especially, Palmer (2001). 
true for temporality, because the prevailing opinion tends to be that the deictic location of states of affairs in time can be realised grammatically by verbal tense marking as well as lexically by adverbial determinations (see, among others, Bertinetto 1986, Vater 1994 and Klein 1994).

With regards to aspectuality, this distinction cannot be easily assumed, as was shown in Chapter 1, even implicitly. Therefore, before we can turn to the theoretical treatment of aspectuality, it is helpful to point out the - also formal parallel between aspectuality and modality: aspectuality expresses a) a semantic function by various linguistic means, as does modality; it can be realised b) as modality both grammatically and lexically - and to varying degrees - and at different levels of the language system (morphologically or syntactically).

Table (1) gives some examples from the four Romance languages dealt with here, which represent concrete linguistic realisations of the categories of modality and aspectuality. The various rows in the table contain examples of modal verbs and so-called "aspect verbs", adverbials, derivational affixes, periphrastic constructions, grammatical verbal categories such as modes or aspects, and tenses. Presented in this way, the items should also show the comparability of the two content categories and thus support the onomasiological perspective on aspectual content in the Romance languages. ${ }^{10}$

Tab. 1: Modality and Aspectuality compared.

\begin{tabular}{llll}
\hline Modality & & Aspectuality & \\
\hline Modal verbs $^{11}$ & It. potere & Aspect & It. iniziare \\
& Fr. devoir & verbs $^{12}$ & Fr. finir \\
& Sp. querer & & Sp. acabar \\
& Cat. voler & & Cat. durar \\
\hline
\end{tabular}

10 Of course, the examples given are not the only options. Although, for example, we see the Catalan Imperfet (volia demanar-te un favor) under the category "tenses as an expression of modal function", the Catalan future tense can also be used with this function. On the other hand, we see the future tense in the French example, yet the imperfect can also be used with this function.

11 Verbs that to varying degrees contain components with modal meaning in the verb stem are also included here. Such verbs are frequently used in more complex periphrastic constructions, e.g., It. dovere + infinitive. For modal periphrases in Italian in general, see Dessì Schmid (2012).

12 Verbs that to varying degrees have components of aspectual meaning in the stem are also included here. Such verbs are frequently used in more complex periphrastic constructions, e.g., It. cominciare $a+$ infinitive. 
Tab. 1 (continued)

\begin{tabular}{|c|c|c|c|}
\hline Modality & & Aspectuality & \\
\hline Adverbials & $\begin{array}{l}\text { It. piano } \\
\text { Fr. adv. ending in -ment } \\
\quad(\text { vraiment })^{13} \\
\text { Sp. adv. ending in -mente } \\
\quad \text { (dulcemente) } \\
\text { Cat. adv. ending in -ment } \\
\quad \text { (ràpidament) }\end{array}$ & Adverbials & $\begin{array}{l}\text { It. mentre } \\
\text { Fr. pendant } \\
\text { Sp. durante } \\
\text { Cat. a poc a poc }\end{array}$ \\
\hline $\begin{array}{l}\text { Further } \\
\text { (derivational) } \\
\text { affixes }\end{array}$ & $\begin{array}{l}\text { It. -icch- (canticchiare) } \\
\text { Fr. -ible (visible) } \\
\text { Sp. -isc- (mordiscar) } \\
\text { Cat. -ible (factible) }\end{array}$ & $\begin{array}{l}\text { Further } \\
\text { (derivational) } \\
\text { affixes }\end{array}$ & $\begin{array}{l}\text { It. -ell- (saltellare) } \\
\text { Fr. re- (reformuler) } \\
\text { Sp. en- (-er) (envejecer) } \\
\text { Cat. -ada (diada) }\end{array}$ \\
\hline $\begin{array}{l}\text { Periphrastic } \\
\text { constructions }^{14}\end{array}$ & $\begin{array}{l}\text { It. essere necessario + } \\
\text { Infinito (è necessario } \\
\text { prendere la macchina) } \\
\text { Fr. il faut + Infinitif/que... } \\
\text { Subj. (il faut que je vienne) } \\
\text { Sp. tener que + Infinitivo } \\
\text { (tengo que hablar contigo) } \\
\text { Cat. haver de + Infinitiu } \\
\quad \text { (he de veure la Rosina) }\end{array}$ & $\begin{array}{l}\text { Periphrastic } \\
\text { constructions }\end{array}$ & $\begin{array}{l}\text { It. venire + Gerundio } \\
\text { (il giudice viene } \\
\text { raccogliendo prove) } \\
\text { Fr. être en train de + } \\
\text { Infinitif (il est en } \\
\text { train de parler avec } \\
\text { Marie) } \\
\text { Sp. andar + Gerundio } \\
\text { (Juan anda haciendo } \\
\text { cosas raras) } \\
\text { Cat. estar + Gerundi } \\
\text { (em vaig estar } \\
\text { despertant tota la nit) }\end{array}$ \\
\hline Modes & $\begin{array}{l}\text { It. Condizionale (vorrei } \\
\text { parlare con te) } \\
\text { Fr. Subjonctif (je ne crois pas } \\
\text { qu'il vienne) } \\
\text { Sp. Gerundio (paso el tiempo } \\
\text { hablando con mi sombra) } \\
\text { Cat. Indicatiu (en Pau toca el } \\
\text { violin) }\end{array}$ & Aspects & $\begin{array}{l}\text { It. Perf. Sem. vs. Perf. } \\
\text { Com. (sognò vs. ha } \\
\text { sognato) } \\
\text { Fr. Pass. Sim. vs. Imp. (il } \\
\text { crut vs. il croyait) } \\
\text { Sp. Perf. Sim. vs. Imp. } \\
\text { (nací vs. nacía) } \\
\text { Cat. Pret. Perf. Per. vs. } \\
\text { Imp. (va parlar vs. } \\
\text { parlava) }\end{array}$ \\
\hline
\end{tabular}

13 On the problem of classifying adverbs ending in -mente as inflectional or derivational see, among others, Schwarze (2005).

14 Periphrastic constructions can differ in their degree of grammaticalisation, see Chapter 6. 
Tab. 1 (continued)

\begin{tabular}{llll}
\hline Modality & Aspectuality & \\
\hline Tenses & It. Imp. (se lo sapevo te lo & Tenses & It. Pres. (sogna) \\
& $\quad$ dicevo) & Fr. Imp. (il croyait) \\
& $\begin{array}{l}\text { Fr. Fut. (Qui sera à la porte?) } \\
\text { Sp. Imp. (¿Pero no estudiabas } \\
\text { para abogado?) }\end{array}$ & Sp. Perf. Sim. (nació) \\
& & Cat. Fut. (parlarà) \\
& Cat. Imp. (volia demanar-te \\
& un favor) & \\
\hline
\end{tabular}

\subsection{Onomasiological approaches to aspectuality}

\subsubsection{Aspectuality in Romance linguistics - De Miguel's concept}

Elena De Miguel's (1999) work constitutes a real exception in Romance research, which includes few studies on aspectuality. Her first definition of aspectualidad already clearly shows her line of interpretation:

El término 'aspecto' abarca un amplio conjunto de informaciones relacionadas con el modo en que tiene lugar el evento descrito por un predicado. El aspecto informa sobre la manera en que un evento se desarrolla o ocurre [.. .]. El aspecto informa también sobre la extensión temporal del evento. [...] Estas informaciones relativas al evento pueden manifestarse en las distintas lenguas a través de diferentes procedimientos; en español, pueden estar contenidas en la raíz verbal, como en llegar frente a viajar; en ese caso, será el comportamiento sintáctico del verbo el que nos ayude a discriminar su información aspectual. Pueden venir proporcionadas por ciertos morfemas derivativos, como ocurre en repeinar enfrente a peinar. Y pueden también ser aportadas por los morfemas flexivos, por perífrasis y por otros elementos del contexto en que se incluye un determinado verbo. (De Miguel 1999, 2979)

The term 'aspect' encompasses a broad set of information related to the way in which an event described by a predicate takes place. Aspect informs about the way in which an event develops or takes place [...]. Aspect also informs about the temporal extension of the event. [...] This information related to the event can be manifested in different languages through different procedures; in Spanish, it can be contained in the verbal root, as in llegar 'to arrive' vs. viajar 'to travel'; in this case, it will be the syntactic behaviour of the verb that helps us to discern its aspectual information. This can be provided by certain derivational morphemes, such as [the prefix re-sds] in repeinar 'to comb repeatedly' vs. peinar 'to comb'. And aspectual information can also be provided by inflectional morphemes, periphrasis and other elements in the context containing a particular verb. 
De Miguel draws up (in clear onomasiological terms) a classification of forms by which aspectuality is expressed in Spanish. She distinguishes between the general content category, understood as semantically homogeneous and which she holds to occur at the verb and sentence level, and its language-particular manifestations or realisations. These in turn can be lexical or grammatical categories and are called "lexical aspect" (aspecto léxico) and "grammatical aspect" (aspecto flexivo) or aspect in the narrower sense. ${ }^{15}$ In addition to these two subcategories, she also distinguishes, following the structuring of aspectuality developed by Maslov (1978, 21), an aspecto léxico-sintáctico, which has the advantage of integrating even more complex and so-called hybrid constructions, such as verbal periphrases, into the schema, and defines elements such as adverbials not only as lexical but also in terms of their syntactic characteristics; this is shown in Table (2).

Nonetheless, De Miguel has not yet completely freed herself from certain traditional (semasiologically derived) distinctions, and the classification criteria that she uses are basically inspired by Bertinetto's (see \$1.3.1) and the general classical literature on the subject. ${ }^{16}$ However, she doesn't deal with aspectuality in its broader sense, and as she understands it herself, since the limits of her investigation are tied to the aspecto léxico - the title of her contribution. It should not, furthermore, be forgotten that De Miguel's article appears in the same grammar, a few pages further on, as Rojo and Veiga's article on temporal relations in the Spanish verbal system, in which they deny the existence of grammatical aspect (see \$1.3.2).

The author herself is very well aware of this problem, this contradiction between a programmatic approach and the terminology used, which cannot accommodate such an approach. She even addresses it directly:

15 Thus, the author shares Comrie's (1976) by now classical definition of the aspectual domain (see also Chapter 1), which is also content based and ignores the distinction between aspect in the narrower sense and Aktionsart: "In treatments of aspect, there is no such uniformity of terminology, so that the term 'aspect' is now used to refer to the general semantic oppositions possible, now restricted to particular grammaticalised oppositions based on these semantic distinctions in individual languages. In the present book we shall speak of semantic aspectual distinctions, such as that between perfective and imperfective meaning, irrespective of whether they are grammaticalised or lexicalised in individual languages.” (Comrie 1976, 6f.). Comrie is generally concerned with the crosslinguistic category of aspectuality (even though he calls this aspect), as he clarifies in the introduction to his book: "The aim of the present book is to provide an introduction to verbal aspect and related concepts. It differs from most other books on aspect in that it is not concerned with any one particular language, nor with comparison of various individual languages, but rather presents aspect as a part of general linguistic theory.” (1976, vii).

16 However, the author emphasises that the analysis of dynamic states of affairs as constituted of phases is based on Pustejovsky (1988, 1991 and 1995). 
Tab. 2: Diagram of Aspectualidad adapted from De Miguel (1999, 2993).

\begin{tabular}{|c|c|c|c|}
\hline \multirow[t]{6}{*}{ Aspectualidad } & \multirow[t]{4}{*}{ verbal } & $\begin{array}{l}\text { oposición de formas de un } \\
\text { mismo verbo (oposición } \\
\text { imperfecto/perfecto simple) }\end{array}$ & aspecto flexivo \\
\hline & & afijos derivativos (re-) & \multirow[t]{2}{*}{ aspecto léxico } \\
\hline & & $\begin{array}{l}\text { oposición de las clases } \\
\text { aspectuales de verbos (“modos } \\
\text { de acción”: viajar, llegar) }\end{array}$ & \\
\hline & & $\begin{array}{l}\text { ciertas combinaciones de verbos } \\
\text { (modos de acción analíticos; } \\
\text { perífrasis verbales) }\end{array}$ & $\begin{array}{l}\text { aspecto léxico- } \\
\text { sintáctico }\end{array}$ \\
\hline & \multirow[t]{2}{*}{ oracional } & $\begin{array}{l}\text { marcas lexicales y funcionales } \\
\text { (adverbios, negación) }\end{array}$ & \\
\hline & & $\begin{array}{l}\text { características gramaticales de } \\
\text { los participantes en el evento } \\
\text { (función semántica y sintáctica, } \\
\text { número, determinación, } \\
\text { cuantificación) }\end{array}$ & \\
\hline
\end{tabular}

Pese a todo, parece conveniente mantener el término de 'aspecto léxico', por tradición, por comodidad y por atender a su especificación original - la que lo distingue del aspecto flexivo (en cuanto que manifestación morfológica productiva y regular) y del tiempo (como categoría también con realización morfológica productiva y regular que no toma en cuenta el significado de la base verbal). Así se hace por lo general, a pesar de que este modus operandi pueda resultar paradójico o inadecuado si no se concibe el término como una mera etiqueta que recubre un concepto más abarcador. (De Miguel 1999, 2987)

In spite of everything, it seems advisable to keep the term 'lexical aspect', because of tradition and convenience and because of its original specification - which distinguishes it from grammatical aspect (as a productive and regular morphological manifestation) and from tense (as a category also with productive and regular morphological realisation that does not take into account the meaning of the verbal base). This is generally done, although this modus operandi may be paradoxical or inappropriate if the term is not conceived of as a mere label covering a more comprehensive concept.

However, since this problem is not resolved, even by calling "pure labels" what in fact are categorial criteria of classification, I will adopt this general onomasiological approach but will take it further with the aim of developing a new classification of the components of aspectuality. 


\subsubsection{The two components of the aspectual domain - Smith's approach}

An opposing view of aspectuality is advocated in the work of Carlota Smith (1991), who developed a bicomponent or bidimensional theory of the aspectual domain, ${ }^{17}$ which can be ascribed to the theoretical framework of universal grammar. ${ }^{18}$

The work is based on the thesis that two separate, though interacting, components merge with the aspectual information in a sentence and thus determine it by and through their interaction. Smith calls these two components situation type $e^{19}$ and viewpoint. The different situation types or situation aspects which are comparable to the traditional Aktionsarten - temporally structure the sentence in general, i.e., they convey the basic temporal structure of a state of affairs. On the other hand, the different viewpoint aspects - which are comparable to the realisations of traditional aspect - focus a part of this structuring in a special way:

Sentences present aspectual information about situation type and viewpoint. Although they co-occur, the two types of information are independent. [...] The receiver of a sentence knows how much of a situation is presented, and to what situation type it belongs. [...] [Aspectual sds] information is given by the linguistic forms of the sentence: situation type is signalled by the verb and its arguments, viewpoint signalled by a grammatical morpheme, usually part of the verb or verb phrase. Tense and adverbials may give additional temporal information. [...] The viewpoint of a sentence presents an event with a particular extent and focus, rather as a camera lens may focus. In framing a sentence the speaker chooses situation type and viewpoint, subject to the pattern of the language. (Smith 1991, 5f.)

The universal character of aspectuality, based on general human cognitive abilities, is confirmed by the author in more than one place, as is the role of the speaker - emphasised at the end of the quote - in choosing both subcomponents of the aspectual domain.

Concerning the situation aspect, compared with other classifications of verb classes Smith adds a further type besides states, achievements, accomplishments

17 This author, too, calls aspect what is referred to here as "aspectuality".

18 The title of the book, The Parameter of Aspect, already shows a clear relation to the principles-and-parameters model of grammar. However, for the formal presentation of her analysis Smith chooses the Discourse Representation Theory (DRT) developed by Heim (1982, 1983a and 1983b), Kamp (1981a and 1982b) and Kamp/Rohrer (1983).

19 "The situation types classify events and states at a level that is general and abstract enough to account for the range of possibilities that occurs. Each type is related to a schema of the essential structure of situations." (Smith 1991, 28). 
and activities, namely semelfactives. ${ }^{20}$ She divides the viewpoint aspect into three subcategories: a perfective viewpoint, focussing on both the starting and endpoint of a state of affairs, an imperfective viewpoint that focusses neither on the beginning nor the end of a state of affairs but only on one of its phases, and, finally, a neutral viewpoint, which is an innovation compared with the traditional divisions of aspect (see §1.2.2). The latter is understood as a default viewpoint, which is used in sentences without explicit morphological aspectual marking and which focusses on a phase of the state of affairs (including its starting point and a certain subinterval of it). The reasons for this innovation, which does not seem to be unproblematic, ${ }^{21}$ are of a theoretical nature and serve to give coherence to Smith's approach, as she herself clearly acknowledges:

The two-component theory requires that all sentences have a viewpoint, since situation type information is not visible without one. This theoretical requirement has the interesting consequence that sentences with no explicit aspectual morpheme must have an aspectual viewpoint. I posit the Neutral viewpoint as a default for such sentences. The default viewpoint gives partial information, which allows for the interpretations that speakers make of such sentences. (Smith 1991, 93)

In the following pages I will discuss Smith's main thesis, namely the subdivision of the general - semantically-universal, cognitively-conceived - aspectual domain into two components, which also differ semantically and are independent of each other.

\subsection{Bidimensional vs. unidimensional approaches to aspectuality}

The presentation of De Miguel's and Smith's approaches - which, as has been shown, represent two opposing lines of research on aspectuality - now leads directly to the crux of the problem and allows us to pose the crucial question for aspectologists, that is, the semantics of the aspectual domain.

20 An overview over these classifications can be found in §1.2.4.

21 On the one hand, the aspectual content, which according to Smith is expressed by the neutral viewpoint (or not expressed, since it is not explicitly marked), might as well be ascribed to the context, i.e., it is explained by pragmatic factors. On the other hand, another possibility for interpreting such ambiguous aspectual contents is with reference to the aspectual polysemy of some forms. This will be discussed and advocated in several places in the following. 


\subsubsection{Aspect and Aktionsart - two categories?}

In recent years, the question of whether it is legitimate and necessary to speak of aspect in the Romance or generally non-Slavic languages has been correctly reformulated as the question of how to speak legitimately of aspect in the different languages of the world. As already pointed out, there has been a remarkable increase in the number of works dealing with the categories of the verbal system. ${ }^{22}$ Some of these have been presented briefly and selectively in this and the previous chapter, some more will be commented on in the following pages, though not in detail but rather via important common questions. ${ }^{23}$

Certainly, these recent contributions may contain some points on which there is a more or less broad consensus: for example, the need to distinguish between language-particular aspectual categories and the universal conceptual category of aspectuality; ${ }^{24}$ or the view that the content of aspectuality can be defined, in particular, as delimitation or demarcation, i.e., very generally as the setting of temporal boundaries in the structuring of states of affairs, and that therefore one of the fundamental distinctions between the different types of states of affairs is precisely that between the delimited and the non-delimited.

With regard to the structuring of the categorial aspectual domain - and thus the relationship between aspect and Aktionsart as categorial dimensions within this domain (see Sasse 2002 and Squartini 1990) - two opposing and incompatible approaches can be clearly identified:

- A bidimensional approach that asserts the existence of a fundamental difference between aspect and Aktionsart on different levels (i.e., not only formal but also semantic), with different authors basing their work on very different foundations resulting in very different theoretical constructs. These represent two clearly distinct subcategories of the aspectual domain (see, among many others, Bache 1982, 1995a and 1995b, Bertinetto 1986 and 1994, Ehrich 1992 and Smith 1991). ${ }^{25}$

- A unidimensional approach - here also with very different results - that does not maintain a categorial subdivision within the aspectual domain.

22 Here, onomasiological work has been carried out mainly in the cognitive and formallogical spheres as well as in the field of typological research. In Romance research, on the other hand, there is still a lack of detailed, comparative studies (Coseriu 1976 is the last contribution).

23 See Sasse (2002) - who will be referred to repeatedly on the following pages - for a critical compilation of recent aspectological research.

24 As mentioned above (\$1.4), the lack of precision on this point has long been noted. 25 See also Depraetere (1995) and Squartini (1990 and 1998). 
Here, it is asserted that on a universal semantic level (i.e., on a general cognitive level) there are no differences between aspect and Aktionsart. Its advocates assume (more or less radically) that it is possible to analyse and describe the various aspectual phenomena on all levels of representation (lexical, morphological, syntactic, etc.) on the basis of a single conceptual dimension, or, in some cases, also as a compact group of basic meanings or concepts (see especially the formally oriented works of Verkuyl 1972 and $\left.1993^{26}\right) .^{27}$

These perspectives and the objections raised against them are now discussed critically and in detail.

Romance research of the last few years, with the very few exceptions that have already been mentioned, is not inclined to follow unidimensional approaches, perhaps also because researchers often follow the work of Bertinetto, one of the most staunch advocates of bidimensional approaches. ${ }^{28}$ But the fact

26 On Verkuyl's approach see §3.5.

27 See also Maslov $(1973,1985)$ for the Slavic languages, Schwall (1991) and De Miguel (1999) for the Romance languages. Works by Herweg (1990), Kamp/Rohrer (1983) and Sasse (1991) are also, in part, considered as adhering to unidimensional theories (on this, see Squartini 1998, 10f.). Sasse himself (2002) distinguishes some "genuine" bidimensional approaches (such as, e.g., Bertinetto's and Smith's, which he describes as composite theories of aspect) from other moderate ones (radical selection theories of aspect): "Radical selection theories can be said to exhibit only moderate bidimensionality insofar as they recognize two distinct components of aspectual relevance, one which continues the traditional 'viewpoint' aspect opposition (ASPECT1) and one which continues the 'Aktionsart' tradition (ASPECT2), but the two 'dimensions' ultimately result from the distribution, over two distinct levels, of what are assumed to be basically the same cognitive categories: ASPECT1 features systematically realize parts of ASPECT2 schemata, i.e., serve to exploit the inherent aspectual potential of verb lexemes in systematic ways.” (Sasse 2002, 225). He considers, for example, Bickel (1996, 1997 and 2000), Breu (1984, 1985 and 1994) and Timberlake (1985) to be in this group. When I speak of advocates of bidimensionalism in this book, I refer to the "more extreme" or "genuine" of these approaches. In this regard, Croft in his latest work takes a special position: "The approach presented here is basically a unidimensional approach, but with an essential contribution from the bidimensional approach. Our primary interest is with the semantic structure of predicates. [...] [A] bidimensional approach [...] contributes an important element to the analysis of aspect that should not be overlooked. Events do not have just an inherent aspectual type, as assumed in some unidimensional approaches: the event may be viewed from different aspectual perspectives or viewpoints. This observation is represented in our approach by the phenomenon of construal [...]. Construal is a generalization of the idea of different viewpoints or perspectives, aspectual or otherwise, on a situation [. . .].” (Croft 2012, 32).

28 See, e.g., Squartini (especially 1990 and 1998) on verbal periphrases, but also Laca (especially 1995, 2002b, 2004a and 2004b); see also, among others, Pérez Saldanya (2002). 
is that many aspectual phenomena are difficult to explain if they are forced into the narrow limits of a categorisation that recognises a semantic difference between Aktionsart and aspect, and that claims it is necessary to separate them. At least when trying to explain these phenomena, one is compelled which from a theoretical standpoint seems less elegant - to speak of "loss", "acquisition" or "transformation" of actional properties, of verbs that change their nature, for example, by "ceasing" to be atelic and becoming telic, of particular affinities or idiosyncrasies between some forms of aspect and Aktionsart, and of aspectually hybrid linguistic forms such as verbal periphrases, which are not easy to assign to one or another category.

Table (3) summarises the differences that are traditionally held to exist between aspect and Aktionsart; ${ }^{29}$ the criteria used to determine these differences are then critically discussed on the following pages.

Tab. 3: Differences between aspect and Aktionsart according to the traditional interpretation.

\section{Aspect}

Exemplified, e.g., via the perfective vs. imperfective opposition marked on the verb

\section{Aktionsart}

Exemplified, e.g., via the verb meanings as anchored in the lexicon, see Vendler's verb classes

\begin{tabular}{ll}
\hline $\begin{array}{l}\text { Grammatical category } \\
\text { Verbal inflection (highly grammaticalised } \\
\text { verbal periphrases) }\end{array}$ & $\begin{array}{l}\text { Lexical category } \\
\text { The meaning of the verb as it is anchored in } \\
\text { the lexicon }\end{array}$ \\
\hline $\begin{array}{l}\text { Obligatory category } \\
\text { because it is grammatical }\end{array}$ & $\begin{array}{l}\text { Optional category } \\
\text { because it is lexical }\end{array}$ \\
\hline $\begin{array}{l}\text { Subjective category } \\
\begin{array}{l}\text { Point-of-view category, via which the speaker } \\
\text { expresses a state of affairs (e.g., as a whole, } \\
\text { completed or in progress) }\end{array}\end{array}$ & $\begin{array}{l}\text { Objective category } \\
\text { Category that is inherent to the state of affairs } \\
\text { (the speaker cannot influence it) }\end{array}$ \\
\hline
\end{tabular}

29 In some works we also find the following distinction: aspect does not occur in all languages (not all languages express aspectual contents by grammatical inflectional morphemes), while Aktionsarten can be found in all languages (in all languages there are different verb types, verb classes) and therefore Aktionsarten can be described as universal. I contradict this thesis in this work, because either aspect and Aktionsart, as defined, belong to the semantics of an individual language (and thus neither are universal), or they are both parts of a superordinate cognitive category, that of aspectuality, which belongs to crosslinguistic semantics (and are therefore both universal). 


\subsubsection{Grammaticality vs. Lexicality, Obligatoriness vs. Optionality, Subjectivity vs. Objectivity}

The differences that are traditionally identified between aspect and Aktionsart can be assigned to the following criteria: Grammaticality vs. Lexicality, Obligatoriness vs. Optionality, Subjectivity vs. Objectivity.

The first distinguishing criterion (Grammaticality vs. Lexicality) - that aspect is a grammatical category and Aktionsart a lexical one - is purely formal. It refers to the ways in which the two categories are expressed. In particular, if the semantic homogeneity of aspect and Aktionsart is recognised, a purely formal criterion may not be sufficient to justify such a strict categorial separation, except from a semasiological perspective, which may be good for examinations of individual languages, but not for contrastive studies. ${ }^{30}$

Even where the focus is on analysing a single language, it seems very difficult to define Aktionsart as a purely lexical category, since the "nature" of a verb, its assignment to a certain Aktionsart, can only be interpreted within the entire context of the syntagma and the sentence (see Verkuyl 1972). As has already been pointed out in \$1.2.4, this also depends on phenomena that are more likely to be related to the grammatical sphere, for example, to the presence or absence of certain verb arguments ${ }^{31}$ and their quantification or the degree of their determination or definiteness, certain adverbial determinations, and many other components that do not necessarily directly convey specific aspectual content (such as syntax, negation, etc.).

The insistence on this criterion of grammaticality/lexicality is further complicated by the thesis now widely held that the distinction between lexical and grammatical elements cannot be understood as an indication of their affiliation to discrete classes, but rather that they should be interpreted as belonging to a continuum, of which lexicon and grammar represent the two poles of variable realities, since linguistic elements may have a greater or lesser degree of grammaticality or lexicality. It is mainly cognitive and typological research ${ }^{32}$ as well as research on grammaticalisation ${ }^{33}$ in recent years that have contributed to this

30 On this see also Coseriu (1987, 125).

31 When comparing verbs such as andare and andare (da Roma) a Parigi, following the traditional verb classification the former would be interpreted as atelic, the latter as telic.

32 See Langacker (2006); see also Bybee (1985), Bybee/Dahl (1989), Bybee/Perkins/Pagliuca (1994) and Dahl (1985 and 2000).

33 See, among others, Haspelmath (1998), Hopper (1991), Hopper/Traugott (2003), Ch. Lehmann (1995 and 2002); for Romance studies Detges/Waltereit (2002), Lang/NeumannHolzschuh (1999) and Marchello-Nizia (2006). The works of advocates of the so-called "split- 
new conception of the relationship between lexical and grammatical elements. And it is now evident how from such a perspective it becomes secondary whether aspectual content, considered to be semantically homogeneous, is expressed grammatically, as in the case of aspect, or lexically, as in the case of Aktionsart.

This seems particularly important in the case of verbal periphrases, which play an essential role in Romance languages in the expression of aspectual meanings, and where it is difficult to determine whether they are grammatical or lexical phenomena - and thus whether they are related to aspect or Aktionsart. For, even when using flexible and convincing definitional solutions, such as that of Squartini (1998), who developed a scalar theory of periphrasticity, it is not easy to decide what degree of grammaticality an aspectual verbal periphrasis has reached, or what remains of its lexicality, as the following examples clearly show:

(1) It. Marta viene [Pres.] raccontando storie bizzarre da tre settimane. [venire + Ger.]

'Marta's been telling bizarre stories for three weeks.'

(2) It. Leo comincia [Pres.] a leggere e a scrivere. [cominciare $a+$ Inf.] 'Leo begins to read and write.'

(3) Fr. Julie vient [Prés.] de chanter. [venir de + Inf.] 'Julie has just sung.'

(4) Fr. Marie-Rose se met [Prés.] à chanter. [se mettre à + Inf.] 'Marie-Rose starts singing.'

(5) Sp. Acabo [Pres.] de escribir una carta. [acabar de + Inf.] 'I have just written a letter.'

(6) Sp. Antonio anda [Pres.] haciendo cosas interesantes. [andar + Ger.] 'Antonio has been doing interesting things. 34

morphology hypothesis", which assumes a strict separation between the grammatical and the lexical domains, argue against this thesis: see, among others, Anderson (1982 and 1988) and Scalise (1984 and 1988). For a comparison of these two types of approaches in consideration of the relationship between grammatical and lexical elements see Haspelmath (2002).

34 This literal translation of example (6) does not fully capture the meaning of the original which is that Antonio not only has been doing but continues to do interesting things. 
(7) Cat. La Rosina comença [Pres.] a llegir el japonès. [començar $a+$ Inf.] 'Rosina begins to read Japanese.'

(8) Cat. M'estic [Pres.] menjant una galeta. [estar + Ger.]

'I'm eating a cookie.'

The degree of grammaticality of periphrases such as the type venire or stare + gerund (in examples (1) and (8)) is indeed greater, and therefore closer to genuine inflectionally marked aspect forms, than that of periphrases of the type cominciare/començar $a+$ infinitive (in examples (2) and (7)). For stare is to be regarded here as a canonical auxiliary verb and shows no (further) traces of the lexical meaning of 'to be, to exist', which it possesses as a full verb. On the other hand, cominciare and començar still exhibit clear traces of the lexical meaning of these verbs, even though they appear here in the function of auxiliary verbs. ${ }^{35}$

At this point, a small parenthesis from the contrastive perspective will allow us to gain a deeper insight into this problematic phenomenon and will show, furthermore, the tendency of German to express aspectual content lexically, for which the Romance languages prefer grammatical means of varying degrees of grammaticalisation. Let us compare (1)-(8) with the following German examples:

(9) Ger. Jakob ist gerade dabei, genüsslich ein Schokocroissant zu essen. 'Jakob is about to enjoy eating a chocolate croissant.'

(10) Ger. Frieder war am Essen, als ich kam.

'Frieder was eating when I arrived.'

(11) Ger. Leo läuft seit drei Wochen mit der komischen Geschichte herum.

'Leo's been going around with that weird story for three weeks.'

There is a relatively broad consensus on the classification of (9) and (10) as grammaticalised - to whatever degree - periphrastic constructions, although they are not as frequent as in the Romance languages and their use, especially (10), is geographically limited to certain regions of Germany. Gerade dabei sein $z u$ essen in (9) is a two-part construction, the meaning of which cannot be obtained compositionally, i.e., by the sum of the meanings of its parts, as in the

35 See Chapter 6 for a more detailed explanation. 
case of a verbal periphrasis, because here gerade dabei sein certainly does not mean 'to exist here and now'. The first element of the periphrasis thus performs some kind of auxiliary verb function and the main lexical information of the entire predicate unit is supplied by the second element, the main verb essen ('to eat'). This is similarly true for (10). In (11), however, the construction used may be considered as lexically dominated (although the aspectual contents expressed here are conveyed in the Romance languages by verbal periphrases such as andare/ir + gerund). In other words, there is no grammaticality in herumlaufen ('to walk around'), as it is not to be understood as having an auxiliary verb function, but is rather the main verb in the sentence and is to be understood as a (more or less purely) lexical representation of aspectual content.

How, then, does one assign barely grammaticalised or actionally controlled periphrases, whether in German or in the Romance languages, where they play a very central role in the aspectual system? Are they Aktionsart or aspect? Is it preferable to talk about them as actional periphrases? And if so, when do they become proper aspectual periphrases? It is precisely such concrete cases that show very vividly the limits of the bidimensional conception of the aspectual domain. Chapter 6 will take a closer look at them.

The second distinguishing criterion (Obligatoriness vs. Optionality) is closely related to the first one, and consequently also to the above-mentioned problems with it. For it is based on the assumption that grammatical categories are obligatory, whereas lexical ones are optional, or dispensable. More precisely, this implies that aspect must necessarily be expressed in an utterance, since the syntax requires an inflectional marker, while Aktionsart does not need to be because the speaker can freely choose to use one or another verbal lexeme.

The effectiveness of this second criterion of distinction can also only be considered valid in a very limited way if the absolute necessity of separating the two categories is to be maintained. Firstly, a verbal lexeme as well as an inflectional marker have to be chosen, for the syntax to work, and a verbal lexeme is just as necessarily connected with Aktionsart (that is, an aspectual lexical content) as an inflectional marker is with aspect. In this sense, both are required, and both are chosen by the speaker with the aim of expressing what $\mathrm{s} /$ he wants to communicate. There are some well-founded objections to the absoluteness of the criterion of obligatoriness. Here, by way of example, mention should be made of the occurrence of neutralisation even in the case of obligatory grammatical morphemes (e.g., the present tense), or the possibility in German as well as in Spanish and Italian of utterances without a finite verbal element (which thus requires omission of obligatory tense marking, see Klein 
1983, 151). Even leaving aside these objections, ${ }^{36}$ as well as those to all the other criteria on the basis of which inflectional and derivational categories are distinguished, it is clear, in any case, that the argument concerning the obligatoriness of aspect or the optionality of Aktionsart can only be valid for a given system of an individual language and not for language comparison. ${ }^{37}$

The third and final distinguishing criterion (Subjectivity vs. Objectivity), which is the subjectivity of aspect and the objectivity of Aktionsart, is, unlike the first two, of a semantic nature. Following this view, Aktionsart represents what the speaker is talking about, that is, the temporal structure of a state of affairs as it is, while aspect is the way in which the speaker speaks of it, that is, the free (thus subjective) representation of the temporal structure of a state of affairs (see, among others, Bache 1995a and 1995b, Bertinetto 1986 and 1994, as well as Smith 1991 for this view).

However, against the supposedly free choice of the speaker, who can determine the perspective of the state of affairs (as perfective or imperfective), it must be objected that this decision is often strongly influenced by the verb used, i.e., by the aspectual (and non-aspectual) information anchored in the verb meaning and then, of course, throughout the entire context of the utterance. Speakers are therefore often limited in their choice of aspect by the (aspectual) possibilities and combinations already given by the context. Consider what traditional grammar calls "preferences" and "idiosyncrasies" in the combination of traits of both aspect and Aktionsart. For example, in contemporary Italian it is impossible to combine the states shown in the following examples with the perfective (12) or the imperfective aspect of the progressive type (13):

(12) It. *Carlo fu biondo.

'Carlo was blonde.'

(13) It. ${ }^{\star}$ Carlo sta essendo biondo. ${ }^{38}$

‘`Carlo is being blonde.'

36 See, e.g., Bybee (1985), Haspelmath (2002), but also cf. advocates of split morphology, for example Scalise (1988). On the argument concerning obligatoriness in general, see Greenberg (1954) and, later, Matthews (1974), as well as Anderson (1982).

37 The fact that the criterion of obligatoriness of grammatical (morphological) markers does not apply equally to all languages should also be borne in mind.

38 For an analysis of the conditions or restrictions in combining verb classes and aspect in Russian see Anstatt (2003). 
Analogously, one can argue with Dahl $(1981,83)$ against the alleged objectivity of Aktionsarten:

- No verb belongs "unchangeably" to a predicate class (or Aktionsart), as shown in the following examples $(14 a / b)-(16 a / b)$, in which the speaker describes the state of affairs as telic (as in (14a)-(16a)) or atelic (as in (14b)-(16b)).

- Moreover, the speaker may choose whether to present a state of affairs as dynamic, as in (17a)-(19a) (in this case, each is an activity), or else as static as in (17b)-(19b):

(14a) It. Leo mangia [Pres.] un gelato.

'Leo is eating an ice cream.'

(14b) It. Leo mangia [Pres.].

'Leo is eating.'

(15a) Eng. Richard eats [Sim. Pres.] sandwiches.

(15b) Eng. Richard eats [Sim. Pres.] a sandwich.

(16a) Ger. Julia isst [Präs.] ein Eis.

'Julia is eating an ice cream.'

(16b) Ger. Julia isst [Präs.].

'Julia is eating.'

(17a) It. Leo vola [Pres.] tra l'Italia e la Germania.

'Leo is flying from Italy to Germany.'

(17b) It. Leo è [Pres.] in volo tra l'Italia e la Germania.

'Leo is on a flight between Italy and Germany.'

(18a) Eng. Richard is flying [Pres. Prog.] from Italy to Germany.

(18b) Eng. Richard is [Sim. Pres.] on a flight between Italy and Germany.

(19a) Ger. Julia fliegt [Prät.] zwischen Italien und Deutschland. 'Julia is flying from Italy to Germany.' 
(19b) Ger. Julia befindet [Prät.] sich auf dem Flug zwischen Italien und Deutschland.

'Julia is on a flight between Italy and Germany.'

Thus, in Krifka's words, we can insist that:

[...] der Begriff des festen oder nicht-festen Endpunktes gar nicht sinnvoll auf ein einzelnes Ereignis angewendet werden kann: Wenn wir ein bestimmtes Ereignis, zum Beispiel ein bestimmtes Lauf-Ereignis, betrachten, dann hat dies natürlich immer einen festen Endpunkt (ebenso wie einen festen Anfangspunkt). Es macht erst Sinn, von festen und nichtfesten Endpunkten zu sprechen, wenn wir berücksichtigen, wie ein Ereignis beschrieben ist. Wenn ein Ereignis e mit laufen beschrieben wird, so ergibt sich der atelische Charakter daraus, dass es Ereignisse e' gibt, die länger dauern, e als Teil enthalten und die noch immer mit laufen beschrieben werden können. Wenn dasselbe Ereignis e hingegen mit drei Kilometer laufen beschrieben wird, so ist der telische Charakter eben darauf zurückzuführen, dass es keine Ereignisse e' gibt, die länger dauern, e als Teil enthalten und mit drei Kilometer laufen beschrieben werden können. Den Unterschied zwischen Telizität und Atelizität kann man also gar nicht an den Ereignissen selbst festmachen, sondern man muß hierzu auf die Ebene der Ereignisbeschreibung, oder alternativ auf die Ebene der Begriffe, hinaufsteigen. (Krifka 1989b, 237)

[...] the terms fixed or non-fixed endpoint cannot be meaningfully applied to a single event. If we consider a certain event (for example, a certain running event), then, of course, this always has a fixed endpoint (as well as a fixed starting point). It only makes sense to speak of fixed and non-fixed endpoints when we consider how an event is described. If an event $e$ is described as running, the atelic character results from the fact that there are events $e$ ' which have a longer duration and contain $e$ as a part and which can still be described as running. If, on the other hand, the same event $e$ is described as running three kilometres, then the telic character can be traced back to the fact that there are no events $e$ ' that have a longer duration, contain $e$ as a part and can be described as running three kilometres. So the difference between telicity and atelicity cannot be determined by the events themselves, but has to be moved up to the level of event description, or alternatively to the level of concepts.

In other words, speakers constantly move - and such a remark is actually banal - between freedoms and obligations. They seek out what they can and must choose from the means made available by their language (which are on a continuum between lexicon and grammar), what they can and must combine to achieve the desired effect: the successful and thus economic and/or expressive conveyance of the contents to be communicated.

Almost all the counter arguments discussed here are also more or less openly accepted by the opponents of - in Bertinetto's words - the "dangerous mixing of aspect and Aktionsart" (1986, 84). Furthermore, advocates of semantic differences within the aspectual domain acknowledge the similarity, the privileged relationship, the "indubbie connessioni che esistono fra queste due fondamentali 
caratterizzazioni semantiche delle forme verbali" ('the undoubted connections that exist between these two fundamental semantic characterisations of verbal forms'; Bertinetto 1986, 84), and even openly point out that the third distinguishing criterion is not correct:

Die so getroffene Unterscheidung [d. h. dass Aktionsarten sich auf kategoriale Eigenschaften von Sachverhalten beziehen, dass sie also unabhängig von der Sicht des Sprechers seien, während Aspekt die Perspektive (als zeitlich offen oder geschlossen) ausdrücke, unter der ein Sachverhalt vom Sprecher gesehen wird sds] berücksichtigt allerdings nicht, daß es auch von der Perspektive abhängt, ob ein Sachverhalt kategorial als zeitlich offener Zustand (die Rose blüht) oder als abgeschlossener Prozeß (die Rose verblüht) gesehen wird. Beide, Aktionsart und Aspekt, bringen zum Ausdruck, wie eine Situation gesehen wird, von innen in ihrem zeitlichen Verlauf oder von außen als zeitlich abgeschlossenes Ganzes. (Ehrich 1992, 74)

The distinction thus made [that Aktionsarten refer to categorial properties of states of affairs, i.e., that they are independent of the speaker's point of view, whereas aspect expresses the perspective (as temporally open or closed) from which a state of affairs is seen by the speaker sds] does not, however, take into account the fact that also dependent on the perspective is whether a state of affairs is seen categorially as temporally open (the rose is flowering) or as a completed process (the rose has withered). Both Aktionsart and aspect express how a situation is seen, from the inside in its temporal development or from the outside as a temporally completed whole.

Just as speakers can (or cannot) choose a type of aspect, they can also choose the lexeme which reflects the chosen perspective. The reason for the insistence on separation must therefore be found elsewhere. Referring to Smith's (1991) distinction between viewpoint aspect and situation aspect, Ehrich claims that the difference lies in the fact that "aspect reflects the current perspective, Aktionsart the conventionalised or 'frozen' one” (Ehrich 1992, 74, orig. Ger.). Objections can be raised against this argumentation from several points of view.

First of all, just as the perspective stored in the lexicon (here, in the verb stem) is "frozen" or conventionalised, so too is the perspective stored in the grammar, in the grammatical rule, which allows for variation, for choice between perfectivity and imperfectivity. In other words, the rule underlying the freely chosen aspectual perspective - the fact that it exists as a binary option following precise combinational possibilities - is to be considered as conventionalised and fixed as that of any Aktionsart. The assumed actuality by the decision for one or the other form of aspect is comparable to the decision for one or the other predicate, one or the other verb meaning. And why, in a linguistic system, should lexical determinations - which moreover are not so purely lexical, since they imply grammatical relationships with their own arguments - be more conventionalised than grammatical ones in the narrower sense? 
Secondly, grammaticalisation theory has also provided further evidence for the considerable flexibility in very transition between the linguistically "frozen" and "non-frozen" or "non-conventionalised". 39

Thirdly, the perspective is valid only in a language-particular system, since each particular conventionalisation is linked to an individual language, which of course means that it can change over time. This becomes evident, for example, when the above-mentioned impossibility of combining states with the perfective aspect in Modern Italian or French (see examples (12) and (13)) is compared with older stages of these two Romance languages: in Old Italian and Old French this combination was completely grammatical, as the following examples demonstrate: ${ }^{40}$

(20) OIt. Messer Polo Traversaro fu di Romagna, e fu lo più nobile uomo di tutta Romagna e tutta quasi la signoreggiava. (Novellino, 41, 2-3) 'Master Polo Traversaro was from Romagna, and was the most noble man in all of Romagna and governed almost all of it.'

(21) OFr. Bels fut li vespres et li soleilz fut cler. (The Song of Roland, v. 157) 'Beautiful was the vesper and clear was the sun.'

Finally, another possible objection can be found again in the analysis of verbal periphrases. As indicated above, it is very difficult, from a synchronic perspective, to assign the various verbal periphrases to aspect or Aktionsart using simple formal criteria because they exhibit different degrees of grammaticality or lexicality. It would be even more difficult, when distinguishing two subcategories of the common semantic domain of aspectuality, to determine the relationship that holds together the system of verbal periphrases synchronically: for what would be the common denominator, the reason for which all verbal periphrases can be classified as aspectual (including also the less grammatical ones, such as, e.g., the ingressive cominciare $a+$ infinitive)? It would also be

39 It should also be noted that this argumentation of actuality vs. conventionality loses its power when one adopts a frame-based conception of states of affairs, in which the current perspective of the state of affairs is linked to the actual constitution of the frame itself. This means that all elements which constitute a frame form this frame only in the actual realisation of their interaction and can only be perceived as its individual elements in the background of the frame.

40 This is related to the fact that the perfective forms in Old Italian and Old French could express several aspectual values, more than the equivalent forms (Passato Remoto and Passé Simple) today. 
very difficult to explain the development of periphrastic constructions diachronically if one were to deny that aspect and Aktionsart have common contents on a more general semantic level. ${ }^{41}$ And how can it be claimed that aspect and Aktionsart are separate synchronically if diachronically they share identical content on a more general semantic level?

\subsection{Limits of unidimensional approaches?}

The criticisms I have made of bidimensional approaches already shows that a unidimensional approach is to be taken here, one that is based on the conviction that from a cognitive point of view no content-related, i.e., semanticconceptual distinction can be made between aspect and Aktionsart:

From a cognitive point of view, aspect and aktionsart [...] are actually one and the same thing, the difference being a matter of individual lexicalization and grammaticalization processes. (Sasse 1991, 32)

At this point, before presenting my model of aspectuality, it is important to summarise the discussion of the two fundamental objections that are often levelled against unidimensional approaches:

- Firstly, the lack of theoretical rigour is attacked, supposedly exposed when different subdivisions of the two categories are intermingled terminologically, and also conceptually, when, for example, conceptual pairs such as telic/atelic and perfective/imperfective are rendered interchangeable. What is being reproached is the levelling out, the masking of the differences associated with levels of language and conceptual and categorial subdivisions.

- Furthermore, attention is drawn to the unsuitability of these approaches, which becomes obvious in the charge that detailed analyses of concrete linguistic phenomena are insufficiently fine-grained for the description and

41 Very often - and quite obviously in the case of Romance languages - the typical diachronic paths of grammaticalisation that lead to the constitution of grammaticalised aspectual periphrases, thereby approaching the category of aspect, start off as actionally characterised constructions (see §6.3.3). See in this regard the position taken by Squartini (1998, 17f.): "It [the progressive sds] is rather to be conceived of as an aspectual form, which derives diachronically (at least in some languages) from a construction constrained to a given actional value. From this point of view, even if aspect and actionality have to be considered as independent notions, a diachronic relationship between the two can be assumed, so that aspect emerges from actionality, or, put another way, aspect derives from the grammaticalization of actionality. This is why a semantic similarity between aspect and actionality can be recognized, [...] for aspect emerges from the same cognitive mould as actionality." 
interpretation of complex linguistic mechanisms. Since the unidimensional approaches are allegedly based on very simple and limited semantic instruments, they are supposedly only able to offer crude classifications that disregard or leave unexplained the finer gradations of linguistic phenomena.

The first objection is certainly justified: the approach is theoretically less consistent and can lead to various kinds of confusion - on the basis of criteria that rest on the existence of two categories that also differ semantically and which are assigned to two different linguistic levels, the grammar and the lexicon - in defining subcategories such as the imperfective and perfective on the one hand and the static, durative, telic etc. on the other hand, only to subsequently reassert the muddled identification of these subcategories with each other (the imperfective with the durative or the perfective with the telic). It is evident that these subcategories of the aspectual domain are, by definition, differently conceived of and therefore cannot be easily identified with each other. But is it really necessary to assume from the beginning the existence of two categories that would later have to be merged again? For this, the onus of proof is on the advocates of bidimensional approaches, as shown in the critical analysis of the distinguishing criteria.

What is needed, therefore, is to show that a unidimensional approach to describing the general category of aspectuality is also able to provide a finegrained description of linguistic phenomena. In the next chapters I present an approach to classifying the content of the aspectual domain which offers the possibility of explaining in detail the gradations of the most varied linguistic phenomena and, moreover, proves to be particularly appropriate for application in language comparison.

Finally, if the bidimensionalist critique is to be avoided completely, the analysis of aspectuality needs, in addition to new terminology, a new categorisation based on more abstract and homogeneous criteria. This will be the subject and task of the following chapters. 



\section{Aspectuality as a Complex, Semantic, Universal Category. Theoretical and Methodological Foundations}

\subsection{Introductory remarks}

Speakers have a basic set of cognitive and communicative skills and they have the biologically based, socially learned and further developed ability ${ }^{1}$ to connect content with expressions and to use them for very diverse communication purposes: language. The expression ${ }^{2}$ of a meaning, of a function, can be served by various means, which are structured according to different organisational principles. The strategies that speakers have developed in their individual languages for producing this combination of content and expressions, and which they choose in a concrete communicative context, display a rich diversity.

Yet the results of many typological investigations carried out in recent years ${ }^{3}$ have made clear the existence of crosslinguistic constants, ${ }^{4}$ especially when it comes to identifying certain very general linguistic functions as universally-conceived content categories.

However, asserting the possibility of identifying crosslinguistic - i.e., universal in a non-absolute sense - content categories does not mean that speakers only need to transfer universal mentalese into sequences of their language, because the efforts that such a language of the mind would have to exert would be

1 On so-called "social cognition" see Tomasello (1999); see also Ferretti (2006) and De Mauro (2009), in general, on the relationship that connects languages and society with human "naturalness": "[. . . even those who tenaciously supported the idea of biological uniqueness, if not human uniqueness then certainly the uniqueness of human linguistic abilities, have in recent years come to radically rethink this idea of uniqueness, of language as uniquely human, and to admit what others have been thinking for some time now, namely that there is a continuity between the drive of other living species to communicate and the emergence of the ability of humans to use languages and language. This emergence and life consequent to this emergence of linguistic abilities are all wrapped up, so to speak, in social conditioning." (De Mauro 2009, 7f., orig. It.).

2 Of course, humans also have an articulatory-auditory apparatus specialised for speech production and reception.

3 See especially the now classic contributions by Bybee (1985), Bybee/Perkins/Pagliuca (1994) and Dahl (1985 and 2000), but also the more recent works in Song (2011), particularly those by van der Auwera/Gast, Bickel, Cristofaro, de Haan, Moravcsik and Stassen.

4 Dahl (1985) speaks in this context of "crosslinguistic categories".

Ә Open Access. (C) 2019 Sarah Dessì Schmid, published by De Gruyter. (cc) BY-NC-ND This work is licensed under a Creative Commons Attribution-NonCommercial-NoDerivatives 4.0 International License.

https://doi.org/10.1515/9783110562088-004 
enormous. ${ }^{5}$ There are indeed several arguments claiming that the historical form of each of our languages influences our respective Weltansicht ('world view'; see Humboldt 1903-1936, VI/1, 22-23), our way of structuring the world. On the one hand, this shows how problematic absolute forms of universalism are, ${ }^{6}$ but, on the other hand, it certainly does not mean that we should indulge in unbridled relativism. ${ }^{7}$ Indeed, some important knowledge comes from the universalist tradition, including rejection of the relativist view that any language can only be described in its own terms, or the assertion that it is possible to identify a limited number of categories that are normally sufficient for reproducing those basic features of any human language related to human cognitive abilities in general.

Although there is theoretical disagreement as to how this happens, ${ }^{8}$ there is widespread consensus about the fact that humans live in a world that they structure through their cognitive abilities, and not just logically or visually, but also linguistically. We can sum this up somewhat succinctly in the words of Ernst Cassirer by stating that the categories of objects and events (Gegenstandsund Ereigniskategorien) are created only through language; in his innovative independent synthesis we can discern Humboldt's legacy:

Wenn es gelänge, eine Provinz des Seelischen aufzuweisen, die spezifisch mit der Sprache verknüpft und die wesentlich auf sie angewiesen ist, so ließe sich an ihrer Struktur vielleicht indirekt ein Zeugnis über das Werden und Wachsen der Sprache gewinnen - so ließe sich an ihrer Entwicklung vielleicht das Bildungs- und Gestaltungsgesetz, dem sie untersteht, in irgendeiner Weise ablesen. [...] Die These, die ich hier vertreten möchte [...], geht nun dahin, daß eine solche Provinz in der Tat besteht, insofern ein wesentlicher und

5 On mentalese see especially Fodor (1975) and Pinker (1994). The idea of a language of the mind, a lingua mentis, accompanies the entire course of western philosophical thought from antiquity to modern times. On those hard-to-imagine efforts that a language of the mind - if there were such a system - would have to perform (i.e., a universal conceptual system on which the meanings of the various individual languages are based) see Waltereit (1998, 9, orig. Ger.): “This system should encompass all possible concepts, should anticipate every conceivable conceptual development - otherwise the conception of linguistic meanings as reductions of a previously given stock of knowledge would not be tenable. It is very unlikely that this is the case."

6 See the more recent wave of works on linguistic relativity hypotheses: Gumperz/Levinson (1996), Lucy (1992, 1996 and 1997), Niemeier/Dirven (2000), Pütz/Verspoor (2000), as well as the more recent cognitively-based studies on language acquisition in general, e.g., Tomasello (2003).

7 While the extreme advocates of linguistic relativism did so, the father of this conception, Wilhelm von Humboldt, certainly did not.

8 See, e.g., Jackendoff's (2002) or Goldberg's (2008) critiques of Chomsky's conception of Universal Grammar (see, e.g., Chomsky 1993 and 1995) and the discussion of Hauser/ Chomsky/Fitch's (2002) theses in Pinker/Jackendoff (2005). 
notwendiger Zusammenhang zwischen der Grundfunktion der Sprache und der Funktion des gegenständlichen Vorstellens anzunehmen ist. [...] Die Sprache tritt nicht in eine Welt der fertigen gegenständlichen Anschauung ein, um hier zu den gegebenen und klar gegeneinander abgegrenzten Einzeldingen nur noch ihre 'Namen' als rein äußerliche und willkürliche Zeichen hinzuzufügen - sondern sie ist selbst ein Mittel der Gegenstandsbildung, ja sie ist im gewissen Sinne das Mittel, das wichtigste und vorzüglichste Instrument für die Gewinnung und den Aufbau einer reinen 'Gegenstandswelt'. (Cassirer 2004 [1932], 115f.) ${ }^{9}$

If it were possible to find a region of the mind which is specifically linked to language and which is essentially dependent on it, then perhaps its structure would indirectly bear witness to the emergence and expansion of language - perhaps it would be possible to read in its development the laws of formation and organisation to which language is subject. [.. . ] The thesis I would like to put forward here [. . . is that such a region does indeed exist, insofar as there is an essential and necessary relationship between the basic function of language and the function of the conception of objects. [...] Language does not enter into a world of fully-realised objectual representation to merely provide given clearly-delimited individual objects with 'names' as purely external and arbitrary signs but it is itself the means of object formation, the mediator par excellence, the most important and precious instrument for acquiring and constructing a pure 'world of objects'.

Certain basic structures of their cognitive abilities allow humans to organise the world - or what they perceive as the world - above all spatially and temporally. Some basic functions or categories of content recurring in the languages of the world can be found to be universal and they indeed correspond to these very general structurings. Although formulated by an early 20th-century philosopher of language, it is a view that is shared by more modern cognitively- and functionally-oriented theories, ${ }^{10}$ in which the most diverse linguistic structures - lexical and grammatical morphemes as well as more complex syntactic units - are understood as "mediators of meaning", as symbolic instruments.

9 For Cassirer, in no way does language only intervene in the domain of objective perception to assign purely externally and arbitrarily understood names to objects that are already given and determined by their reciprocal relationship. Rather, language intervenes actively, i.e., creatively, in establishing this process and reciprocally determining the objects. In Cassirer's view, what language in all its diversity does for people's lives can only be understood if we consider that it is not just a theoretical image of the world (as a mediator between subjectivity and objectivity, between mind and experience), but also a practical, moral and social image, the image of the ego and the other. The signifying communicative mechanism of language mediates between the mental and the sensual only at the dialogical moment. And this mediation gives rise to the domain of concepts, the will and objects.

10 These include, among others, the works by Croft (1991), Fauconnier (1984, 1999), Lakoff (1987), Lakoff/Johnson (1980 and 1999), Langacker (1987, 1991 and 1999) and Talmy (1985, 2000), as well as those (defined in some studies as functionalist) by Fillmore (1975, 1977 and 1985). See also the contributions in Geeraerts/Cuyckens (2007). 
Cassirer's humans live in a world of self-created signs and images, and each of their symbolic activities - for language represents only one of the "symbolische Formen” ('symbolic forms', see Cassirer 2001 [1923]) - has its productive function, as a form of objectification of the mind, and its hermeneutic function, as a form of understanding the world at the same time. In the view of Cognitive Semantics, humans also live in a similarly symbolically designed world: from this point of view, the creativity of language comes from the general tendency of humans, also active in other domains of cognition, to symbolise, in other words, to form categories which can then be combined (or expressed) in the various languages in particular patterns according to their individual rules, to form certain typical sentences or discourse schemas. In Tomasello's words, this can be summarised as follows:

[...] the Cognitive/Functional view sees language universals as resulting from human cognitive and social universals and the way languages have evolved. All groups of human beings have certain experiences they wish to communicate to others and have evolved the ability to use conventional symbols to do so. All groups of human beings have the ability to categorize these symbols and form combinations of them, and to extract schematic patterns of those combinations involving hierarchical organization. All groups of human beings engage in certain forms of social interaction and attention directing. All groups of human beings have the same vocal-auditory channel, which requires them to communicate their experiences by expressing symbols linearly, one at a time. Given these 'constraints', all groups of human beings have at their disposal some combination of four and only four linguistic devices for communicating experience: individual symbols (lexical items), markers on symbols (grammatical morphology), ordering patterns of symbols (word order), and prosodic variations of speech (e.g., stress, intonation) [...]. Different languages have evolved different ways of using these four linguistic devices in the service of specific communicative functions specific to the culture, and the evolution of particular languages shows a very interesting interplay between the 'choices' that are made. ${ }^{11}$ (Tomasello 1995, 150)

From this perspective, syntax - or grammar - and semantics cannot be seen as opposing each other: lexical, morphological and syntactic units are all symbolic connections, are the combination of form and content (meaning or function). ${ }^{12}$

This view, merely outlined here, I now also adopt in analysing the linguistic representation of conceptual structures and in dealing with the processes and

11 See Bates/MacWhinney (1982) and Slobin (1985), to whom Tomasello himself refers.

12 The idea of the inseparability of syntax (of grammar in general) from semantics (as opposed to Chomskian modularism) has been more recently advocated, especially in Langacker's model of Cognitive Grammar (1987). Langacker claims that morphological and syntactic structures are inherently symbolic, that is, they represent the organisation and symbolisation of the semantic content. Lexicon, morphology and syntax form a continuum of symbolic structures that are only separated arbitrarily and/or for practical reasons. 
patterns through which conceptual contents of a temporal nature are organised in language. Of course, I do so fully aware that it is only one possible view, one possible model, but one that proves to be particularly useful here. This does not imply that I question the value of other models, especially for semasiologically oriented investigations.

In the mechanism of reference - which determines this combination of form and content - a fundamental ontological distinction between objects and states of affairs is assumed. However, in this work I will not be concerned with ontologies in this sense, but will focus instead on analysing the symbolic ways of representing states of affairs, and will deal, in particular, with the symbolic representations of the content category of aspectuality that can be found in them. In explaining the phenomena dealt with here, it is assumed that language does not depict objective properties of states of affairs but rather conveys conceptualisations, i.e., the mental representations of states of affairs. When speakers act linguistically, that is, when they express a content for a communicative purpose through the means at their disposal, they represent states of affairs symbolically. Here, we assume that the unity of the sentence contains all the essential structures which serve to represent states of affairs. Indeed, at the sentence level, it is possible to accurately examine various basic linguistic functions - or the interplay of different and differently expressed formal content categories. ${ }^{13}$ For practical reasons, the sentence is chosen as the preferred unit in this study, although attention is frequently paid to the smaller units of syntagmas and the larger units of text, in which, of course, aspectuality is also found.

\subsection{Aspectuality and frames}

\subsubsection{Aspectuality and the levels of language}

This book deals specifically with aspectuality, with the general content category, which includes all the information pertaining to the internal temporal structuring inherent in a state of affairs - this is explained in more detail in this and the next chapter. The orientation of the investigation is - in accordance with the discussion in the previous section - cognitive-functional and onomasiological, and the conception of an "onomasiologie 'éclairée”" in the sense of Koch is adopted. It is

13 In general, it should be pointed out briefly that in linguistics, which deals with sentence semantics, a distinction is made between different levels of the sentence structure: the syntactic level, the semantic level (or level of thematic roles), the pragmatic level and the level of information structure. 
a view that does not regard the relations between mental and linguistic structures as direct, that is to say, as literal translations of one into the other; and a view that asserts the need to strictly control the efficiency of the onomasiologically chosen categories, including by analysing their uses in individual languages: ${ }^{14}$

La démarche onomasiologique est légitime à condition que l'on soumette sa grille descriptive à un contrôle sémasiologique. En d'autres termes: il faut considérer comme concept possible tout ce qui est désigné par un mot, ne serait-ce que dans une seule langue du monde. Toutefois, cela ne revient pas à dire que l'essence du concept soit forcément de nature langagière. Les mots des langues particulières ressemblent plutôt à des balises signalant des 'désignés' extra-langagiers qui les débordent largement du point de vue cognitif. (Koch 2003, 91)

The onomasiological approach is legitimate provided that the descriptive grid is submitted to semasiological control. In other words, we must consider as a possible concept everything that is designated by a word, even if it occurs in only one language of the world. However, this does not mean that the essence of the concept is necessarily of a linguistic [i.e., language-particular] nature. The words of particular languages instead resemble markers indicating extralinguistic designata that, from a cognitive point of view, largely extend beyond them.

Accordingly, in this work I examine the onomasiological model of aspectuality presented in Chapters 4, 5 and 6 - in terms of its efficiency in the study of individual languages through concrete examples, and apply it to Italian, French, Spanish and Catalan. This will allow us to look at the same time at some of the lexical and grammatical phenomena of Romance languages in a new light, including a) the so-called "telic states of affairs", a well-known issue in aspectological studies, b) the "perfective-imperfective" opposition of the past tenses prototypically treated there, and c) the numerous and diverse forms of verbal periphrases.

Such a complex category as aspectuality requires that it be analysed on different - but interacting - levels. In order to make the necessary differentiation

14 Koch, for his part, refers to Trabant's (1998) criticism of Pinker's (1994) mentalese. It has often been stressed that the onomasiological and semasiological perspectives can be very fruitful, not only in lexicology, and that onomasiological work does not necessarily mean abstract work remote from linguistic reality: "The prerequisites for semasiological examination of linguistic systems are suitable formal categories, for onomasiological examination they are correspondingly appropriate conceptual categories. Before any examination of the conjugation system of a given language, the categories by means of which this is to be undertaken must be examined. The most important postulate is that the categories used can be assigned to each other in a uniform system. This requirement has nothing to do with an attempt to press linguistic realities into the straitjacket of an a priori system: it is not about language, but about the categories used to investigate it in this first stage.” (Heger 1963, 6, orig. Ger.). 
between these levels for the investigation, I use an adaptation of Coseriu's (1981) subdivision of language levels (Ebenen des Sprachlichen) and distinguish between the following: ${ }^{15}$

a) A universal level of language (langage), of the human ability to speak, to refer, and the general contents, semantic categories and concepts that constitute the linguistic expression of reality. This level is usually concerned with complex semantic categories, functions that can be found in the most diverse languages and which are based on human cognitive abilities (such as the mechanisms of association and categorisation); it is their basic set of cognitive functions that allow humans to shape reality through perception and conceptualisation. These, therefore, are categories that are traditionally referred to, for instance, as "temporality”, “modality”, etc.; analogously, the term "aspectuality" is used here. ${ }^{16}$

b) A historical level, that of individual languages in their plurality as historical (dia-)systems, with their signifying and signified units, with their systems of relations, which represent a - historically created and given - realisation of the possibilities of the universal categories of the universal level of language a). In short, these are systems that result from operations of reference ${ }^{17}$ and the selection of different linguistic means - or the frequency of using such mechanisms - in the expression of the universal-language content. ${ }^{18}$ The grammatical and lexical categories, such as "tense”, "mode”, "aspect” and "Aktionsart”, of Italian, French, German, etc., are classified on this level.

c) An individual level of language, that of the concrete realisation of speech in discourse. This is therefore the level of practice, of concrete speaking in an individual language, which in turn represents the historical level of language b). It is driven by the communicative intentions of individual speakers.

The production and understanding of any aspectual information takes place in and through the interaction of all these levels, because the aspectual information

15 On this classification of language levels see also Koch/Oesterreicher (1990); see also Koch $(2003,87)$ for the subdivision of the linguistic vs. the extralinguistic-conceptual entity.

16 In some works, aspectuality is defined as a subcategory of temporality, since the distinction between deictic and non-deictic categories is subordinate there, see, e.g., Schwarze (1988). Here, not least for practical and explanatory reasons (i.e., to outline the subject of the investigation more precisely), the two content categories are treated separately.

17 Naturally, the operations of reference as such belong to the level of the activity of speaking.

18 On the historical level, Koch (1997) adds another important distinction, i.e., between the level of individual languages and that of the various discourse traditions. This cannot, however, be dealt with here. 
is diverse, complexly structured and combinable. Through speaking, speakers realise one or more of the possible combinations of these pieces of information in a concrete context; they do this to achieve the most diverse communicative goals through various communicative strategies (economy, expressivity, ...) and by using various pragmatic mechanisms (implicatures, inferences, ...). ${ }^{19}$

In order to provide a coherent explanation of aspectuality as a linguistic category, it is necessary to attend to the role of each of the various levels mentioned above and the locations of their interaction. However, it is equally necessary to maintain the separation of these levels and to stress that the analysis of aspectuality refers to the universal level of language a), while in looking at the aspectual systems of French, Italian, etc. we are referring to the historical level b). Finally, examination of how the interacting information which codifies the internal temporal structuring of a particular state of affairs is concretely verbalised in the utterance, how it is realised by the speaker by special means (forms, rules and strategies), is dealt with on the individual language level c).

\subsubsection{Frames as basic structures of the categorisation of reality}

This investigation is based on a special conception of human categorisation mechanisms for temporally structuring states of affairs. Therefore, of the various theoretical options available, a frame-based interpretation of aspectuality is chosen here. ${ }^{20}$ But before setting out the advantages of such an approach, let me first say a few words about frames as basic structures of the human categorisation of reality in general and the areas where the notion of frame may be applied.

Fundamental to frame theory are the now classic works of Fillmore (1975, 1977 and 1985) and Minsky (1975), ${ }^{21}$ who define the term "frame" as a special data structure created from memory "for representing a stereotyped situation" (Minsky 1975, 212), or as a structured "coherent schematization of [...] experience" (Fillmore 1985, 223). ${ }^{22}$ In other words, "frame" is understood as a

19 And this is rooted in the level of the activity of speaking.

20 In general, regarding the research that led to a new conception of the category in linguistics, see Berlin/Kay (1969), Rosch (1973 and 1977), Rosch et al. (1976) and Rosch/Mervis (1975). 21 Particularly important for the analysis of grammatical phenomena are the works by Langacker (e.g., 1987), who speaks rather of domain.

22 See also Barsalou's theory, popular in research on Artificial Intelligence (AI) and interesting for its dynamic conception of frames: "Because frames also represent the attributes, values, structural invariants, and constraints within a frame, the mechanism that constructs frames builds them recursively. The frame theory I propose borrows heavily from previous frame theories, although its collection of representational components is somewhat unique. Furthermore, frame 
structured and coherent knowledge context, which may be of a general conceptual or culturally-specific nature, by means of which humans address various everyday situations (making decisions, coping with problems, ...).

The most cited examples of frames include, on the one hand, the more culturally-specific, such as FLY (on board a plane) (see Handke 1995, 102), or RESTAURANT (VISIT) (Schank/Abelson 1977), in which various components interacting with each other can be recognised: locations (plane, ... or restaurant, ...), roles (pilot, passengers, ... or waiters, guests, ...), sets of actions (the passengers board the plane, the pilot flies the plane, ... or the guests are greeted by the waiter and escorted to the table, the waiter brings the menu, ...).

On the other hand, one of the more conceptual, more abstract examples of frames is the human conceptualisation of time and space (the notion of time and space belongs to human world knowledge).

In the last thirty years, in both Cognitive Linguistics and AI research, numerous studies have emerged that use the term "frame" as a very general model for knowledge contexts or experiential contexts of various kinds. ${ }^{23}$ Here, "frame" has been defined variously as static or dynamic, and frame models have been used to represent very different forms of the human conceptual organisation of reality, from the simplest to the most complex. The difficulties with such a theoretical model are not unstated. ${ }^{24}$

theorists generally assume that frames are rigid configurations of independent attributes, whereas I propose that frames are dynamic relational structures whose form is flexible and context dependent.” (Barsalou 1992, 21). In Romance research, see, especially, Blank (1997) and Koch (1999a and 2001a).

23 The variety of studies has, of course, generated a variety of terminologies: besides frame, there is scenario, schema, domain, script, etc. Generally, it should be noted that while terms such as frame and domain (Langacker 1987, 147) can be used to designate a static, abstract-conceptual situation, scenario or script is used to designate whole (communicative) processes. See Croft (1993) for domain, Schank/Abelson (1977) on the term script.

24 "Speakers and hearers have a common knowledge of the details of the restaurant visit; they do not need to make sure of this themselves, but can assume that the standard scene of the restaurant visit is known to both. But is this knowledge really a huge data structure with predetermined branches and defined terminal nodes that are able to establish contact with the environment or to embed subframes themselves? [. . . In everyday practice, however, it does not seem that it is the ability to reproduce stereotypical actions that is decisive, but on the contrary the ability to cope with situations in which the options for action cannot be derived from given instructions or even only from decision branches. [. . . ] In order to be able to depict the entire complexity of human experiential contexts, a frame theory would probably have to be able to fall back on a binding knowledge of the structure of cognitive processes. This is apparently hardly possible at the moment." (Waltereit 1998, 17, emphasis in the Ger. orig.). See also Konerding's (1993) critical remarks, quoted by Waltereit. 
Given that in the present work I am conscious of the difficulties pointed out here, the choice of a frame-based interpretation implies a general decision to conceive of the content category of aspectuality ${ }^{25}$ as a form of perception or conceptualisation, as a form of human conceptual organisation of temporal reality. ${ }^{26}$ Accordingly, among the many alternative terms, I choose here "frame", which is common in research. ${ }^{27}$ At the same time, a detailed model of the internal structuring of frames is rejected in favour of restriction to the intuitively plausible assumption "that experiential relationships are also an important principle of the organisation of knowledge and thus provide an environment in which referential indeterminacies can be disambiguated" (Waltereit 1998, 17, orig. Ger.).

In other words, it is merely assumed here that our perception and categorisation abilities recognise concepts and subconcepts in connection with each other and that they are stored thus in memory. It is also assumed that while, on the one hand, a frame is constituted only through the combination of its closely-related component parts, the individual subcomponents, on the other hand, ultimately acquire their configuration only within and against the background of the entire frame: frames consist of elements that are in contiguity with one another, they are networks of contiguity (Koch 1995, 1996a, 1996b, 1999a, 2001a, 2004 and 2012, Blank 1997, Waltereit 1998). But what exactly is meant by contiguity?

\subsubsection{Contiguity and the figure-ground effect}

One of the important basic theoretical assumptions of Gestalt psychology is that humans have the ability to group spatially or temporally related individual phenomena together as gestalts (see, e.g., Fitzek/Salber 1996, Herrmann 1976, Köhler 1947, Metzger 1986, Wertheimer 1925). ${ }^{28}$ It is well known that Cognitive Linguistics

25 In the case of aspectuality, in particular, it is not the variety of possible frame-relevant relationships that some critics consider difficult to manage and therefore arbitrary. Rather, it is two elementary and comparatively well-established relations: part/whole and temporal contiguity (see Chapter 4). On contiguity see Koch (2004 and 2012), Peirsman/Geeraerts (2006a), as well as Croft's (2006) position regarding the latter and Peirsman/Geeraerts' response (2006b).

26 Here, reliance is placed on the models of description and interpretation developed in Gestalt theory; see the following section.

27 For Romance research see Blank (1997), Detges (2001), Koch (1994, 1999a, 2001a, 2001b and 2004) and Waltereit (1998).

28 Of course, such observations had already been made before Gestalt psychology. Koch (2007, 11) reports how Aristotle, in the context of a theory of remembering, defines the three associative relations of similarity, contrast and contiguity. In the same essay, he tackles an important and exciting undertaking: he shows what Husserlian phenomenology can 
was also based on this fundamental idea of Gestalt psychology and dealt in different ways with what was formulated by the latter as the principles of perception: ${ }^{29}$ the principles of supra-summativity (Übersummativität), good Gestalt (also called the principle of salience), similarity and figure-ground effect. $^{30}$ Since here the figure-ground effect - which is closely connected with the principle of contiguity - plays an important role, ${ }^{31}$ these are discussed in more detail below.

When we assume that human perception and categorisation abilities recognise concepts and subconcepts in connection with each other - in the form of frames - and stores them thus in the memory, we also assume that these experiential contexts are a kind of cognitive added value, which is more than just the sum of the individual components of the respective frames. ${ }^{32}$

But how exactly are such elements related to each other, i.e., how can this connection of concepts - of gestalts - be described? Many of the gestalts, the

contribute to the constitutional analysis of language (see Husserl 1993 [1922] and 1995 [1929]). Koch resorts to this approach, on the one hand, and Gestalt psychology, on the other, to give a non-mechanistic interpretation of the associative relations (which are now of central importance in Cognitive Linguistics). In this context, he also refers to the work of Holenstein (1972), whose merits he points out - and not only for his interpretation of Husserl's phenomenology.

29 In particular, Cognitive Linguistics also deals with the connection between these principles, the conceptualisations that underlie them, and the strategies through which they are realised verbally.

30 On "Wertheimer's Figures" and other well-known images from Gestalt psychology which illustrate these principles graphically, see, among others, Wertheimer (1925), Holenstein (1972), Raible (1983), Blank (1997 and 2001), Metzger (1986), Rubin (1921) and Wittgenstein (1995).

31 In general, this principle plays a central role in Cognitive Linguistics - and especially in the context of construal problems: see, among others, Croft/Cruse (2004), Langacker (1987), Talmy (2000) and Ungerer/Schmid (1997). Incidentally, in this work I make little reference to Croft's latest book (2012), as it was only published after I had developed the model presented here. Still, I would like to point out an important difference between the models: Croft also deals with the idea of boundedness in the constitution of states of affairs, but, unlike my model, his does not take a purely aspectual perspective and offers a so-called two-dimensional analysis. He suggests distinguishing between qualitative boundedness ( $q$-boundedness) and temporal boundedness ( $t$-boundedness): "In sum, the property of boundedness that is considered to be a part of the root of the verbal meaning, i.e. the existence of a natural end point or telos for the event, is represented by the states defined on the q dimension, while boundedness of a particular event in a particular occurrence is defined by the existence of profiled beginning and ending phases on the t dimension.” (Croft 2012, 81).

32 See, among others, Fauconnier (1984 and 1999), Goldberg (1995 and 2006), Lakoff (1987) and Langacker (1987, 1990 and 1991). 
situations of everyday human life, are indeed structured in a very complex way: in these conceptual structurings, similar items are perceived and grouped together as a figure and it is only by contrast that this figure is distinguished from other figures which then recede into the background. When grouping elements into larger contexts, what matters is visual or conceptual proximity, so that what has been grouped as a figure (in contrast to the ground) and what as a ground (in contrast to the figure) lie close to one another. This is exactly what is meant when we speak of the principle of contiguity: gestalts and concepts that come into contact spatially, temporally and logically with each other. Between the gestalts in contact - represented as figure and ground - there can be an interplay, which has been called the "figure-ground effect". Figure (1), which shows either a white cross on a dark background (to which the white figure is related) or a dark cross on a white background (to which the dark figure is related), represents the contiguity between white and dark elements as well as the interplay between what is the role of the figure and the role of the ground; because only one of them can be the figure (perceived as a cross) and one of them the ground - they cannot both be seen at the same time: ${ }^{33}$

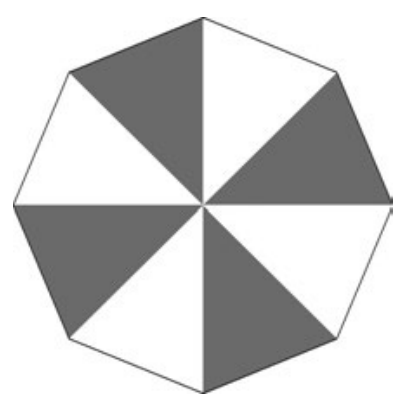

Fig. 1: Representation of the figure-ground principle, after Wittgenstein $(1995,541)$.

On a more abstract level, these types of visual representation (and others) make it possible for those figure-ground effects that are induced by contiguity to also be imagined within frames, as frames are composed of elements which are

\footnotetext{
33 If we follow Koch's terminology (2007 and 2008), inspired by Husserl (1993 [1922]), and Holenstein's interpretation (1972), to explain the mechanisms of contiguity, we can also explain such mechanisms from a different theoretical perspective and talk about "presented" and "appresented" components in categorisation: in our perception, besides "presented" components (which represent the thematic core), other "appresented" components are evoked, which are contiguous to the "presented" ones and which form the opened "horizon" around the thematic core.
} 
related by contiguity. In fact, the contiguity relation that keeps the frame together allows the figure-ground effect within a frame to be seen in the form of a re-perspectivisation, a change in the windowing of attention. Two main types of figure-ground effects can be distinguished, those generated between the individual elements of a frame and those generated between each of its constitutive elements and the frame as a whole; these are illustrated in Figures (2) and (3), respectively:

Frame

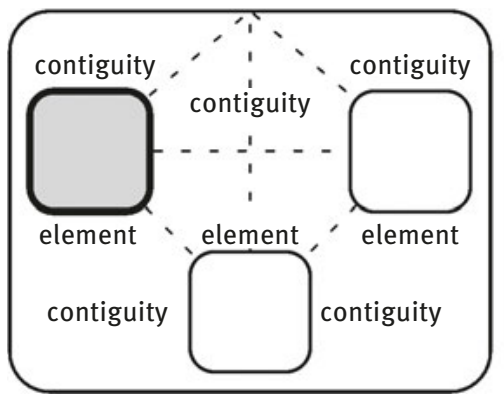

Frame

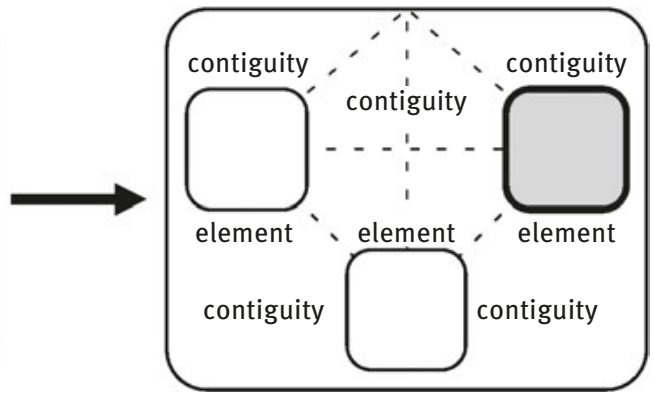

Fig. 2: Figure-Ground Effect I, after Koch $(2012,267)$ with modifications.

Frame

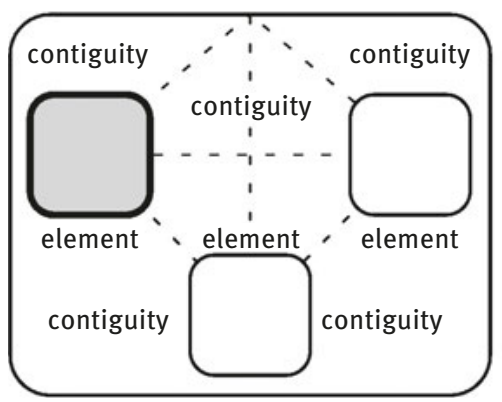

Frame

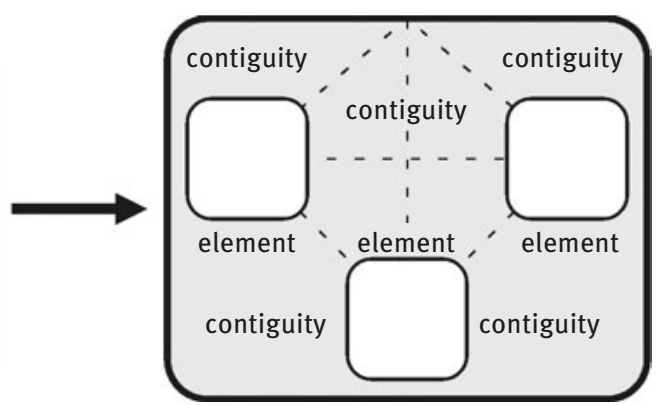

Fig. 3: Figure-Ground Effect II, after Koch $(2012,267)$ with modifications.

These (re-)perspectivisations - known as "windowing of attention" or "highlighting" - have been used very successfully in Cognitive Linguistics research to describe various linguistic phenomena (see, among others, Taylor 1995, Croft 1993, 
Ungerer/Schmid 1997, Talmy 1996 and 2000, especially Chapter 4). The present work will also move along this line: in the next section I build a bridge between contiguity relations/figure-ground effects in the frame and aspectuality, in which various areas of linguistic application of the frame concept are presented.

\subsubsection{Areas where the notion of frame can be applied}

The notion of frame has numerous applications, and plenty of advantages follow from the decision to adopt a frame-based theory (see, in particular, Lee 2001, 8ff., to which I refer in the following). A frame is a multidimensional concept with a conceptual and a social dimension that also allow for a fruitful treatment of certain forms of polysemy. ${ }^{34}$ At the lexical level, we can see that a lexeme is connected in various ways with many different frames that represent the contexts, the experiential connections, in which the speaker has learned it and uses it. In each of these contexts, one of its meanings is highlighted through its combination with the other elements in the frame: in other words, these are somehow conceptually in contact (e.g., metonymically related to each other and held together in our frame-structured experience, our world knowledge), rather than being derived from an assumed "core value" of the lexeme. For example, when trying to explain the meaning or different meanings of a lexeme such as "sister", that might best be done by showing how the different meanings emerge in different frames: a) in the "biological frame" (in which it is the daughter of the same mother); b) in the "social frame" (in which it is, for example, a very close friend who is perceived as being like a sibling; c) in the "professional frame" (a nurse) or d) in the "vocation frame" (a nun), etc. ${ }^{35}$

However, it is not just to the meanings of individual lexemes of the type described above that such a model can be applied; good use can also be made of a similar representation and interpretation model to analyse the linguistic structuring of temporal - and here, especially, aspectual - contents of entire

34 On the conception of polysemy in Romance research, see especially Blank (1997), Koch (1999c, 2001b and 2005) and Marzo (2013).

35 See also the possibilities of analysing a lexeme like weekend (Fillmore 1982, 119). In other words, this is the old problem of connotation, which, however, can be better understood with the frame concept than in formally-oriented models. Our world knowledge structured in different frames contributes to understanding the meaning(s) of lexemes, such as when, for example, two different lexemes designate the same phenomenon (meaning that the referent/ phenomenon is stored with two different frames for two different uses). 
states of affairs with similar advantages, as analysis of the following examples shows:

(1) Ger. Der Regen fiel [Prät.] langsam zu Boden. 'The rain fell slowly to the ground.'

(2) Ger. Die Feder fiel [Prät.] langsam zu Boden. 'The feather fell slowly to the ground.'

States of affairs such as those presented in examples (1)-(2) have different aspectual contents, which are defined here firstly in traditional terminology. While (1) represents a telic, durative, but reiterated state of affairs, in (2) we have a telic and unique state of affairs. This interpretation is related to the combination of the verb fallen with the respective first arguments: based on his/her encyclopaedic knowledge, the speaker is aware that the falling of a feather attracted by gravity is a non-recurring process (the falling of a single feather, which has a clearly defined individual reference), while the falling of the collective noun "rain" means the falling of many, light, dense, etc. raindrops. A semantic explanation of the words and structures of language, which understands these not as simple, immediate expressions of concepts (with which they would then also have a 1:1 equivalence), but as tools that trigger in speakers and hearers activation of certain areas of their world knowledge depending on the context ${ }^{36}-$ i.e., a semantic explanation of words and structures of language, which takes into account human encyclopaedic knowledge - has the enormous advantage of being able to deal comprehensively with historical (language change) and socio-cultural factors of communication.

At this point, however, further clarification should be given, which sheds light on the application of the notion of frame in this investigation. Of course, relatively concrete frames can be used to explain linguistic phenomena, and research in this field has for the most part done precisely that (see the analysis of the frames RESTAURANT and SISTER above). However, to explain certain linguistic problems requires more abstract frame models that represent whole classes of frames (this is the case, for example, in Talmy's typology of motion verbs). ${ }^{37}$ The aspectuality frames discussed here will now be classified on a comparable abstract level (Chapter 4 presents a more detailed discussion).

36 Here, different areas are activated to varying degrees in different contexts of use.

37 Talmy (2000, esp. Chapter 2) does not analyse individual motion processes, but only elements of a very abstract MOTION event-frame: MOTION, PATH, MANNER, etc. 
If frames consist of elements related by contiguity, aspectuality consists of elements which are related via special forms of contiguity. In explaining phenomena such as "perspectivisation" within a situation frame or a "windowing of attention", in particular, ${ }^{38}$ the notion of frame has, according to Koch (2001a, 202f.), ${ }^{39}$ proved particularly fruitful.

\subsubsection{Aspectuality and situation frames - a first definition}

The present study of aspectuality ${ }^{40}$ is based on results drawn from cognitivelyoriented semantics ${ }^{41}$ in that it conceives of states of affairs, which are the expression of this content category, as situation frames and retains the concept of "perspectivisation within a situation frame", which proves to be particularly useful, especially in explaining the mechanisms underlying aspectuality. It seems to be no coincidence that this idea of perspectivisation, in particular, has also been traditionally associated with aspectuality: in 1829, Reiff introduced the French term aspect (from the Latin aspicere 'to watch', 'to observe') as a translation of the Russian vid. ${ }^{42}$

The particular conception of aspectuality that results from such a perspective will be further clarified on the following pages and in subsequent chapters, but first I give here a short, very general definition:

38 On "perspectivisation", "highlighting" and "windowing of attention" see, among others, Croft (1993), Dirven et al. (1982), Fillmore (1977), Talmy (1996 and 2000), Taylor (1995) and Ungerer/Schmid (1997). More recent publications on Cognitive Linguistics in general include Croft/Cruse (2004), Evans/Green (2006), Geeraerts (2006) and Geeraerts/Cuyckens (2007).

39 The "process of perspectivisation within frames" (Koch 2001a, 203) could be spoken of from an onomasiological as well as a semasiological point of view. In the first case, "one raises the [...] question of how different perspectives of a frame are expressed linguistically"; in the second case, the problem is whether different uses "of a given linguistic expression correspond to different perspectives within the same frame" (Koch 2001a, 203).

40 See Chapter 2 on the history of the notion of aspectuality and the different ways it can be understood.

41 For a general introduction to Cognitive Semantics, see, among others, Lee (2001), Taylor (2002) and Ungerer/Schmid (1997). Given the Romance orientation of his work, reference is also made here to Blank (1997 and especially 2001).

42 On the etymology of the term as well the history of the category in general, see Pollak (1960 and 1988); see also §1.2.3. 
Aspectuality is the universal content category through which speakers linguistically structure the manner of the development and the distribution of a state of affairs in time; it contains that complex of information which relates to the temporal structuring of a given state of affairs, independent of any reference to the point of speech.

Definition 1: Aspectuality

If aspectuality is defined here as the internal temporal structuring of a state of affairs conceived as a situation frame, ${ }^{43}$ then the relations between the elements of this situation frame or between the frame as a whole and its constitutive elements are defined as relations of contiguity. These constitutive elements can now be focussed within the situation frame, i.e., perspectivised (see §§3.2.3-3.2.4). According to what is placed in the foreground, aspectuality can be subdivided into three dimensions, three perspectives: the external aspectuality of a state of affairs or its absolute delimitation; the adjacency-related aspectuality of a state of affairs or its relevance for its (direct) environment; the internal aspectuality of a state of affairs or its further internal subdivision (for a complete representation see §4.4).

This means, on the one hand, that the investigation uses a very abstract frame model to represent aspectuality, while, on the other hand, it offers no complete analytical model of states of affairs in general, as is often the case in frame theory. Rather, the investigation is focussed exclusively on a single level, namely, the aspectual or internal-temporal. Accordingly, graphic representations of specific frames are designed for this level (see Chapters 4 and 5).

The category of aspectuality is understood in this work as:

- semantically homogeneous in the sense of unidimensional approaches (see §2.4);

- universal, in the relativised sense above;

- complex, composed in a sense that is not purely mathematically additive nor compositional, but corresponds to the structures and dynamics of constellations;

- based on a few homogeneous abstract criteria, mainly based on the principle of temporal delimitation;

- realised on the various levels of the language system, i.e., by different organisational principles (morphological, syntactic, etc.) using different

43 The diachronic perspective, in particular, which is facilitated by the excellent documentation of the Romance languages, enables insights to be made into the cognitive basis of aspectual delimitation, since semantic change is based on cognitive processes. See, among others, Blank/Koch $(1999,1)$ and Sweetser (1990, 45f.). 
linguistic means (lexical or grammatical), and, of course, in a variety of ways on the level of individual languages.

To further elucidate all these points - also on the basis of the model designed we will now follow in detail the path that led to this definition and outline its theoretical assumptions and its consequences. In the next chapter, the model of the classification of aspectual content developed on the basis of these theoretical assumptions will be presented in detail.

\subsection{Semanticity - abolishing the semantic distinction between aspect and Aktionsart}

I argue in this work that language-particular categories are not suitable for comparative studies (see Haspelmath 2007, 126 and also Chapter 2 of this work). In agreement with Bybee (1985), Bybee/Perkins/Pagliuca (1994), Smith (1991) and many of the more recent works on TMA (tense/mode/aspect) categories, ${ }^{44}$ I assume that the expression of aspectual contents is not language dependent but crosslinguistic and is based on human cognitive abilities, ${ }^{45}$ which are responsible for the temporal structuring of states of affairs. Therefore, a more general, abstract semantic category called "aspectuality" or "aspectual delimitation" is assumed here, which subsumes all the possibilities that the various historical-natural languages have at their disposal to express, through different means, temporal structurings of states of affairs. With regard to aspectuality, in order to explain exactly what is meant by "semantic" or "content category" here, and in a large part of the literature on the aspectual domain, and thus also to prevent any possible terminological misunderstanding, ${ }^{46}$ one important distinction is to be borne in mind, i.e.,

44 See, among others, at least Dahl (1985 and 2000), Hopper (1982a), Talmy (2000) and Thieroff/Ballweg (1994-1995). Terminologically, it should be noted (as discussed in Chapter 1 in more detail) that these works often use the term "aspect" even in referring to what is called "aspectuality" here, namely, the general aspectual domain and not the category marked grammatically on the verb. On this, see also Sasse (2002).

45 "I will assume that the aspectual categories are not language dependent, but are based in human cognitive abilities.” (Smith 1991, xvii).

46 Koch (1996a) emphasises that although, on the one hand, conceptual, extralinguistic knowledge was disregarded in Structural Semantics, in Cognitive Semantics, on the other hand, the individual-language character of linguistic signs, i.e., the existence of the semantics of an individual language, was misjudged. In its synthesis, Raible's semiotic model offers, according to Koch, the possibility to address the central problems of both theories. 
that between crosslinguistic-conceptual and language-particular meaning. ${ }^{47}$ For this purpose, Raible's (1983) semiotic model is used: ${ }^{48}$

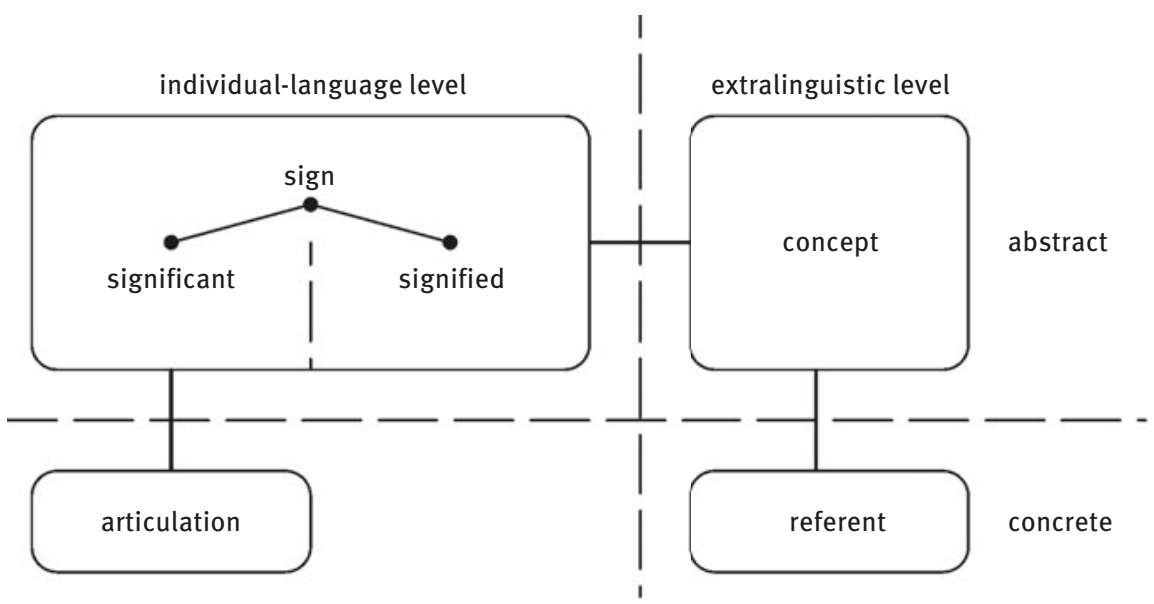

Fig. 4: Semiotic model, Blank (2001, 9) after Raible (1983).

Two important distinctions underlie this semiotic model: that between a concrete and an abstract level, on the one hand, and that between an individual-language level and an extralinguistic level, on the other hand. This can be represented in the form of a cross-classification, because the overlapping of these criteria gives rise to a language-particular concrete entity (the articulation), a languageparticular abstract entity (the linguistic sign), an extralinguistic concrete entity (the referent) and an extralinguistic abstract entity (encyclopaedic knowledge, the concepts). The linguistic sign, in turn, consists of a linguistic form (the significant), language-particular phonological knowledge, a content (the signified) and sememic knowledge (of the language-particular semantics).

When speaking of aspectual content or information here, I am referring, in particular, to the extralinguistic - that is, the conceptual, cognitive, universal, or crosslinguistically understood - structuring of states of affairs. Aspectuality defined in these conceptual, abstract and universal terms is located on a completely different level to that of aspect and Aktionsart, which are understood as the specific (grammatical or lexical) categories of individual historical languages and

47 On the possible types of relation between concept (extralinguistic and universal world knowledge) and linguistic meaning (language-particular world knowledge), see Waltereit (1998, 7ff.).

48 This is an adaptation of Blank's (2001) model, which shows some terminological innovations compared with Blank (1997). 
which are bound to the semantics of a particular language. An onomasiological treatment of the general content category of aspectuality is therefore expressed first and foremost in its universal-semantic view, which must go beyond any interpretative framework that emerges from historical facts and analyses of individual languages. ${ }^{49}$

If we now acknowledge that aspect and Aktionsart are homogeneous in terms of content on a universal semantic level, ${ }^{50}$ i.e., when they are subsumed in a superordinate category of aspectuality, then they differ only in the fact that one is a grammatical category, the other a lexical one. And this distinction can be of use only in the context of a semasiological, language-particular investigation, which describes the distribution of the possibilities of expressing aspectual information in the particular language considered, and is based not least on the separation of grammar and lexicon, a stance strictly followed in traditional research. ${ }^{51}$ However, if the general aspectual domain is considered from an onomasiological perspective, then the traditional non-semantic distinction between aspect and Aktionsart ceases to be relevant. An insistence on this distinction ${ }^{52}$ would lead to circular conclusions, since, after losing the differences in content described above, the only difference remaining is the definitional difference, which is self-evident. ${ }^{53}$ Thus, an investigation that

49 See $\S 1.2 .3$ for a history of the discovery and the terminological and definitional specification of the verbal categories "aspect" and "Aktionsart".

50 In the traditional literature on aspect and Aktionsart, the semantics of these two timestructuring verbal categories is also frequently discussed, and even opponents of the "dangerous mixing" of them - commented on in detail in Chapter 1 - recognise the undeniable semantic connections, the clear similarity between aspect and Aktionsart. See, e.g., Bertinetto (1986, 82ff.) and Pérez Saldanya (2002, 2602).

51 It has already been pointed out in Chapter 2 how recent typological research has shown that the distinction between the grammatical and lexical elements of language is not necessarily to be seen as a distinction between rigid, discrete categories, but as one between elements on a continuum; see, among others, Bybee (1985), Dahl (1985 and 2000), Hopper/Thompson (1980) and Talmy (2000). See also the research on grammaticalisation in general, including Ch. Lehmann (1995), Hopper/Traugott (2003), Haspelmath (1998), Lang/Neumann-Holzschuh (1999), Detges/Waltereit (2002), Detges (2004), Marchello-Nizia (2006) and Klump (2007). See, furthermore (and synchronically), the studies in Construction Grammar, including the anthologies by Fischer/Stefanowitsch (2006), Stefanowitsch/Fischer (2008) and Lasch/Ziem (2011).

52 Coseriu $(1987,125)$ emphasises that this is a distinction on the status-relational level and not the semantic level, and explains how many misunderstandings and confusions have arisen precisely for these reasons in dealing with the category aspect.

53 It is self-evident, since the argumentation is often as follows: aspect is defined as a grammatical category, Aktionsart as a lexical one. Aspect and Aktionsart are therefore different categories, which is proved by the fact that aspect is expressed grammatically and Aktionsart lexically. 
advocates the semanticity of aspectuality must relativise a distinction that is based on the criterion of grammaticality vs. lexicality and must be carried out from a semasiological perspective. ${ }^{54}$ From an onomasiological perspective, the most interesting point is the description of the content, and only in the second instance the verbalisation of this content by different means. Of course, this does not mean - and I would like to stress this point - that it is not possible nor useful to divide the linguistic signs of the world's languages into two subsystems: open or lexical classes and closed or grammatical classes (see, e.g., Talmy 2000, I, 20ff.). Nor does this mean that from a semasiological and individual-language (such as Russian) perspective the question of what weight should be given to the form cannot be answered otherwise, much less that lexical and grammatical forms of realisation are absolutely identical.

\subsection{Universality - cognition and the crosslinguistic perspective}

If, now, we start from the above-described perspective of the semantic homogeneity of the aspectual domain, it must be possible to identify a criterion on which the various representations of aspectual information are based and by which they can be explained. Such a criterion must justify the aspectuality of the various types of information - traditionally divided into aspect and Aktionsart - in their similar semantic content, while at the same time serving to subclassify these types of information. The criterion in question must be specific and precise enough to describe the plurality of the content-related (that is, semantic) and non-formal ${ }^{55}$ presentation of aspectuality. At the same time, it must be general enough to be able to find correspondence in the various languages of the world, to permit comparative linguistic investigations, and to serve effectively as a tertium comparationis. Therefore, it must be sought at the level of the universal cognitive abilities of humans, at the level of conceptualisations.

Aspectuality, then, is of course manifested differently in the various individual languages in terms of the selection of the methods they use to express it and the quantitative and qualitative distribution and differentiation of such methods and their interaction. Those aspectual contents, which are expressed in one language by a complex inflectional system, can indeed be expressed in another language by

54 This distinction can also be based on a special conception of grammar, see, e.g., Ehrich (1992) and Smith (1991).

55 This means, then, that it seems secondary whether aspectual contents are expressed by morphological, syntactic or lexical units. 
lexical means. ${ }^{56}$ This is particularly striking when comparing Romance languages (Italian, French and Spanish in the following examples) with German. With regard to the temporal delimitation and non-delimitation of states of affairs, these languages express the same (general) aspectual meanings either by grammatical or by lexical markings:

(3) It. Leo seppe [Perf. Sem., compl./perf. inflectional marker] la notizia dalla bocca di Julia.

'Leo came to know the news from Julia's mouth.'

(3') It. Leo sapeva [Imp., incompl./imperf. inflectional marker] la notizia dalla bocca di Julia.

'Leo knew the news from Julia's mouth.'

(4) Fr. Léo sut [Pass. Sim., compl./perf. inflectional marker] la nouvelle par la radio. 'Leo came to know the news from the radio.'

(4’) Fr. Léo savait [Imp., incompl./imperf. inflectional marker] la nouvelle par la radio.

'Leo knew the news from the radio.'

(5) Sp. Leo supo [Perf. Sim., compl./perf. inflectional marker] la noticia de la boca de Julia.

Leo came to know the news from Julia's mouth.'

(5’) Sp. Leo sabía [imp., incompl./imperf. inflectional marker] la noticia de la boca de Julia.

'Leo knew the news from Julia's mouth.'

(6) Ger. Leo erfuhr [Prät., compl./lexical marker] dies aus Julias Munde.

'Leo came to know this from Julia's mouth.'

(6') Ger. Leo wusste [Prät., incompl./lexical marker] dies aus Julias Munde. 'Leo knew this from Julia's mouth.'

In the Romance examples (3)/(3')-(5)/(5'), the so-called "perfective" (Passato Remoto, Passé Simple, Pretérito Perfecto Simple) and "imperfective" (Imperfetto,

56 See Chapter 5 for a contrastive linguistic analysis which deals with such cases in more detail. 
Imparfait, Pretérito Imperfecto) verbal inflection markers appear to express states of affairs that are, respectively, (punctually) delimited and (duratively) non-delimited. In the German examples (6)/(6'), on the other hand, these different temporal structures are expressed through different semantic information contained in the verb stem (in (6) erfahren 'to come to know' and in (6') wissen 'to know') although the verbs bear the same inflectional markers (past tense). The temporal structures are therefore communicated lexically by the so-called Aktionsarten: according to the traditional terminology based on Vendler (1957), erfahren is a transformative verb or an achievement (punctual or non-durative, telic, dynamic), and wissen a stative verb (durative, non-telic, non-dynamic).

Aspectual information can therefore be imagined as "conceptual building blocks" of an aspectual nature, as basic conceptualisations of the internal temporal structuring of states of affairs. These basic conceptualisations are located on a universal level, which seems adequate for the needs of an onomasiologically-guided analysis. These aspectual building blocks, as already stated above, can then be packaged differently in the linguistic material - grammatically or lexically - as the comparison between examples $(3) /\left(3^{\prime}\right)-(5) /\left(5^{\prime}\right)$, on the one hand, and (6)/(6'), on the other hand, shows. They can also be packaged differently in so far as they are expressed as a cluster or as syntagmatic material: regardless of whether a given state of affairs is presented as in (7) or in (8), it contains the same aspectual content, has the same internal temporal structure: ${ }^{57}$

(7) It. Ho appena mangiato [Perf. Com.].

'I have just eaten.'

(8) Fr. Je viens [Prés.] de manger.

'I have just eaten.'

There is no doubt that the combinations and hierarchisations of individual aspectual contents - which are called "basic conceptualisations of aspectuality" here - are very different. However, aspectuality can be found in all the world's languages, all - or almost all - have developed means of expressing aspectual content. $^{58}$ In other words, it is a universal phenomenon displaying languageparticular manifestations (see Bybee 1985, 2). ${ }^{59}$ In choosing a cognitive approach

57 See here Talmy's important contributions to the categorisation of linguistic structures in general and motion verbs in particular; a complete collection can be found in Talmy (2000).

58 See Dahl (2001) for an analysis of the so-called languages without aspect.

59 "Aspect is a parameter which is realized differently across languages." (Smith 1991, 3). 
this work distances itself from De Miguel's (1999) likewise onomasiological study (see §2.3.1) with regard to an important issue: here I propose extending the investigation towards defining the cognitive operations which underlie the aspectual structuring of states of affairs. ${ }^{60}$

\subsection{Complexity - the structuredness of the category and the interplay in the sentence}

Another central step in this approach to aspectuality consists in viewing it as a complex category. What exactly is meant here, and above all, what is not meant here - i.e., that aspectuality is not based on a purely additive mathematical principle of composition - is further specified and explained in what follows as well as in subsequent chapters through the analysis of different representations of states of affairs. Yet, I will make some essential remarks at this point:

We speak of a complexity of aspectuality on two levels:

- on the level of the onomasiological foundation, the structuring of the category as such;

- on the level of the convergence of the diverse elements by which aspectuality is realised in concrete sentences. ${ }^{61}$

In Chapters 4 and 5, in presenting the model of aspectuality, which describes certain very abstract types of perspectivisations in situation frames, I will show what is meant by "complexity" or "constellation-ness" in the sense of a): the interplay between the different options in external, adjacency-related and internal aspectuality. Undoubtedly, it is this discussion of complexity on the level of the onomasiological foundation of the category as such that constitutes the focus of this investigation. We will have to look for an explanation of complexity which has nothing to do with compositionality in the sense of Frege or with the convergence of different elements in the sense of Construction Grammar, since both are compositional principles that are certainly well suited for analyses on the level of the interplay of elements in the sentence, but not for those

60 On Gestalt rules and association principles in general, see Herrmann (1976) and Metzger (1986); see also Blank (2001, 43), Croft/Cruse (2004), Koch (1999a and 2012) etc.

61 This corresponds to the onomasiological perspective chosen here. However, work in this field rarely takes an onomasiological perspective in looking at how the content category of aspectuality is linguistically expressed, but looks instead at the semasiological question of the nature of aspectuality as the sum of the individual elements in the interpretation of sentences. 
on the purely conceptual level of a - not yet formally expressed - content category.

On the following pages, however, I first discuss what is meant by complexity in the sense of b), in other words, what are the elements that serve the expression of aspectuality in a sentence and what happens between these elements.

The aspectual structuring of a state of affairs conceived as a situation frame is expressed in a complex way, in that it is expressed in the sentence by very different subcomponents interacting with one another. These can convey aspectual contents directly or only influence them, and they can be found at different organisational levels (lexical, morphological, syntactic, ...).

If we address the question of what the elements that serve to express aspectuality in the sentence are, we first of all find the verb, traditionally the central issue in research on aspect. As regards the analysis of aspectual information from a semantic-functional perspective, the verb is undoubtedly central as far as semantics is concerned. However, consideration of aspectuality in the verb stem alone and in isolation merely provides information about the potential of the verb in question, because what constitutes this centrality is the constitutive function of the verb valence in the sentence semantics. So, if one goes beyond the notion of verb valence in the analysis of aspectual information as well, there is certainly no point in speaking of aspectuality expressed solely through a verb ${ }^{62}$ without involving its participants and its environment.

The need for an analysis that can accommodate the possible combinations of the verb and its arguments was advocated by Verkuyl in the 1970 s. ${ }^{63}$ He was the first to emphasise - and was critical of theoretical lines that did not - that the aspectual information contained in the verb stem differs depending on its arguments, and that in order to interpret it correctly it must be considered in the verbal syntagma. ${ }^{64}$ How the aspectual behaviour of most verbs changes depending on the realisation of one or another of their arguments in the utterance is shown by the following examples, which are described using the traditional terminology of Vendler's verb classifications:

62 Of course, it would make even less sense to speak of the aspectual nature of a verb. This investigation - which does not intend to offer any verb classification, even though this is certainly very valuable in other contexts - is not concerned with ontology. As the differences between the various aspectual contents cannot be ascribed to the states of affairs themselves, I prefer to keep to presenting or describing the states of affairs.

63 His 1993 monograph continues his work on aspectuality begun in the seventies and modifies several points of his theory.

64 See also the advocates of this position in Slavic research: Anstatt (2003) and V. Lehmann (1992, 1997 and 1999). 
(9) It. Leo bussò [Perf. Sem.] alla porta. [punctual: non-durative + non-telic] ${ }^{65}$ 'Leo knocked on the door.'

(9') It. Leo bussò a lungo/tre volte alla porta. [punctual + iterative] 'Leo knocked long/three times on the door.'

(10) Fr. Léo mange [Prés.]. [durative + non-telic] 'Leo eats.'

(10’) Fr. Léo mange une pomme. [durative + telic] 'Leo eats an apple.'

(11) It. La pioggia cade [Pres.] leggera sulla terra. [durative + non-telic] 'The rain falls lightly on the ground.'

(11') It. Il sasso cade pesantemente nell'acqua. [non-durative + telic] 'The stone falls heavily into the water.'

(12) Sp. Leo encontró [Perf. Sim.] una seta en un bosque de pinos. [non-durative + telic]

'Leo found a mushroom in a pine forest.'

(12') Sp. Leo encontró setas en un bosque de pinos. [non-durative + telic or durative + non-telic]

'Leo found mushrooms in a pine forest.'

In all the cases listed above, the verb can be assigned to one or the other so-called actional class, depending on whether:

- as in (9) and (9'), an adverbial expressing durativity or quantification (here a lungo or tre volte) is present in the sentence or not;

- as in (10) and (10'), a second argument (here a direct object, une pomme) is present in the sentence or not;

- as in (11) and (11'), the first argument (the subject) is a collective group noun $^{66}$ or a count noun (here, respectively, la pioggia or il sasso);

65 This sentence can also be interpreted as reiterative, which already in this context speaks for polysemy of the verb.

66 For a classification and interpretation that - besides count/mass nouns - also takes into account so-called group and generic nouns, see Mihatsch (2006). 
- as in (12) and (12'), a second argument in the sentence is present with singular or plural quantification (indefinite-specific, in this case una seta or setas).

This verb classification, which is determined contextually, is undoubtedly the prevalent position in aspectological research today. However, the influence of other elements in the sentence on the aspectual value is rarely taken into account, ${ }^{67}$ nor is the impact of extralinguistic and pragmatic factors, such as the iterative and/or habitual interpretation in the case of the logically contradictory combination of punctual Aktionsarten with an imperfective aspect or, as seen above, with adverbials expressing durativity. Verkuyl's more recent works (see Verkuyl 1993) - onomasiologically oriented and formally implemented - are mainly concerned with the verb and its arguments and deal only marginally with the influence of the other elements in the state of affairs, yet these are of great relevance in the present study: ${ }^{68}$

It is precisely in 'the linguistic tradition in the first half of this century', [. . . ] that aspectologists have become conscious of the fact that a pure morphosyntactic approach to aspect falls short of recognising the importance of the interaction between the organisation of the verbal lexicon and the aspect markers and/or aspectual interpretation cues operating on the morphosyntactic level. (Sasse 2002, 220)

The aspectual interpretation of a state of affairs - the view advocated here thus results from a much more complex interaction of several elements or subcomponents in the state of affairs understood as a frame. Even the elements that do not directly convey any aspectual information interact with those that do, thereby influencing the overall interpretation of the state of affairs:

67 It has already been pointed out that in Verkuyl's theory (especially its first version) the compositionality of the aspectual components is applied in terms of V and NP and that the role of adverbials is not properly brought to the forefront. See, in particular, Dowty's (1986) criticism of Verkuyl's approach.

68 An important criticism of his theory of aspectuality (1972) - though rejected by Verkuyl $(1993,17)$ as unjustified - argues that it deals essentially with the logical structures of the syntactic level and excludes the semantic level, see e.g., Dowty (1986), Krifka (1989a) and Sasse (2002). Regardless of the validity of this criticism, however, the following has to be noted: if, on the one hand, Verkuyl rejects any verb classification that seeks to abstract from the context and defends a strictly unidimensional view of aspectuality (i.e., the absence of the distinction of further categories within aspectuality), on the other hand, he deals mainly with morphosyntactic units in the context, because "context" here means rather the syntagma (see also Sasse 2002). While I also choose a unidimensional approach to aspectuality, although based on other criteria, I do not share Verkuyl's view in this regard and favour instead a more semantic aspectological research. 
(13) Fr. Marie-Rose se mit [Pass. Sim.] à chanter.

'Marie-Rose began to sing.'

(14) Fr. Timidement Marie-Rose se mit à chanter.

'Shyly Marie-Rose began to sing.'

The state of affairs illustrated in example (13) clearly shows how different elements play a central role in the overall interpretation of aspectuality:

- Marie-Rose: this is a special kind of noun, a proper name (nomen proprium), which has a high degree of definiteness and various semantic features (e.g., 'living', 'human', 'female').

- chant(-er): if this verb stem is considered as a (lexical) form "in itself" - i.e., regardless of its combination with any inflectional marking (or with the other elements of the verbal periphrasis with which it is associated here) or with its arguments in the utterance - it can be seen as representing a socalled activity, in other words a durative, non-telic, dynamic verb concept, whose initial boundary does not coincide with its final boundary, $t_{x} \neq t_{y}$, and which strives for no natural endpoint.

- se mit à (chant-)er: this is a periphrastic verbal construction consisting of three elements. Two of the elements (se mettre and chanter) are verbal, the other (à) is prepositional; the first verb is inflected (here Passé Simple) and has the function of an auxiliary verb (though not at a very high level of grammaticalisation); ${ }^{69}$ the second has the form of a non-finite full verb. Through this construction, through the combination of these three elements, the temporal (here past), modal (here indicative) and aspectual (here ingressive, punctual and delimited or completed) contents are transmitted cumulatively. It should also be emphasised that the meaning or function of this construction cannot be reduced to the simple sum of the meanings of its three subcomponents, since, for example, neither se mettre nor chanter in themselves have the characteristic of non-durativity independently of the context.

Now the elements of the state of affairs represented in example (14) are the same as those in (13), with a single exception: timidement. And it is precisely the presence of this - on closer inspection modal and not temporal - adverb in (14) which leads to a radically different aspectual interpretation of the state of

69 On grammaticalisation processes and the scalarity of auxiliary verbs, see Heine (1993), on those of verbal periphrases, see Squartini (1998); see also Chapter 6 for verbal periphrases. 
affairs. While - as just stated - the state of affairs in (13) has an internal temporal structuring of the type ingressive, non-durative and delimited, that in (14) is of the type ingressive, durative and delimited. For while the beginning of singing in (13) is something connected with a moment (the very moment of the first note being produced), in the case of a timid beginning to sing in (14) that moment is (based on world knowledge) reinterpreted and in a way stretched out, insofar as all the preparations and attempts to begin singing are contained in this extended period of time. The lexical and grammatical constructions shown in the two examples are related to two different frame structures that represent the contexts, the experiential connections, in which the speaker has learned them and uses them; as such, they are polysemous (see §3.2.4).

An additional example sheds further light on this:

(15) Sp. Leo encontró setas en un bosque de pinos.

'Leo found mushrooms in a pine forest.'

The state of affairs consists in finding several mushrooms by an individual named Leo in a pine forest. The individual components of the state of affairs presented in (15) can be analysed straight away using traditional terminology and it can be seen how the various contents and forms in their mutual interaction participate in its entire tempo-aspectual constitution:

- Leo: this is a special kind of noun, a proper name (nomen proprium), which has a high degree of definiteness and various semantic features (e.g., 'living', 'human', 'male').

- encontr(-ar): if this verb stem is considered in itself (i.e., independently of its combination with any inflectional marking and its arguments in the utterance), here encontrar represents a so-called achievement, in other words a non-durative, telic verb concept whose initial boundary thus coincides with its final boundary $\left(t_{x}=t_{y}\right)$ and which strives for a natural endpoint.

- (encontr-)ó: this is a - cumulative - morphological verbal marking through which temporal (here past), modal (here indicative) and aspectual (here perfective) contents are transmitted.

- seta-s: this is a common noun (nomen appellativum), in particular a plural concrete noun. The use of the plural without the concomitant presence of a particular article shows an absence of definiteness: here we are not dealing with a single or particular mushroom (or several mushrooms that are precisely identified or measured in their quantity), but with any mushrooms 
whose number is unspecified. ${ }^{70}$ It is precisely this absence of determinateness that creates the condition so that the process presented in the state of affairs can be interpreted as reiterated: since no specific mushroom is found and because finding in itself must always be the finding of something in particular, and therefore a striving for a natural endpoint (see above), the state of affairs is reinterpreted as being constituted of several repetitions of the process itself (finding mushrooms).

- en un + bosque (de pinos): this is an adverbial determination (locative) consisting of a preposition (en), an indefinite article (un) and a noun (bosque); the presence of the indefinite article intensifies the absence of definiteness.

Among the various elements, there is apparently an interaction that causes mutual reinforcement, specification, revision, correction and abolition of the wealth of information concerning the temporal internal structure of the state of affairs, and which is regulated by different cognitive mechanisms. This is why it is not always easy to analyse a complex entity, such as a sentence or even a sequence of sentences, in terms of its constitutive parts. The complex unity of a state of affairs, consisting of the combination of two or more components, also possesses semantic autonomy, which arises from this special combination and is linked to its specific context of use. Accordingly, it can only be restrictively analysed when its components are isolated. But that is also why it does not make much sense to speak of verbs (or lexical verb stems) as such, and why I reject a conception of aspectuality based on verb classification and choose instead a frame-based analysis which always considers the components of a situation frame in their relation to the other elements and in their concrete realisation, specific to each case.

We can only hint at an answer to the above-mentioned, legitimate and important question of how the meaning (or meanings) of the subcomponents combine to form the overall interpretation of the state of affairs presented in the sentence, in other words, how these subcomponents are linked together and by which methodological principle this connection is best described and analysed.

One possibility would be to use, as Verkuyl does, the principle of compositionality attributed to Frege, according to which "the meaning of a complex expression [...] [is] a function of the meaning of its parts and its type of syntactic

70 However, it should be noted that here, if the sentence is to be used in a meaningful way in a text it must have a specific indefinite reference, as in un bosque. In other words, the speaker must know that there was this forest and that there were mushrooms that were found by (this specific) Leo. 
connection" (von Stechow 1991, 95, orig. Ger.). ${ }^{71}$ Without doubt, there are many areas of human language in which the principle of compositionality is efficient; or, more precisely, there are certainly structures in a natural language that are compositionally analysable in this sense. However, such a principle can in no way be generalised, as there are several well-known exceptions which cannot be analysed in terms of compositionality, a fact that is well illustrated by, e.g., compounds and phraseologisms (e.g., collocations): ${ }^{72,73}$

(16) Fr. rouge-gorge

'robin'

(17a) Ger. ein starker Mann

'a strong man'

(17b) Ger. eine starke Frau

'a strong woman'

(17c) Ger. ein starker Wein

'a strong wine'

(17d) Ger. ein starkes Argument

'a strong argument'

The meanings of expressions such as in (16) rouge-gorge ('robin') and (17a)(17d) ein starker Mann ('a strong man'), eine starke Frau ('a strong woman'), ein starker Wein ('a strong wine') and ein starkes Argument ('a strong argument') are not simple mathematically-additive compositions of the meanings of their constituents. It is not possible to reconstruct from the sum of the meanings of rouge ('red') and gorge ('throat') that the referent in question here is a bird. ${ }^{74}$

71 The principle of compositionality has been defined in different ways (and also in varying degrees), as in Montague (1974), Wunderlich (1987), etc. For an overview of these and an analysis of the consequences of their differences as well as the general problems arising from the principle of compositionality (also for generative syntax), see von Stechow (1991).

72 Coseriu calls these non-compositionally analysable compounds "exocentric". See Coseriu (1977).

73 The analysis of the following examples in part follows Lee (2001, esp. 73ff.).

74 Let us consider compounds such as Wassermühle ('watermill'), Windmühle ('windmill'), Papiermühle ('paper mill'), Schrotmühle ('grist mill'), Pfeffermühle ('pepper mill'), Sägemühle ('sawmill'), etc.: the word Mühle ('mill') refers to a building or an apparatus in which power (in various forms) is used to drive (various types of) tools in order to obtain a variety of results 
The fact that 'strong' varies semantically from example (17a) to example (17d), and the fact that aspects of encyclopaedic (including cultural) knowledge come into play in interpreting each of these expressions, show that meanings are much better analysed as being the product of a complex interaction between the frames connected to the respective words, and not as a combination of their meanings in a narrower and more traditional sense.

It should now be noted that this access to compositionality cannot only say little about the constructions depicted in (16)-(17a-d), but also about some complex constructions ${ }^{75}$ which contain linguistic realisations of aspectuality, such as those in examples (18)-(20). Another way to address the question of how the elements that linguistically express aspectuality in concrete sentences are linked together would be to adopt an approach based on Construction Grammar.

However, I do not want to adopt a particular model of meaning constitution on the level described above as b), because the perspective chosen in this work and the model arising from it is to be found - let me emphasise this once again - on the other side of the problem, on the level a). In conjunction with the proposal outlined in the next chapters, different approaches are possible, which can build on models based on different theoretical schools of thought, i.e., different semantic assumptions. ${ }^{76}$

(such as producing electricity, pumping water or making a product). This means that different specified semantic linking options are available as targets for the mapping of suitable concepts. In windmill and watermill, the concepts WIND and WATER are classified in the slot TYPE OF POWER SOURCE; in pepper mill and grist mill, the concepts PEPPER and GRIST are arranged in the slot RAW MATERIAL/PRODUCT, and in sawmill, the concept SAW is arranged in the TYPE OF TOOL slot (see Lee 2001). Very interesting here is the extraordinary ability of German to produce compounds: for example, a Windpfeffersägemühle ('wind pepper sawmill') would be a mill that saws pepper with wind power.

75 Constructions in the narrower sense - in the sense of Construction Grammar - are only indirectly dealt with in this book, as the focus and analytical perspective here are onomasiologically oriented. If aspectuality were dealt with from a semasiological perspective, the combination with this approach would certainly be conceivable here. On Construction Grammar in a narrower sense, see among others the works by Fillmore/Kay/O’Connor (1988), Fillmore/Kay (1987), Kay/Fillmore (1999), Croft (2001), Goldberg (1995 and 2006), Tomasello (2003) and, especially on morphology, Booij (2010), as well as, in research on German, Fischer/ Stefanowitsch (2006), Stefanowitsch/Fischer (2008), Lasch/Ziem (2011) and Wildgen (2008).

76 Among the many possible models one could, depending on the theoretical framework, assume, for example, a lexically specified default value that is contextually modified by coercion, or aspectually underspecified predicates which either in principle can assume any aspect value in context or determine the possible aspect values by the frequency of their contexts (this would be the case, e.g., in a use-based approach, etc.). 
But let me present a few more considerations and examples:

(18) Fr. La neige est tombée [Pass. Com.] pendant la nuit. 'Snow fell during the night.'

(19) Fr. La neige est tombée du toit pendant la nuit. 'Snow fell from the roof during the night.'

(20) Fr. La pierre est tombée pendant la nuit.

'The stone fell during the night.'

The verb tomber ('to fall') has a number of specified semantic linking options as targets for the classification of suitable concepts (e.g., in (18) and (19) la neige and in (20) la pierre). However, it is only in the respective frames represented by the examples that the meaning of tomber (and its aspectual configuration) takes on its definitive form. It is only through their world knowledge that the speaker/hearer can express/interpret the aspectual structuring of (18) as that of a reiterative state of affairs: they know that snow (collective) consists of many different flakes, and they assume that when it falls it does not do so all at once but rather the many flakes fall gradually (and then remain on the ground and colour the paths white,...). The aspectual meaning constituted by the interplay of the elements in (18) is thus more than the sum of the meanings of the individual components and the syntactic rule which links them together; and this more results from its emergence in the particular experiential context, from its interaction with world knowledge. Something similar happens in the state of affairs represented by (20). World knowledge enables the speaker/hearer to express/interpret the aspectual structuring of (20) as that of a state of affairs uniquely taking place: they know that the stone is a single object (heavy, subject to gravity, ...) and that, when it falls, unlike in (18), this happens once (then it remains on the ground and ...). It is just this (unique) aspectual meaning that is also expressed by the falling of the snow in example (19), because it can be assumed from the fact that the snow falls from the roof and not from the sky that this is not a series of flakes but rather a compact mass of snow falling all at once (because it has accumulated on the roof first, and we know it will fall all at once). The presence of $d u$ toit, which in itself has no aspectual content, thus considerably influences the aspectual interpretation of the frame on the basis of world knowledge.

Diverse cognitive processes underlie and regulate the combinability of aspectual contents with each other and with other functions of language in the 
scenarios realised in communication. ${ }^{77}$ This combinability makes it possible to attain the most diverse communicative goals, because the possibilities of refinement, modification and correction of aspectual information are almost unlimited: ${ }^{78}$

(21) It. Esplodeva [Imp.] lentamente in mille colori, riempendo il cielo sino a traboccare. L'ultimo fuoco d'artificio svanì [Perf. Sem.] d'improvviso lasciando un bimbo seduto sul suo letto che non s'addormentava [Imp.] per ore. Guardava [Imp.] e riguardava [Imp.] dalla finestra, per ore. Si era fatto quasi giorno e lui guardava [Imp.] dalla finestra. Piano piano il sole sorse [Perf. Sem.], lo salutava [Imp.] sorridente: da due minuti s'era fatto giorno. Leo si alzò [Perf. Sem.] e non si alzò [Perf. Sem.], si girò [Perf. Sem.] e si rigirò [Perf. Sem.] fino a che sua madre strisciò [Perf. Sem.] in un lampo nella stanza portandogli il solito latte col miele.

'It exploded slowly in a thousand colours, filling the sky to overflowing. The last firework faded away suddenly, leaving a boy sitting on his bed unable to sleep for hours. He looked and looked out of the window for hours. It was almost daybreak and he was (still) looking out of the window. Very slowly the sun rose, he greeted it with a smile: day had broken two minutes ago. Leo got up, he didn't get up, he turned over and over again until his mother in a flash crept into the room bringing his usual milk and honey.'

In such a complex text as shown in (21), we can once again clearly see how each additional element influences the overall aspectual content and, in turn, allows for combinations that show its extensibility. Esplodere ('to explode'), which in the traditional classifications of Aktionsart is described as punctual (i.e., non-durative + non-telic), acquires through combination with the durative element, lentamente ('slowly'), aspectual information selected specially for this frame. The reverse behaviour can be seen in the combination of the durative strisciare ('to creep') with the punctual in un lampo ('in a flash', 'in an instance'). The role of the negation in non s'addormentava per ore seems to be particularly interesting (literally 'he did not fall asleep for hours', but here to be understood as 'he was unable to sleep for hours'), because only the presence of the negation allows the transformative addormentarsi (i.e., non-durative + telic) to be combined with a durative element such as per ore ( ${ }^{\star}$ s'addormentava per ore).

77 Here, as will be seen, aspectuality is mainly about contiguity-based processes.

78 In Chapter 4 I show that the combinations are, of course, not completely arbitrary and that there are also combinations which for logical reasons are impossible, i.e., there are restrictions or constraints. 
In summing up again the elements which can express or influence aspectuality on the semantic level of the sentence, ${ }^{79}$ the following need to be mentioned:

- The aspectual information anchored in the verb stem. This represents a particular aspectual configuration (e.g., Fr. être blond vs. rêver) insofar as it contains information about its own combinability with other elements and contents in the frame - of an aspectual or other nature - that can add to the predicate and to the sentence in general. ${ }^{80}$ It interacts with the arguments of the predicate/verb, which in turn can directly constitute an aspectual component, and create a temporal structuring (It. esplosione vs. passeggiata) and links to other nodes of interaction, such as determiners and quantifiers (Sp. comer una manzana vs. comer manzanas vs. comer tres manzanas).

- Further aspectual building blocks are expressed by morphological or morphosyntactic markers (verb stem modifications, derivational or inflectional markers, periphrastic constructions). They also interact with morphosyntactic elements of a non-aspectual nature (for example, with tense or mode markers).

- Adverbials can directly convey aspectual information or evoke it (It. entrò lentamente vs. entrò timidamente).

- Quantification and negation influence the entire aspectual situation frame and not only in conjunction with the arguments (It. non si svegliava per ore

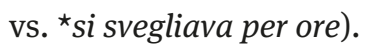

- Finally, word order plays an important role in interpreting the combination of aspectual and non-aspectual elements, cf. It. dall'una alle due pranzo con i miei colleghi vs. pranzo con i miei colleghi dall'una alle due, where in the first case the preferred interpretation is habitual (= dall'una alle due pranzo sempre/normalmente con $i$ miei colleghi), in the second case it is rather a one-off event (= oggi pranzo con i miei colleghi dall'una alle due).

79 It is clear that pragmatic factors can also influence the interpretation of the aspectual situation frame. Combinations of aspectual information that would be logically contradictory may, for example, be interpreted on the basis of inferences or implicatures.

80 The aspectual information interacts with other information of a non-aspectual nature, which is also anchored in the verb stem. See the semantically-founded (but ontologicallyoriented) verb classifications, such as Schumacher's (1986), in which a distinction is made between a) verbs of general existence, b) verbs of special existence, c) verbs of difference, d) verbs of relation and mental action, e) verbs of scope of action, f) verbs of verbal expression and g) verbs of vital needs. But see also the more comprehensive classifications of experience construal, such as, e.g., Halliday/Matthiessen (1999), who distinguish between different domains of experience: "happening and doing” (material), “sensing” (mental), "verbal” (saying), "being and having” (relational). See also Halliday (1985) and Matthiessen (1995). 
Table (1) briefly summarises the above-mentioned elements:

Tab. 1: Formal elements of aspectuality.

\begin{tabular}{|c|c|}
\hline \multirow{6}{*}{$\begin{array}{l}\text { Forms and structures of possible } \\
\text { expressions of aspectual } \\
\text { information }\end{array}$} & verb (stem) \\
\hline & (verb) arguments \\
\hline & morphological marking (inflectional and derivational) \\
\hline & morphosyntactic marking (verbal periphrases) \\
\hline & adverbial determination \\
\hline & $\cdots$ \\
\hline \multirow{7}{*}{$\begin{array}{l}\text { Forms and structures which } \\
\text { interact with aspectual } \\
\text { information }\end{array}$} & (verb) arguments and nodes connected to the arguments \\
\hline & morphological marking (e.g., temporal, modal, ...) \\
\hline & adverbial determination \\
\hline & quantifiers \\
\hline & negation \\
\hline & word order \\
\hline & $\ldots$ \\
\hline
\end{tabular}

\subsection{Summary and a first interim conclusion}

Aspectual information is diverse, structured and combinable. Like all word, sentence and text structures, i.e., every combination of elements resulting in turn from the connection between a form and a meaning, it is based on a principle of productive and selective composition. ${ }^{81}$ This view of aspectuality can be

81 The combination of various aspectual (and other) semantic contents creates patterns that yield either more (through the emergence of new structures or further rules of combinability) or less (through selection) than the sum of the respective parts (see, among others, Fauconnier 1984 and 1999, Goldberg 1995 and 2006, Lakoff 1987 and Langacker 1987, 1990 and 1991). However, with Wildgen (2008) it must also be acknowledged that this conception of compositionality can be problematic: "The operations that Langacker calls construal, Lakoff mapping, Goldberg fusion and Fauconnier blending, have at their core the problem of combining two contents, where the whole is either more (through the emergence of a new structure) or less 
explained particularly well in a frame-based conception of states of affairs - for both the above-mentioned levels (see §3.5) at which we can speak of "aspectual complexity".

On level b) of the realisation of aspectual meaning in a sentence, this meaning is expressed in an utterance in the interplay of various elements that are distributed across all organisational levels of language, from the typically lexical to the typically grammatical. This means that there are a number of specified semantic linking options serving as goals for the classification of suitable concepts with the formal solutions favoured by the respective languages, and that these take on their definitive form only in the respective frame. Co-occurrence of the various elements can mean that the wealth of information pertaining to the temporal structuring of a state of affairs undergoes a mutual process of reinforcement, specification, revision, correction and elimination. On the one hand, the elements that interact in the expression of aspectuality in the sentence can directly serve as an expression of an aspectual (basic) conceptualisation (which does not exclude them also conveying other meaning components, that is, other conceptualisations). But it is also possible that they only influence them and do not convey aspectual information of their own. More specifically, aspectual conceptualisations can be conveyed, for instance, by verb meaning components (cf. It. essere vs. diventare, Fr. partir vs. arriver, Sp. florecer vs. desflorecer), verb arguments (cf. It. la pioggia cade vs. il piatto cade, It. vivere vs. vivere una cosa magnifica, Fr. je mange vs. je mange une pomme), adverbial determination (cf. It. arriva a casa dalle tre in poi vs. arriva a casa vs. arriva a casa alle tre), etc. On the other hand, the elements that only influence them, and that therefore do not convey aspectual information per se, are: adverbials (cf. It. entrò timido/timidamente in classe vs. entrò in classe), negations (cf. It. ${ }^{\star}$ sta lavorando a Roma vs. non sta lavorando (più) a Roma), word order (cf. It. dalle tre alle quattro faccio colazione vs. faccio colazione dalle tre alle quattro), etc.

In discourse, the speaker uses the most varied goals of communication via different communicative strategies (economy, expressiveness, ...) and with the

(through selection) than the sum of the parts. This is also a classic problem in Gestalt psychology. All these concepts may be very specifically realised in individual models, but they all underlie the following problem: given two simultaneously available contents (in perception or in memory), how can they be brought together to create a new meaningful whole that is so stable in its new form that it can also be remembered and communicated. A central problem here is the complexity of the parts and the possible hypercomplexity of the whole, i.e., if the composition exceeds a certain threshold of complexity, the outcome of the composition becomes unstable and thus useless, worthless for thought and communication." (Wildgen 2008, 200, orig. Ger.). 
help of multiple pragmatic mechanisms (implicatures, inferences, ...) to express one or more possible combinations of aspectual information. Each individual language selects its own patterns of delimitation and combination, shows tendencies and preferences, and sets priorities concerning the choice of means by which it expresses the aspectual building blocks and with regards to the levels of organisation on which they are situated in this language. ${ }^{82}$

To approach aspectuality as a complex, universal content category certainly does not mean to deny the diversity of its realisations in the different languages of the world, nor does it mean mixing the means and the procedures it uses or the levels of language on which it is manifested. Rather, it means changing the perspective and trying to insert that diversity into a coherent interpretative framework that insists on its linguistic universality and emphasises its semantic homogeneity. Here, aspectuality is the dimension through which speakers organise a state of affairs according to its particular inherent temporal structure.

The following chapters will present in detail a model for analysing aspectuality and its complex structuring in three perspectives (mentioned above as complexity in the sense of a)), and their possible realisations in the Romance languages.

82 However, some common crosslinguistic patterns can be identified. 


\section{The Model of Aspectuality as an Internal Temporal Structuring of States of Affairs}

\subsection{Introductory remarks}

Human cognitive abilities allow for the conceptualisation and varied combination of pieces of aspectual information with each other and with further - i.e., temporal or modal - content, which contribute to the structuring of a state of affairs. Yet, the fourth chapter will focus specifically on a cognitive principle that plays an important, if not the central role in the aspectual structuring of a state of affairs, namely the figure-ground principle (see §3.2.3), since it is aspectuality as a crosslinguistic content category that will be discussed here in particular (which was explained in detail in Chapter 3). For this purpose, a description and classification principle of aspectual content is used, which, in accordance with the chosen onomasiological analytical perspective, is based on a general level, or even on the level of basic human cognitive ability: the delimitation principle. As will be seen, aspectuality is to be understood here as "aspectual delimitation". What this means exactly will be discussed on the following pages, where a new model of aspectuality based on this principle is systematically developed.

In order to avoid the danger lamented by various scholars, that the use of terminology established for the semasiological analysis of aspect and Aktionsart could provoke misunderstandings or a confusion of levels in an onomasiologically guided analysis, this work also proposes a new general - and homogeneous - terminology ${ }^{1}$ which reflects the chosen classification criterion of aspectuality and the delimitation principle, and which therefore seems suited to the semantic consideration of the category. In the following, therefore, we will speak less of perfective vs. imperfective, durative vs. non-durative or telic vs. atelic as, on the one hand, these traditional terms cannot reflect the new categorisation presented here, while, on the other hand, they may evoke associations that rather obstruct their correct understanding.

\footnotetext{
1 See Chapters 1 and 2 for a historical reconstruction of the traditional definitions of aspectual categories (aspect and Aktionsart), as well as the differences between unidimensional and bidimensional approaches with regards to the more general content category of aspectuality, whose respective advocators maintain a mutually critical attitude. In those two chapters, the reasons for the need to introduce new terminology for this work are also explained in more detail.
}

¿ Open Access. (C) 2019 Sarah Dessì Schmid, published by De Gruyter. (cc)BY-NC-ND This work is licensed under a Creative Commons Attribution-NonCommercial-NoDerivatives 4.0 International License.

https://doi.org/10.1515/9783110562088-005 


\subsection{Aspectual situation frames}

Aspectuality has been defined as a semantic category - as a universal content category in a relativised sense - that contains the complexity of information relating to the particular internal temporal structuring of a state of affairs. By "internal" I mean a temporal category that is independent of the relationship between the point of speech and the point of the event (i.e., non-deictic), and states of affairs are perceived as situation frames (see Chapter 3). I therefore assume that our ability to perceive and categorise allows us to structure concepts and categories into experiential contexts and also store them as such in memory. By choosing this frame-based interpretation framework, the analysis relies on the results and terminology of Cognitive Semantics. ${ }^{2}$

Once we assume that frames can be conceived as perceptual or conceptual gestalts, as forms of the human conceptual organisation of reality, we can explain states of affairs, on the one hand, as situation frames in general, and, on the other hand, aspectual contents in particular (presented in states of affairs conceived as situation frames) as figure-ground constellations. This approach relies on the description and interpretation models developed by Gestalt theory, which have the great advantage of recognising that the principle of combinability that underlies such constellations is complex and dynamic (see §3.2.3). ${ }^{3}$

I would like to claim here that the most important role in the aspectual structuring of states of affairs is played by the figure-ground process. The differently shaped aspectual frames and their elements or components which are interrelated by contiguity - and which can form subframes - are therefore interpreted as conceptual gestalts that allow for the emergence of figure-ground constellations or effects. These subframes, in turn, can produce further figure-ground effects, because a concept that is highlighted as a figure (in relation to a ground) in a given frame can in turn serve as a ground for another concept highlighted as a figure. ${ }^{4}$ The cognitive association principle of contiguity, which is central in this context, is defined - with Koch - as: ${ }^{5}$

2 As regards the motivation for choosing an interpretation framework based on the notion of frames and for a list of fundamental works on frame theory, see Chapter 3.

3 On Gestalt theory, see Köhler (1947), Wertheimer (1925), Herrmann (1976) and Metzger (1986).

4 On the general interpretation of frames and their components as figure-ground constellations, see Langacker (1987).

5 Here, see Koch (1996b, 1999a, 2001a and 2004); for classic treatments of metonymy see, e.g., Jakobson (1971 [1956]) and Ullmann (1962). On contiguity, which in the language is typically realised by metonymy, see, among others, Talmy (2000, esp. chapter 5), Fauconnier (1999), Langacker (1999), Peirsman/Geeraerts (2006a), as well as Croft's (2006) comment on the latter and Peirsman/Geeraerts' (2006b) response to Croft. 
[...] the relation existing between elements of a prototypical conceptual/perceptual frame or between the frame as a whole and each of its elements. [...] Of course, elements of a frame can, in turn, constitute (sub-)frames. (Koch 2001a, 202)

Thus, if the frame represents the entity at the macro-level, then the relations based on contiguity are the organising principle at the micro-level, which holds the individual elements of the frame together (see also Waltereit 1998, 17). If aspectuality is now defined as an internal temporal categorisation, as a temporally structuring delimitation of a state of affairs perceived as a situation frame, the relationships between the elements of that frame or between the frame as a whole and its constituent elements are also defined as relations of contiguity. Here, "temporally structuring delimitation" means, very generally, "determination" or "boundary setting", which - as an internal temporal constituting act of the state of affairs - entails the emphasis of or focussing on some temporal realities over others, which in turn recede into the background. This makes it clear that, when we speak of contiguity relationships within the frame, we refer to a very general, conceptual level. Figure (1) illustrates these particular relationships of contiguity within the frame.

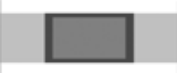

Fig. 1: Delimitation - the temporal constituting act of the state of affairs.

In Figure (1), which represents the frame as a whole, the three colours represent what can be focussed in the frame as being in the foreground or highlighted in relation to the rest (which then recedes into the background): the delimitation of the state of affairs is black, the internal structuring dark grey, the relation to the adjacency of the state of affairs light grey. By this, it also becomes evident that these elements are related to each other by contiguity and that the entire frame can only be generated on the basis of the relations existing between them. Once again, it should be emphasised that the contents distinguished here in the sense of concepts or conceptualisations and categories are to be understood as hypothetically-assumed basic units whose plausibility - but not their mental reality - can be shown by the analysis of an individual language or by language comparison. ${ }^{6}$

6 See the discussion in Chapter 3; here, esp. Aschenberg (2008), Koch (2003). 


\subsection{The delimitation principle}

The chosen criterion, which allows for the description, analysis and classification of aspectual information, therefore revolves around one principle: the delimitation principle. On the one hand, such a classification criterion seems to be sufficiently general and homogeneous in terms of semantics to take account of the needs of comparative investigations - i.e., to also serve as a tertium comparationis on a comparative crosslinguistic level. On the other hand, it is not too general that it cannot adequately grasp and describe the plurality of the aspectual contents - in the plurality of phenomena in which they become manifest in individual languages. ${ }^{7}$

What does the "delimitation principle" mean in concrete terms here? While delimiting generally means "defining”, “determining”, “demarcating”, or "setting boundaries", in the specific case of aspectuality it means "setting boundaries - initial, final, subdivision boundaries or points - in the temporal development of a state of affairs": ${ }^{8}$ Hence, the complex internal temporal structuring particular to a state of affairs is determined by the aspectual delimitation (or boundary setting); this will be illustrated in more detail in Figures (2a) and (2b), which will be commented on below. They represent states of affairs, which

7 The lack of a description of aspectual content based on a few conceptual primitives is already lamented by Sasse: "In order to understand the (language-specific or type-specific) mechanisms of interaction, it is necessary to define a number of conceptual primitives in terms of which all kinds of interaction can be described. I take it that the most important of these primitives are the different types of boundedness/unboundedness that we have come across in the course of our considerations in this paper: intrinsic bounds, arbitrary bounds, temporal bounds, bounds established by situations in a text, and perhaps others.” (Sasse 2002, 263).

8 See Talmy (2000) for an analysis - related in its theoretical approach but different in its application - of "systems" or "schemas" (“configurational structures") which represent temporal structurings of states of affairs.

Here, it shall be only briefly remarked that Talmy, in analysing the relationships between lexical forms/grammatical markers and the structures of states of affairs, distinguishes between the categories of "plexity" and "state of boundedness"; the schemas, the patterns that emerge from these categories, can then be further nested ("configurational nesting"): "Schemas from all the schematic systems and the cognitive operations they trigger can be nested to form intricate structural patterns. Specifically, schemas from the plexity and boundedness categories of the configurational schematic system can nest in this way. Nesting can be illustrated first for events in time with the verb (to) flash. The basic uniplex status of this verb is seen in The beacon flashed (once). The uniplex event can be multiplexed as in The beacon kept flashing. This can be bounded as in The beacon flashed 5 times in a row. This can then be treated as a new uniplexity and remultiplexed as in The beacon kept flashing 5 times at a stretch. And this can in turn be rebounded, as in The beacon flashed 5 times at a stretch for 3 hours.” (Talmy 2011, 628). 
in the first case cover a time span, i.e., a period of time, and in the second case do not:

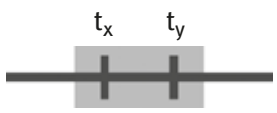

Fig. 2a: Temporal boundaries and contiguity: time span.

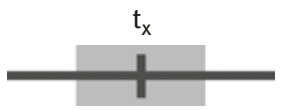

Fig. 2b: Temporal boundaries and contiguity: point of time.

In fact, when setting boundaries we have to deal with several entities related by contiguity:

- with the boundary $t_{x}$ itself or the boundaries $t_{x}, t_{y}, \ldots t_{n}$, if various are set;

- with the adjacency before and after a set boundary $t_{x}$ (i.e., $t_{a}: t_{a}<t_{x}$ and $t_{n}$ : $t_{n}>t_{x}$ ), or, in case of two boundaries $t_{x}$ and $t_{y}$, with one before $t_{x}\left(i . e ., t_{a}: t_{a}<t_{x}\right.$ ) and one after $t_{\mathrm{y}}\left(\right.$ i.e., $\left.t_{\mathrm{n}}: \mathrm{t}_{\mathrm{n}}>\mathrm{t}_{\mathrm{y}}\right) ;^{9}$

- with the interval $I=\left|t_{\mathrm{y}}-\mathrm{t}_{\mathrm{x}}\right|$, enclosed by two set boundaries ( $\mathrm{t}_{\mathrm{x}}$ and $\mathrm{t}_{\mathrm{y}}$ ), as long as they don't coincide $\left(t_{x} \neq t_{y}\right)$.

It should be added at this point by way of specification that, considered in more detail, even in the case where two boundaries $t_{x}$ and $t_{y}$ coincide (represented as $t_{x}$ in Figure (2b)), this is an interval, because strictly speaking one cannot speak of points without an extension in time. Thus, in any case, it is the interval $\left(I=\left|t_{y}-t_{x}\right|\right)$ that arises between two set temporal boundaries $t_{x}$ and $t_{y}$ and that can occur in two forms: $a)$ in the form that encloses a time $\operatorname{span}\left(t_{x} \neq\right.$ $\left.t_{y}\right),{ }^{10}$ and $\left.b\right)$ in the form that does not include a time span $\left(t_{x}=t_{y}\right)$, i.e., in the "coincidence of $\mathrm{t}_{\mathrm{x}}$ and $\mathrm{t}_{\mathrm{y}}$ ", which was mentioned above. ${ }^{11}$

Thus, what is commonly defined as a temporal point is in fact not a point but an interval, albeit the smallest possible perceptible one. But since the interval represented by each temporal $t_{x}$ is so small, it is conventionally considered

9 The adjacency also makes up the constitutive condition of a boundary.

10 This is traditionally referred to as "durative".

11 This is traditionally referred to as "punctual". 
negligible and it has become common to speak of points and/or setting of points on the temporal axis. ${ }^{12}$ It is this convention that will be followed in this work.

In the following graphic representations - which are intended to represent the elements related by contiguity participating in the process of the temporal constitution of a state of affairs - the levels of temporality and aspectuality (or "external temporality" and "internal temporality", see Comrie 1976, 5) are compared. On the one hand, this is meant to show how, in a state of affairs, temporal-aspectual contents interact with each other (how they contribute together to the overall temporal constitution of a state of affairs and how they also are often expressed by means of cumulative morphemes), while, on the other hand, it should emphasise once again that the analysis presented here is focussed on the level of aspectuality.

The first of the following representations (Figure (3)) shows the interval $\left(I=\left|\mathrm{t}_{\mathrm{y}}-\mathrm{t}_{\mathrm{x}}\right|\right)$, which is the time span arising between two different temporal boundaries $t_{x}$ and $t_{y}\left(t_{x} \neq t_{y}\right)$. " $E$ " refers to the state of affairs on the temporal level (here, Reichenbach’s typical abbreviation is used; for more details see §1.2.1):

Aspectual level

$t_{x} \quad t_{y}$

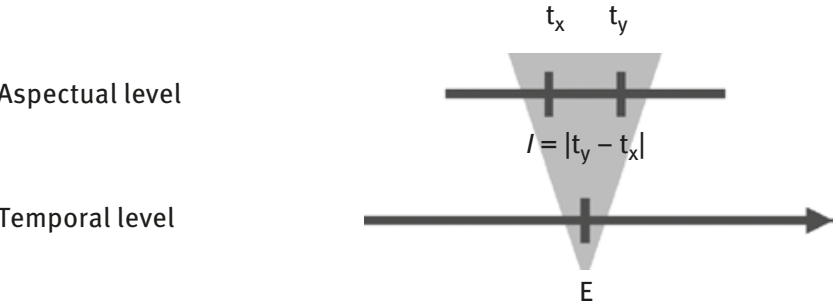

Fig. 3: Interval $\left(I=\left|t_{y}-t_{x}\right|\right)$ : time span.

Figure (3) shows examples of states of affairs of the following type, in all of which a more or less extensive period of time is recognisable:

(1) It. Leo ha mangiato [Perf. Com.] tutte le ciliegie. 'Leo ate all the cherries.'

(2) Fr. Julie parla [Pass. Sim.] de ta mésaventure avec Marie. 'Julie talked about your misadventure with Marie.'

12 Strictly speaking, it would be more correct to speak of the smallest interval of the length $\delta t_{x}$ instead of a point $t_{x}$. $\delta t_{x}$ represents the interval in which the human perception cannot distinguish two events as temporally different and is expressed as: $I=\left|\left(\mathrm{t}_{\mathrm{x}}+\delta \mathrm{t}_{\mathrm{x}} / 2\right)-\left(\mathrm{t}_{\mathrm{x}}-\delta \mathrm{t}_{\mathrm{x}} / 2\right)\right|=\delta \mathrm{t}_{\mathrm{x}}$. 
(3) Sp. Carlos comió [Perf. Sim.] muchos caracoles.

'Carlos ate a lot of snails.'

(4) Cat. Rosina va escriure [Pret. Perf. Per.] una novel-la molt maca. [anar + Inf.] 'Rosina wrote a very nice novel.'

The states of affairs presented in examples (1)-(4), which - in traditional terminology - share the feature of durativity, show in detail different aspectual patterns. Thus, examples (1), (3) and (4) represent states of affairs which traditional analysis would call "telic" and, more precisely, "resultative" ("accomplishment”), while (2) would be "atelic", i.e., "continuous" ("activity"), which will be further investigated on the following pages (see footnote 10).

The second representation (Figure (4)), on the other hand, shows the smallest possible interval $\left(I=\left|\mathrm{t}_{\mathrm{y}}-\mathrm{t}_{\mathrm{x}}\right|\right)$, arising between two set temporal boundaries $t_{x}$ and $t_{y}$ if they coincide $\left(t_{x}=t_{y}\right)$. For the sake of simplicity it has been defined as a point (see footnote 11):

Aspectual level

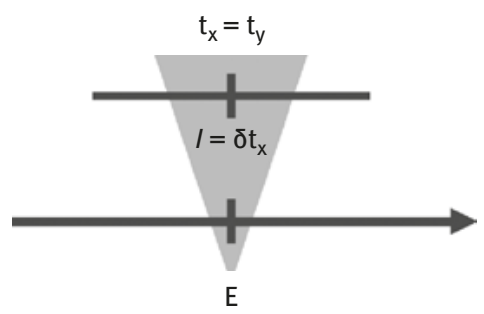

Fig. 4: Interval $\left(I=\delta t_{x}\right)$ : point of time.

Figure (4) represents examples which express states of affairs of the following type:

(5) It. Leo ha starnutito [Perf. Com.].

'Leo sneezed.'

(6) Fr. Il est arrivé [Pass. Com.].

'He has arrived.'

(7) Sp. La bomba explota [Pres.] dentro de la atmósfera terrestre sin hacer ruido.

'The bomb explodes into the Earth's atmosphere without making any noise.' 
(8) Cat. El príncep va ensorrar [Pret. Perf. Per.] la porta del castell. [anar + Inf.] 'The prince broke through the castle door.'

For the states of affairs in examples (5)-(8) - which share the so-called characteristic of "punctuality" or "non-durativity" - a similar remark is also true: they show in detail different aspectual patterns, ${ }^{13}$ which will be dealt with in greater detail on the following pages.

Hence, if it has become clear that the process of delimitation in a complex unit connects different temporal realities which are in contiguity with each other, the next step is to clarify how the mechanisms of aspectuality function in detail.

Each state of affairs conceived as a situation frame represents a complex combination of several components of aspectual information, of various realisations of aspectuality, which are also referred to here as "basic conceptualisations" or "aspectual building blocks". These are nothing other than the differently set cuts or boundaries and the resulting adjacencies and intervals, which are focussed within the temporal structuring of the states of affairs, i.e., which are highlighted compared with other pieces of information that serve as background in the complex state of affairs. Any set boundary - and this should be emphasised once more - can be considered by itself and in relation to its adjacency, for this adjacency determines and is determined simultaneously by this boundary. Thus, in each state of affairs different aspectual basic conceptualisations are combined. It should be noted, however, that the flexibility of the combinatory possibilities of the aspectual information in the state of affairs, in its concrete realisation in a context, cannot be interpreted in terms of complete arbitrariness: in other words, it is certainly not possible to combine everything with everything. As the analysis below will show more clearly, there are logical implications that do not allow the combination of some aspectual conceptualisations with others ("constraints"). The model presented here will also show what limitations the combination of the realisations of an onomasiologically perceived content category of aspectuality is subject to.

13 Thus, one would traditionally say that (5), (7) and (8) represent atelic states of affairs (more precisely, according to Smith (1991), (5) and (8) would be referred to as 'semelfactive', i.e., expressing singular, unique occurrences of states of affairs), while (6) would be defined as telic, as a state of affairs introducing a definitive change of state. 


\subsection{The three dimensions of aspectuality}

\subsubsection{External, adjacency-related and internal aspectuality}

Although each state of affairs is constituted by different, not only aspectual, components interacting with each other, the model presented below will focus on the structuring of aspectual content and will only treat further components of another (including temporal-deictic) nature if their presence in the sentence modifies the overall aspectual interpretation of the state of affairs. ${ }^{14}$

Aspectuality can be subdivided into three dimensions depending on what is emphasised in the situation frame. For, in the delimitation process, the participating elements - the boundary $\left(t_{x}\right)$ itself, the adjacencies before and after the set boundaries and the interval enclosed by two set boundaries (unless they coincide, see $\$ 4.3$ above) - are brought into focus according to three different perspectives (see Table (1) below). These are:

a) the external aspectuality of a state of affairs or its absolute delimitation: this is the determination of the state of affairs as a whole as delimited between a starting point $t_{x}$ and an endpoint $t_{y}$, and therefore completed or not delimited if such a delimitation does not exist;

b) the adjacency-related aspectuality of a state of affairs or the relevance of a state of affairs for its (direct) adjacency: this indicates whether the situation frame in any way determines or influences its subsequent $\left(t_{y+n}\right)$ and/or previous $\left(t_{x-m}\right)$ adjacency, e.g., by presenting or not its beginning or end;

14 The strict focus of the work on aspectual contents as a purely temporal structuring of states of affairs is also the reason why "reiterativity" and "habituality" are not treated separately in the model: both contain not only purely temporal (aspectual) semantic components; in both, quantity plays an essential role; in the case of the habitual, other semantic components are also important. For a critical discussion of the aspectual character of "habituality" see, among others, Carlson (2012); for a different opinion cf. Bertinetto/Lenci (2012). In some frames, the presence of, for example, temporal and/or modal adverbials plays a major role in the overall i.e., also in the particular or non-deictic, that is, aspectual - temporal structuring of the frame. This is particularly evident in comparison to cases such as It. Giulio cominciò a parlare, rompendo il silenzio che durava da ore and Giulio cominciò lentamente a parlare, rompendo il silenzio che durava da ore, where, in the second example, the presence of the modal adverb lentamente influences the temporal structure given in the first example by stretching the expressed time span; or compared to cases such as the following: It. (a) Giulio venne a trovarci, (b) Giulio venne a trovarci alle tre, (c) Giulio venne a trovarci tre volte, (d) Giulio venne a trovarci per tutta l'estate. For while (a) and (b) have an internally-temporally (i.e., aspectually) similar structure (the presence of alle tre in b) has an intensifying function), the combination with tre volte in (c) yields a reiterative reading and that of per tutta l'estate in (d) a habitual one. 
c) the internal aspectuality of a state of affairs or its further internal subdivision: here, whether or not the state of affairs is internally subdivided becomes evident; in other words, whether between $t_{x}$ and $t_{y}$ further points $t_{x 1}, t_{x 2}, \ldots t_{x n}$ are identifiable, in which the interval $I=\left|\mathrm{t}_{\mathrm{y}}-\mathrm{t}_{\mathrm{x}}\right|$ can be structured. ${ }^{15}$ It is therefore a question of whether the state of affairs is pluriphasic or monophasic.

Each of these dimensions is perceived as a figure in relation to the others which are the corresponding ground. In the chosen framework of this work and in accordance with the principle of aspectual delimitation, the definition (1) of aspectuality given in $§ 3.2 .5$ can be specified as follows:

Aspectuality expresses the possibilities of external (absolute delimitation or non-delimitation), adjacency-related (adjacency relevance or non-adjacency relevance) and internal (subdivision or non-subdivision) temporal structuring of a state of affairs.

Definition 2: Aspectuality and its dimensions

Table (1) illustrates the three subdivisions of aspectuality by showing, on the one hand, what is considered from the chosen perspective (black in the drawing) and, on the other, by illustrating that each focussing is only possible by referring to a background (grey in the drawing). The state of affairs can be interpreted in its entirety, but is constituted only in the particular combination of its individual parts, the aspectual basic conceptualisations, which complement and enable each other as foreground and background. Analytically, these parts can be viewed in isolation, as intermediaries of aspectual content only in the function of their mutual relationship within the state of affairs, and on the common background of the state of affairs (abbreviated as SA in the table):

Tab. 1: The three dimensions of aspectuality.

\begin{tabular}{lll}
\hline$\nabla \quad \nabla$ & $\nabla$ & \multicolumn{1}{c|}{$\boldsymbol{\nabla}$} \\
\hline \multicolumn{1}{|l|}{$\begin{array}{l}\text { EA - External Aspectuality } \\
\text { (delimitation of an SA) }\end{array}$} & $\begin{array}{l}\text { AA- Adjacency-related } \\
\begin{array}{l}\text { Aspectuality } \\
\text { (adjacency relevance of an SA) }\end{array}\end{array}$ & $\begin{array}{l}\text { IA - Internal Aspectuality } \\
\text { (subdivision of an SA) }\end{array}$ \\
\hline
\end{tabular}

15 Of course, this also applies to an externally non-delimited state of affairs, i.e., a state of affairs in which neither starting nor endpoint $t_{x}$ and $t_{y}$ are highlighted. 
As regards external aspectuality (EA), here the extent of the state of affairs is focussed as a whole, as a unit delimited or not delimited between a $t_{x}$ and $a t_{y}$. The figure here is therefore the delimitation of the state of affairs (black in the drawing), while the subdivision of the state of affairs as well as its relation to its adjacency and other states of affairs recede into the background (marked in grey).

In the case of adjacency-related aspectuality (AA) the focus is on the adjacency relevance of the state of affairs, i.e., whether and how it structures - as its beginning or end - a state of affairs of its adjacency and, therefore whether or not it is relevant for the temporal constitution of its adjacency, and, if so, in what form. The figure here is the relationship between the state of affairs delimited by $a t_{x}$ and $a t_{y}$ and its adjacency (black in the drawing), while the delimitation itself and the structuring of the state of affairs recede into the background (marked in grey).

As far as internal aspectuality (IA) is concerned, the internal structure of the state of affairs is focussed independently of its consideration as a whole, i.e., its subdivision or non-subdivision into phases, into intervals, by the setting of possible temporal boundaries (different $t_{i}$ ). The figure here is the structuring of the considered state of affairs (black in the drawing) independent of its delimitation and its relation to its adjacency and to other states of affairs, which then represent the ground (marked in grey).

However, renunciation of an ontological-categorial, verb-classificationbased conception of aspectuality certainly does not mean that the model developed here disregards criteria that structure states of affairs purely in terms of time. Rather, it means - and vice versa - the exclusion of criteria from this analysis which do not concern the temporal level. ${ }^{16}$ Consequently, we neither speak of "telic" or of "atelic" states of affairs here, nor is this criterion considered in any of the analytical categories of this study. ${ }^{17}$ We simply forego telicity understood as a classification criterion for states of affairs with an inherent natural (or intended) endpoint (see, e.g., Depraetere 1995). We do this not only because such a view is in fact not just a criterion that relates to the ontological-

16 For a criticism of Vendler in this sense see also Verkuyl (1993, esp. 33ff.). In contrast to the approach advocated here, Verkuyl opts for a strictly mathematical conception of compositionality as the principle of the connection of aspectual information.

17 At the same time, this makes it possible - even though in a radical way - to avoid another important criticism levelled by advocators of bidimensional approaches: the complaint - as discussed in more detail in Chapter 2 - that the criteria of delimitation and telicity are confused and mixed. See, among others, Krifka (1998) for an analysis of a differently conceived telicity: he identifies it more with the Depraeterian delimitation, since he is also convinced that "the nature of the endpoint does not affect the points to be made" $(1998,197)$. 
categorial level of verbs, but also because it is one that does not just encompass purely temporally structuring components: telicity ${ }^{18}$ is about the nature (and not just about the temporal structure) of these endpoints or delimitations. ${ }^{19}$ When we speak of "adjacency-related aspectuality" here, this must in no way be confused with telicity: (final) adjacency-related aspectuality is concerned with the relevance of a state of affairs expressed by a predicate and other components for its (previous) adjacency, and not with reaching an endpoint towards which the predicate itself strives.

In the model developed here, therefore, external aspectuality (EA) or delimitation includes the criterion of duration. For, by definition, time is duration: it consists not only of a succession of points of time $\left(t_{1}, t_{2}, t_{3}, \ldots t_{n}\right)$ and possible starting and endpoints $\left(t_{x}\right.$ and $\left.t_{y}\right)$, but also necessarily the time spans between them (which are again subdivisible, but do not consist merely of points). Thus, if states of affairs that are delimited externally by two points of time, $t_{x}$ and $t_{y}$, which do not coincide, they are states of affairs with a duration; but also externally not delimited states of affairs, i.e., states of affairs which are not delimited externally by two coinciding points of time $t_{x}$ and $t_{y}$ and necessarily consist of several points of time $\left(t_{1}, t_{2}, t_{3}, \ldots t_{n}\right)$ must have a duration. $^{20}$

18 At least in some of the literature on telicity. As noted in the previous footnote, in his interpretation of telicity Krifka distances himself from this widespread view.

19 If we consider so-called telic verbs not per se, but rather in their concrete realisation in the state of affairs, we can see that only those states of affairs can be called "telic" which have an aspect marking of completion: It. (a) La nave approdò [perf. past marking] vs. (b) La nave approdava [imperf. past marking]. In the state of affairs presented in (a) the Aktionsart expressed by the verb could easily be defined as telic; but whether the telos of the state of affairs shown in example (b) is reached remains open, so that, taking a bidimensional approach, we are forced to speak of an abolition of the telos, of "interferences between aspect and Aktionsart" (see Dowty (1977) on the known paradox of the imperfective). Often this argument is used to emphasise the need to distinguish between "(un) boundedness" and "(a)telicity" (in other words, between aspect and Aktionsart), see, in particular, Declerck (1989) and Depraetere (1995). As regards the criterion of (non-)delimitation, states of affairs are classified on the basis of "actual (concrete, realised in context, in the sentence) temporal delimitation"; as regards the criterion of (a)telicity, states of affairs are classified on the basis of "potential endpoints". Croft (2012) introduced in this sense the distinction between "temporal boundedness" ("t-boundedness") and "qualitative boundedness" (“q-boundedness").

20 Only if $t_{x}$ and $t_{y}$ are identical, i.e., if they coincide, are they punctual states of affairs, i.e., those that we can define as having no duration; cf. in this regard $\S 4.3$ above. 
By contrast, adjacency-related aspectuality (AA) encompasses the criterion of ingressivity/resultativity and the change of state in time. If the state of affairs delimited between $a t_{x}$ and $a t_{y}$ is relevant for the temporal constitution of its subsequent adjacency, this means that a focus is being made, based on the fact that the state of affairs serves as the beginning to its adjacency: in Ger. Marie-Rose fing an zu singen ('Marie-Rose began singing'), the beginning of the singing influences its subsequent adjacency by establishing its beginning (Marie-Rose started singing, and probably she continues to sing). On the other hand, when the state of affairs is relevant for its previous adjacency, it structures its end: in Ger. Marie-Rose kam zu Hause an ('Marie-Rose arrived home'), the arriving home influences its previous adjacency by presenting it as its end (Marie-Rose has reached the house and is no longer on the way home). ${ }^{21}$

Finally, internal aspectuality (IA) includes the criterion of dynamicity/stativity. ${ }^{22}$ Only if it is possible to set further subdivision points or boundaries in the temporal structuring of the state of affairs, is there the possibility of variability in time, since this consists in the change of state, the formation and ending of intervals, and thus a temporal boundary setting. In other words, where no discrete, qualitatively different temporal subintervals can be considered, there can be no change in time (and vice versa). Thus, monophasic states of affairs - whose internal structure is homogeneous and is not internally temporally further subdivided (into further points $t_{x 1}, t_{x 2}, \ldots t_{x n}$, into which the interval $t_{x} \ldots t_{y}$ could be subdivided) - are static, while pluriphasic states of affairs - whose internal structure is temporally further subdivided - are dynamic.

\subsubsection{Realisations of the three dimensions of aspectuality}

The three above-mentioned dimensions of aspectuality - external, adjacencyrelated and internal - can in turn be subdivided into a limited number of subtypes in which they are realised in an individual frame: the aspectual basic conceptualisations. There are also cases in which individual aspectual dimensions cannot be identified as delimited or not delimited (i.e., as externally delimited or not, as adjacency-relevant or not adjacency-relevant, as subdivided or not subdivided), since they are not delimitable. Table (2) summarises these basic conceptualisations schematically to give a first overview. A detailed

21 Naturally, $t_{x}$ and $t_{y}$ can also coincide and it can be a punctual state of affairs.

22 In research on aspect and Aktionsart it is common to distinguish not just between "telic" and "atelic", "durative" and "non-durative", but also "static" and "dynamic" states of affairs. 
analysis of the possible realisations of the three aspectual perspectives (as well as the cases resulting from the impossibility of combining certain aspectual information) will be presented on the following pages using different examples, firstly by considering these realisations in isolation, then in their combination in different states of affairs. The abbreviations used are also explained in detail below:

Tab. 2: Aspectuality - overview of the basic conceptualisations.

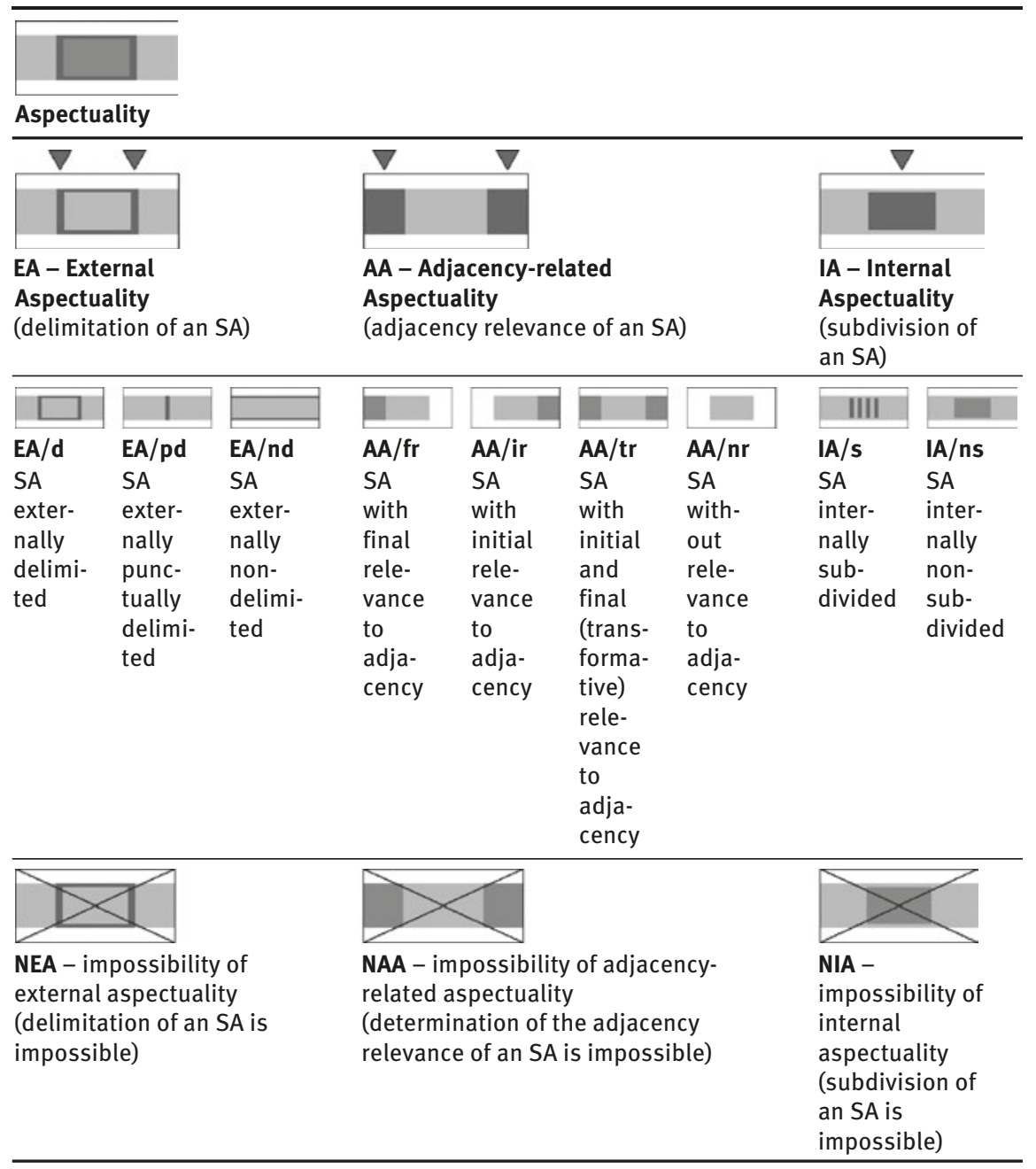




\subsubsection{External aspectuality - delimitation of a state of affairs}

Before an analysis of the various realisations of aspectuality can be made in detail, it should be emphasised again that it is actually impossible to give examples of individually isolated aspectual perspectivisations in a situation frame, since the aspectual organisation of a state of affairs is made up of a combination of the different perspectives of aspectuality. ${ }^{23}$ Therefore, it should be clarified once again that the examples given below for the individual perspectives of aspectuality serve only for analytical presentation, which should lead to a better understanding of the model developed, and do not correspond to an absolute reality. Indeed, in aspectual information, several dimensions of aspectuality are always connected with each other, of course with different emphases: the temporally structured state of affairs unanimously represents a complex constellation of elements related by contiguity (the basic conceptualisations, which each represent realisations of the three dimensions of aspectuality), which is reached only at the level of the situation frame. Thus, for the analysis of the examples given here a focus is set, and the other dimensions are initially excluded. Consequently, some examples appear in several places: they are then used to exemplify the realisation of a particular aspectual perspective that occurs in the frame.

In the case of external aspectuality (EA), the focus lies on the delimitation of the state of affairs, while its subdivision and adjacency relevance recede into the background. It can have three realisations:

- A state of affairs may be externally delimited and can be extended (EA/d); in this case it is a delimited state of affairs $\left(t_{x} \ldots t_{y}\right)$ whose initial boundary does not coincide with its final boundary $\left(t_{x} \neq t_{y}\right)$.

- A state of affairs can be externally delimited and cannot be extended, i.e., it is punctual (EA/pd); in this case it is a delimited state of affairs $\left(t_{x} \ldots t_{y}\right)$ whose initial boundary coincides with its final boundary $\left(t_{x}=t_{y}\right)$.

- A state of affairs cannot be externally delimited (EA/nd); in this case, it is a non-delimited state of affairs $\left(t_{1}, t_{2}, t_{3}, \ldots t_{n}\right)$, thus it has no initial $\left(t_{x}\right)$ and no final delimitation $\left(\mathrm{t}_{\mathrm{y}}\right)$.

The following Table (3) illustrates the different realisations of EA (what is focussed, i.e., the delimitation of the state of affairs, is marked in black in the

23 The basic conceptualisations are not only combinable with each other on the higher level of the entire state of affairs (and combined in the respective currently-expressed state of affairs), but can then also be perspectivised further. This means that they can also be further focussed within the state of affairs (this will be discussed in more detail later, especially in Chapter 6). 
first row and dark grey in the second row of the table; what functions as background is in both rows shown in light grey):

Tab. 3: External aspectuality.

EA
$\begin{aligned} & \text { EA/d } \\ & \text { delimitation of a state of affairs (SA) }\end{aligned}$
$\begin{aligned} & \text { externally delimited SA } \\ & \text { (with delimitation of the }\end{aligned}$

As indicated above, however, in the case of EA there is also another possibility that does not correspond to any of the basic conceptualisations so far presented but concerns a more abstract level of (non-)delimitability (see the last row in Table (3), but also in Table (2)). There are special aspectual constellations, in which, for logical reasons, certain combinations of aspectual information are excluded, and for which it is therefore not possible to make a statement regarding EA. ${ }^{24}$ These are cases that may be referred to as externally non-delimitable, or cases of impossible external aspectuality and external non-delimitability (NEA). These are, for example, states of affairs in which there is a semantic combination with a high degree of genericity and an absence of any aspectual information concerning absolute delimitability, so that we have an externally

24 This level is not to be confused with what Smith (1991) calls "neutral viewpoint aspect" (see Chapter 2). 
atemporal, and therefore absolutely valid, level, as is evident in the following example, commented on in more detail in $§ 4.4 .3 .4$ :

(9) Fr. Les hommes sont mortels.

'Men are mortal.'

Of the various examples (and example types) of realisations of external aspectuality (EA) that could be given - and of the impossibility of external aspectuality or external non-delimitability (NEA) - only a few will be presented and briefly commented on in what follows.

All of the following examples represent possible states of affairs conceived as situation frames in which different types of aspectuality can be identified; this applies not only to the examples in which EA is presented, but also to those that show all the other realisations of aspectuality, which are analysed in the sections below.

These are examples, commented on side by side, a) of all four Romance languages examined here, in which b) aspectuality is expressed both by lexical and by grammatical means, and which, moreover, c) mostly have different tenses.

This is not in line with the usual classification and treatment of states of affairs in which categories of aspect and Aktionsart are distinguished, and this is intentional for several reasons, consistent with the theoretical approach underlying this work.

First of all, the parallel treatment of examples from several Romance languages serves to show the variety of formal means available to them to express aspectual content. This is intended to show that different languages can have different means for expressing the same aspectual content, and also that one and the same language can have several options for doing so. ${ }^{25}$

Furthermore, presentation of these differences makes it clear that there is no inevitable correspondence between a particular realisation of aspectuality and a precise morphological marking or a particular type of predicate. We cannot say, for example, that only the verb forms traditionally labelled perfective - such as the Passé Simple and the Passé Composé in French, or the Passato Remoto and the Passato Prossimo in Italian - express the presence of an external delimitation of the state of affairs, as this can be expressed by other tense forms (the present tense, for example) or by lexical or lexical-syntactic forms (such as adverbs or

25 For example, It. Ho appena mangiato [tense marker Passato Prossimo + lexical, adverbial element] vs. Fr. Je viens de manger [periphrastic construction: venir + de + Inf.]; but in French there are some alternatives for Je viens de manger: J'ai juste terminé de manger vs. Je termine en ce moment/à l'instant de manger. Similar possibilities exist in Italian. 
combinations of verb stems with special arguments). ${ }^{26}$ This makes it very clear that the model developed here is situated on a radically different, onomasiological level, and that there is no direct correspondence between the three dimensions of aspectuality in their various realisations and the categories of aspect and Aktionsart as they are understood traditionally and from a semasiological point of view. Thus, it would not be possible, for example, to trace back - or, so to speak, to translate - aspect oppositions in general to external aspectuality and Aktionsart in general to internal aspectuality.

Finally, the comparative presentation serves once more to show that a large number of elements contribute to the overall interpretation of the situation frame.

\subsubsection{Externally delimited states of affairs (EA/d)}

Situation frames exhibiting external delimitation can be found in the following examples:

(10) It. Leo ha giocato [Perf. Com.] una partita a calcio con i suoi amici. (EA/d) 'Leo played a football game with his friends.'

(11) Fr. Julie a mangé [Pass. Com.] une pomme en trois minutes. (EA/d) 'Julie ate an apple in three minutes.'

(12) Sp. Marta no me habló [Perf. Sim.] durante mucho tiempo. (EA/d) 'Marta hasn't talked to me for a long time.'

(13) Cat. Fa una setmana que no escolto [Pres.] la ràdio. (EA/d) 'I haven't listened to the radio in a week.'

When considering aspectuality from an external perspective, as it appears in the states of affairs expressed in (10)-(13), it is to be noted that all the

26 An example such as It. Avrei voluto un morso di quel bel cornetto al cioccolato che aveva comprato Daniel, ma l'ha mangiato Leo shows perfectly the tendency of the Romance languages to express aspectuality by grammatical means. Here, ha mangiato is the 3rd Pers. Sing. of the Passato Prossimo or, following the terminology of Bertinetto (1986), the Perfetto Compiuto; the morphological (inflectional) marking cumulatively expresses here +tense/past, +mode/indicative and +aspect/perfective (as it is defined in traditional terminology). However, comparison of examples such as Leo viaggia da Roma a Parigi and Leo viaggia volentieri shows very well that such contents cannot be expressed by grammatical means only: here, the presence of different lexical and non-grammatical elements (especially viaggiare da Roma a Parigi) exerts an influence on the external aspectuality. 
examples are cases of EA/d, i.e., aspectually externally delimited states of affairs where $t_{x} \neq t_{y}$ is true, which, in other words, represent an interval $I=\mid t_{y}-$ $t_{x} \mid$ that human perception can recognise as a time span. Analysing (10) and (11) in more detail, we can say that the states of affairs that Leo had a football game with his friends and that Julie ate an apple in three minutes are each delimited by two temporally non-coinciding boundaries $t_{x}$ and $t_{y}$ : by a starting point $t_{x}$ (the moment when the referee's whistle blew to start the game or Julie's first bite into the apple) and an endpoint $t_{\mathrm{y}}$ (the moment the referee blew the final whistle or Julie's last bite from the apple). We can also describe (12) and (13) in a similar way: the interval ${ }^{27}$ between the moment $t_{x}$ when Marta started no longer talking to me and the moment $t_{\mathrm{y}}$ when she stopped doing so, and that between the $\mathrm{t}_{\mathrm{x}}$ (= one week ago) when I stopped listening to the radio and $t_{\mathrm{y}}$ (= the moment of speaking) when I claim this, are both intervals that are perceived as a time span.

\subsubsection{Externally punctually delimited states of affairs (EA/pd)}

The following will be considered examples of externally punctually delimited states of affairs (thus, where $t_{x}=t_{y}$ ):

(14) It. All'una finalmente Julia si è addormentata [Perf. Com.]. (EA/pd) ${ }^{28}$ 'At one o'clock, Julia finally fell asleep.'

(15) Fr. À cinq heures Daniela frappe ${ }^{29}$ [Prés.] à la porte; Julien l'attendait. (EA/pd)

'At five o'clock Daniela knocked on the door; Julien was waiting for her.'

27 The presence of mucho tiempo in example (12), and of fa una setmana in (13) emphasises the fact that it concerns an interval with a time span.

28 It is interesting to compare the states of affairs described in the examples above (It. All'una finalmente Julia si è addormentata, and, of course, Sp. Juan se ha despertado a las tres) and a similar example, It. si è addormentata dolcemente/lentamente/a poco a poco/bruscamente/improvvisamente/di scatto, which is not an externally punctually delimited state of affairs.

29 This is a typical case illustrating the benefits of a frame-based versus a traditional interpretation: if an unequivocal assignment of frapper (which can function as both a semelfactive and a reiterative verb) proves to be problematic for the classic verbal classification, in a model like the one presented here the contextual variants and the polysemies of the verb lexemes can be easily taken into account. Only in the concrete context - in the convergence of various aspectual and non-aspectual contents in the utterance - can we speak of the respective aspectual values of the individual components of the state of affairs or situation frame. In this case, it is the presence of à cinq heures that contributes to a semelfactive interpretation. 
(16) Sp. Explotó [Perf. Sim.] sin hacer ruido. (EA/pd)

'It exploded quietly.'

(17) Cat. El nen va esternudar [Pret. Perf. Per.]. (EA/pd) [anar + Inf.]

'The child sneezed.'

Examples (14)-(17) also express externally delimited states of affairs, i.e., states of affairs that are represented as delimited by a starting point $t_{x}$ and an endpoint $t_{y}$, but here $t_{x}$ and $t_{y}$ coincide. The starting points $t_{x}$ and endpoints $t_{y}$ of the falling asleep of Julia in (14), the knocking on the door by Daniela in (15), the exploding in (16) and the sneezing of the child in (17) are alike insofar as they do not have a duration; or, to put it better, in all the examples they form an interval in which two events are perceived as not being temporally different (i.e., $I=\left|\mathrm{t}_{\mathrm{y}}-\mathrm{t}_{\mathrm{x}}\right|$, where $\mathrm{t}_{\mathrm{x}}=\mathrm{t}_{\mathrm{y}}$; thus $I=\delta \mathrm{t}_{\mathrm{x}}$ ). In examples (14) and (15), moreover, the presence of the temporal, deictic, adverbial determinations all'una and à cinq heures further reinforces the aspectual contents contained in the situation frame. Thus, in these states of affairs an external delimitation of the punctual type can be identified, an EA/pd.

\subsubsection{Externally non-delimited states of affairs (EA/nd)}

Situation frames which do not have an external delimitation can be found in the following examples:

(18) It. La nave approdava [Imp.]. (EA/nd)

'The ship was reaching shore.'

(19) Fr. Marie chante [Prés.] merveilleusement. (EA/nd) $)^{30}$

'Marie sings wonderfully.'

(20) Sp. Mientras Julio comía [Imp.], Carlos hablaba con Marta. (EA/nd)

'While Julio was eating, Carlos was talking to Marta.'

30 This example also shows very clearly how contextualisation of the utterance (i.e., the interpretation of the concretely expressed state of affairs) is essential for determining aspectuality. Example (19) can indeed have different aspectual combination patterns (or delimitation schemas): 1) $[(\mathrm{EA} / \mathrm{nd})+(\mathrm{AA} / \mathrm{nr})+(\mathrm{IA} / \mathrm{ns})]$, when interpreted as a general description of the quality of Marie's singing; 2$)[((\mathrm{EA} / \mathrm{nd})+(\mathrm{AA} / \mathrm{nr})+(\mathrm{IA} / \mathrm{s}))>((\mathrm{EA} / \mathrm{pd})+(\mathrm{AA} / \mathrm{nr})+(\mathrm{IA} / \mathrm{ns}))]$, when it refers to a presentation that is currently taking place. 
(21) Cat. La Rosina sap [Pres.] parlar moltes llengües. (EA/nd) [saber + Inf.] 'Rosina can speak many languages.'

The external aspectuality takes the form of an EA/nd in the states of affairs outlined in (18)-(21), an external non-delimitation. Neither a starting point $t_{x}$ nor an endpoint $t_{\mathrm{y}}$ of the whole state of affairs is focussed here: neither the beginning nor the end of the ship reaching shore in (18); neither the beginning nor the end of the wonderful singing of Marie in (19); neither the beginning nor the end of Julio's eating (and Carlos' and Marta's speaking) in (20) nor Rosina's ability to speak many languages in (21) are in the spotlight. Although (in some of the examples) temporal constitutive moments of the states of affairs can be focussed, ${ }^{31}$ it is their beginning and end which cannot be emphasised. In other words, the delimitation, which therefore represents the completion of the states of affairs, is not presented here: they are states of affairs that are not presented as a whole, in their entirety, and are thus presented as not completed.

\subsubsection{Externally non-delimitable states of affairs (NEA)}

In the following examples, external aspectuality is realised in a very different way: at the abstract, logical level of the impossibility of its determination, and not at the more concrete level of the possibility of its various realisations or basic conceptualisations (such as those in Table (1) and the first part of Table (3)). Indeed, (22)-(25) serve as examples of NEA or nondelimitability (illustrated in the last row of Table (3)), i.e., the impossibility of determining any realisation of external aspectuality:

(22) It. I neonati mangiano [Pres.] e dormono [Pres.]. (NEA) 'Babies eat and sleep.'

(23) Fr. Les hommes sont [Prés.] mortels. (NEA)

'Men are mortal.'

(24) Sp. El tiempo pasa [Pres.]. (NEA)

'Time passes.'

(25) Cat. Els nens creixen [Pres.]. (NEA)

'Children grow up.'

31 See, on this issue, the paragraphs on internal aspectuality below. 
Unlike in all other cases analysed in these paragraphs, in examples (22)-(25) it is in fact impossible to make statements regarding external aspectuality (EA), at least if they are intended and understood as universally valid statements about the world in general. ${ }^{32}$ They are states of affairs that simply are not temporally delimitable, since they lack any kind of external aspectual content, due to their high degree of genericity ${ }^{33}$ that results from the absence of morphological (inflectional) markings of an aspectual nature in combination with the argument structure and pragmatic, i.e., contextual and extralinguistic, information. In other words, we are dealing here with universal valid states of affairs, which are therefore alien to any temporal delimitation: in the eating and sleeping of the babies in (22), in the being mortal of the people in (23), in the passing of time in (24) or in the growing of the children in (25), there are no aspectual markings on the predicate (which is expressed in the present tense), nor can we find contents that would allow for an aspectual delimitation in the first argument of each example (i.e., i neonati, les hommes, el tiempo and els nens, which include all babies and all people in the world and in the course of time, i.e., representing the whole class of these individuals). In these particular constructions, in these situation frames, $i$ neonati, les hommes, el tiempo and els nens express no individual reference, but rather genericity: they refer to classes of individuals - or to abstract nouns, as in the case of el tiempo. Here it also becomes particularly clear the great influence of the subject, which as a noun normally does not carry aspectual information, on the interpretation of the frame.

It is logical that all situation frames that are non-delimitable, i.e., cannot be delimited (NEA), are also de facto non-delimited (while of course this is not true the other way around). The fact that there is nevertheless an external aspectual difference between situation frames that have an EA/nd and those that

32 This is not contradicted by the fact that the same sentences can be statements about concrete individual states of affairs in the case of a concrete realisation in a different frame. Interpretation of example (22) varies so much that - depending on the concrete situation frame or state of affairs in which it is realised - very different combinations of the dimensions of aspectuality can result: 1) the state of affairs presented in (22) is understood and used as a generally valid statement about the world in general (all components of the frame are generic in such a case); 2) the state of affairs described in (22) is interpreted as a special statement by a paediatric nurse who, at the end of a long and tiring day, reports the situation of the ward when handing it over to a colleague (in which case the components of the frame are not generic).

33 On genericity in general see Carlson (2005) and Carlson/Pelletier (1995). 
have an NEA can be better explained by comparative analysis of the following cases:

(26) It. Leo è [Pres.] rosso di capelli. (EA/nd)

'Leo is red haired.'

(26') It. Leo era [Imp.] rosso di capelli. (EA/nd)

'Leo was red haired.'

(27) Fr. Daniel est [Prés.] architecte. (EA/nd)

'Daniel is an architect.'

(27’) Fr. Daniel était [Imp.] architecte. (EA/nd)

'Daniel was an architect.'

(28) Sp. Marta tiene [Pres.] miedo de la lluvia. (EA/nd)

'Marta is afraid of the rain.'

(28') Sp. Marta tenía [Imp.] miedo de la lluvia. (EA/nd)

'Marta was afraid of the rain.'

(29) Cat. És [Pres.] una dona romàntica i maquísima. (EA/nd)

'She's a romantic and very beautiful woman.'

(29') Cat. Era [Imp.] una dona romàntica i maquísima. (EA/nd)

'She was a romantic and very beautiful woman.'

(30) It. I neonati mangiano [Pres.] e dormono [Pres.]. (NEA)

'Babies eat and sleep.'

(30') It. I neonati mangiavano [Imp.] e dormivano [Imp.]. (EA/nd)

'The babies were eating and sleeping.'

(31) Fr. Les hommes sont [Prés.] mortels. (NEA)

'Men are mortal.'

(31') Fr. Les hommes étaient [Imp.] mortels. (EA/nd)

'The men were mortal.' 
(32) Sp. El tiempo pasa [Pres.]. (NEA)

'Time passes.'

(32') Sp. El tiempo pasaba [Imp.]. (EA/nd)

'The time was passing.'

(33) Cat. Els nens creixen [Pres.]. (NEA)

'Children grow up.'

(33’) Cat. Els nens creixien [Imp.]. (EA/nd)

'The children were growing up.'

In the first example pairs (26/26')-(29/29'), the absence of morphological temporal-aspectual markings in the examples expressed in the present tense, (26)-(29), or their presence (in examples (26')-(29') through the various Romance imperfect forms) has no influence on the realisation of external aspectuality, which is always EA/nd. Whether an ideal she (a personal pronoun standing for a particular individual and not for a class of individuals) is now romantic and beautiful or used to be, both cases represent a state of affairs that is not perceived as a completed whole (one cannot identify a $t_{x}$ in which she began to be romantic and beautiful, nor a $t_{y}$ in which she stopped being so), i.e., as a state of affairs that is thus not externally delimited.

On the other hand, in the other example pairs (30/30')-(33/33'), the absence of morphological temporal-aspectual markings in examples (30)-(33) expressed in the present tense or their presence (in examples (30')-(33') expressed through the various Romance imperfect forms) play an important role in the constitution of external aspectuality in the respective situation frames. Examples (30')-(33') all represent cases of EA/nd, like (26/26')-(29/29') above. For example, in (30’) it is not possible to identify $a t_{x}$ in which the babies (and here it is recognisable from the past tense that these must be some particular babies and not the entire class of babies) began to eat and sleep (here in the imperfect and not the present tense), nor a $t_{y}$ in which they stopped doing so. Similarly, in example (32') time must be a particular time (the time of a life, the time available to a person for a particular act, etc.) and not the extralinguistic, not further defined, eternal flowing time that regulates the destinies of the world and people, ${ }^{34}$ and that time passed (morphologically marked by the imperfect) without us being able to

34 In the absence of any further determination, the reference to this prototypical physical time is established, understood as an implicature, as in example (32). 
identify a $t_{x}$ or a $t_{y}$ delimiting the beginning and ending of that passing. Again, this is a typical example of an externally non-delimited state of affairs.

However, it should be emphasised here once again that it is not just the morphological aspectual marking (in these examples, the presence of the respective Romance forms of the imperfect) that is solely responsible for the indeterminability of the external aspectuality and therefore for the entire aspectual interpretation of the situation frame or the state of affairs. As has been shown, the degree of genericity of the respective arguments of the verb also plays an essential role.

\subsubsection{Adjacency-related aspectuality - adjacency relevance of the state of affairs}

In the case of adjacency-related aspectuality (AA), the relevance of the state of affairs for its adjacency - that which temporally lies before and after the state of affairs and which can be represented as an interval $I=\left|\mathrm{t}_{\mathrm{y}}-\mathrm{t}_{\mathrm{x}}\right|-$ is focussed, while its structuring and delimitation recede into the background. The AA is subdivided into four realisations, four different basic conceptualisations:

- A state of affairs can be relevant to its adjacency as a final delimitation (AA/fr); in this case, it is a state of affairs that has an influence on the structuring of its adjacency by functioning as a final delimitation of its previous adjacency: it thus determines its end.

- A state of affairs can be relevant to its adjacency as an initial delimitation (AA/ir); in this case, it is a state of affairs that has an influence on the structuring of its adjacency by functioning as the initial delimitation of its subsequent adjacency: it determines its beginning.

- A state of affairs can be relevant to its adjacency as a final and an initial (i.e., transformative) delimitation (AA/tr); in this case, it is a state of affairs that has an influence on the structuring of its adjacency, namely by exerting an influence on its previous and subsequent adjacency as a final delimitation and as an initial delimitation: it determines its beginning and end, thus entailing a transformation, a change of state.

- A state of affairs can be irrelevant to its adjacency (AA/nr); in this case, it is a state of affairs that has no influence on the structuring of its adjacency, neither as an initial nor as a final delimitation.

Table (4) illustrates the different realisations of AA (with the state of affairs and its delimitation highlighted in light grey, while the adjacency which the state of 
affairs influences or for which it is relevant is black in the first row, dark grey in the second):

Tab. 4: Adjacency-related aspectuality.

AA- Adjacency-related Aspectuality
adjacency relevance of a state of affairs (SA)

In the case of $\mathrm{AA}$, too, there is another possibility that does not correspond to any of the basic conceptualisations presented above, but relates to a more abstract level of adjacency-related non-delimitability (NAA) (see the last row of Table (4)). There are aspectual situation frames, i.e., special delimitation constructions, where no statement regarding AA is possible. These are cases that are not contextually delimitable, when a state of affairs is not externally delimited or - more abstractly - not delimitable, so that if it has an external delimitation of the type EA/nd or NEA, it can logically have no effect on its adjacency, because the latter cannot exist without a boundary (and therefore, of course, it cannot be relevant for such an (inexistent) adjacency).

Of the various examples and example types that could be cited for the realisations of adjacency-related aspectuality - in particular AA and NAA - the following are a first selection and, as in the case of external aspectuality, a few of them will be briefly discussed below. 


\subsubsection{States of affairs with final relevance to adjacency (AA/fr)}

Let's take a look at the following examples:

(34) It. Il sole è appena tramontato [Perf. Com.]. (AA/fr)

'The sun has just set.'

(35) Fr. Marie-Rose vient [Prés.] de chanter. (AA/fr) [venir de + Inf.] 'Marie-Rose has just sung.'

(36) Sp. Juan se comió [Perf. Sim.] su osito de gominola con gran gusto. (AA/fr) 'Juan ate his jelly baby with great delight.'

(37) Cat. Acabo [Pres.] de parlar amb el president de la república italiana. (AA/fr) [acabar de + Inf.]

'I have just spoken to the President of the Italian Republic.'

When dealing with aspectuality from the adjacency-related perspective, as it appears in the states of affairs expressed in examples (34)-(37), it should be noted that all these examples are cases of AA/fr, in other words, states of affairs that have an influence on the structuring of their adjacencies insofar as they function as a final delimitation of their previous adjacency and represent its end.

When analysing the examples in more detail, one can further say that the facts shown in (34) and (35) - i.e., that the sun has just set and Marie-Rose has just sung - as well as Juan's pleasurable eating of a jelly baby in (36) and the conclusion of the conversation with the President of the Italian Republic in (37) present states of affairs that are relevant to their adjacencies in a particular way. That the sun has just set means that it no longer shines in the sky (and also that it is no longer possible a) that it continues to shine, b) that it continues to go down). Similarly, the fact that Juan has eaten his jelly baby means that the jelly baby is no more at the end of the process. With this disappearance, both the continuation of the process (he cannot continue eating the jelly baby) and the reversal of the state of affairs are impossible. Similarly, the fact that I have just finished my conversation with the Italian President determines that I am no longer talking to him now. In both cases, the previous adjacency of the state of affairs has been finished by the state of affairs itself. 


\subsubsection{States of affairs with initial relevance to adjacency (AA/ir)}

Among the examples that express states of affairs with initial adjacency-related relevance, the following should be analysed in more detail:

(38) It. Il sole sta [Pres.] per sorgere silenzioso. (AA/ir) [stare per + Inf.] 'The sun is about to rise quietly.'

(39) Fr. Petit à petit Julie se met [Prés.] à chanter. (AA/ir) [se mettre à + Inf.] 'Little by little Julie starts singing.'

(40) Sp. Juan comienza [Pres.] a despertarse. (AA/ir) [comenzar a + Inf.] 'Juan begins to wake up.'

(41) Cat. La lluna terrestre es va formar [Pret. Perf. Per.] més tard que la resta del sistema solar. (AA/ir) [anar + Inf.]

'The Earth's moon formed later than the rest of the solar system.'

Considering aspectuality from the adjacency-related perspective, as it appears in the states of affairs expressed in (38)-(41), we find that these represent cases of AA/ir. These are therefore states of affairs which have an influence on the structuring of their adjacencies insofar as they function as an initial delimitation of their subsequent adjacency and they therefore represent its beginning.

The fact expressed in (38) that the sun is about to rise quietly, as well as what is expressed in (39), (40) and (41), respectively, that Julie slowly begins to sing, that Juan begins to awaken, and that the moon was formed after the rest of the solar system, all represent states of affairs that are relevant to their adjacencies in a special way. That the sun is about to rise quietly means that at the end of the process the sun will rise (which was not the case before the beginning of this process). Similarly, the fact that the moon was formed after the rest of the solar system means that it will continue to exist after the process of creation (i.e., after the end of the state of affairs itself). In all the cases discussed, the subsequent adjacency of the states of affairs begins with the respective state of affairs.

\subsubsection{States of affairs with initial and final (transformative) relevance to adjacency (AA/tr)}

States of affairs that have both initial and final adjacency-related relevance can be illustrated by the following examples: 
(42) It. Leo arrossisce [Pres.] davanti a Julia. (AA/tr)

'Leo blushes in front of Julia.'

(43) Fr. Le printemps s'installa [Pass. Sim.] dans les jardins tout doucement. (AA/tr)

'Spring came to the gardens very slowly.'

(44) Sp. Las ventas de la pastelería aumentan [Pres.]. (AA/tr)

'Bakery sales are increasing.'

(45) Cat. Xavier cada dia està [Pres.] més boig. (AA/tr)

'Xavier gets more and more crazy every day.'

Considering the adjacency-related aspectuality of the states of affairs expressed in (42)-(45), it can be seen that these are cases of final and initial adjacencyrelated relevance $(\mathrm{AA} / \mathrm{tr})$, or states of affairs that are relevant for their entire adjacency by representing the end of the previous and the beginning of the subsequent adjacency in relation to a coherent complex of state of affairs. In other words, they function as state-changing states of affairs. ${ }^{35}$

The fact that in (42) Leo blushes when looking at Julia, determines the end of the previous adjacency in which Leo still had a normal complexion, and marks the beginning of the subsequent one, in which blush of shame shows in Leo's face. Similarly formed is the adjacency-related aspectuality in example (43): spring slowly coming to the garden determines the end of the winter state of the garden and the beginning of spring. The states of affairs presented in examples (44) and (45) warrant a similar analysis: that the turnover of baked goods (or the degree of Xavier's craziness) increases determines the end of the previous adjacency in which there was a lower turnover (or degree of craziness), and marks the beginning of the subsequent one where it is greater.

\subsubsection{States of affairs without relevance to adjacency (AA/nr)}

Finally, situation frames without adjacency-related aspectuality can be illustrated by the following examples:

35 Interesting in this regard is the comparison between the Romance languages and German. Both tend to express this aspectual building block by special - derivational - morphological means: the Romance languages by the so-called parasynthesis (e.g., It. arrossire, invecchiare, Sp. engordarse) and German by prefixation (e.g., umziehen, umfärben, umdrehen). 
(46) It. Leo esce [Pres.] da casa e fa [Pres.] un giro sulla bicicletta nuova. (AA/nr) 'Leo leaves the house and goes for a ride on his new bike.'

(47) Fr. À cinq heures Béatrice frappe ${ }^{36}$ [Prés.] à la porte. (AA/nr)

'At five o'clock Béatrice knocks on the door.'

(48) Sp. El oso polar se acarició [Perf. Sim.] su hermoso pelo con gracia glacial. (AA/nr)

'The polar bear stroked its beautiful fur with glacial grace.'

(49) Cat. En Jordi va parlar [Pret. Perf. Per.] amb la Pili. (AA/nr) [anar + Inf.] 'Jordi talked to Pili.'

A closer analysis of the examples (46)-(49) from the perspective of adjacencyrelated aspectuality shows that in all cases these are states of affairs of the type $\mathrm{AA} / \mathrm{nr}$. In other words, they are states of affairs that have absolutely no influence on the structuring of their adjacencies: they are completely irrelevant to their respective adjacencies insofar as they do not determine either the beginning nor the end of any other state of affairs in their adjacencies.

Closer analysis of the above examples reveals that all four of the states of affairs presented - Leo's little ride with his new bike in (46), Béatrice's knocking on the door at 5 o'clock in (47), the polar bear's graceful stroking of its beautiful fur (48), as well as the speaking of Jordi to Pili in (49) - have no relevance for the time before and time after the ride on the new bike, the knocking, the stroking and the speaking. In all cases, the states of affairs do not in any way influence their previous and subsequent adjacencies, nor do they determine any beginning or end of other states of affairs of the adjacencies.

\subsubsection{Adjacency-related non-delimitable states of affairs (NAA)}

Adjacency-related aspectuality is treated on another level in the examples below: the abstract level of the impossibility of determining it, and not the more concrete possibility of its realisations or basic conceptualisations in the various situation frames (see the first part of Table (4) and the previous analysis). Indeed, (50)-(57) serve rather to exemplify NAA or the non-delimitability of adjacency relevance (see the last row of Table (4)), i.e., the impossibility of

36 The interpretation of this example also poses some problems for the traditional verb classification which analyses the elements on their own and not in the context of a frame, as frapper (here 'to knock'), considered on its own, has both a semelfactive and a reiterative component. 
determining the presence or absence of any realisation of adjacency-related aspectuality:

(50) It. I neonati mangiano [Pres.] e dormono [Pres.]. (NAA)

'Babies eat and sleep.'

(51) It. Leo ha [Pres.] i capelli rossi. (NAA)

'Leo has red hair.'

(52) Fr. Les hommes sont [Prés.] mortels. (NAA)

'Men are mortal.'

(53) Fr. Julie était [Imp.] grande. (NAA)

'Julie was tall.'

(54) Sp. Pablo era [Imp.] un gran gato, de pelo corto de color naranja y blanco. (NAA)

'Pablo was a great cat, with short orange and white hair.'

(55) Sp. El tiempo pasaba [Imp.]. (NAA)

'The time was passing.'

(56) Cat. Els nens creixen [Pres.]. (NAA)

'Children grow up.'

(57) Cat. La Rosina sap [Pres.] parlar moltes llengües. (NAA) [saber + Inf.]

'Rosina can speak many languages.'

Unlike all the other cases analysed in paragraphs 4.4.4.1-4.4.4.4, it is impossible to make any statement regarding adjacency-related aspectuality with respect to examples (50)-(57). These are very different states of affairs, which in part should be considered here from more than one aspectual perspective:

- On the one hand, these are states of affairs that are either not delimited (i.e., EA/nd realisations as in (51), (53), (54), (55) and (57)), which includes the cases that are not delimitable (and therefore realisations of NEA as in (50), (52) and (56)). ${ }^{37}$ By way of example, we can analyse in detail (51) (in

37 Of course, in particular interpretation contexts, states of affairs such as these may be interpreted differently in terms of aspectuality. See on this issue §4.4.3.4. 
which no moment $t_{x}$ in which Leo begins to have red hair can be focussed, nor any moment $\mathrm{t}_{\mathrm{y}}$ in which he stops), or (50) in which - as mentioned above - the eating and sleeping of the babies bear neither aspectual markings on the predicate nor contents in the first argument of each example that would allow for an aspectual delimitation. In fact, in this type of state of affairs - due to the absence of a form of delimitation of the state of affairs as a whole - there is no adjacency-related aspectual content. For logical reasons, the absence of temporal boundaries excludes the possibility of determining its adjacency: without a temporal delimitation, without an interval $I=\left|\mathrm{t}_{\mathrm{y}}-\mathrm{t}_{\mathrm{x}}\right|$, there can be no before or after this delimitation.

- On the other hand, these are also states of affairs that are not internally subdivided and hence realise the internal aspectuality of type IA/ns, as found in examples (51), (53), (54) and (57) (which includes cases that are not subdivisible and are therefore realisations of NIA (see §4.4.5.3), as in (50), (52) and (56)). For, if a state of affairs is monophasic, if no constitutive, individually isolable phases (or points in time $t_{x 1}, t_{x 2}, \ldots t_{x n}$ ) can be identified within it, which in turn are nothing other than the setting of temporal boundaries, then there is no possibility of a variation in time, dynamicity, because this consists precisely in the possibility of a change of state, the beginning and ending of intervals in the state of affairs. And where no discrete temporal subintervals can be identified, as is the case with states of affairs that are not internally subdivided, there can be no change in time nor at its boundaries, and thus there can be no aspectual adjacency reference. Here, too, we can take a closer look at example (51), in which no moment $t_{\mathrm{y}}$ different from the other moments of Leo's having-red-hair can be focussed (just as no beginning or end of having red hair is focussed).

In this case, too, it follows logically that all situation frames that are nondelimitable in terms of adjacency (NAA) are also non-delimited in terms of their adjacency relevance $(\mathrm{AA} / \mathrm{nr})$.

\subsubsection{Internal aspectuality - subdivision of the state of affairs}

In the case of internal aspectuality (IA) the focus is on the structuring of the state of affairs, i.e., the possible realisations of the subdivision of a state of affairs, regardless of its (external) delimitation and its adjacency reference, which recede into the background. Two realisations of IA can be distinguished: 
- A state of affairs may be internally subdivided (IA/s); in this case it is a state of affairs that is internally temporally subdivided and is therefore pluriphasic. Between $t_{x}$ and $t_{y}$ of the interval $I=\left|t_{y}-t_{x}\right|$ (i.e., between the delimitation points, which can be given if the state of affairs has an external delimitation (EA/d)), but also generally in the temporal structure of the state of affairs, if it is a state of affairs without external delimitation $(\mathrm{EA} / \mathrm{nd})$, there are other points $\mathrm{t}_{\mathrm{x} 1}, \mathrm{t}_{\mathrm{x} 2}, \ldots \mathrm{t}_{\mathrm{xn}}$ into which the state of affairs can be subdivided.

- A state of affairs can be internally non-subdivided (IA/ns); in this case, it is a homogeneous, internally temporally not further subdivided state of affairs, i.e., it is monophasic: between a starting point $t_{x}$, possibly focussed in the external aspectuality, and an endpoint $\mathrm{t}_{\mathrm{y}}$ or within the externally non-delimited state of affairs, no further points $t_{x 1}, t_{x 2}, \ldots t_{x n}$ can be identified into which the temporal development of the state of affairs in general may be subdivided.

Table (5) illustrates the various realisations of IA (the state of affairs in its internal structuring is black in the first row of the table, dark grey in the second row, and its delimitation and adjacency are shown in light grey):

Tab. 5: Internal aspectuality.
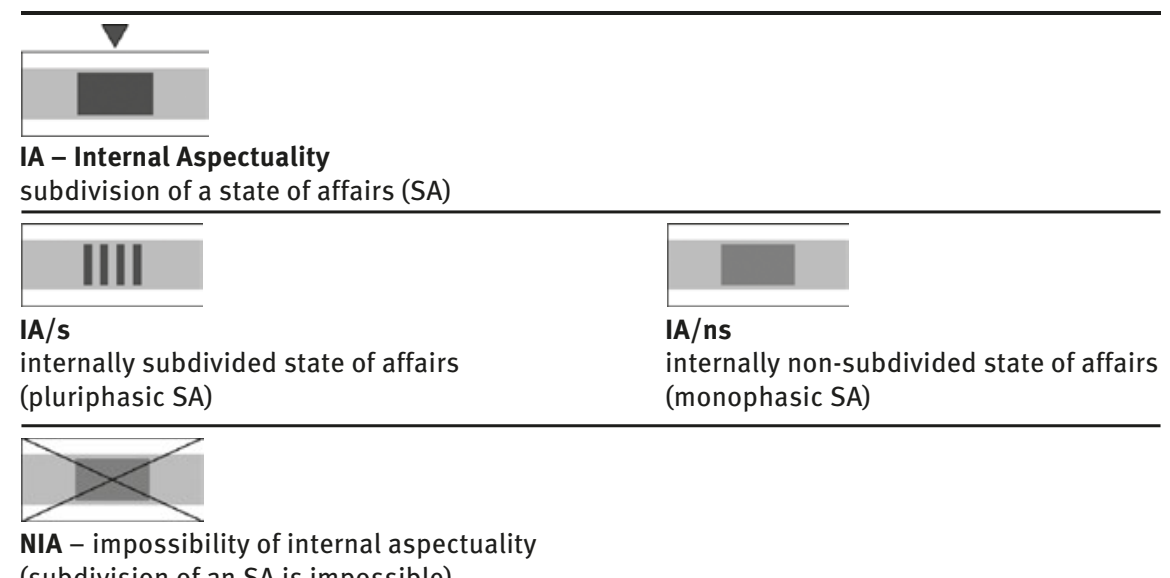

(subdivision of an SA is impossible)

As with the other two perspectives of aspectuality, in the case of IA there is another possibility for the realisation or non-realisation of aspectual content (see the last row of Table (5)). This does not represent two possible realisations, 
but concerns a more abstract level of non-subdivisibility: there are indeed states of affairs where (in particular delimitation constellations) no statement regarding IA is possible. These are cases of NIA which, for logical reasons, cannot be determined in terms of internal aspectuality, as is the case with constructions that have external punctual aspectuality (EA/pd). When dealing with an externally delimited state of affairs whose initial boundary $t_{x}$ coincides with its final boundary $t_{y}\left(t_{x}=t_{y}\right)$, it is impossible to postulate the existence of further points $t_{x 1}, t_{x 2}, \ldots t_{x n}$ (i.e., a period of time) in the state of affairs into which the interval comprising the state of affairs $I=\left|t_{y}-t_{x}\right|$ can be subdivided, because the interval is perceived as so small that we can speak of a single point (without temporal extension). And what is presented without temporal extension cannot logically be subdivided into further temporal delimitations or subintervals.

As done above for external and adjacency-related aspectuality, let us first comment on some examples of the two realisations of IA and of NIA.

\subsubsection{Internally subdivided states of affairs (IA/s)}

Let us consider the following examples:

(58) It. Leo mangia [Pres.] un cornetto al cioccolato con evidente soddisfazione. (IA/s)

'Leo is eating a chocolate croissant with obvious satisfaction.'

(59) Fr. Julie a frappé [Pass. Com.] à la porte maintes et maintes fois. (IA/s)

'Julie knocked on the door over and over again.'

(60) Sp. Juan duerme/dormía [Pres./Imp.] con un ojo abierto. (IA/s) 'Juan is sleeping/was sleeping with one eye open.'

(61) Cat. La Rosina escriu [Pres.] una novel-la fantàstica. (IA/s)

'Rosina is writing a fantastic novel.'

When focussing on internal aspectuality, as expressed in the states of affairs in (58)-(61) - i.e., on the possible subdivision of these states of affairs - it can be stated that all the examples are internally subdivided states of affairs (IA/s), i.e., they are pluriphasic. On the level of internal aspectuality, various constitutive intervals or points of time $\left(t_{x 1}, t_{x 2}, \ldots t_{x n}\right)$ can be identified (irrespective of whether the state of affairs is delimited or not). There are several (substantially) different moments $t_{x 1}, t_{x 2}, \ldots t_{x n}$ in Leo's eating of a croissant (58), in Julie's 
repeated knocking on the door (59), in Juan's sleeping with one eye open (60), and in Rosina's writing a fantastic novel (61). Leo eats (or Julie knocks on the door, Juan sleeps or Rosina writes a novel) in $t_{x 1}$, just as he (or she) eats (knocks, sleeps or writes) in $t_{x 2}$ and $t_{x 3}, t_{x n} \ldots$, and these single moments can be separated and focussed on as being different from each other. All these states of affairs consist of different phases, discrete moments $t_{x 1}, t_{x 2}, \ldots t_{x n}$, which, since they can be individually focussed on, allow for the perception of dynamicity.

\subsubsection{Internally non-subdivided states of affairs (IA/ns)}

Situation frames that, on the other hand, are not subdivided can be seen in the following examples:

(62) It. Leo ha [Pres.] i capelli rossi. (IA/ns)

'Leo has red hair.'

(63) Fr. Je suis [Prés.] très petite. (IA/ns)

'I am very small.'

(64) Sp. Marta tiene [Pres.] miedo de la lluvia. (IA/ns)

'Marta is afraid of the rain.'

(65) Cat. La Rosina sap [Pres.] parlar moltes llengües. (IA/ns) [saber + Inf.] 'Rosina can speak many languages.'

If we consider the internal aspectuality expressed in the states of affairs presented in (62)-(65), i.e., their subdivision, we can say that all the examples are internally non-subdivided states of affairs (IA/ns), i.e., they are monophasic. On the level of internal aspectuality, here we cannot identify any structuring, any constitutive phases (or points of time $t_{x 1}, t_{x 2}, \ldots t_{x n}$ ) that can be individually isolated and focussed. In other words, there are no (substantially) different moments $t_{x 1}, t_{x 2}, \ldots t_{x n}$ (which thus cannot be focussed) in the fact that Leo has red hair (62), that I am very small (63), that Marta is afraid of the rain (64), or that Rosina can speak many languages (65). ${ }^{38}$

38 As a brief reminder, internal aspectuality includes the criterion of dynamicity/stativity; see $\S 4.4 .1$ for more details. 


\subsubsection{Internally non-subdivisible states of affairs (NIA)}

In the following examples - as above with external and adjacency-related aspectuality - internal aspectuality is finally also dealt with on a more abstract level, namely, that of the impossibility of its determination. The following examples (66)-(69) should therefore serve to exemplify NIA or non-subdivisibility (see the last row in Table (5)), i.e., the impossibility of determining the presence or absence of any realisation of internal aspectuality:

(66) It. La nave dell'ammiraglio approdò [Perf. Sem.] alle tre e un quarto. (NIA) 'The admiral's ship reached shore at 3:15.'

(67) Fr. Il toussa [Pass. Sim.] fort une seule fois. (NIA) 'He coughed hard only once.'

(68) Sp. Explotó [Perf. Sim.] sin hacer ruido. (NIA) 'It exploded quietly.'

(69) Cat. El príncep truca [Pres.] tímid a la porta del castell. (NIA) 'The prince knocks shyly on the door of the castle.'

(70) It. I neonati mangiano [Pres.] e dormono [Pres.]. (NEA) 'Babies eat and sleep.'

(71) Fr. Les hommes sont [Prés.] mortels. (NEA) 'Men are mortal.'

(72) Sp. El tiempo pasa [Pres.]. (NEA) 'Time passes.'

(73) Cat. Els nens creixen [Pres.]. (NEA) 'Children grow up.'

Unlike all the other concrete realisations or basic conceptualisations of internal aspectuality analysed in $\S \S 4.4 \cdot 5.1-4.4 .5 .2$, it is impossible in the cases of (66)-(73) to make any statement regarding internal aspectuality. These are very different states of affairs, which in part should be considered here from more than one aspectual perspective:

- On the one hand, these are states of affairs that are not temporally subdivisible due to their punctual constitution, their lack of a perceptible temporal extension. In examples (66)-(69), the initial boundary $t_{x}$ (the moment 
when the ship reaches shore, in which he coughs once, in which something exploded quietly and in which the prince shyly knocks on the door of the castle) coincides with the final boundary $t_{y}$ (precisely the moment when the ship reaches shore, when he coughs once, when something exploded quietly and when the prince shyly knocks on the door of the castle). It is therefore impossible to postulate the existence of further points $t_{x 1}$, $\mathrm{t}_{\mathrm{x} 2}, \ldots \mathrm{t}_{\mathrm{xn}}$ in the state of affairs in which the interval $I=\left|\mathrm{t}_{\mathrm{y}}-\mathrm{t}_{\mathrm{x}}\right|$ with $\mathrm{t}_{\mathrm{y}}=\mathrm{t}_{\mathrm{x}}$ that represents the delimited state of affairs could be subdivided. Thus, the temporally barely perceivable interval (precisely the smallest possible interval of the length $\delta t_{x}$ of, for example, the quiet exploding) could not by definition be further subdivided.

- On the other hand, these are states of affairs of the type NEA and NAA, as in examples (70)-(73).

Logically, what has already been stated for external and adjacency-related aspectuality also applies to internal aspectuality: states of affairs that are not subdivisible (NIA) are also internally non-subdivided (IA/ns).

\subsection{A second interim conclusion}

In this chapter, the first steps have been taken to introduce a new unidimensional model of aspectuality. On the basis of the cognitive principle of delimitation, the definition of aspectuality - the content category by which speakers linguistically structure the internal nature of the development and distribution of a given state of affairs in time - was further clarified: namely as a content category through which speakers express the possibilities of external, adjacency-related and internal temporal structuring of states of affairs.

The various realisations of the three dimensions of aspectuality, the aspectual basic conceptualisations, were presented here individually and illustrated with examples, which were, however, analysed only in relation to the perspective under consideration, while the other two dimensions were disregarded in order to provide a better understanding of the model. In the overall aspectual meaning of a situation frame, however, several perspectives of aspectuality and hence several aspectual basic conceptualisations are always connected to each other. It will now be my task in the next chapter to present the entire aspectual structuring of states of affairs perceived as situation frames, i.e., the possibilities of combining aspectual content in the constitution of the overall aspectual meaning of states of affairs. 



\section{Combinations of the Dimensions of Aspectuality in the Situation Frame: the First Level of the Model Applied}

\subsection{Introductory remarks}

In this chapter, I present an inventory of the combination patterns of the aspectual basic conceptualisations, as understood in the framework of the model presented in Chapter 4. These patterns are represented by schemas which illustrate the compositions of the three delimitation perspectives. I will refer to these as delimitation schemas. Each of the schemas is preceded by examples, some of which have already been partially presented in Chapter 4, where they were analysed from only one of the three perspectives of aspectuality. The inventory includes all possible and impossible combinations of the aspectual basic conceptualisations presented in the previous chapter. However, this illustrates only the first level of delimitation that has been considered so far, which means that further perspectivisations such as what would be called "progressive" in a traditional analysis of states of affairs - have no place here for the moment. In Chapter 6, I will present this second level of aspectuality, which is formally expressed by, in particular, verbal periphrases.

The inventory of the delimitation schemas is also a first application of the model developed here.

\subsection{Aspectual delimitation schemas}

\subsubsection{A comprehensive inventory of delimitation schemas}

The graphical representations of the aspectual delimitation schemas that illustrate the examples in this chapter (Tables (2)-(13)) show the now known tripartite division into the external, the adjacency-related and the internal perspectives of aspectual delimitation. The first three columns of the tables contain the diagrams already presented in Table (2) in the previous chapter (§4.4.2), which represent the complete inventory of the aspectual basic conceptualisations. The right-hand column contains a summarising illustration of the respective combinations of aspectual basic conceptualisations of the three perspectives of aspectuality where a combination is possible (these figures are introduced here); the impossibility of a combination is indicated by an X. 
There are only 11 possible combinations of the three realisations (or basic conceptualisations) of external aspectuality, the four realisations of adjacencyrelated aspectuality and the two realisations of internal aspectuality, that is, only 11 delimitation schemas and not 24 , which is due to the fact that a number of combinations are not possible. For example, states of affairs that are not externally delimited (EA/nd), and those that are represented as not internally subdivided (IA/ns) cannot be determined with regard to their adjacency, in other words they are indeterminable in terms of their adjacency relevance (NAA, see $\S 4.4 .4 .5)$. The former, for example, cannot be relevant for their adjacency, since they have no adjacency and therefore can only be combined with one realisation of adjacency-related aspectuality, namely that of non-relevance (AA/nr). Furthermore, states of affairs which are represented as externally punctually delimited (EA/pd) cannot be subdivided, are not internally subdivisble (NIA, see 4.4.5.3), since they have no duration; these can therefore only be combined with one realisation of internal aspectuality, i.e., the internally non-subdivided (IA/ns; for a more detailed explanation of these constraints see Chapter 4).

Table (1) first of all presents the entire inventory of the combinations of aspectual basic conceptualisations, which are explained in more detail in Tables (2)-(13): ${ }^{1}$

Tab. 1: Inventory of the delimitation schemas.

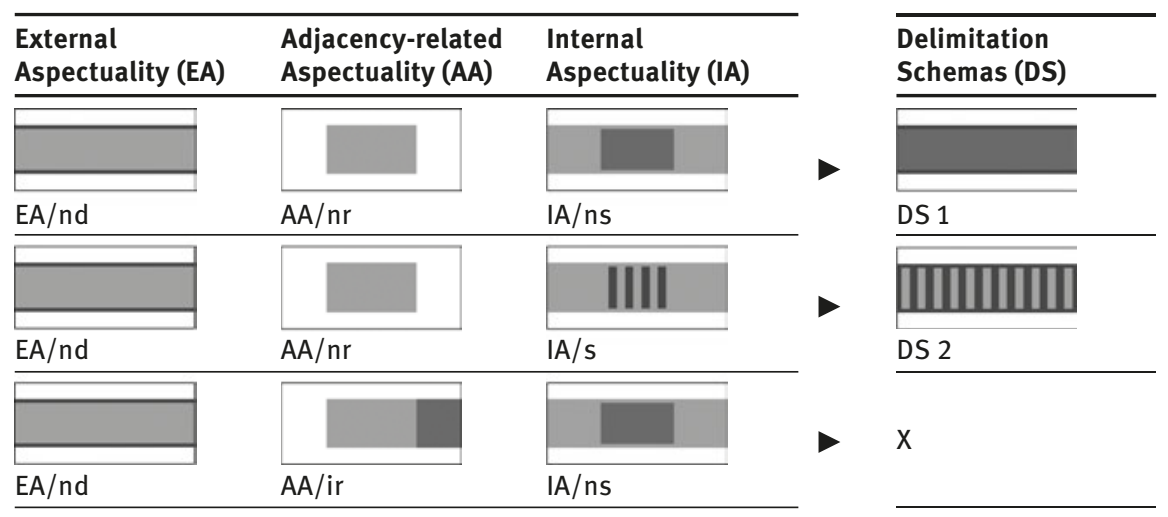

1 Apart from DS 12, combinations with NEA, NAA and NIA are not shown in this table because these three basic conceptualisations are contained respectively in EA/nd, AA/nr and IA/ns (see §4.4.3.4, §4.4.4.5 and §4.4.5.3). 
Tab. 1 (continued)

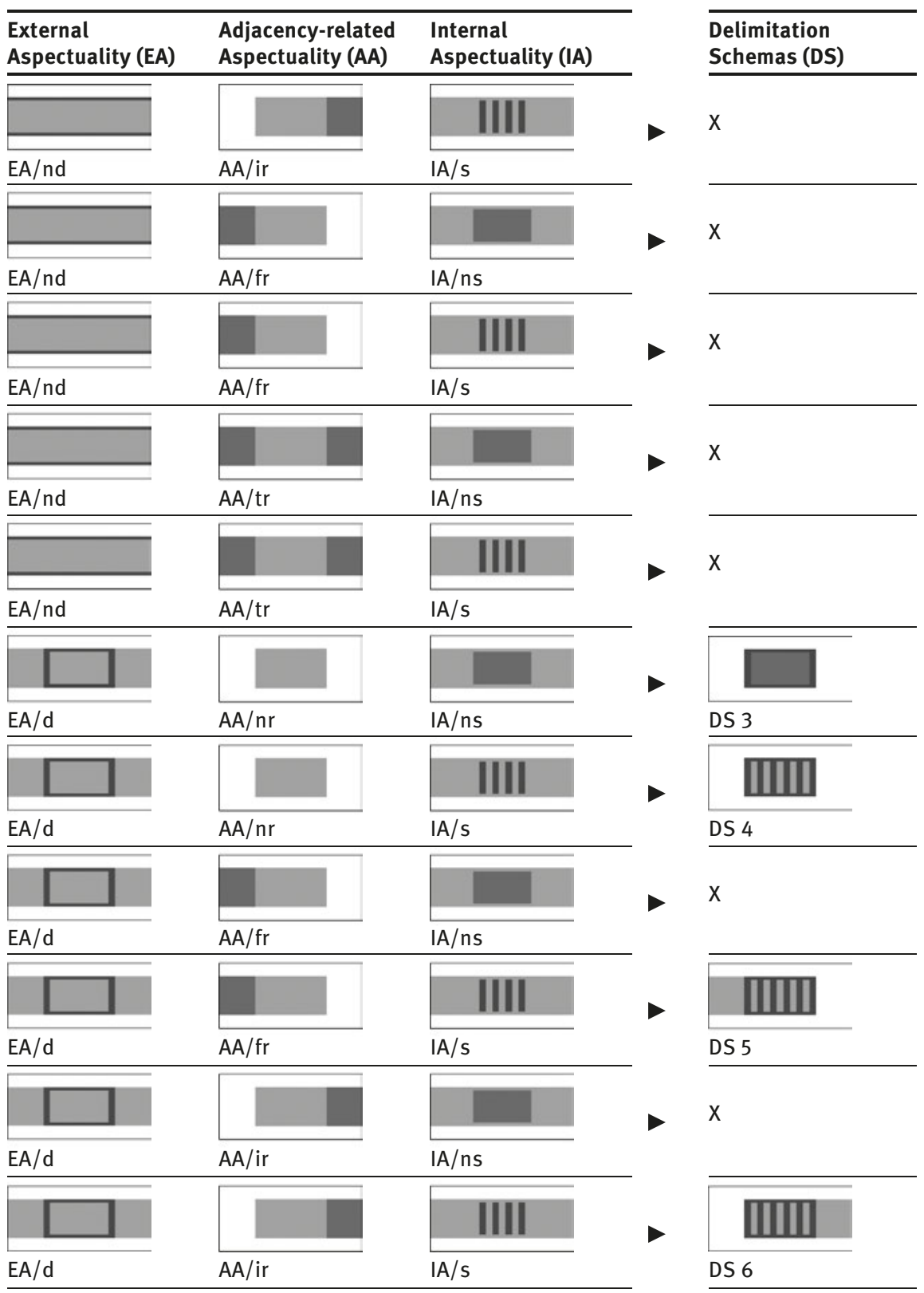


Tab. 1 (continued)

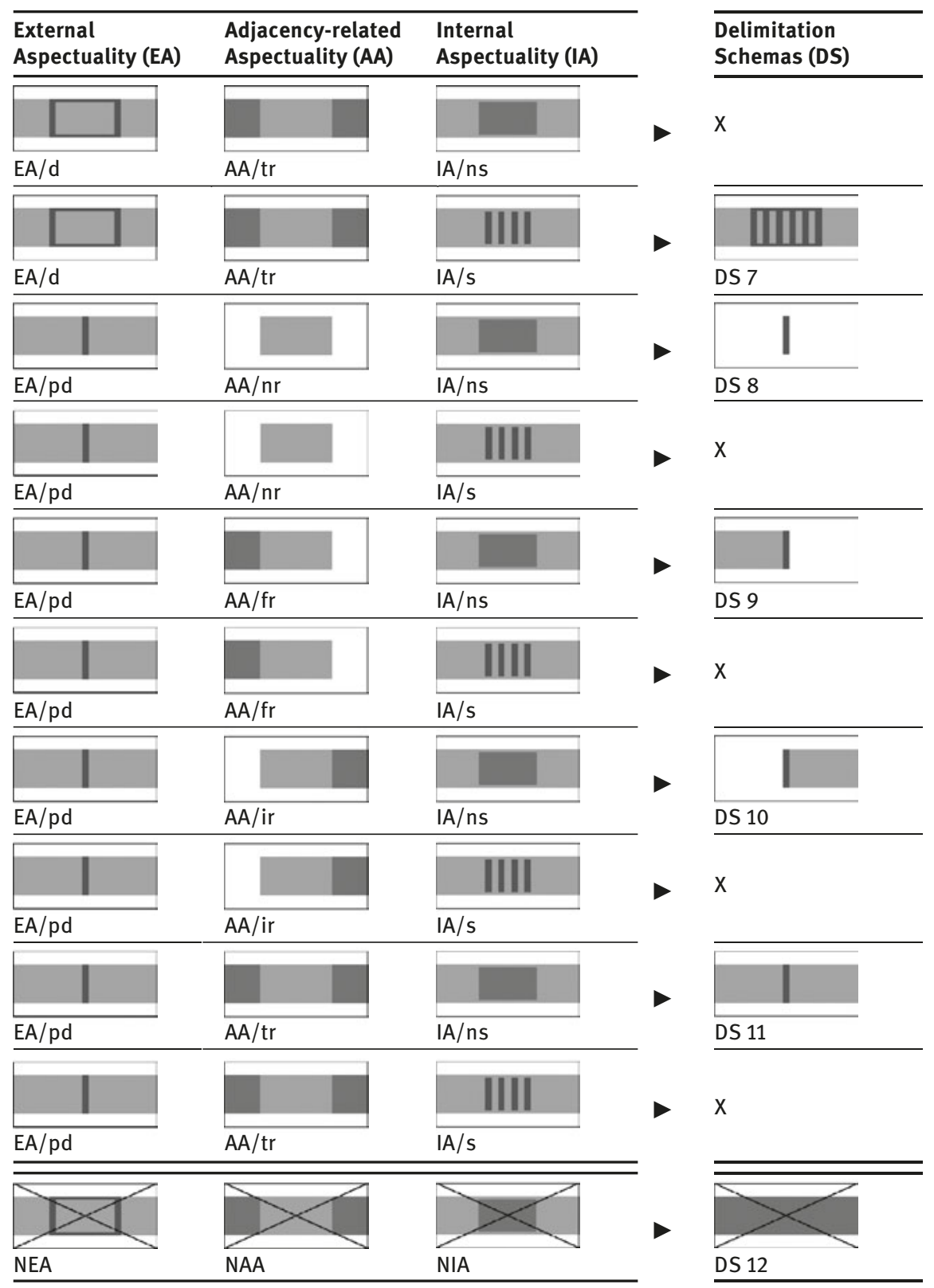


Delimitation schema number 12 is a special one (Table (13)). It is not the result of a combination of possible realisations of the three perspectives of aspectuality, but of non-aspectuality. It therefore represents atemporal states of affairs in which no aspectuality can be determined from either of the three perspectives. For this reason, it is listed separately in the complete inventory in Table (1).

As in the previous chapter (§§4.4.3ff.), examples from the four Romance languages examined, in which the content category of aspectuality is expressed by both lexical and grammatical means and which mostly have different tenses, are cited here and commented on in parallel to emphasise once again how different the formal means by which the Romance languages can express the same aspectual content information can be. ${ }^{2}$

\subsubsection{Presentation of the individual delimitation schemas}

\subsubsection{Delimitation Schema 1: $[(E A / n d)+(A A / n r)+(I A / n s)]$}

(1) It. Leo ha [Pres.] i capelli rossi. 'Leo has red hair.'

(2) Fr. Julie était [Imp.] grande pour son âge. 'Julie was tall for her age.'

(3) Sp. Marta tiene [Pres.] miedo de la lluvia. 'Marta is afraid of the rain.'

(4) Cat. La Rosina sap [Pres.] parlar moltes llengües. 'Rosina can speak many languages.'

States of affairs such as those illustrated in (1)-(4) exhibit a combination of aspectual basic conceptualisations of the following type:

a) externally non-delimited (EA/nd)

b) not relevant to adjacency $(\mathrm{AA} / \mathrm{nr})$

c) not internally subdivided (IA/ns)

2 Temporal markings of a deictic nature, that is, of the tense forms in the examples, are indicated in square brackets in the examples; special periphrastic constructions are noted in square brackets after the examples. 
In (1)-(4), a) neither a starting point $t_{x}$ nor an endpoint $t_{y}$ of the respective whole states of affairs is focussed, for neither the beginning nor the end of Leo having red hair in (1), Julie's height in (2), Marta's fear of rain in (3), nor Rosina's talent for languages in (4) are focussed: the respective states of affairs are not presented in their entirety and thus not in their completedness. Here, it is also b) logically impossible to determine the adjacency relevance, the relevance of Leo having red hair (as well as of Julie's height, Marta's fear of rain, or Rosina's talent for languages) for its adjacency, because, on the one hand, it is precisely the initial boundary $t_{x}$ and the final boundary $t_{y}$, which would constitute an adjacency, that are missing. On the other hand, c) (1)-(4) are monophasic states of affairs: no focussable moments $t_{x 1}, t_{x 2}, \ldots t_{x n}$ that could be (substantially) distinguished from each other can be found in the fact that Leo has red hair, that Julie is tall for her age, that Marta is afraid of the rain and that Rosina speaks many languages. I have already explained in $\$ 4.4 .1$ how the possibility of a change in time can only arise if there is a possibility of setting further subdivision points or boundaries in the temporal structuring of the state of affairs, since this variability lies precisely in the possibility of a change of state, the formation and ending of intervals and thus a temporal boundary setting. There can be no change in time where there are no discrete temporal subintervals, and vice versa: it is not possible to distinguish a moment $t_{x 1}$ of Leo having red hair (or of Julie's height, Marta's fear of rain, or Rosina's talent of languages) which is different from another $t_{\mathrm{x} 2}$ of his having red hair, in which he is more or less red-haired or in which he is red-haired in a different way. In this sense, we can define monophasic states of affairs as static states of affairs whose internal structure is homogeneous, not internally temporally further subdivided (that is, into further points $t_{x 1}, t_{x 2}, \ldots t_{x n}$ into which the interval $t_{x} \ldots t_{y}$ could be subdivided). I would like to briefly revert back to the discussion in Chapter 1 on the different types of "states" (see \$1.2.4) and recall that in the case of (1)-(4) these are states of affairs in which both so-called "individual level predicates", such as 'having red hair' and 'being tall', as well as "stage level predicates”, such as 'being afraid', are recognisable.

Let us now return to our analysis. If in a state of affairs conceived as a frame no individually perceptible moments can be focussed, as is precisely the case here, then of course for their part, they cannot serve as a boundary to the adjacency of the state of affairs itself.

Such combinations of aspectual basic conceptualisations within the frame can be represented by the delimitation schema as in Table (2): 
Tab. 2: Delimitation Schema 1: [(EA/nd) + (AA/nr) + (IA/ns)].

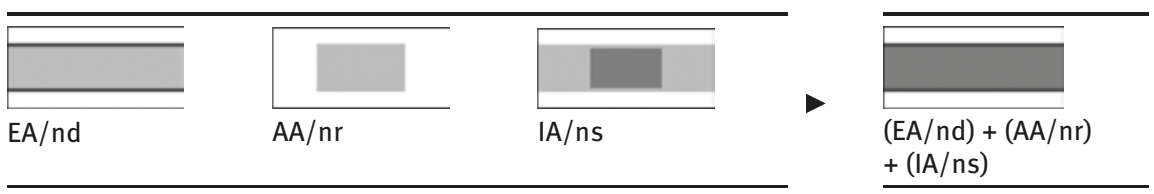

\subsubsection{Delimitation Schema 2: [(EA/nd) + (AA/nr) + (IA/s)]}

(5) It. Il gatto di Franca dormiva [Imp.] a lungo perché mangiava sempre troppo.

'Franca's cat (always) slept long because he always ate too much.'

(6) Fr. Marie mangeait [Imp.] volontiers.

'Marie enjoyed eating.'

(7) Sp. Leo dormía [Imp.] con un ojo abierto. ${ }^{3}$

'Leo slept with one eye open.'

(8) Cat. El temps passava [Imp.] i els nens creixien.

'Time passed and the children grew up.'

The states of affairs shown in examples (5)-(8) represent a combination of aspectual basic conceptualisations of the following type:

a) externally non-delimited (EA/nd)

b) not relevant to adjacency (AA/nr)

c) internally subdivided (IA/s)

In (5)-(8) a) neither a starting point $t_{x}$ nor an endpoint $t_{y}$ of the respective whole state of affairs is focussed - for neither the beginning nor the end of the long sleeping of Franca's cat (or its continuous overeating) in example (5), Marie's pleasurable eating (6), Leo's sleeping with one eye open in (7), or the passing of

3 Duerme/dormía con un ojo abierto can have two aspectual meanings: the first - represented here by dormía - is a temporally absolute meaning (he usually/always sleeps/slept with one eye open, i.e., he had this characteristic or this habit); the second, on the other hand, expresses the consideration of a particular moment $t_{x}$ of the state of affairs, in other words, what the traditional analysis of temporal-aspectual relations calls "progressive" ('Leo is/was sleeping with one eye open'). These frames have a different organisation or structure, another delimitation schema. An analysis of these cases can be found in the next chapter. 
time in example (8) are focussed: in other words, the respective states of affairs are not shown in their entirety and thus their completedness. Furthermore, it is b) logically impossible to find relevance for the adjacency of the state of affairs that Franca's cat always slept for a long time (and that Marie enjoyed eating, Leo slept with one eye open, or that time passed) because each lacks the initial boundary $t_{x}$ and the final boundary $t_{y}$ of the state of affairs itself (represented as EA/nd), which would allow the constitution of its adjacency. Finally, c) there are (substantially) different moments $t_{\mathrm{x} 1}, \mathrm{t}_{\mathrm{x} 2}, \ldots \mathrm{t}_{\mathrm{xn}}$ (which are therefore considered here in isolation, focussed on) in the fact that Franca's cat slept long (Marie liked to eat, Leo slept with one eye open and time passed).

Only if, as is the case here, there is a possibility to set further subdivision points or boundaries in the temporal structuring of the states of affairs, to recognise discrete temporal sections, does the possibility arise of a change in time. Thus, states of affairs such as those in (5)-(8), whose internal structure is temporally further subdivided, are dynamic states of affairs: Franca's cat slept through all these moments $t_{x 1}, t_{x 2}, \ldots t_{x n}$, and each of these moments can be viewed and represented individually and in isolation (similarly, Marie was eating during all the individual points of time $t_{x 1}, t_{x 2}, \ldots t_{x n}$, etc.). In other words, the states of affairs expressed in examples (5)-(8) are pluriphasic. Of course, it could be objected here that this internal subdivision is postulated without providing any linguistic evidence for it. It could also be asked how the phases of these pluriphasic states of affairs are focussed. However, a characteristic, by definition, of an onomasiological-cognitive model, such as the one presented here, is that the question of linguistic evidence cannot be posed in the same way as in a semasiological analysis. We could and should rather seek proof of the cognitive structuring of the delimitation schemas by empirical evidence, ${ }^{4}$ which, however, is beyond the limits of this investigation.

This type of combination of aspectual basic conceptualisations can be illustrated as in Table (3):

Tab. 3: Delimitation Schema 2: [(EA/nd) + (AA/nr) + (IA/s)].

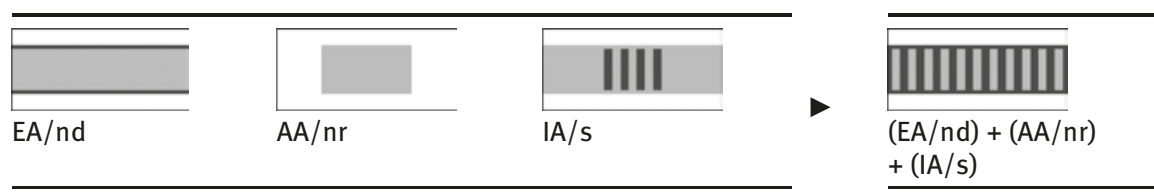

4 An approach to proving empirically the cognitive structuring of verbal semantics can be found, for example, in Siskind's work (Siskind 1997 and 2001). 


\subsubsection{Delimitation Schema 3: [(EA/d) + (AA/nr) + (IA/ns)]}

(9) It. Carlo è stato [Perf. Com.] un uomo di saldi principi. 'Charles was a man of firm principles.'

(10) Fr. Toute sa vie Marie a été [Pass. Com.] généreuse.

'All her life Marie was generous.'

(11) Sp. Nunca he tenido [Perf. Com.] miedo a volar.

'I was never afraid to fly.'

(12) Cat. La Núria va ser [Pret. Perf. Per.] una dona molt maca. 'Núria was a very beautiful woman.'

In the states of affairs presented in examples (9)-(12) a combination of aspectual basic conceptualisations of the following type can be found:

a) externally delimited (EA/d)

b) not relevant to adjacency $(\mathrm{AA} / \mathrm{nr})$

c) not internally subdivided (IA/ns)

In these examples, a) the respective states of affairs expressed - the fact that Carlo was a man of firm principles in (9), that Marie was generous all her life in (10), that I was never afraid to fly in (11), and that Núria was a very beautiful woman in (12) - are represented in their entirety. Thus, each state of affairs is represented as delimited between a starting point $t_{x}$ - the moment in which Carlo started being a man of principles, in which the life of Marie and Nurria began (and that they were then, respectively, generous and beautiful), in which I started not to be afraid of flying (which coincides with the point at which I actually started to fly and did not feel any fear at all) - and an endpoint $t_{y}$, the moment in which Carlo stopped being a man of principles (due to a moral conversion or his death), or the moment when the lives of Marie and Núria ended (and they could therefore no longer be generous or beautiful, because they no longer existed), etc. There is b) no influence of this state of affairs on its adjacency, and it is c) an internally non-subdivided, monophasic state of affairs: that Carlo was a man of principles (or that Marie was generous all her life, etc.) has no consecutive $t_{x}, t_{y}, t_{z} \ldots$ that would be individually perceptible (qualitatively different, isolable moments of firm adherence to principles or generosity, beauty or absence of fear of flying cannot be focussed in the respective frames), into which each of the states of affairs could be further subdivided, and if no individual perceptible moments can be focussed they cannot serve as the boundary of their adjacency (see b) above). 
This type of combination of aspectual basic conceptualisations can be illustrated as in Table (4):

Tab. 4: Delimitation Schema 3: [(EA/d) + (AA/nr) + (IA/ns)].

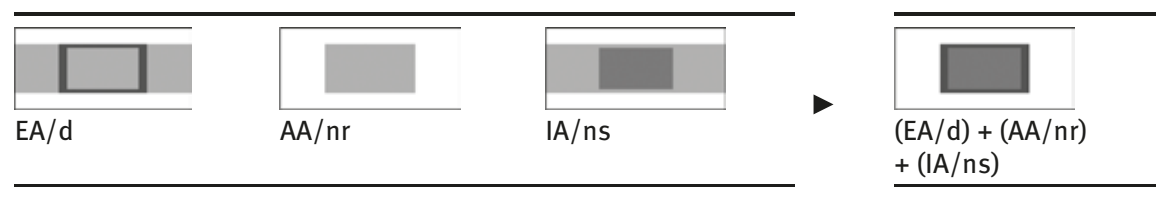

5.2.2.4 Delimitation Schema 4: [(EA/d) + (AA/nr) + (IA/s)]

(13) It. Julia ha viaggiato [Perf. Com.] molto.

'Julia has travelled a lot.'

(14) Fr. Christine cuisine [Prés.] et appelle ses filles pour manger.

'Christine cooks and calls her daughters to eat.'

(15) Sp. Marta no me habló [Perf. Sim.] durante mucho tiempo.

'Marta didn't talk to me for a long time.'

(16) Cat. Vaig veure una pel-lícula [Pret. Perf. Per.] meravellosa. [anar + Inf.] 'I saw a marvellous film.'

In examples (13)-(16), states of affairs are shown with the following combination of aspectual basic conceptualisations:

a) externally delimited (EA/d)

b) not relevant to adjacency $(\mathrm{AA} / \mathrm{nr})$

c) internally subdivided (IA/s)

In (13)-(16), a) each state of affairs - the fact that Julia has travelled a lot in (13), that Christine is preparing dinner in (14), that Marta has not spoken to me for a long time in (15) and that I (the 1st Pers. Sing. subject of the sentence) saw a marvellous film in (16) - is represented in its entirety; i.e., it is represented as delimited between a starting point $t_{\mathrm{x}}$ (the moment when Julia started to travel, Christine started to cook, Marta stopped talking to me and the film started) and an endpoint $t_{\mathrm{y}}$ (the moment Julia stopped travelling, Christine finished cooking and called her children to dinner, when Marta started talking to me again, and the moment when the film ended). However, b) this type of 
state of affairs is completely irrelevant to its adjacency: that Julia has travelled a lot or that I saw a marvellous film does not represent the end of any state of affairs in the previous adjacency (i.e., the starting of Julia's travel activity or the beginning of the film does not end anything that was taking place before the beginning of the travel activity or the film), nor the beginning of any state of affairs in the subsequent adjacency, i.e., what takes place once the travelling or film is over (nothing starts with the ending of the travelling or of the film). ${ }^{5}$ And finally, c) each state of affairs is internally subdivided, i.e., it is pluriphasic, since Julia's travelling, Christine's cooking, Marta's not talking and my watching a marvellous film have different, individually perceptible, consecutive $t_{x 1}, t_{x 2}, \ldots t_{x n}$, in all of which Julia is away, Christine is cooking, Marta is not talking to me and I was watching the film.

This type of combination of aspectual basic conceptualisations can be illustrated as in Table (5):

Tab. 5: Delimitation Schema 4: [(EA/d) + (AA/nr) + (IA/s)].

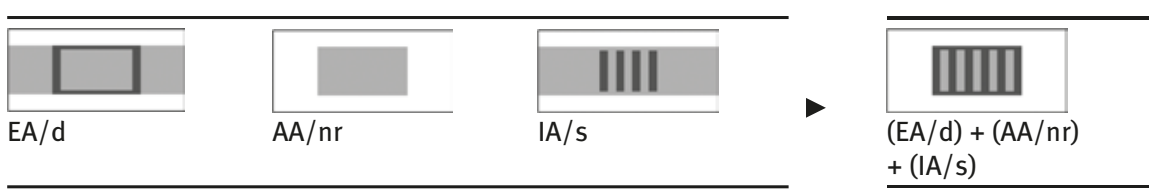

\subsubsection{Delimitation Schema 5: [(EA/d) + (AA/fr) + (IA/s)]}

(17) It. La fiamma si spense [Perf. Sem.] lentamente.

'The flame went out slowly.'

(18) Fr. Daniel a démoli [Pass. Com.] une maison (qui était délabrée).

'Daniel demolished a house.'

(19) Sp. Acabo [Pres.] de comer un osito de gominola. [acabar de + Inf.] 'I have just eaten a jelly baby.'

5 In the case of (14) the second part of the utterance (the coordinated sentence 'and calls her children to dinner') is the element that contributes to the interpretation of the first part ('Christine cooks') as 'Christine has finished cooking'. 
(20) Cat. El cotxet s'atura [Pres.] a poc a poc (i en Pau en baixa). 'The small car gradually stops.'

In examples (17)-(20), states of affairs with a combination of aspectual basic conceptualisations of the following type are represented:

a) externally delimited (EA/d)

b) with final adjacency relevance (AA/fr)

c) internally subdivided (IA/s)

The states of affairs expressed in examples (17)-(20) are a) each shown in their entirety as delimited, since the initial moment $t_{x}$ and the final moment $t_{y}$ are focussed; the respective initial and final boundaries do not coincide. In examples such as (18) and (19), this seems easier to understand: that between the initial moment $t_{x}$, in which Daniel started to demolish the house and I began to eat the jelly baby, and the final moment $t_{\mathrm{y}}$ in which Daniel completed demolishing the house and I finished eating the jelly baby, there are many more consecutive $t_{x 1}, t_{x 2}, \ldots t_{x n}$ and that $t_{x 1}$ and $t_{x 2}$ do not coincide, is provided by the world knowledge of the speaker, that for demolishing a house and eating a jelly baby time is needed. However, a state of affairs such as the one expressed in (17) may require further explanation. This is another opportunity to show the difference between the model presented here and those models based on Vendler's verb classification. Here, the comparison with Delimitation Schema 9 will be important and sheds light on various interesting issues (see §5.2.2.9, especially example (33)).

In example (17) - as in (18) and (19) - a) the state of affairs is shown in its entirety as delimited (the initial moment $t_{x}$ and the final moment $t_{y}$ of the slow extinction of the flame are focussed and its initial and final boundaries do not coincide). The semantics of its various components in mutual interaction contributes to this realisation: the morphological marking of the verb (through the Passato Remoto); semantic elements in the stem (spegnersi); adverbials such as lentamente; the presence of an individual noun functioning as a first argument (fiamma, accompanied by the determiner la). At the end of the state of affairs, the flame will not burn anymore (see b) below), and the extinction of the flame is a slow process that takes time. Thus, this is a state of affairs that shows other aspectual contents than those in (33) La fiamma si spense (in un istante). ${ }^{6}$ This is due to the presence of the temporal adverb

6 Traditionally, verbs such as spegnersi are interpreted as punctual (- durative, - telic). 
lentamente in (17), ${ }^{7}$ which - in connection with the other elements in the situation frame - contributes to this particular aspectual interpretation of the state of affairs, for while the extinction of the flame in (33) is something that is related to and represents a moment $t_{x}$ (the precise moment of extinction itself), in the case of the slow extinction in (17), this moment is interpreted and represented on the basis of the speaker's world knowledge as - so to speak - "stretched", insofar as this extended period of time contains all the moments of extinction, in which the flame became increasingly weaker or in which it seemed that the flame was just about to extinguish and yet continued to burn, albeit more weakly. The states of affairs presented in the two examples (17) and (33) are thus connected to two different frames that represent the contexts, the experiential connections, in which the speaker learned them and uses them (see also Chapter 3 in this respect). Example (17) can be interpreted in a similar way to example (20), because the stopping of the car, which is otherwise perceived in a different combination of linguistic elements as a punctual state of affairs, is also interpreted and represented by the presence of a poc a poc in such a way that in this extended period of time one can see all the $t_{x 1}, t_{x 2}, \ldots t_{x n}$ of the slowing down of the car until its final stop.

In addition, b) this type of state of affairs, as seen in (17)-(20), is relevant for its previous adjacency: it structures it by delimiting its end. That the flame has slowly gone out represents the end of the previous adjacency of the state of affairs itself, the burning of the flame (it has just gone out); that Daniel demolished a house in (18) represents the end of the existence of the house; that the subject in (19) has just finished eating the jelly baby represents the end of the jelly baby's existing; and finally, the fact that the car stopped in (20) represents the end of the previous adjacency of the state of affairs, namely the driving of the car.

In states of affairs of this type it is finally possible c) to find (i.e., to focus) the different, individually perceptible consecutive $t_{x 1}, t_{x 2}, \ldots t_{x n}$ into which they are subdivided: in (17), these are the individual, isolated and qualitatively differently perceived moments of the slow extinction of the flame (which is also connected to the presence of lentamente in the frame), which raises the question as to in what way - besides temporality, which is certainly of primary importance for delimitation - quantity plays a role in the structuring of the state of affairs; in (18) it is the individual moments of the demolishing of the

7 A modal adverb like dolcemente ('in a sweet/nice way') could have also represented the same aspectual meaning when combined with the same elements in the situation frame. In that case, dolcemente would have been reinterpreted as a temporal (i.e., aspectual) adverb and would have taken on the meaning 'slowly' in this context (see §5.2.2.6 for an analysis of such a case). 
house (in which the house is demolished); in (19) the individual moments of the eating of the jelly baby; and in (20) the stopping of the car, dependent on the presence of a poc a poc in the frame (cf. example (36), §5.2.2.9).

This type of combination of aspectual basic conceptualisations can be illustrated as in Table (6):

Tab. 6: Delimitation Schema 5: $[(E A / d)+(A A / f r)+(I A / s)]$.

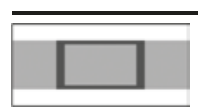

$\mathrm{EA} / \mathrm{d}$

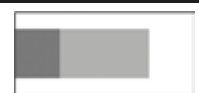

$\mathrm{AA} / \mathrm{fr}$

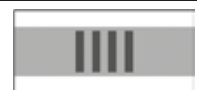

$\mathrm{IA} / \mathrm{s}$

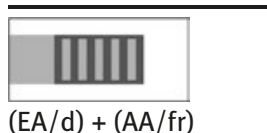

$(\mathrm{EA} / \mathrm{d})+(\mathrm{AA} / \mathrm{fr})$ $+(\mathrm{IA} / \mathrm{s})$

\subsubsection{Delimitation Schema 6: [(EA/d) + (AA/ir) + (IA/s)]}

(21) It. L'auto cominciò [Perf. Sem.] a muoversi lentamente. [cominciare $a+$ Inf.] 'The car began to move slowly.'

(22) Fr. Doucement Marie-Rose se met [Prés.] à chanter. [se mettre à + Inf.] 'Slowly, Marie-Rose starts singing.'

(23) Sp. El día nació [Perf. Sim.] tímidamente.

'The day dawned timidly.'

(24) Cat. La lluna terrestre es va formar [Pret. Perf. Per.] més tard que la resta del sistema solar. [anar + Inf.]

'The Earth's moon formed later than the rest of the solar system.'

In (21)-(24), states of affairs with the following combination of aspectual basic conceptualisations are represented:

a) externally delimited (EA/d)

b) with initial adjacency relevance (AA/ir)

c) internally subdivided (IA/s)

In these examples, a) the respective states of affairs are shown in their entirety as delimited, since both the starting point $t_{x}$ and the endpoint $t_{y}$ of the car beginning to move in (21), the beginning of Marie-Rose's singing in (22), the 
dawning of the day in (23) or the progressive formation of the moon in (24) are focussed. The initial and the final boundaries do not coincide here, because the car starts to move slowly, Marie-Rose begins to sing little by little, the day begins to break gradually and the formation of the moon takes time. The semantics of various components in mutual interaction contributes to the aspectual realisation of the respective states of affairs: the morphological marking of the verb (expressed by the Passato Remoto of the auxiliary verb in connection with the infinitive of the main verb in the periphrastic construction cominciare $a+$ infinitive in (21); the present tense of the auxiliary verb in connection with the infinitive of the main verb in the periphrastic construction se mettre $\grave{a}+$ infinitive in (22); the Perfecto Simple in (23) and the Pretèrit Perfet Perifràstic in (24)), the semantic elements in the stem (cominciare a muoversi, se mettre à chanter, nacer and formarse) ${ }^{8}$ and the adverbials (lentamente, doucement and tímidamente).

Again, comparison with examples (37)-(40) of Delimitation Schema 10 (§5.2.2.10) is very important for a better understanding of the role played by the individual components - in particular, adverbs such as lentamente -

8 Since Dowty's (1979) analysis, predicates such as formarse have been defined as "degree achievements". Dowty notes that these verbs denote a change of state and claims that they share some semantic and syntactic properties with "achievements". In investigations with standard tests, they show both telic and atelic properties. In this context see also Hay/Kennedy/ Levin (1999).

In this book, my analysis is not based on verbal properties, but rather I conceive states of affairs as situation frames. In addition, the relation between telicity and change of state (properties which are deemed essential for so-called degree achievements) is considered in a new light: the concept of telicity is radically renounced, since only purely temporal, aspectual criteria are considered here and since the idea related to telicity of a goal to be attained certainly goes beyond this simply temporal structuring of states of affairs. The notion of change of state is found again in different constellations, combinations of aspectual building blocks and realisations of the three dimensions of aspectuality (see, in particular, the realisations of AA, and in detail the analyses regarding DS 5 - DS 7, DS 9 - DS 11, DS 2/9 - DS 2/11 and DS 2/9, 9, $9, \ldots-\mathrm{DS} 2 / 11,11,11,11 \ldots$ ). Traditionally, the notions of transformative, ingressive and terminative, for example, have been used for verbs that imply a change of state. With regard to the presence of graduality (more precisely, the "degree"), this is related to the possibility of finding (i.e., focussing) - or not - different, individually perceptible consecutive $t_{x 1}, t_{x 2}, \ldots t_{x n}$ within the state of affairs which express a change of state. More specifically, DS 7, which is a combination of $(\mathrm{EA} / \mathrm{d})+(\mathrm{AA} / \mathrm{tr})+(\mathrm{IA} / \mathrm{s})$, displays a $(\mathrm{tr}=$ "transformative") change of state with internal graduality; DS 11, which is a combination of $(\mathrm{EA} / \mathrm{pd})+(\mathrm{AA} / \mathrm{tr})+(\mathrm{IA} / \mathrm{ns})$, displays a change of state without internal graduality. It is clear that no linguistic evidence obtained by tests (e.g., to investigate telicity) is possible nor useful because the addition of an element would change the whole frame. 
within and in the background of the entire frame in expressing this combination of aspectual building blocks. Direct comparison of (22) and (38), MarieRose se met à chanter, reveals that the states of affairs presented in the two examples relate to two different frames representing the contexts - the experiential connections - in which the speaker has learned them and uses them. The speaker knows, on the basis of her/his world knowledge, that while the beginning of the singing in (38) is something connected with a (particular) moment (the exact moment of the first note being sung), this moment is stretched, as in (22), when the singing begins slowly. This period of time stretched in such a way - i.e., the gradual beginning of the singing - includes all the preparations and attempts of singing: the throat-clearing as well as the hesitation before beginning.

Furthermore, states of affairs of this sort, b) are relevant to their adjacencies because they structure their respective subsequent adjacencies by representing their beginnings: the car that begins to move slowly will then continue to move; Marie-Rose who gradually starts to sing will then continue to sing; the day that breaks is there and will continue to be there; the moon that has formed will remain there for the time being.

Finally, c) in these states of affairs different, consecutive $t_{x 1}, t_{x 2}, \ldots t_{x n}$ can be perceived (those of the gradual starting to sing, etc.). This is made possible in examples (21)-(23) by the presence of elements such as lentamente, doucement and timidamente in the frame, since these elements - this was explained in a) above - stretch the interval $I=\left|\mathrm{t}_{\mathrm{y}}-\mathrm{t}_{\mathrm{x}}\right|$ which exists between the initial and final boundaries $\left(t_{x}\right.$ and $\left.t_{y}\right) .{ }^{9}$ Example (24) could be represented as internally subdivided (i.e., pluriphasic), even irrespective of the presence of such an adverb, which thus intensifies or emphasises the aspectual structuring of the situation frame because the pieces of aspectual information which convey this are connected in this frame to the verb stem: the formation of the moon is anchored in the speaker's world knowledge with a temporal graduality, which entails duration.

This type of combination of aspectual basic conceptualisations can be illustrated as in Table (7).

9 It is precisely the presence of the adverb doucement in (22), for example, that modifies the whole set of relations in the situation frame and causes this particular aspectual interpretation of the state of affairs. While the state of affairs shown below in (38) has an internal temporal structuring of the type $(\mathrm{EA} / \mathrm{pd})+(\mathrm{AA} / \mathrm{ir})+(\mathrm{IA} / \mathrm{ns})$, that in (22) has a delimitation schema of the type $(\mathrm{EA} / \mathrm{d})+(\mathrm{AA} / \mathrm{ir})+(\mathrm{IA} / \mathrm{s})$. 
Tab. 7: Delimitation Schema 6: [(EA/d) + (AA/ir) + (IA/s)].

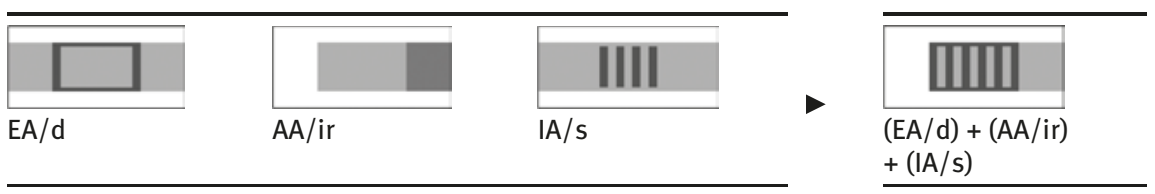

\subsubsection{Delimitation Schema 7: [(EA/d) + (AA/tr) + (IA/s)]}

(25) It. Quest'autunno le foglie sono ingiallite [Perf. Com.] molto lentamente. 'This autumn the leaves turned yellow very slowly.'

(26) Fr. Le printemps s’installa [Pass. Sim.] dans les jardins tout doucement. 'Spring came to the gardens very slowly.'

(27) Sp. El niño ha engordado [Perf. Com.] en el curso de tres años. 'The child has put on weight over the course of three years.'

(28) Cat. La nena va créixer [Pret. Perf. Per.] molt lentament. 'The girl grew very slowly.'

In (25)-(28), states of affairs with a combination of aspectual basic conceptualisations of the following type are presented:

a) externally delimited (EA/d)

b) with initial and final (transformative) adjacency relevance (AA/tr)

c) internally subdivided (IA/s)

In these examples, a) each state of affairs is shown in its entirety as delimited, for both the starting point $t_{x}$ and the endpoint $t_{y}$ of the slow yellowing of the leaves in (25), the coming of spring to the garden in (26), the increase in weight of the child (over three years) in (27) and the slow growing of the girl in (28) are focussed. Here, the initial and the final boundaries of the respective states of affairs do not coincide, because these processes are anchored in the speaker's world knowledge as those that evolve over a period of time.

In addition, b) states of affairs as in (25)-(28) are relevant to their respective adjacencies and structure their previous and subsequent adjacencies. The leaves are not yellow before turning yellow and will continue to be yellow afterwards; spring, which was not there before it came, will continue to reign in the garden thereafter; the child, who was previously thinner, will remain fatter 
after the third year if s/he does not lose weight again; finally, the girl who was smaller before growing will be taller afterwards.

Finally, c) in these states of affairs, different, successive $t_{x 1}, t_{x 2}, \ldots t_{x n}$ can be perceived separately (the different moments in which, respectively, the leaves have slowly turned yellow, spring has come to the garden, the child has become fatter, etc.). This is possible not only because of the presence of verbs such as 'to turn yellow' in (25) or 'to grow'10 in (28) (the speaker knows from her/his world knowledge that these are states of affairs with a time span), but also by the presence of adverbials such as lentamente in (25) or en el curso de tres años in (27), which further emphasise the interval $I=\left|\mathrm{t}_{\mathrm{y}}-\mathrm{t}_{\mathrm{x}}\right|$ that exists between the initial and final boundaries $\left(t_{x}\right.$ and $\left.t_{y}\right)$ of the respective states of affairs.

This type of combination of aspectual basic conceptualisations can be illustrated as in Table (8):

Tab. 8: Delimitation Schema 7: [(EA/d) + (AA/tr) + (IA/s)].

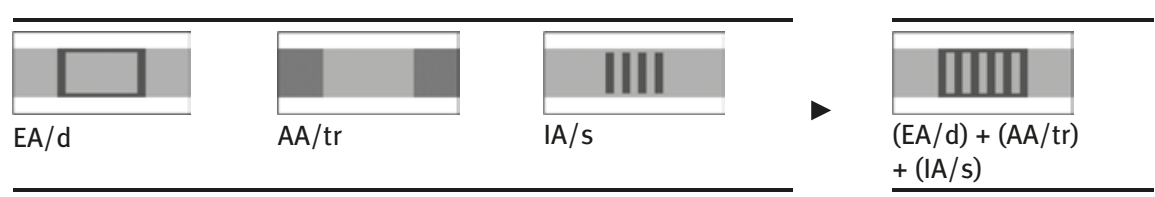

\subsubsection{Delimitation Schema 8: [(EA/pd) + (AA/nr) + (IA/ns)]}

(29) It. Bussò [Perf. Sem.] alla porta alle tre in punto.

'He knocked on the door at exactly three o'clock.'

(30) Fr. Il toussa [Pass. Sim.] fort et jeta sa cigarette par terre.

'He coughed hard and threw his cigarette on the floor.'

(31) Sp. El delincuente disparó [Perf. Sim.] un tiro con su arma.

'The criminal fired a shot with his gun.'

10 For a discussion of so-called "degree achievements", to which verbs such as ingiallire or créixer are traditionally assigned, see the analysis of DS 6 in §5.2.2.6 and, in general, Dowty (1979). 
(32) Cat. El nen va esternudar [Pret. Perf. Per.].

'The child sneezed.'

In examples (29)-(32) states of affairs with the following combination of aspectual basic conceptualisations are shown:

a) externally punctually delimited (EA/pd)

b) not relevant to adjacency $(\mathrm{AA} / \mathrm{nr})$

c) not internally subdivided (IA/ns)

In (29)-(32), a) the states of affairs are shown in their entirety as delimited, as both the starting point $t_{x}$ and the endpoint $t_{y}$ of the knocking on the door at exactly three o'clock in (29), the hard coughing in (30), the criminal's firing of the shot in (31) and the sneezing of the child in (32) are focussed. In each case, the initial and final boundaries coincide, which is evident from the presence of various elements combined in the state of affairs: in example (29) a particular aspectual content of bussare alla porta is understood (in different frames this verb can express different aspectual contents, depending on the other components in the frame; in this context, the punctual and not the reiterative meaning is expressed); furthermore, the morphological inflectional marking of the Passato Remoto and the temporal adverb alle tre in punto are both elements that contribute to a punctual interpretation. This is also the case in the other examples.

The states of affairs in (29)-(32) b) do not structure their adjacency, in fact, they are irrelevant to their respective adjacencies because the knocking on the door does not influence either the temporal constitution of its previous adjacency (that which was before the knocking) nor that of its subsequent adjacency; similarly, the coughing does not influence either the temporal constitution of what was before the coughing, or what occurred afterwards, etc.

And finally, c) no statement can be made about the further subdivisibility of the states of affairs of this type, which follows logically from the external punctual delimitation: if the knocking in (29) and the sneezing in (32) consist of $a t_{x}$ (or of the interval $\delta t_{x}$, which results from the coincidence of $t_{x}$ (the beginning of the knocking or sneezing) and $t_{\mathrm{y}}$ (the ending of the knocking or sneezing)), it is not subdivisible into further points $t_{x 1}, t_{x 2}, \ldots t_{x n}$, into which the interval $\delta t_{x}$ - as the smallest interval humanly perceivable - could be subdivided.

This type of combination of aspectual basic conceptualisations can be illustrated as in Table (9): 
Tab. 9: Delimitation Schema 8: [(EA/pd) + (AA/nr) + (IA/ns)].

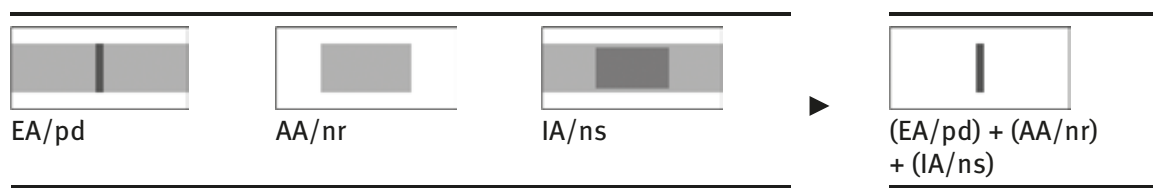

\subsubsection{Delimitation Schema 9: [(EA/pd) + (AA/fr) + (IA/ns)]}

(33) It. La fiamma si spense [Perf. Sem.] (in un istante). 'The flame went out (in an instant).'

(34) Fr. À cinq heures maman s'est endormie [Pass. Com.] dans son fauteuil. 'At five o'clock, mum fell asleep in her chair.'

(35) Sp. El autobús acaba [Pres.] de parar. [acabar de + Inf.] 'The bus has just stopped.'

(36) Cat. El cotxet es va aturar [Pret. Perf. Per.] improvisadament.

'The small car suddenly stopped.'

In (33)-(36), states of affairs with the following combination of aspectual basic conceptualisations are represented:

a) externally punctually delimited (EA/pd)

b) with final adjacency relevance (AA/fr)

c) not internally subdivided (IA/ns)

The states of affairs shown in examples (33)-(36) - the flame going out in a moment in (33), the mother falling asleep at five o'clock in (34), the bus stopping just previously in (35) and the sudden stopping of the car in (36) - a) are focussed in their entirety as delimited (and therefore as completed). In these cases, the respective initial and final boundaries $t_{x}$ and $t_{y}$ coincide, in other words, they do not represent a time span. Several of the components of the states of affairs contribute to this realisation of aspectuality: in examples (33) and (34), in particular, these are the morphological marking of the verb (by the Passato Remoto and the Passé Composé), semantic elements in the respective stems (spegnersi and s'endormir), the presence of the adverbials in un istante and à cinq heures, the presence of individual nouns acting as first arguments (fiamma and maman, the former accompanied by the determiner la). In these cases, the convergence of 
this aspectual information in the frame has a reinforcing effect (the comparison with example (17) of Delimitation Schema 5 given in §5.2.2.5 highlights the different outcomes of different interactions, because there the other adverbials had instead a corrective effect).

In addition, b) these states of affairs structure their previous adjacencies by determining their end: that the flame has gone out means that it no longer burns and, of course, that it will not go out anymore (the state of affairs is completed and irreversible); that mum fell asleep on the sofa at five o'clock means that she is no longer awake; that the bus has just stopped and the car stopped suddenly implies that they are not moving anymore.

Finally, c) logically, no statement can be made about the further subdivisibility of these punctual states of affairs: if the flame going out in a moment (just like the falling asleep of mum, or the stopping of the vehicles) consists of the $t_{x}$ of its beginning that coincides with the $t_{y}$ of its ending, this $t_{x}$ is not subdivisible into any further points $t_{x 1}, t_{x 2}, \ldots t_{x n}$. The beginning and ending of these processes is thus an interval $\delta t_{x}-$ the smallest possible interval for human perception - which, by definition, cannot be subdivided any further.

This type of combination of aspectual basic conceptualisations can be illustrated as in Table (10):

Tab. 10: Delimitation Schema 9: [(EA/pd) + (AA/fr) + (IA/ns)].

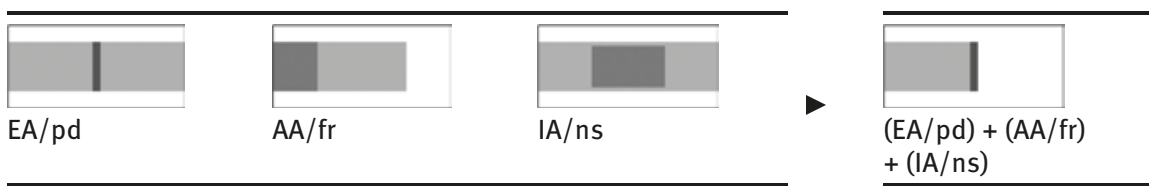

\subsubsection{Delimitation Schema 10: [(EA/pd) + (AA/ir) + (IA/ns)]}

(37) It. Entrò [Perf. Sem.] nella stanza.

'He entered the room.'

(38) Fr. Marie-Rose se met [Prés.] à chanter. [se mettre à + Inf.]

'Marie-Rose starts singing.' 
(39) Sp. Juan se ha despertado [Perf. Com.] a las tres en punto. 'Juan woke up at three o'clock.'

(40) Cat. La barca va sortir [Pret. Perf. Per.]. 'The ship departed.'

In examples (37)-(40) states of affairs with the following combination of aspectual basic conceptualisations are shown:

a) externally punctually delimited $(\mathrm{EA} / \mathrm{pd})$

b) with initial adjacency relevance (AA/ir)

c) not internally subdivided (IA/ns)

In these examples, a) the respective states of affairs are represented in their entirety as delimited, since both the starting point $t_{x}$ and the endpoint $t_{y}$ of entering the room in (37), beginning to sing in (38), waking up at exactly three o'clock in (39) and the departing of the ship in (40) are focussed. The initial and final boundaries of the states of affairs therefore coincide, because his entering the room, Marie-Rose's starting to sing, and so on, are instantaneous. If we focus on the beginning of the singing - as in a frame such as (38) where there are no further elements that influence or modify this interpretation through other (temporal) contents ${ }^{11}$ - we automatically focus on the end of this beginning, which itself has no duration.

These are also states of affairs b) that influence the beginning of their subsequent adjacencies: when he enters the room, he is in the room afterwards; when Marie-Rose begins to sing, the subsequent adjacency is then filled with singing; when Juan wakes up at three o'clock, he will be awake afterwards; and when the ship has left, it will be on its journey.

Finally, c) such states of affairs, as externally punctually delimited ones, are not internally delimitable because they display no time span: no statement can be made about the subdivisibility of the entering of the room (or the beginning to sing, etc.) because this state of affairs is also a case of an interval $\delta t_{x}$ which cannot be subdivided into any further points $t_{x 1}, t_{x 2}, \ldots t_{x n} \cdot{ }^{12}$

This type of combination of aspectual basic conceptualisations can be illustrated as in Table (11):

11 See the analysis of examples (21)-(24) of Delimitation Schema 6 (§5.2.2.6).

12 It is interesting to compare this conception of aspectuality with the traditional classification of aspect and Aktionsart. Here, it should be emphasised that si mette a cantare vs. si mise a cantare reveals a difference that manifests itself only on the temporal and not on the aspectual level. 
Tab. 11: Delimitation Schema 10: [(EA/pd) + (AA/ir) + (IA/ns)].

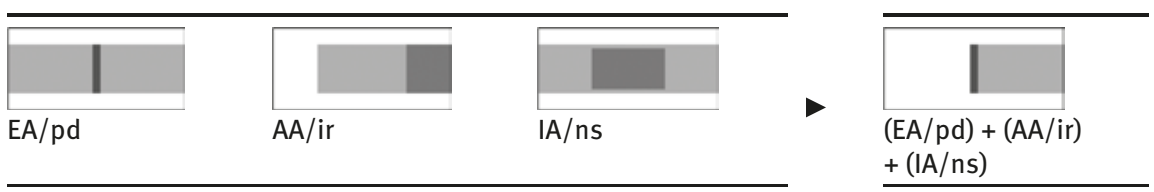

\subsubsection{Delimitation Schema 11: [(EA/pd) + (AA/tr) + (IA/ns)]}

(41) It. Il palloncino esplose [Perf. Sem.] improvvisamente (provocando il pianto dei bambini).

'The balloon suddenly burst (making the children cry).'

(42) Fr. Marie rougit [Pass. Sim.] soudainement: elle avait vu Gérard!

'Marie suddenly blushed: she had seen Gérard!'

(43) Sp. ¡He engordado [Perf. Com.] un kilo en un segundo: maldita Nocilla!

'I've put on a kilo in one second: damn Nutella!'

(44) Cat. En Xavier s'enamorà [Pret. Perf. Sim.] del mar just l'instant en què el veié.

'Xavier fell in love with the sea the moment he saw it.'

In examples (41)-(44), states of affairs with the following combination of aspectual basic conceptualisations are represented:

a) externally punctually delimited (EA/pd)

b) with initial and final (transformative) adjacency relevance (AA/tr)

c) not internally subdivided (IA/ns)

In these examples, a) the states of affairs are shown in their entirety as delimited, for both the starting point $t_{x}$ and the endpoint $t_{y}$ of the bursting of the balloon in (41), the sudden blushing of Marie in (42), the gaining of weight in a second in (43), and the instant falling in love with the sea in (44) are focussed. Here, the respective initial and final boundaries of the states of affairs coincide, because the balloon burst as instantaneously as Xavier fell in love; no period of time can be perceived in any of these states of affairs. Here too, the role played by the individual components in the frame must be taken into account: in (44), for example, these are the morphological marking of the verb (through the Preterit Perfet), the semantic elements in the stem (enamorarse) 
and the presence of the complex subframe just l'instant en què el veié, which contains further adverbial and verbal punctual determinations.

Furthermore, b) these states of affairs are relevant to their adjacencies, structuring both their previous and their subsequent adjacencies: the balloon is intact before bursting and will be damaged after the bursting; Marie is not red before blushing and will continue to be so afterwards; I am one kilo lighter before gaining weight and will (unfortunately) remain a kilo heavier afterwards, and Xavier is not in love before falling in love and will continue to be in love afterwards.

Finally, c) no statement can be made about the subdivisibility of states of affairs of this kind. The falling in love with the sea in (44) is - like all punctual states of affairs - not subdivisible into any further points $t_{x 1}, t_{x 2}, \ldots t_{x n}$ : the beginning of Xavier's falling in love coincides with its end and therefore displays no time span in which further points $t_{x 1}, t_{x 2}, \ldots t_{x n}$ of falling in love could be perceived in isolation.

This type of combination of aspectual basic conceptualisations can be illustrated as in Table (12):

Tab. 12: Delimitation Schema 11: [(EA/pd) + (AA/tr) + (IA/ns)].

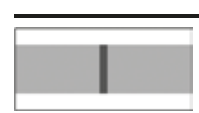

$\mathrm{EA} / \mathrm{pd}$

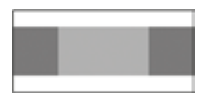

$\mathrm{AA} / \mathrm{tr}$

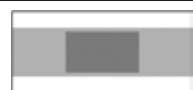

$\mathrm{IA} / \mathrm{ns}$

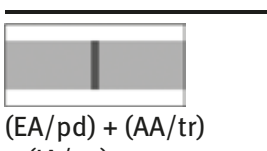

$+(\mathrm{IA} / \mathrm{ns})$

\subsubsection{Delimitation Schema 12: [(NEA) + (NAA) + (NIA)]}

(45) It. I neonati mangiano [Pres.] e dormono [Pres.].

'Babies eat and sleep.'

(46) Fr. Les hommes sont [Prés.] mortels.

'Men are mortal.'

(47) Sp. ¡La vida es [Pres.] breve!

'Life is short!' 
(48) Cat. Els nens creixen [Pres.]. ${ }^{13}$

'Children grow up.'

Finally, in examples (45)-(48) states of affairs of a very special kind are represented, namely those in which no combination of the aspectual basic conceptualisations of the three dimensions of aspectuality is evident. Instead, we have here a general impossibility of delimitation. In other words, they are atemporal states of affairs, where no particular realisation of aspectuality can be represented. They are:

a) not externally delimitable (NEA)

b) relevance for adjacency cannot be determined (NAA)

c) not internally subdivisible (NIA)

They thus represent combinations of all three perspectives of aspectuality on an abstract, logical level of the impossibility of their determination, in other words non-aspectuality.

As long as the states of affairs presented in examples (45)-(48) are intended and understood as universal statements about the world in general, a) they are not delimitable. Indeed, in this framework of interpretation they are absolutely valid and therefore alien to any temporal delimitation: in the 'shortness of life' in (47) there are neither aspectual markings on the predicate (which is expressed in the present tense), nor contents in the first argument (la vida, which is 'life in general', the life of all people in the world and in the course of time) that would allow for an aspectual delimitation (and of course the same applies to the babies' eating and sleeping in (45), to the 'mortality' of men in (46), and to the growing of children in (48)).

Furthermore, b) non-delimitable states of affairs are those in which no statement regarding their adjacency relevance can be made (because they also have no delimitation that could make up an adjacency).

13 If example (48) were contextualised in a non-universally valid interpretation frame, in some other situation frame, then els nens would not be all children but rather particular children, such as mine, whose growing I am reporting on, and it would no longer be a generally valid state of affairs but one that would have to be interpreted as progressive (in English 'The children are growing up'). Similar examples of aspectual polysemy have already been pointed out. In this case, a different delimitation schema would be assigned to the states of affairs, which would have a further level of focussing: DS 2/11, 11, 11, . : $[((\mathrm{EA} / \mathrm{nd})+(\mathrm{AA} / \mathrm{nr})+(\mathrm{IA} / \mathrm{s}))>((\mathrm{EA} / \mathrm{pd})+$ $(\mathrm{AA} / \mathrm{tr})+(\mathrm{IA} / \mathrm{ns})),((\mathrm{EA} / \mathrm{pd})+(\mathrm{AA} / \mathrm{tr})+(\mathrm{IA} / \mathrm{ns})),((\mathrm{EA} / \mathrm{pd})+(\mathrm{AA} / \mathrm{tr})+(\mathrm{IA} / \mathrm{ns})), \ldots$. $)$. See Chapter 6 (in particular §6.2.2.8) for an exact analysis of such cases. 
Finally, c) no statement can be made as to their subdivisibility, since states of affairs without any temporal delimitation cannot be further subdivided into subintervals: the shortness of life is an eternal state of affairs, valid beyond time, and thus would not be subdivisible into any points $t_{x 1}, t_{x 2}, \ldots t_{x n}$ of life being short, and if no single perceptible moments can be focussed in the eternal shortness of life, these cannot serve as the boundary of an adjacency (cf. b) above).

This type of combination of aspectual basic conceptualisations can be illustrated as in Table (13):

Tab. 13: Delimitation Schema 12: [(NEA) + (NAA) + (NIA)].

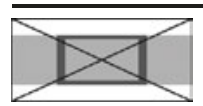

NEA

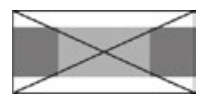

NAA

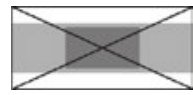

NIA

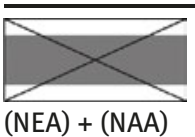

$+(\mathrm{NIA})$

\subsection{A third interim conclusion}

In this chapter, a new onomasiological and unidimensional model for describing the interaction of aspectual content in states of affairs - understood as frame structures - was presented, which makes use of a classification principle based on a basic human cognitive ability: the delimitation principle. Aspectuality is understood here as aspectual delimitation and defined as a universal content category that expresses the possibilities of external (absolute delimitation or non-delimitation), adjacency-related (adjacency relevance or non-relevance) and internal (subdivision or non-subdivision) temporal structuring of a state of affairs.

Since the traditional terminology for aspectual categories arises from a semasiological perspective and is based on the distinction between two categories within the more general semantic field of aspectuality, it could not be used in the present study. A general revision of the terminology was therefore necessary, which, of course, also reflects a theoretical difference at the foundational level of the category: there is no inevitable correspondence between the realisations of aspectuality presented here and the semasiologicallyobtained language-particular categories of aspect and Aktionsart.

At this point, I should make explicit what has already been hinted at or indicated in some of the footnotes, namely that it is no coincidence that no 
(syntactic) tests were used in the classification presented here for analysing the frames under consideration. In aspectology, it is common in making verb classifications to verify them by adding adverbial elements, such as "in $\mathrm{x}$ hours" or "for y days", to test the properties of predicates (according to known criteria of telicity, durativity, etc.). This is neither useful nor possible when investigating states of affairs considered as frames, as each addition of an adverbial test element modifies the entire frame and therefore its aspectual interpretation.

The inventory given in this chapter of the various realisations of aspectual content (aspectual basic conceptualisations) and their possible (and impossible) combinations within a frame also represents an application of the model developed here. I have shown that by analysing aspectuality as a universal semantic category it is possible to describe the aspectual content of states of affairs in a way that is at least as fine-grained as those methods that make use of the means advocated by bidimensional approaches - including the subdivision of aspectual content into two categories, aspect and Aktionsart, and the description of the convergence of different subtypes of these two categories. The second level of perspectivisation in situation frames presented in the next chapter will lend support to this and develop it further. Romance verbal periphrases, which are particularly common on the second level, will serve as the basis for further examination of the model regarding its possibilities for description and analysis.

We have already seen on these pages two advantages of the model: it is cognitively adequate, since it departs from a single and fundamental cognitive principle, the delimitation principle, and it is semantically homogeneous, since it can describe all possible contexts with combinations of the three perspectives of aspectuality which provide a limited but comprehensive set of basic conceptualisations. 



\section{The Second Level of the Aspectuality Model Applied}

\subsection{Introductory remarks}

This chapter deals with the second level of perspectivisation of the model of aspectuality within situation frames, a level that is created through further recursive perspectivisation (or focussing) of some of the outcomes of the first level of perspectivisation.

In the first part of Chapter 6 I will - as previously in Chapter 5 - give an exact, but in this case not fully comprehensive, description of the possible and impossible combinations of basic conceptualisations on the second level. In the Romance languages, it is mainly constructions such as verbal periphrases that are used to express those complex structurings of aspectuality which the model conceives as a second level of perspectivisation within situation frames. However, this second level is not expressed exclusively by verbal periphrases (it has been stressed several times that languages have several means to express the same aspectual content), nor can all aspectual verbal periphrases be regarded exclusively as realisations of this second level of perspectivisation. In the previous chapter some of these constructions were analysed as the expression of combinations of the three perspectives of aspectuality on the first level (see, among others, example (19) in §5.2.2.5 or (21) and (22) in §5.2.2.6). However, the possibility cannot be excluded that there are languages that express this second level of perspectivisation only through purely lexical (e.g., adverbs) or purely morphological forms (e.g., synthetic verb markers) and in which verbal periphrases either do not occur or they play an insignificant role. ${ }^{1}$

In the second part of the chapter, I examine in more detail the phenomenon of periphrastic verbal constructions, which are very important in the Romance languages and almost a classic issue in Romance linguistics. The theoretical leitmotif of the second part of the chapter is a general discussion of the problem of what the underlying factor is that unites all aspectual verbal periphrases and to which aspectual categories - semantically separate in the bidimensional conception they are to be assigned, in other words, the question of whether aspectual verbal periphrases are to be considered aspect or Aktionsart. On the basis of the theoretical approach to aspectuality presented here, a new analysis of the phenomenon is

1 This is the case in Russian, for example, where verbal periphrases play a more peripheral role and are not grammaticalised, apart from the formation of the future with budu.

¿ Open Access. (C) 2019 Sarah Dessì Schmid, published by De Gruyter. (cc) BY-NC-ND This work is licensed under a Creative Commons Attribution-NonCommercial-NoDerivatives 4.0 International License. 
undertaken that strongly relativises the relevance of this question, which is difficult to answer with the traditional semasiological approach.

\subsection{Aspectual delimitation schemas of the second level of the model}

\subsubsection{An inventory of the delimitation schemas of the second level}

In Chapter 5 (see §5.2.1) an inventory of all the possible and impossible combinations of the aspectual basic conceptualisations was presented and illustrated graphically with delimitation schemas. However, only the first level of aspectual delimitation was presented, and the inventory did not include further perspectivisations - such as those that emerge, for example, from the analysis of states of affairs with more complex temporal structures, as they are examined in more detail in this chapter. On the following pages, the individual delimitation schemas of this second level of the model are presented.

First, however, I must explain what exactly is meant by the second level of perspectivisation. Aspectuality has been defined as internal temporal structuring, as the temporal-structuring delimitation of a state of affairs conceived as a situation frame, while the relations between the elements of this frame and between the frame as a whole and its constitutive elements have been defined as relations of contiguity (see $§ 3.2 .3$ on the association principle of contiguity in general). In this context, "temporal-structuring delimitation" has been understood in very general terms as "determination" or "boundary setting”, which - as an internally temporal constituting act of a state of affairs - necessarily emphasises or focusses on some temporal realities over others, which in turn recede into the background (see §4.2).

These focussing operations are recursive, repeatable within the frame, and can therefore occur on several levels. In a state of affairs in which aspectual basic conceptualisations of the following type [externally non-delimited (EA/nd) + not relevant to adjacency (AA/nr) + internally subdivided (IA/s)] are combined - and this represents the first level of focussing within the situation frame - a moment $t_{x}$ or several of the constitutive moments $t_{x 1}, t_{x 2}, \ldots t_{x n}$ of the state of affairs can, for their part, be focussed, and in relation to this/these new boundary setting(s) the three perspectives of aspectuality are newly conceived.

Figures (1) and (2) illustrate this. For practical reasons, the images in both figures summarise the three perspectives of aspectuality (while in §§6.2.2.1-6.2.2.12 all basic conceptualisations are illustrated individually using examples). Figure (1) shows how a single moment $t_{x}$ of the first level of the state of affairs (highlighted 
with an outline) is further focussed on the second level, while Figure (2) represents the further focussing of several moments on the second level:

1st level: DS $2[(E A / n d)+(A A / n r)+(I A / s)]$

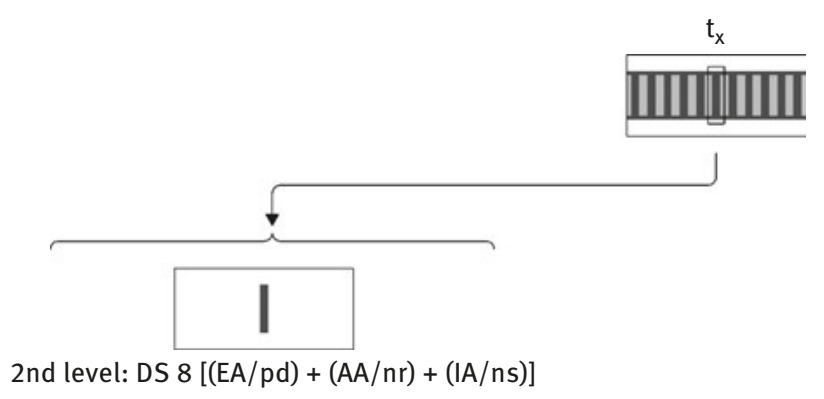

Fig. 1: Second level of focussing, a first example.

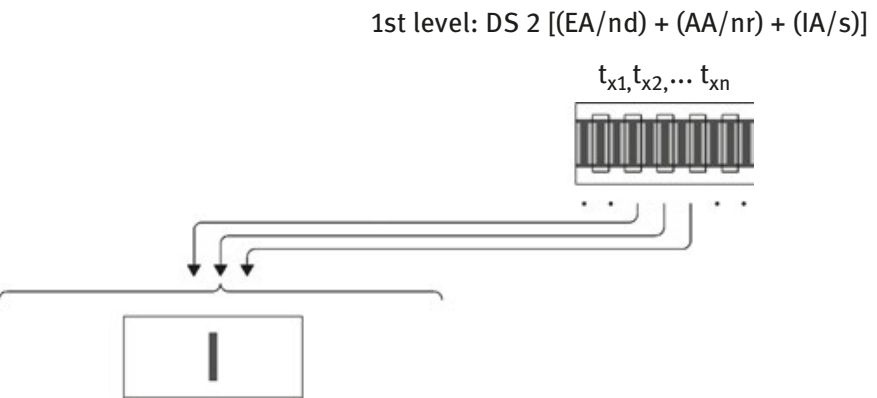

2nd level: $D S$ 8, 8, 8, .. [((EA/pd) + (AA/nr) + (IA/ns)) + ((EA/pd) + (AA/nr) + (IA/ns)) $+((E A / p d)+(A A / n r)+(I A / n s))+\ldots]$

Fig. 2: Second level of focussing, a second example.

These perspectivisations on several levels within the situation frame represent complex temporal structurings of states of affairs, such as the so-called "progressive" aspectual structurings, which need to be analysed in more detail here.

The inventory of second-level aspectual delimitation schemas is thus based on those of the first level, although, logically, only those with pluriphasic situation frames, in other words, those with an internal aspectuality of the type "subdivided" (IA/s), because it is only here that further focussing is possible. Only where different moments $t_{x 1}, t_{x 2}, \ldots t_{x n}$ are perceptible, can they be (individually or severally) further highlighted within the situation frame. 
Table (1) presents those first-level delimitation schemas that are open to further perspectivisation: these were labelled in §5.2.1 as delimitation schemas (DS) 2, 4, 5, 6 and 7. This numbering is also used to denote the combination of delimitation schemas on the two perspectivisation levels - separated by a slash - according to the pattern DS $\mathrm{x} / \mathrm{y}$, where $\mathrm{x}$ represents the delimitation schema of the first level, $\mathrm{y}$ that of the second.

Tab. 1: Inventory of the further perspectivisable delimitation schemas.

\begin{tabular}{|c|c|c|c|}
\hline $\begin{array}{l}\text { External } \\
\text { Aspectuality } \\
\text { (EA) }\end{array}$ & $\begin{array}{l}\text { Adjacency- } \\
\text { related } \\
\text { Aspectuality (AA) }\end{array}$ & $\begin{array}{l}\text { Internal } \\
\text { Aspectuality } \\
\text { (IA) }\end{array}$ & $\begin{array}{l}\text { Delimitation } \\
\text { Schemas (DS) }\end{array}$ \\
\hline $\mathrm{EA} / \mathrm{nd}$ & $\mathrm{AA} / \mathrm{nr}$ & $\mathrm{IA} / \mathrm{s}$ & DS 2 \\
\hline$E A / d$ & $\mathrm{AA} / \mathrm{nr}$ & $\mathrm{IA} / \mathrm{s}$ & DS 4 \\
\hline $\mathrm{EA} / \mathrm{d}$ & $\mathrm{AA} / \mathrm{fr}$ & $\mathrm{IA} / \mathrm{s}$ & DS 5 \\
\hline $\mathrm{EA} / \mathrm{d}$ & $\mathrm{AA} / \mathrm{ir}$ & $\mathrm{IA} / \mathrm{s}$ & DS 6 \\
\hline$E A / d$ & $\mathrm{AA} / \mathrm{tr}$ & $\mathrm{IA} / \mathrm{s}$ & DS 7 \\
\hline
\end{tabular}

In the Romance languages dealt with here, delimitation schemas 2, 4, 5, 6 and 7 are not all equally relevant for the second level of aspectuality, i.e., not all the possible combinations of these DSs are actually realised. They are also not formally realised in the same way in all Romance languages, because, for example, only in Spanish and Catalan can certain aspectual DSs be expressed by verbal periphrases.

In the following paragraphs (§§6.2.2.1-6.2.2.12) I will present the various possibilities of further perspectivisation individually and analyse them in more detail. However, a complete inventory is not provided here, as it was in Chapter 5, for in such a - non-typologically-oriented - classification, there would be too many 
omissions in the various (only partially given) representations of the Romance languages analysed here (which also reflect their various preferences). It is therefore more economical to focus the analysis on the most important and most frequent cases in which aspectuality is expressed on the second level of the model.

This does not imply that it is not possible for other languages to make use of all possible combinations exhaustively, nor that the model presented here is weakened by this, because the complete inventory with the systematisation given here would always be available for any languages that require it.

As in the previous chapters (\$§4.4.3ff. and §§5.2.2ff.), examples from the four Romance languages dealt with are commented on in parallel as far as possible. In these, the content category aspectuality is expressed by different means - lexical and grammatical - and they mostly have different tenses. $^{2}$

\subsubsection{Presentation of the individual delimitation schemas}

\subsubsection{Delimitation Schema 2/8: $[((E A / n d)+(A A / n r)+(I A / s))>((E A / p d)+$} $(\mathrm{AA} / \mathrm{nr})+(\mathrm{IA} / \mathrm{ns}))]$

(1) It. La gatta di Leo sta [Pres.] dormendo profondamente. [stare + Ger.] 'Leo's cat is sleeping deeply.'

(2) Fr. Daniela était [Imp.] en train de parler avec Julien. [être en train de + Inf.] 'Daniela was speaking with Julien.'

(3) Sp. ¡Mira! Juan duerme [Pres.] con un ojo abierto. ${ }^{3}$

'Look! Juan is sleeping with one eye open.'

2 Here, too, information on temporal markings of a deictic nature is given in square brackets within the examples themselves; special periphrastic constructions are noted in square brackets after the examples.

3 Duerme/dormía con un ojo abierto can have two aspectual meanings (see also §5.2.2.2, Delimitation Schema 2: [EA/nd) + (AA/nr) + (IA/s)]) and these are made more or less explicit by the context. The first (shown in Chapter 5) is a temporally absolute meaning (he always sleeps/slept with one eye open); in contrast, the second (the one in question here) expresses the closer observation of a special moment $t_{x}$ of Juan's sleeping. This moment is highlighted within the situation frame, which is already temporally structured on the first level, and further aspectual coordinates of this $t_{x}$ can be determined (i.e., which combination of aspectual basic conceptualisations is represented in relation to this focussed moment). 
(4) Cat. La Rosina estava [Imp.] menjant tranquil·lament. ${ }^{4}$ [estar + Ger.] 'Rosina was eating calmly.'

The states of affairs represented in examples (1)-(4) show a combination of aspectual basic conceptualisations of the following type: ${ }^{5}$

First level:

a) externally non-delimited (EA/nd)

b) not relevant to adjacency $(\mathrm{AA} / \mathrm{nr})$

c) internally subdivided (IA/s)

Second level:

a') externally punctually delimited (EA/pd)

b') not relevant to adjacency $(\mathrm{AA} / \mathrm{nr})$

c') not internally subdivided (IA/ns)

In (1)-(4), on the first level of the combination of aspectual basic conceptualisations, a) neither a starting point $t_{x}$ nor an endpoint $t_{y}$ of the respective entire states of affairs is focussed - i.e., neither the beginning nor the end of the deep sleeping of Leo's cat in (1), of Daniela speaking with Julien in (2), of Juan sleeping with one open eye in (3), or of Rosina's eating in (4). In other words, the state of affairs in question is not presented as a whole and therefore not as completed. Therefore, $b$ ) it is also logically impossible to find any relevance for its adjacency, because there is no initial boundary $t_{x}$ and no final boundary $t_{y}$ of the respective states of affairs, which would allow the constitution of their adjacencies. Finally, c) (substantially) different moments $t_{x 1}, t_{x 2}, \ldots t_{x n}$ can be found in the pluriphasic state of affairs: Leo's cat slept through all these

4 A sentence like La Rosina estava menjant tranquil-la una galeta would have exactly the same delimitation schema. To show once again how the interaction of different elements in the frame leads to different delimitation schemas, it can be compared with the sentence $L a$ Rosina estava menjant tranquil.la galetes, which has a DS $2 / 8,8,8, \ldots$ as in $\S 6.2 .2 .5$. The presence of galetes here in the plural (and without further indicators of definiteness, such as the definite article) influences this reading: the speaker knows from his/her world knowledge that eating several biscuits is an iterated process with a duration, and therefore expresses the state of affairs in this way.

5 The aspectual structuring of states of affairs of this type corresponds to what in traditional studies has been termed "progressive-focalised" (see, among others, Bertinetto 1995a and $\S 6.3 .3$ here). 
moments $t_{x 1}, t_{x 2}, \ldots t_{x n}$ and each of these moments can be viewed and represented individually and in isolation - in each $t_{x 1}$ Leo's cat slept differently (deeper, more lightly, etc.) than in $t_{x 2}$ (likewise, in each $t_{x 1}$ Daniela spoke to Julien further and slightly differently than in $t_{x 2}$, Juan slept differently with one open eye and Rosina ate more or less calmly).

It is exactly this aspect that is the prerequisite for further perspectivisation within the situation frame, for only if it is possible, as is the case here, to set further subdivision points or boundaries in the temporal structuring of the state of affairs, i.e., to set discrete temporal subintervals $t_{x 1}, t_{x 2}, \ldots t_{x n}$, is it also possible to further focus one or more of these subintervals (this was already emphasised above), around which subframes emerge. In (1)-(4) a special $t_{x 1}$ is focussed in each case (a single moment in the sleeping of Leo's cat, in Daniela's speaking with Julien, etc.) and this represents a subframe within the whole frame. The respective subframes in turn represent the following combination of aspectual basic conceptualisations: they are a') externally punctually delimited $(\mathrm{EA} / \mathrm{pd})$ : the beginning and the end of the moment $\mathrm{t}_{\mathrm{x} 1}$ in the sleeping of Leo's cat are evidently focussed, out of which this sleeping is presented, and the beginning and the end coincide (thus it is a $\delta t_{x 1}$ ). In addition, these subframes b') in the states of affairs are not relevant for their adjacencies (AA/nr): the sleeping of Leo's cat and Daniela's speaking with Julien, etc., do not influence their adjacencies, because they determine neither the beginning nor the end of a new state of affairs, nor the beginning or the end of the states of affairs themselves (the sleeping or speaking). Finally, the respective subframes c') are not internally subdivided (IA/ns), as is logically the case with states of affairs of the type EA/pd.

This is formally represented by the strongly grammaticalised periphrastic constructions of the type STARE + gerund in (1) and (4), by être en train de + infinitive in (2) and by the present tense in (3) (supported by further elements such as imira!, which excludes a generic reading here), in combination with the verbs 'to sleep', 'to speak' and 'to eat' and their respective first arguments (la gatta di Leo, Daniela, Juan and Rosina). This type of combination of aspectual basic conceptualisations can be illustrated as in Table (2): 
Tab. 2: $D S$ 2/8: $[((E A / n d)+(A A / n r)+(I A / s))>((E A / p d)+(A A / n r)+(I A / n s))]$.

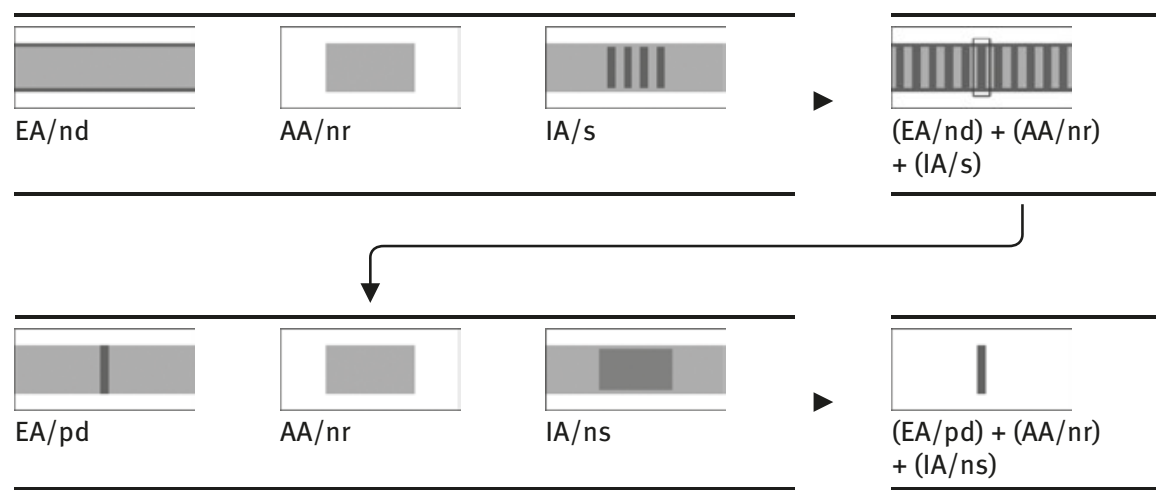

6.2.2.2 Delimitation Schema 2/9: $[((E A / n d)+(A A / n r)+(I A / s))>((E A / p d)+$ $(\mathrm{AA} / \mathrm{fr})+(\mathrm{IA} / \mathrm{ns}))]$

(5) It. Leo sta [Pres.] tornando a casa dal primo giorno di scuola. [stare + Ger.] 'Leo is coming home from his first day at school.'

(6) Fr. Julie est [Prés.] en train de terminer sa thèse de doctorat. [être en train de + Inf.]

'Julie is (currently) finishing her doctoral thesis.'

(7) Sp. Juan regresaba [Imp.] a su país, cuando lo encontré en el tren. 'Juan was returning to his country, when I met him on the train.'

(8) Cat. El dia estava [Imp.] morint lentament. [estar + Ger.] 'The day was slowly dying.'

The states of affairs represented in examples (5)-(8) have the following combination of aspectual basic conceptualisations:

First level:

a) externally non-delimited (EA/nd)

b) not relevant to adjacency (AA/nr)

c) internally subdivided (IA/s) 


\section{Second level:}

a') externally punctually delimited (EA/pd)

b') with final adjacency relevance (AA/fr)

c') not internally subdivided (IA/ns)

In (5)-(8), on the first level of the combination of aspectual basic conceptualisations, a) neither a starting point $t_{x}$ nor an endpoint $t_{y}$ of the respective entire states of affairs is focussed - i.e., neither the beginning nor the end of Leo's coming home in (5), of Julie's finishing her doctoral thesis in (6), of Juan's returning in (7) or of the slow dying of the day in (8) -, so that the respective states of affairs are presented as not completed. Therefore, b) these states of affairs are irrelevant for their adjacencies (since there are no initial and final boundaries $t_{x}$ and $t_{y}$ of the states of affairs themselves, which would allow the constitution of their adjacencies). Finally, c) substantially different moments $t_{x 1}, t_{x 2}, \ldots t_{x n}$ can be found here, i.e., it is possible to identify discrete temporal subintervals in Leo's coming home (in each of which he comes home), in Julie's finishing her work, in Juan's returning and in the slow dying of the day.

The realisation of internal aspectuality within the situation frame is the prerequisite for further perspectivisation: of the various $t_{x 1}, t_{x 2}, \ldots t_{x n}$ in Leo's coming home in (5) a particular $t_{\mathrm{x} 1}$ is further focussed (as well as a single moment in Julie's finishing her work in (6), in Juan's returning in (7) and in the slow dying of the day in (8)). This $t_{x 1}$ represents a temporal boundary around which a subframe is formed within the entire frame, which expresses the following combination of aspectual basic conceptualisations: the subframes are a') externally punctually delimited (EA/pd): the focus is on the beginning and the end of the moment $t_{x 1}$ in Leo's coming home, from the perspective of which this coming home is represented, and these moments coincide (thus it is a $\delta t_{x 1}$ ). The subframes have b') final adjacency relevance (AA/fr): the $t_{x 1}$ in Leo's coming home, which is focussed (as is the $t_{x 1}$ in Julie finishing her work or in the slow dying of the day), influences its previous adjacency (here $t_{x 1-1}$, the moment before that which is focussed) by determining its end (the end of the previous adjacency of the subframe, that is, not that of the whole state of affairs). In the focussed $t_{x 1}$, Leo is closer to his final coming home than in $t_{x 1-1}$. It is precisely this realisation of the adjacency reference that denotes the dynamicity within the situation frame. Finally, the subframes c') are not internally subdivided (IA/ $\mathrm{ns),} \mathrm{as} \mathrm{is} \mathrm{logical} \mathrm{for} \mathrm{states} \mathrm{of} \mathrm{affairs} \mathrm{with} \mathrm{EA/pd.}$

The aspectual content described here is conveyed by verbal periphrases of the type STARE + gerund in (5) and (8) (with the auxiliary verb in the present tense and the imperfect, respectively) and the type être en train de + infinitive in (6) (with the auxiliary verb in the present tense), and by the imperfect in (7) 
in combination with the verbs 'to come home', 'to finish the dissertation', 'to return' and 'to die' (and their respective first and, in part, further arguments). This type of delimitation schema (2/9) can be illustrated as in Table (3):

Tab. 3: $D S 2 / 9[((E A / n d)+(A A / n r)+(I A / s))>((E A / p d)+(A A / f r)+(I A / n s))]$.

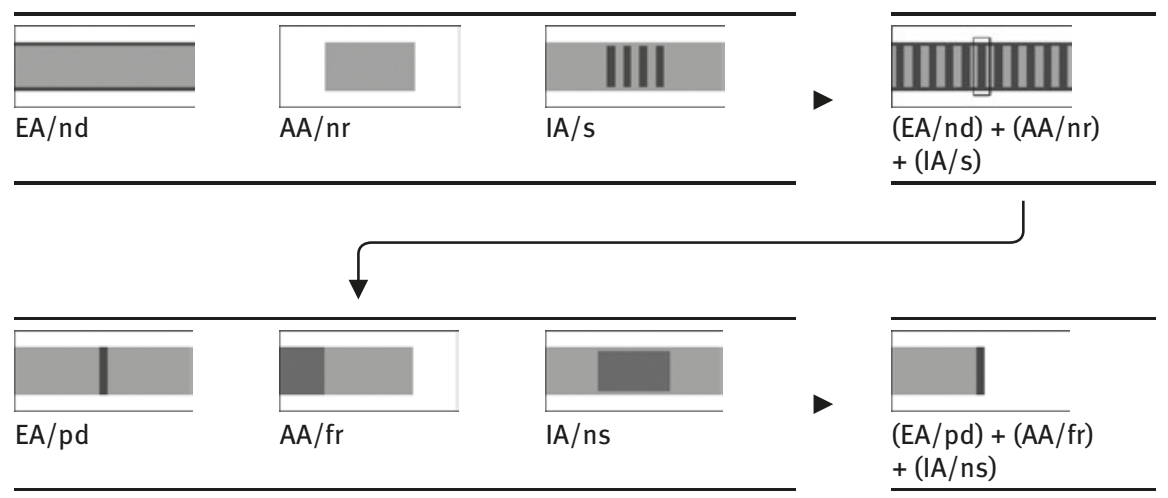

6.2.2.3 Delimitation Schema 2/10: $[((E A / n d)+(A A / n r)+(I A / s))>((E A / p d)+$ $(A A / i r)+(I A / n s))]$

(9) It. Leo sta [Pres.] partendo per l'Italia. [stare + Ger.]

'Leo is leaving for Italy.'

(10) Fr. Elle était $[\mathrm{Imp}$.$] en train de quitter son bureau. [être en train de + Inf.]$ 'She was leaving her office.'

(11) Sp. Juan salía [Imp.] para Córdoba, cuando lo encontré en la estación. 'Juan was leaving for Cordoba, when I met him at the station.'

(12) Cat. La lluna estava [Imp.] sortint. [estar + Ger.] 'The moon was rising.'

The states of affairs in examples (9)-(12) represent a combination of aspectual basic conceptualisations of the following type: 
First level:

a) externally non-delimited (EA/nd)

b) not relevant to adjacency $(\mathrm{AA} / \mathrm{nr})$

c) internally subdivided (IA/s)

Second level:

a') externally punctually delimited (EA/pd)

b') with initial adjacency relevance (AA/ir)

c') not internally subdivided (IA/ns)

In (9)-(12), on the first level of the combination of aspectual basic conceptualisations, a) neither a starting point $t_{x}$ nor an endpoint $t_{y}$ of the respective entire states of affairs is focussed - i.e., neither the beginning nor the end of Leo's and Juan's departure in (9) and (11), the leaving of the office in (10) or the rising of the moon in (12) -, so that the respective states of affairs are represented as not completed. Therefore, b) this type of state of affairs is irrelevant for its adjacency. Finally, c) different moments $t_{x 1}, t_{x 2}, \ldots t_{x n}$, specific temporal subintervals, in Leo's and Juan's departure in (9) and in (11), the leaving of the office in (10) and the rising of the moon in (12) can be identified.

The realisation of internal aspectuality within the situation frame is - and this has been clarified several times - the prerequisite for further perspectivisation. Of the various $t_{x 1}, t_{x 2}, \ldots t_{x n}$ in Leo's and Juan's departure in (9) and (11), a particular $t_{x 1}$ is focussed, as is a single moment in the leaving of the office in (10) and in the rising of the moon in (12). This $t_{x 1}$ represents a temporal boundary around which a subframe is formed within the entire frame.

The combination of aspectual basic conceptualisations is expressed as follows: the respective subframes are a') externally punctually delimited (EA/pd): the beginning and the end of the moment $t_{x 1}$ in Leo's departure, out of which this departure itself is presented, are focussed, and these boundaries coincide.

The respective subframes have b') initial adjacency relevance (AA/ir): the $t_{x 1}$ in Leo's and Juan's departure that is focussed (as is the $t_{x 1}$ in Julie's leaving her office, etc.), influences its subsequent adjacency (here $t_{x 1+1}$, i.e., the moment after the focussed one) by determining its beginning (the beginning of the subsequent adjacency of the subframe, that is, not of the whole state of affairs). In the focussed $t_{x 1}$ Leo is closer to his departure from home than in $t_{x 1+1}$. The dynamicity in the situation frame is represented precisely by this realisation of the adjacency reference.

Finally, the respective subframes c') are not internally subdivided (IA/ns), as is logical for states of affairs with EA/pd. The aspectual contents described are conveyed as follows: by verbal periphrases of the type STARE + gerund in (9) 
and (12) (with the auxiliary verb in the present tense and the imperfect, respectively) or the type être en train de + infinitive in (10) (with the auxiliary verb in the imperfect), or by the imperfect in (11) in combination with the verbs 'to leave for Italy (or Cordoba)', 'to leave the office', and 'to rise' (and their respective first and, in part, further arguments). The role of the subordinate clause cuando lo encontré en la estación in (11) seems to be particularly important in order to disambiguate the interpretation of the entire situation frame: the moment of the meeting at the station is also the precise moment of the main clause Juan salía para Córdoba that is highlighted and further focussed.

Table (4) illustrates this combination of basic conceptualisations (DS 2/10):

Tab. 4: DS 2/10: $[((E A / n d)+(A A / n r)+(I A / s))>((E A / p d)+(A A / i r)+(I A / n s))]$.

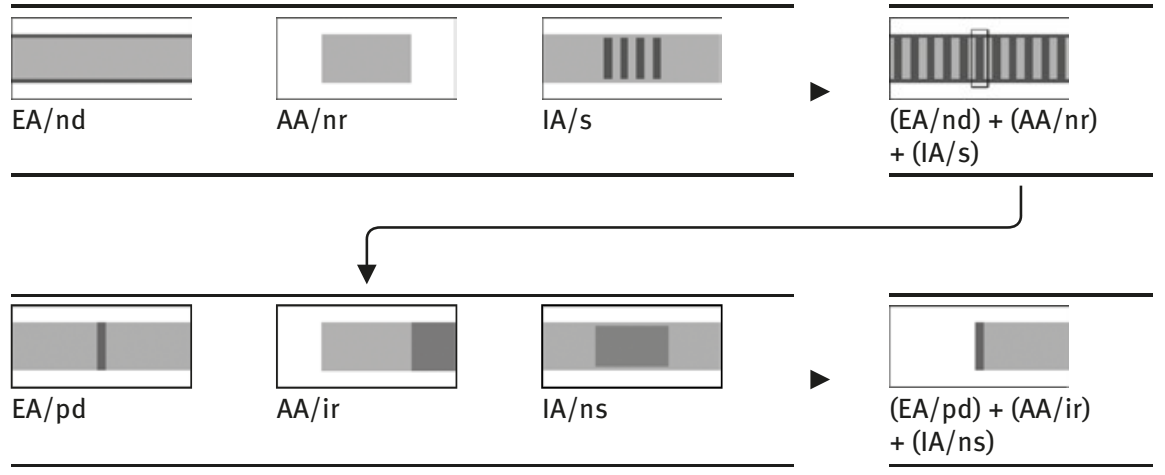

\subsubsection{Delimitation Schema 2/11: $[((E A / n d)+(A A / n r)+(I A / s))>((E A / p d)+$ $(\mathrm{AA} / \mathrm{tr})+(\mathrm{IA} / \mathrm{ns}))]$}

(13) It. Guarda: il fuoco d'artificio sta [Pres.] esplodendo nel cielo! [stare + Ger.] 'Look: the firework is exploding in the sky!'

(14) Fr. La guerre éclatait [Imp.] de partout, quand il naquit.

'War was breaking out everywhere, when he was born.'

(15) Sp. La bailarina estaba [Imp.] enrojeciendo de repente por culpa de su maestra, cuando la vi la primera vez. [estar + Ger.]

'The dancer was suddenly blushing because of her teacher, when I saw her for the first time.' 
(16) Cat. Vaig conèixer en Xavier en el moment que s'enamorava [Imp.] perdudament del mar.

'I met Xavier at the moment he was falling hopelessly in love with the sea.'

The states of affairs in examples (13)-(16) represent a combination of aspectual basic conceptualisations of the following type:

First level:

a) externally non-delimited (EA/nd)

b) not relevant to adjacency $(\mathrm{AA} / \mathrm{nr})$

c) internally subdivided (IA/s)

Second level:

a') externally punctually delimited (EA/pd)

b') with initial and final (transformative) adjacency relevance (AA/tr)

c') not internally subdivided (IA/ns)

Before analysing the above cases, I will discuss an objection that could be raised against examples (13) and (14) from the perspective of the traditional bidimensional interpretation of aspectuality. In §5.2.2.11 (Delimitation Schema 11), example (41) (It. Il palloncino esplose improvvisamente provocando il pianto dei bambini) was presented as an expression of a type of state of affairs with the following combination of aspectual basic conceptualisations: [(EA/pd) + (AA/tr) + (IA/ns)]. Now, how can a state of affairs expressing external aspectuality of the type punctual be further perspectivised, when it is only where $t_{x 1}, t_{x 2}, \ldots t_{x n}$ are perceptible that one or several of them can be highlighted within the situation frame? The reason is simple: that a state of affairs represents a special combination of aspectual basic conceptualisations is related to the convergence, the interaction or interdependence of different elements in this situation frame. It does not depend exclusively - as is assumed from the perspective of verb classification, which also separates aspect (markings) and Aktionsart - on the semantic (lexical) meaning of an aspectual nature (which is called Aktionsart) of the verb itself, independent of the context of use. The polysemous verb esplodere expresses external aspectuality of the type punctual only if it occurs in combination with elements such as those in (41), DS 11, §5.2.2.11. But when it appears in a situation frame like that in (13), it takes on another of its possible meanings and a different delimitation schema. This requires more detailed analysis.

In (13)-(16), on the first level of the combination of aspectual basic conceptualisations, a) neither a starting point $t_{x}$ nor an endpoint $t_{y}$ of the respective 
entire states of affairs is focussed - i.e., neither the beginning nor the end of the exploding of the firework in (13), the breaking out of war in (14), the blushing of the dancer in (15) or the falling in love of Xavier in (16) -, so that the respective states of affairs are represented as not completed. This type of state of affairs is therefore b) irrelevant to its adjacency. Finally, c) different, consecutive $t_{x 1}, t_{x 2}, \ldots t_{x n}$, discrete temporal subintervals, can be perceived in the exploding of the firework in (13) (as well as in the breaking out of war, the blushing of the dancer or the falling in love of Xavier), because the 'exploding of a firework' is also anchored in the speaker's world knowledge with a certain duration, as is the breaking out of war with its temporal graduality.

It is precisely this realisation of internal aspectuality (IA/s) that constitutes the prerequisite for further perspectivisation within the situation frame. Of the different $t_{x 1}, t_{x 2}, \ldots t_{x n}$ in the exploding of the firework (and in the breaking out of war, etc.) a special $t_{x 1}$ is further focussed, so that we could speak of a "zoom effect". Around this $t_{x 1}$, a subframe is formed with the following combination of aspectual basic conceptualisations: the subframe is a') externally punctually delimited (EA/pd): the beginning and the end of the moment $t_{x 1}$ in the exploding of the firework, from which this exploding itself is depicted, are prominently in focus and these boundaries coincide. The subframe has b') transformative adjacency relevance (AA/tr): the $t_{x 1}$ in the exploding of the firework (and in the breaking out of war, the blushing of the dancer or the falling in love of Xavier), which is focussed, influences its previous and subsequent adjacencies (these are labelled $t_{x 1-1}$ and $t_{x 1+1}$, respectively, the moment before and the moment after the focussed $t_{x 1}$ ) by determining, respectively, their end and their beginning. The focussed $t_{x 1}$ in (13) is a moment in an explosion of a firework which does not yet exist in $t_{x 1-1}$ and no longer exists in $t_{x 1+1}$. Finally, the respective subframes c') are not internally subdivided (IA/ns), since they are subframes with EA/pd. The aspectual contents described are conveyed by the following different forms: verbal periphrases of the type STARE + gerund in (13) and (15) (with the auxiliary verb in the present tense and imperfect, respectively), and by the imperfect in (14) and (16) in combination with the verbs 'to explode', 'to break out', 'to blush' and 'to fall in love' (and their first and, in part, further arguments) and with the connectors quand and cuando. The role of the elements guarda in (13), quand il naquit in (14), cuando la vi la primera vez in (15) and en el moment que s'enamorava del mar in (16) is also very important, as they disambiguate the interpretation of the entire situation frame: the moment in which the speaker demands the attention of the hearer by means of guarda, the moment of the birth, of the first encounter and the moment in which he 
fell in love with the sea, represent a precise moment, highlighted within the main clause, which is further focussed.

Table (5) illustrates this delimitation schema (2/11):

Tab. 5: $D S$ 2/11: $[((E A / n d)+(A A / n r)+(I A / s))>((E A / p d)+(A A / t r)+(I A / n s))]$.

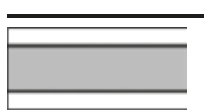

$\mathrm{EA} / \mathrm{nd}$

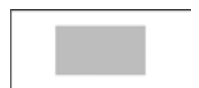

$\mathrm{AA} / \mathrm{nr}$

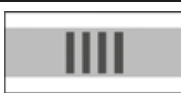

$\mathrm{IA} / \mathrm{s}$

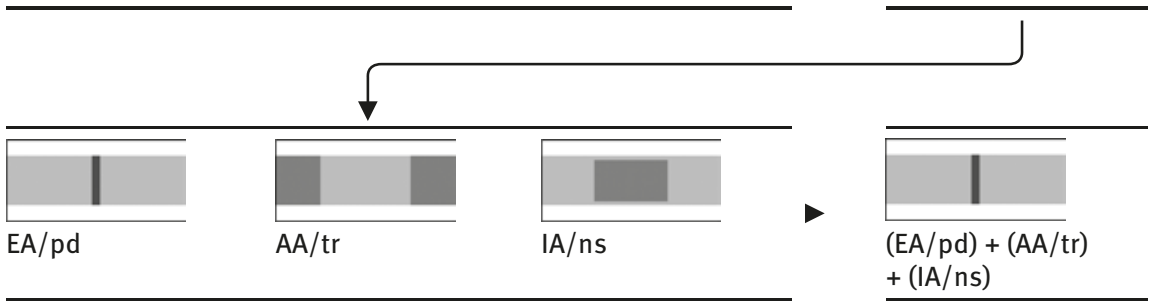

\subsubsection{Delimitation Schema 2/8, 8, 8, ...: [((EA/nd) + (AA/nr) + (IA/s)) >} $((E A / p d)+(A A / n r)+(I A / n s)),((E A / p d)+(A A / n r)+(I A / n s)),((E A / p d)+$ $(A A / n r)+(I A / n s)), \ldots]$

(17) It. Guardai dalla finestra e vidi la pioggia che stava [Imp.] cadendo. ${ }^{6}$ [stare + Ger. $]$

'I looked out the window and saw the rain that was falling.'

6 This example is particularly suitable for further investigation of a question already addressed in \$3.5, where the following examples were compared: (11) It. La pioggia cade leggera sulla terra and (11') It. Il sasso cade pesantemente nell'acqua. So far, the examples have been commented according to traditional terminology. Now, these can be described according to the model presented here: while states of affairs such as those in (11) represent a DS of the type $2 / 8,8,8 \ldots$, i.e., a combination of the following aspectual basic conceptualisations: $[((\mathrm{EA} / \mathrm{nd})+(\mathrm{AA} / \mathrm{nr})+(\mathrm{IA} / \mathrm{s}))>$ $((\mathrm{EA} / \mathrm{pd})+(\mathrm{AA} / \mathrm{nr})+(\mathrm{IA} / \mathrm{ns})),((\mathrm{EA} / \mathrm{pd})+(\mathrm{AA} / \mathrm{nr})+(\mathrm{IA} / \mathrm{ns})),((\mathrm{EA} / \mathrm{pd})+(\mathrm{AA} / \mathrm{nr})+(\mathrm{IA} / \mathrm{ns})), \ldots]$, those such as in (11') represent a DS of the type $2 / 8$, i.e., with the combination $[((\mathrm{EA} / \mathrm{nd})+(\mathrm{AA} / \mathrm{nr})$ $+(\mathrm{IA} / \mathrm{s}))>((\mathrm{EA} / \mathrm{pd})+(\mathrm{AA} / \mathrm{nr})+(\mathrm{IA} / \mathrm{ns}))]$. Of course, different elements contribute to this, not least the first arguments in the sentences ('rain' and 'stone', respectively): the speaker has learned in two different experiential contexts that the temporal (aspectual) meaning of 'to fall' in connection with 'rain' has durative and iterative traits (the rain falls continuously over time, because 'rain' is a collective noun that subsumes countable entities), whereas in connection with 'stone' it conveys punctuality. 
(18) Fr. Le voleur était [Imp.] en train de préparer le plan de braquage de la banque depuis longtemps. [être en train de + Inf.]

'The thief had been preparing the plan for the bank robbery for a long time.'

(19) Sp. Juan anda [Pres.] haciendo cosas que no puedo impedir. [andar + Ger.] 'Juan is going around doing things that I cannot prevent.'

(20) Cat. Fa tres hores que el Leo estava [Imp.] menjant galetes. [estar + Ger.] 'Leo's been eating biscuits for three hours.'

The states of affairs in examples (17)-(20) represent the following combination of aspectual basic conceptualisations: ${ }^{7}$

First level:

a) externally non-delimited (EA/nd)

b) not relevant to adjacency $(\mathrm{AA} / \mathrm{nr})$

c) internally subdivided (IA/s)

Second level:

a') externally punctually delimited (EA/pd)

b') not relevant to adjacency (AA/nr)

c') not internally subdivided (IA/ns)

a”) externally punctually delimited (EA/pd)

b’) not relevant to adjacency (AA/nr)

c") not internally subdivided (IA/ns)

a”’) externally punctually delimited (EA/pd)

b"’') not relevant to adjacency (AA/nr)

c",') not internally subdivided (IA/ns)

a",’) $\ldots$

7 The aspectual structuring of states of affairs of this type corresponds to what is called "progressive-durative" in traditional studies (see Bertinetto 1995a, among others). This delimitation schema, in which quantity also plays a role due to the multiple focussing of different moments $t_{x 1}, t_{x 2}, \ldots t_{x n}$, is also suitable for describing iteration in states of affairs. That not only pure iteration but also habit can be represented in the state of affairs has nothing to do with the purely temporal structure of the state of affairs, so this is not only related to aspectuality and quantity. 
In (17)-(20), on the first level of the combination of aspectual basic conceptualisations, a) neither a starting point $t_{x}$ nor an endpoint $t_{y}$ of the respective entire states of affairs is focussed - i.e., neither the beginning nor the end of the falling of the rain in (17), of the preparation of the plan for the bank robbery in (18), of Juan's repeatedly doing things that I cannot prevent in (19), or of Leo's eating biscuits for three hours in (20). In other words, the respective states of affairs are not presented as completed. Therefore, b) it is logically impossible to find relevance for their adjacencies. Finally, c) (substantially) different moments $t_{x 1}$, $t_{x 2}, \ldots t_{x n}$ can be perceived in (17) in the falling of the rain. The rain fell in all these $t_{x 1}, t_{x 2}, \ldots t_{x n}$ and each of these moments can be viewed and represented individually and in isolation, i.e., in each $t_{x 1}$ the rain fell differently (stronger, lighter etc.) than in $t_{x 2}$, and the same can be said for the preparation of the plan for the bank robbery in (18) and for the states of affairs in (19) and (20).

Here, too, it is precisely this realisation of internal aspectuality of the entire state of affairs that is the prerequisite for further perspectivisation within the situation frame, because only if, as is the case here, further subdivision points or boundaries in the temporal structuring of the state of affairs can be set, only if discrete temporal subintervals $t_{x 1}, t_{x 2}, \ldots t_{x n}$ can be perceived, will it be possible to further focus one or - as is the case in (17)-(20) - several such subintervals. That several - but each separately $-t_{x 1}, t_{x 2}, \ldots t_{x n}$ are further focussed in the state of affairs, and that each of these moments sets temporal boundaries around which a subframe is formed within the entire frame, reflects the structuring of an iterated state of affairs, because, as we will see, each $t_{\mathrm{x} 1}$ is represented as a subframe with delimited aspectuality, i.e., as completed, and the next $t_{x 2}$ can only be a new subframe (also represented as completed). ${ }^{8}$ Speakers know from their world knowledge that rain is a collective noun consisting of individual drops that fall individually to the ground, and when the falling of rain is represented as in (17), then it is done in such a way that the (several, iterated) individual moments of falling are themselves focussed in the state of affairs presented as a whole. These moments, around each of which a subframe is formed with reference to the entire state of affairs, are now characterised by a') external punctual aspectuality (EA/pd), b') no adjacency relevance (AA/nr) and c') no subdivision of their internal aspectuality (IA/ns). Every moment $t_{\mathrm{x} 1}$, $t_{x 2}, \ldots t_{x n}$ of the falling of the rain is focussed along with its boundaries (thus we have different $\left.\delta t_{x 1}, \delta t_{x 2}, \ldots \delta t_{x n}\right)$; no fallen drop of rain determines the

8 DS $2 / 8,8,8, \ldots-$ DS $7 / 11,11,11, \ldots$ are cases which are traditionally treated as degree achievement; see also §5.2.2.6. 
beginning nor the end of the rain ( $t_{x 1}$ does not affect $t_{x 1-1}$ or $t_{x 1+1}$ in any way); nor can any $\delta t_{x 1}, \delta t_{x 2}, \ldots \delta t_{x n}$, in which the rain has fallen, be internally subdivided either. The situation is similar in (18), where in the state of affairs presented as a whole the individual - multiple - moments of preparation for the bank robbery are presented and each is further focussed, or in (19), where Juan's doing things that the speaker cannot prevent is also presented in its individual constitutive, further focussed moments.

The aspectual contents described are conveyed here by the following different forms: verbal periphrases of the type STARE + gerund in (17) and (20) or of the type être en train de + infinitive in (18) (with the auxiliary verb in the imperfect), or by the special verb periphrasis, common only in Spanish, andar + gerund in (19) (with the auxiliary verb in the present tense) in combination with the verbs 'falling of the rain', 'preparing a plan', 'doing things' and 'eating biscuits' (and their first and, in part, further arguments). An important role is played here by the arguments cosas in (19) and galetes in (20) appearing in the plural and without definite articles. Table (6) illustrates this delimitation schema $(2 / 8,8,8, \ldots)$ :

Tab. 6: Delimitation Schema 2/8, 8, 8, . . : $[((E A / n d)+(A A / n r)+(I A / s))>((E A / p d)+(A A / n r)+$ $(I A / n s)),((E A / p d)+(A A / n r)+(I A / n s)),((E A / p d)+(A A / n r)+(I A / n s)), \ldots]$.

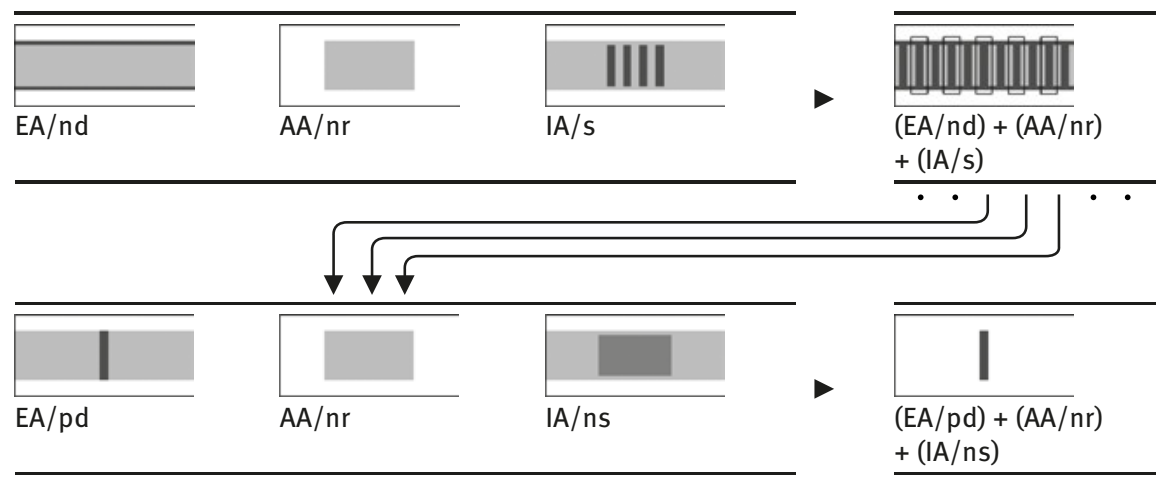

6.2.2.6 Delimitation Schema 2/9, 9, 9, ...: [((EA/nd) + (AA/nr) + (IA/s)) > $((E A / p d)+(A A / f r)+(I A / n s)),((E A / p d)+(A A / f r)+(I A / n s)),((E A / p d)+$ $(\mathrm{AA} / \mathrm{fr})+(\mathrm{IA} / \mathrm{ns})), \ldots .$.

(21) It. Il giudice viene [Pres.] raccogliendo prove contro l'imputato. [venire + Ger.] 'The judge has been going about gathering evidence against the defendant.' 
(22) Fr. Je viens [Prés.] ramassant mes affaires depuis un mois. ${ }^{9}$ [venir + Ger.] 'I have been gathering my things for a month.'

(23) Sp. Te lo vengo [Pres.] diciendo desde el principio. [venir + Ger.] 'I've been telling you this from the beginning.'

(24) Cat. Fa molt de temps que vinc [Pres.] parlant d'aquest problema. [venir + Ger.] 'I have been talking about this problem for a long time.'

The states of affairs in examples (21)-(24) represent the following combination of aspectual basic conceptualisations (for reasons of space only one $t_{x 1}$ of the sublevel is shown here by way of example):

First level:

a) externally non-delimited (EA/nd)

b) not relevant to adjacency $(\mathrm{AA} / \mathrm{nr})$

c) internally subdivided (IA/s)

Second level:

a') externally punctually delimited (EA/pd)

b') with final adjacency relevance (AA/fr)

c') not internally subdivided (IA/ns)

a’) $\ldots$

In (21)-(24), on the first level of the combination of aspectual basic conceptualisations, a) neither a starting point $t_{x}$ nor an endpoint $t_{y}$ of the respective entire states of affairs is focussed - i.e., neither the beginning nor the end of the judge gathering (pieces of) evidence in (21), the gathering of my things in (22), the fact that I've been telling you this since the beginning in (23) or that I've been

9 Coseriu (1976) and Schwall (1991), referring to Coseriu, point out that this type of verbal periphrasis is used in this way in Modern French, but also that it is extremely rare. Attention has already been drawn to the fact that the frequency of this verbal periphrasis had already drastically decreased by the Middle French period. A corpus-oriented study would offer insights into current usage and would therefore be highly desirable. On French verbal periphrases in general see Gougenheim (1929) and also Laca (2004a), Mitko (1999 and 2000) and Pusch (2003a); on French verbal periphrases in previous stages of the language see Werner (1980). 
talking about this problem for some time in (24). In other words, each of these entire states of affairs is presented as not completed. Therefore, it is logically impossible b) to find the relevance of this type of state of affairs for its adjacency. Finally, c) in the gathering of evidence in (21) (substantially) different moments $t_{x 1}, t_{x 2}, \ldots t_{x n}$ can be perceived, and the judge gathers different pieces of evidence in all these $t_{x 1}, t_{x 2}, \ldots t_{x n}$ and each of these moments can be viewed and represented individually and in isolation, i.e., in each $t_{x 1}$ the gathering is different than in $t_{x 2}$ and the same can be said for my gathering in (22) and for the pluriphasic states of affairs in (23) and (24).

It is precisely this realisation of internal aspectuality of the entire state of affairs that is the prerequisite for further perspectivisation within the situation frame. Here, too, it is possible to further focus one or several temporal subintervals $t_{x 1}, t_{x 2}, \ldots t_{x n}$. That each of these $t_{x 1}, t_{x 2}, \ldots t_{x n}$ represents a temporal boundary around which a subframe is formed within the entire frame reflects the structuring of an iterated state of affairs (the speaker knows from his/her knowledge of the world that the gathering of evidence consists in the repeated gathering of individual pieces of evidence and represents this by means of this aspectual structuring). Each of these subframes expresses the following combination of aspectual basic conceptualisations: it is a') externally punctually delimited (EA/pd), the initial and final boundaries of each $t_{x 1}, t_{x 2}, \ldots t_{x n}$ in which the judge collects evidence against the defendant are focussed and these boundaries coincide (thus, they represent different $\delta \mathrm{t}_{\mathrm{x} 1}, \delta \mathrm{t}_{\mathrm{x} 2}, \ldots \delta \mathrm{t}_{\mathrm{xn}}$ ); every single moment $t_{x 1}$ of gathering evidence has $b$ ') final adjacency relevance (AA/fr), i.e., it influences its previous adjacency $\left(t_{x 1-1}\right)$ by determining its end (the end of the previous adjacency of the subframe, that is, not that of the entire state of affairs); finally, each $\delta t_{x 1}, \delta t_{x 2}, \ldots \delta t_{x n}$ in which the judge has collected evidence is c') not internally subdivided. The states of affairs in (22)-(24) can be analysed similarly. The aspectual contents described are here conveyed by the following forms: verbal periphrases of the type VENIRE + gerund in (21)-(24) (with the auxiliary verbs in the present tense) in combination with the verbs 'to gather evidence', 'to gather my things', 'to tell' and 'to talk about this problem' (and their first and, in part, further arguments). Table (7) illustrates this delimitation schema $(2 / 9,9,9, \ldots)$ : 
Tab. 7: $D S 2 / 9,9,9, \ldots:[((E A / n d)+(A A / n r)+(I A / s))>((E A / p d)+(A A / f r)+(I A / n s)),((E A / p d)+$ $(A A / f r)+(I A / n s)),((E A / p d)+(A A / f r)+(I A / n s)), \ldots]$.

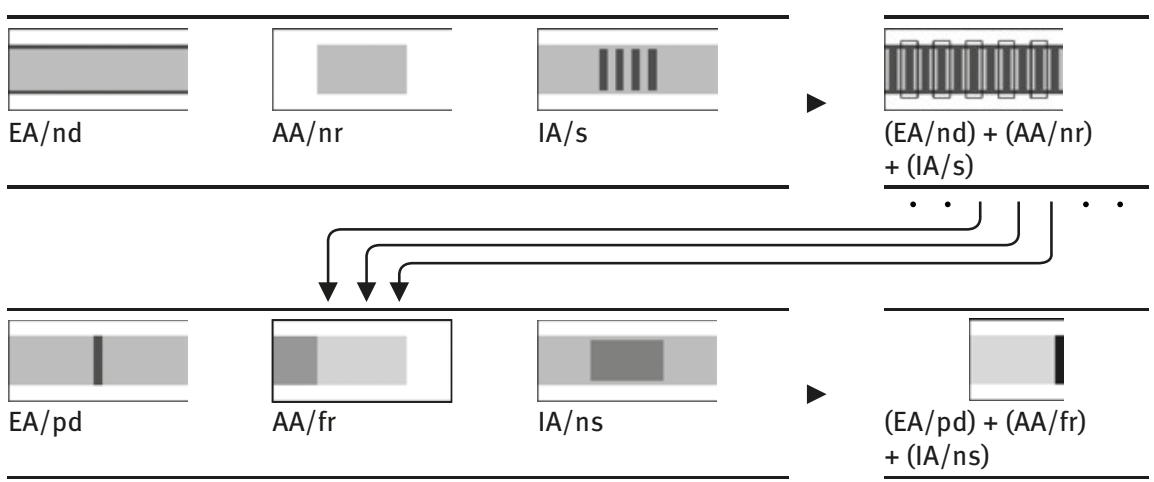

6.2.2.7 Delimitation Schema 2/10, 10, 10, ...: $[((E A / n d)+(A A / n r)+(I A / s))>$ $((E A / p d)+(A A / i r)+(I A / n s)),((E A / p d)+(A A / i r)+(I A / n s)),((E A / p d)+$ $(\mathrm{AA} / \mathrm{ir})+(\mathrm{IA} / \mathrm{ns})), . .$.

(25) It. Te lo vado [Pres.] dicendo da mesi! [andare + Ger.] 'I’ve been telling you that for months!'

(26) Fr. Tout doucement, il va [Prés.] s'approchant de la fenêtre. [aller + Ger.] 'Very slowly, he's been making his way towards the window.'

(27) Sp. La tormenta se va [Pres.] acercando más y más. [ir + Ger.] 'The storm is getting closer and closer.'

(28) Cat. Els grups parlamentaris s'anaven [Pres.] asseient a la taula de treball. [anar + Ger.]

'The groups of parliamentarians have been sitting at the negotiating table.'

The states of affairs in examples (25)-(28) represent the following combination of aspectual basic conceptualisations:

First level:

a) externally non-delimited (EA/nd)

b) not relevant to adjacency $(\mathrm{AA} / \mathrm{nr})$

c) internally subdivided (IA/s) 
Second level:

a') externally punctually delimited (EA/pd)

b') with initial adjacency relevance (AA/ir)

c') not internally subdivided (IA/ns)

a’) $\ldots$

In (25)-(28), on the first level of the combination of aspectual basic conceptualisations, a) neither a starting point $t_{x}$ nor an endpoint $t_{y}$ of the respective entire states of affairs is focussed - i.e., neither the beginning nor the end of my telling you about it in (25), of his making his way to the window in (26), of the storm approaching in (27), or of the parliamentarians' sitting at the negotiating table in (28). The respective entire states of affairs (thus presented as not completed) therefore b) do not have relevance for their respective adjacencies. Finally, c) (substantially) different moments $t_{x 1}, t_{x 2}, \ldots t_{x n}$ can be perceived in the approaching of the storm in (27) and each of these moments can be viewed and represented individually and in isolation, i.e., in $t_{x 1}$ the storm is approaching differently to $t_{x 2}$, and the same can be said for the pluriphasic states of affairs in (25), (26) and (28).

It is precisely this realisation of internal aspectuality of the entire state of affairs that is the prerequisite for further perspectivisation within the situation frame. In (25)-(28) several temporal divisions $t_{x 1}, t_{x 2}, \ldots t_{x n}$ are further focussed, and around each of these $t_{x 1}, t_{x 2}, \ldots t_{x n}$ a subframe is formed within the whole frame (an iterated state of affairs is presented in each case, as explained in more detail above). Each of these subframes expresses the following combination of aspectual basic conceptualisations: they are a') externally punctually delimited (EA/pd), the initial and final boundaries of all the $t_{x 1}, t_{x 2}, \ldots t_{x n}$ in which, for example, the storm approaches in (27) are focussed and these boundaries coincide (and are therefore different $\delta \mathrm{t}_{\mathrm{x} 1}, \delta \mathrm{t}_{\mathrm{x} 2}, \ldots \delta \mathrm{t}_{\mathrm{xn}}$ ). Every single moment $t_{x 1}$ of the approaching of the storm has b') initial adjacency relevance (AA/ir), that is, it influences its subsequent adjacency $t_{x 1+1}$ by determining its beginning (again, of course, only the beginning of the subframe, not the beginning of the subsequent adjacency of the whole state of affairs). In each $t_{x 1+1}$, $t_{x 2+1}, \ldots t_{x n+1}$ the storm is closer than in each $t_{x 1}, t_{x 2}, \ldots t_{x n}$. Finally, each moment $\delta t_{x 1}, \delta t_{x 2}, \ldots \delta t_{x n}$ in which the storm is approaching is $\left.c^{\prime}\right)$ not internally subdivided. The states of affairs in (25), (26) and (28) can be analysed likewise.

The aspectual contents described above are conveyed through the following forms: verbal periphrases of the type VADERE + gerund in (25)-(28) (with the auxiliary verb in the present tense in all cases) in combination with the verbs 'to say for months', 'to make his way to the window', 'to approach', and 'to sit 
at the table' (and their first and, in part, further arguments). Table (8) illustrates this delimitation schema $(2 / 10,10,10, \ldots)$ :

Tab. 8: $D S 2 / 10,10,10 \ldots:[((E A / n d)+(A A / n r)+(I A / s))>((E A / p d)+(A A / i r)+(I A / n s)),((E A / p d)+$ $(A A / i r)+(I A / n s)),((E A / p d)+(A A / i r)+(I A / n s)), \ldots]$.

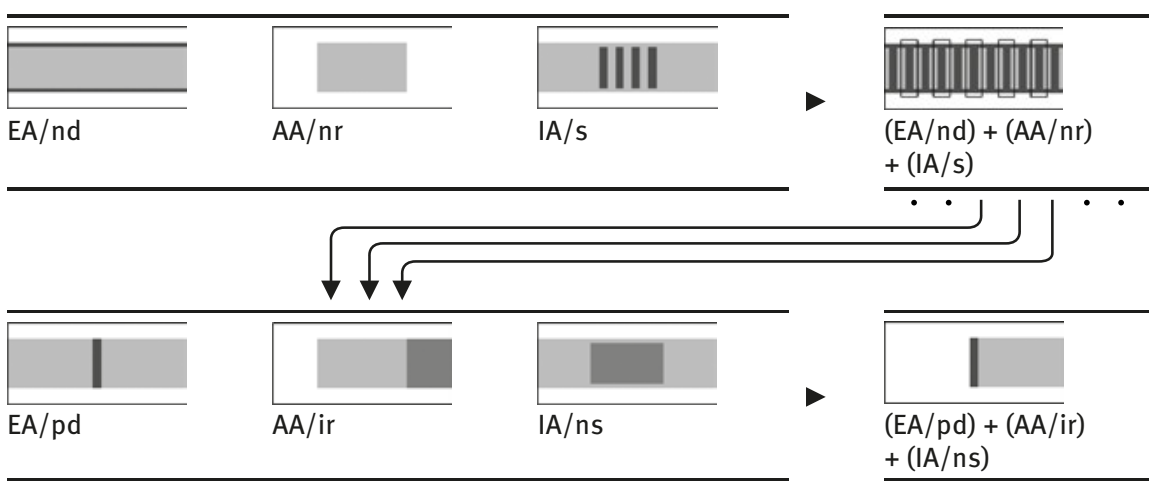

6.2.2.8 Delimitation Schema 2/11, 11, 11, ...: $[((E A / n d)+(A A / n r)+(I A / s))>$ $((E A / p d)+(A A / t r)+(I A / n s)),((E A / p d)+(A A / t r)+(I A / n s)),((E A / p d)+$ $(\mathrm{AA} / \mathrm{tr})+(\mathrm{IA} / \mathrm{ns})), \ldots]$

(29) It. Ho perso ancora una volta le chiavi: è segno che sto [Pres.] impazzendo. [stare + Ger.]

'I have lost my keys once again: it's a sign that I'm going crazy.'

(30) Fr. La jeune danseuse rougissait [Imp.] toujours plus, alors que Luca l'observait durant sa danse. ${ }^{10}$

'The young dancer blushed more and more, while Luca watched her during her dance.'

(31) Sp. Tengo la impresión de que María se vuelve [Pres.] loca cada vez más. 'I have the impression that Maria is going more and more crazy.'

(32) Cat. M'estic [Pres.] enamorant del Joan cada dia més i més. [estar + Ger.] 'I'm falling in love with Joan more and more every day.'

10 Cf. the Spanish example (15) in §6.2.2.4. The presence or absence of an adverb in interaction with the other elements in the situation frame influences the entire aspectual structuring. 
The states of affairs in examples (29)-(32) represent the following combination of aspectual basic conceptualisations:

First level:

a) externally non-delimited (EA/nd)

b) not relevant to adjacency $(\mathrm{AA} / \mathrm{nr})$

c) internally subdivided (IA/s)

Second level:

a') externally punctually delimited (EA/pd)

b') with initial and final (transformative) adjacency relevance (AA/tr)

c') not internally subdivided (IA/ns)

a') $\ldots$

In (29)-(32), on the first level of the combination of aspectual basic conceptualisations, a) neither a starting point $t_{x}$ nor an endpoint $t_{y}$ of going crazy in (29) and (31), the dancer's increasing blushing in (30), or of me falling more and more in love with Joan in (32) is focussed. The respective entire states of affairs (thus presented as not completed) therefore $b$ ) have no relevance for their respective adjacencies. Finally, c) in the going crazy in (29) and (31), in the increasing blushing of the dancer in (30) and in me gradually falling in love with Joan in (32), (substantially) different moments $t_{x 1}, t_{x 2}, \ldots t_{x n}$ can be perceived. In (29), for example, my going crazy in each of these moments can be viewed and represented individually and in isolation, i.e., in each $t_{x 1}$ the going crazy is different from the one in $t_{x 2}$ (this also goes for the pluriphasic states of affairs in (30)-(32)).

That (substantially) different moments $t_{x 1}, t_{x 2}, \ldots t_{x n}$ can be perceived in the respective states of affairs is precisely the prerequisite for their further perspectivisation within the situation frame. In (29) several $t_{x 1}, t_{x 2}, \ldots t_{x n}$ of my going crazy are further focussed and around each of these $t_{x 1}, t_{x 2}, \ldots t_{x n}$ a subframe is formed within the entire frame, which expresses the following combination of aspectual basic conceptualisations: it is a') externally punctually delimited (EA/pd), the initial and final boundaries of every $t_{x 1}, t_{x 2}, \ldots t_{x n}$ in which I am going crazy are focussed and these boundaries coincide (thus, they are $\delta t_{x 1}, \delta t_{x 2}, \ldots \delta t_{x n}$ ). Every single moment $t_{x 1}$ of my going crazy has $b$ ') initial and final (thus transformative) adjacency relevance (AA/tr), i.e., each influences its previous $\left(t_{x 1-1}\right)$ and subsequent $\left(\mathrm{t}_{\mathrm{x} 1+1}\right)$ adjacencies by determining, respectively, its end and its beginning. That is to say, in every moment $t_{x 1-1}, t_{x 2-1}, \ldots t_{x n-1} I$ am a little less crazy than I am in every $t_{x 1}, t_{x 2}, \ldots t_{x n}$ and even less crazy than I will be in every $t_{x 1+1}, t_{x 2+1}, \ldots$ $t_{x n+1}$. Every $\delta t_{x 1}, \delta t_{x 2}, \ldots \delta t_{x n}$ in which I'm going crazy is finally c') not internally subdivided. The states of affairs in (30)-(32) can be analysed similarly. 
The aspectual contents described above are conveyed through very different forms and constructions, and it is worthwhile looking at the components of each example sentence individually. In (29) we have a verbal periphrasis of the type STARE + gerund (with the auxiliary verb in the present tense) in combination with the intransitive verb impazzire 'going crazy', which the speaker's world knowledge informs is a gradual state of affairs. In (30), too, a complex, gradual state of affairs is shown, which can be represented by DS $2 / 11,11,11, \ldots$. This is expressed not only by the first part of the sentence (la jeune danseuse rougissait toujours plus) with the intransitive verb 'to blush' in the imperfect (anchored in the speaker's world knowledge as a gradual state of affairs), reinforced by the adverbial toujours plus 'ever more', but also by the second part of the sentence (alors que Luca l'observait durant sa danse), which provides a temporal frame within which the 'blushing' is represented in its progression. In (31) we again find an intransitive verb, volverse loco 'to go crazy', but with present tense morphological marking, and the adverbial cada vez más, which considerably reinforces the idea of graduality and escalation. Finally, (32) contains the verbal periphrasis STARE + gerund (in which the auxiliary verb is in the present tense) in combination with the intransitive verb enamorarse (also recognised as a gradual state of affairs in the speaker's world knowledge $)^{11}$ and the adverbial cada dia més $i$ més, which emphasises this further and more strongly. Table (9) illustrates this delimitation schema $(2 / 11,11,11, \ldots)$ :

Tab. 9: $D S$ 2/11, 11, 11, . . : [((EA/nd) + (AA/nr) + (IA/s)) > ((EA/pd) + (AA/tr) + (IA/ns)), ((EA/pd) $+(A A / t r)+(I A / n s)),((E A / p d)+(A A / t r)+(I A / n s)), \ldots .$.

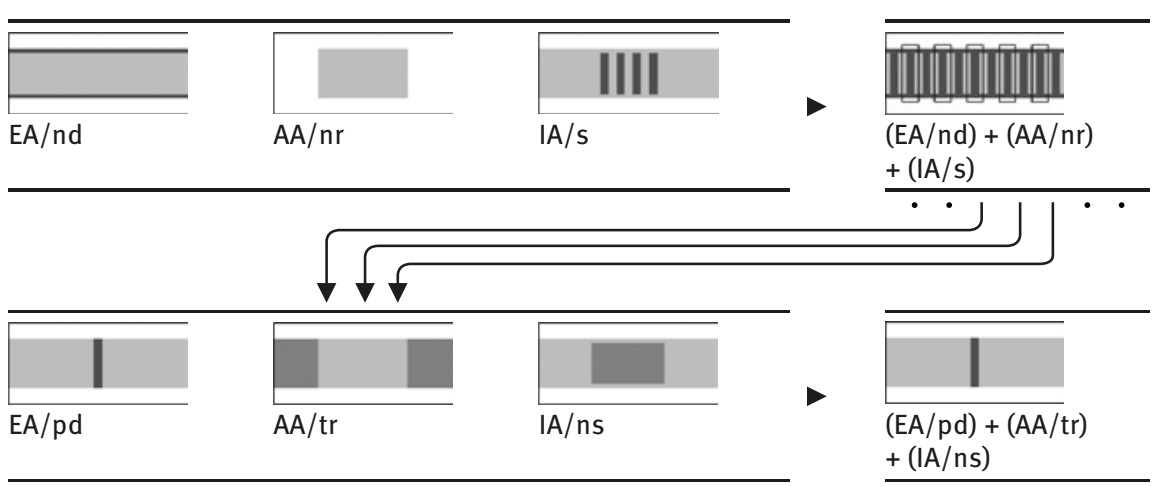

11 The verb 'to fall in love' is, of course, polysemous: 'to fall in love at first sight' is anchored differently in the speaker's world knowledge in other experiential contexts. 
6.2.2.9 Delimitation Schema 4/8, 8, 8, ... : [((EA/d) + (AA/nr) + (IA/s)) > ((EA/ pd $)+(A A / n r)+(I A / n s)),((E A / p d)+(A A / n r)+(I A / n s)),((E A / p d)+(A A /$ $n r)+(I A / n s)), \ldots]$

(33) Sp. Estuve [Perf. Sim.] comiendo toda la noche. [estar + Ger.] 'I've been eating all night.'

(34) Cat. La Rosina va estar [Pret. Perf. Per.] cantant tot el dia. [estar + Ger.] 'Rosina has been singing all day.'

The states of affairs in examples (33) and (34) represent the following combination of aspectual basic conceptualisations:

First level:

a) externally delimited (EA/d)

b) not relevant to adjacency $(\mathrm{AA} / \mathrm{nr})$

c) internally subdivided (IA/s)

Second level:

a') externally punctually delimited (EA/pd)

b') not relevant to adjacency (AA/nr)

c') not internally subdivided (IA/ns)

a") $\ldots$

In (33) and (34), on the first level of the combination of aspectual basic conceptualisations, a) both the starting point $t_{x}$ and the endpoint $t_{y}$ of the respective entire states of affairs - i.e., both the beginning and end of my eating (observed in its progression) in (33) (because before the night I was not eating and afterwards I will no longer be eating) and of Rosina's singing in (34) - are focussed. In other words, the respective states of affairs are presented as completed and b) irrelevant for their adjacencies (for neither my eating nor Rosina's singing determines the end or the beginning of their previous or subsequent adjacencies). Finally, c) in the nocturnal eating (as in Rosina's singing) substantially different moments $t_{\mathrm{x} 1}, t_{\mathrm{x} 2}, \ldots t_{\mathrm{xn}}$, in which I was eating (and Rosina was singing) can be perceived.

Here, too, it is precisely this realisation of internal aspectuality of the entire state of affairs that is the prerequisite for further perspectivisation within the 
situation frame. Several $t_{x 1}, t_{x 2}, \ldots t_{x n}$ - but each individually - in the entire states of affairs are further focussed (and it is exactly this that permits a dynamic representation of the states of affairs); each of these moments represents a temporal boundary around which a subframe is formed within the entire situation frame (so that there are as many subframes as there are $t_{x 1}, t_{x 2}, \ldots t_{x n}$ ) and each has the following delimitation schema: a') external punctual aspectuality (EA/pd), b') not relevant to adjacency (AA/nr) and c') no subdivision of their internal aspectuality (IA/ns). Every $t_{x 1}, t_{x 2}, \ldots t_{x n}$ of my eating is focussed together with its coinciding boundaries, since each time a moment that is individually isolated and considered completed is focussed (so they are different $\left.\delta \mathrm{t}_{\mathrm{x} 1}, \delta \mathrm{t}_{\mathrm{x} 2}, \ldots \delta \mathrm{t}_{\mathrm{xn}}\right)$; none of the moments during the eating affects the beginning of the next moment of eating nor the ending of the previous moment (thus, $t_{x 1}$ does not affect $t_{x 1-1}$ nor $t_{x 1+1}$ in any way); each $\delta t_{x 1}, \delta t_{x 2}, \ldots \delta t_{x n}$ during which $I$ was eating all night cannot logically be internally subdivided. A similar analysis can be given for (34).

The aspectual contents described above are conveyed in examples (33) and (34) by a verbal periphrasis of the type STARE + gerund with the auxiliary verb in the Pretérito Indefinido and Pretèrit Perfet Perifràstic, respectively. The combination with the perfect tenses is a peculiarity of the Ibero-Romance construction of this type (cf. §6.3.3) and has no correspondence in Italian and French. ${ }^{12}$ This construction interacts here with the verbs 'to eat' and 'to sing' (and their first arguments) and with their respective adverbials toda la noche and tot el dia, which reinforce the representation of the duration of the iterated state of affairs.

Table (10) illustrates this combination of aspectual basic conceptualisations (DS 4/8, 8, 8, ..):

12 Herein lies another advantage of the onomasiological model presented here. Aside from the observation, quite possible from a semasiological perspective, that only the IberoRomance estar-periphrasis occurs with perfective tenses such as the Spanish Preterito Indefinido and the Catalan Pretèrit Perfet Perifràstic etc., a precise position in the conceptual system of aspectuality can now be assigned to this Ibero-Romance idiosyncrasy (and the gap in the other Romance languages accounted for) (cf. the DS in §§6.2.2.9-6.2.2.12 and the analysis there of examples (33)-(40)). 
Tab. 10: Delimitation Schema 4/8, 8, 8, . : $:[((\mathrm{EA} / \mathrm{d})+(\mathrm{AA} / \mathrm{nr})+(\mathrm{IA} / \mathrm{s}))>((\mathrm{EA} / \mathrm{pd})+(\mathrm{AA} / \mathrm{nr})+$ $(I A / n s)),((E A / p d)+(A A / n r)+(I A / n s)),((E A / p d)+(A A / n r)+(I A / n s)), \ldots]$.

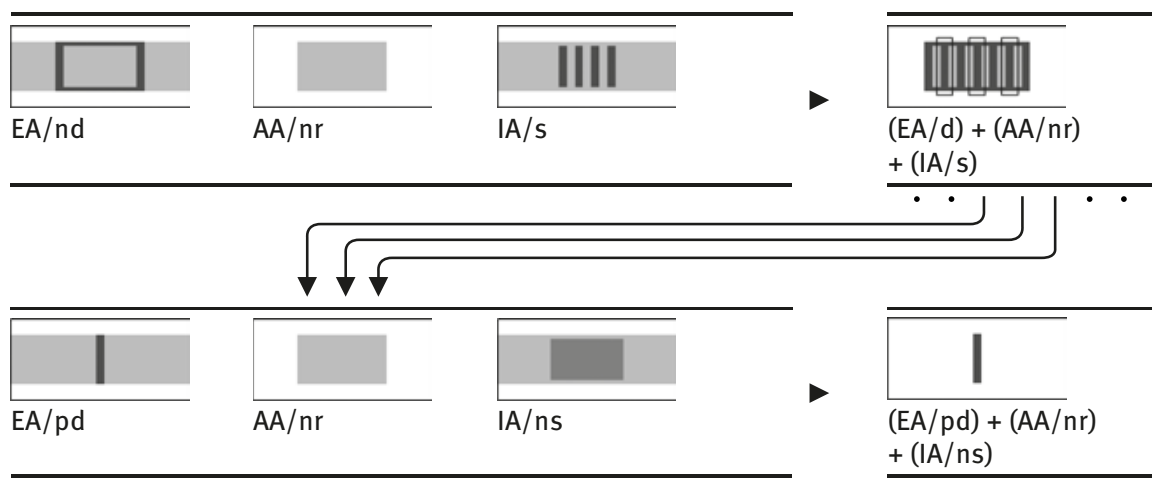

6.2.2.10 Delimitation Schema 5/9, 9, 9, ... : [((EA/d) + (AA/fr) $+(I A / s))>((E A /$ pd $)+(A A / f r)+(I A / n s)),((E A / p d)+(A A / f r)+(I A / n s)),((E A / p d)+(A A /$ fr) $+(I A / n s)), \ldots]$

(35) Sp. El material de construcción estuvo [Perf. Sim.] llegando por meses. [estar + Ger.] 'Building material has been arriving for months.'

(36) Cat. Els passatgers van [Pret. Perf. Per.] estar embarcant tot el dia. [estar + Ger.] 'The passengers have been embarking all day long.'

The states of affairs in examples (35) and (36) represent the following combination of aspectual basic conceptualisations:

First level:

a) externally delimited (EA/d)

b) with final adjacency relevance (AA/fr)

c) internally subdivided (IA/s)

Second level:

a') externally punctually delimited (EA/pd)

b') with final adjacency relevance (AA/fr)

c') not internally subdivided (IA/ns)

a") $\ldots$ 
In (35) and (36), on the first level of the combination of aspectual basic conceptualisations, $a$ ) both the starting point $t_{x}$ and the endpoint $t_{y}$ of the respective entire states of affairs - i.e., both the beginning and the end of the arriving of the building material in (35) (considered continuously in its progression) and the embarking of the passengers in (36) - are focussed. In other words, the respective states of affairs are presented as completed and have b) final adjacency relevance (because both the arriving of the building material and the one-daylong embarking of the passengers determine the end of their respective previous adjacencies: when the material has (completely) arrived, it will no longer arrive; when all passengers have embarked, they will no longer do so). Finally, c) substantially different moments $t_{x 1}, t_{x 2}, \ldots t_{x n}$ can be perceived in the arriving of the building material (as well as in the embarking of the passengers), in which the building material has arrived (and the passengers have embarked).

Here, too, it is precisely this realisation of internal aspectuality of the entire state of affairs that is the prerequisite for further perspectivisation within the situation frame. Several - but each one separately $-t_{x 1}, t_{x 2}, \ldots t_{x n}$ in the entire states of affairs are further focussed (and it is exactly this which permits a dynamic representation of the states of affairs). Each of these moments represents a temporal boundary around which a subframe is formed within the entire situation frame (so that there are as many subframes as $t_{x 1}, t_{x 2}, \ldots t_{x n}$ ), each of which has the following delimitation schema: a') external punctual aspectuality (EA/pd), b') final adjacency relevance (AA/fr), and c') no subdivision of the internal aspectuality (IA/ns). Each $t_{x 1}, t_{x 2}, \ldots t_{x n}$ of the arriving of the building material is focussed together with its coinciding boundaries, since each time a moment that is individually isolated and considered completed is focussed (thus, there are different $\delta \mathrm{t}_{\mathrm{x} 1}, \delta \mathrm{t}_{\mathrm{x} 2}, \ldots$ $\delta \mathrm{t}_{\mathrm{xn}}$, in each of which a part of the building material has arrived). Each of the moments in which a part of the building material has arrived determines the end of the previous moment of arriving (in $t_{x 1}$ there is a little more material than in $t_{x 1-1}$ ) and each $\delta t_{x 1}, \delta t_{x 2}, \ldots \delta t_{x n}$ in which the material has arrived cannot logically be internally subdivided. Example (36) can be analysed similarly.

The aspectual contents described above are conveyed in examples (35) and (36) by a verbal periphrasis of the type STARE + gerund with the auxiliary verb in the Pretérito Indefinido and Pretèrit Perfet Perifràstic, respectively, which, as already mentioned, is a special feature of this type of Ibero-Romance construction (see §6.3.3). This construction interacts here with the verbs 'arriving of the building material' and 'embarking of the passengers' (and their first arguments) and with their respective adverbials por meses and tot el dia, which intensify the representation of the duration of the iterated states of affairs.

Table (11) illustrates this combination of aspectual basic conceptualisations (DS 5/9, 9, 9,...): 
Tab. 11: Delimitation Schema 5/9, 9, 9, . : $[((\mathrm{EA} / \mathrm{d})+(\mathrm{AA} / \mathrm{fr})+(\mathrm{IA} / \mathrm{s}))>((\mathrm{EA} / \mathrm{pd})+(\mathrm{AA} / \mathrm{fr})+$ $(I A / n s)),((E A / p d)+(A A / f r)+(I A / n s)),((E A / p d)+(A A / f r)+(I A / n s)), \ldots]$.

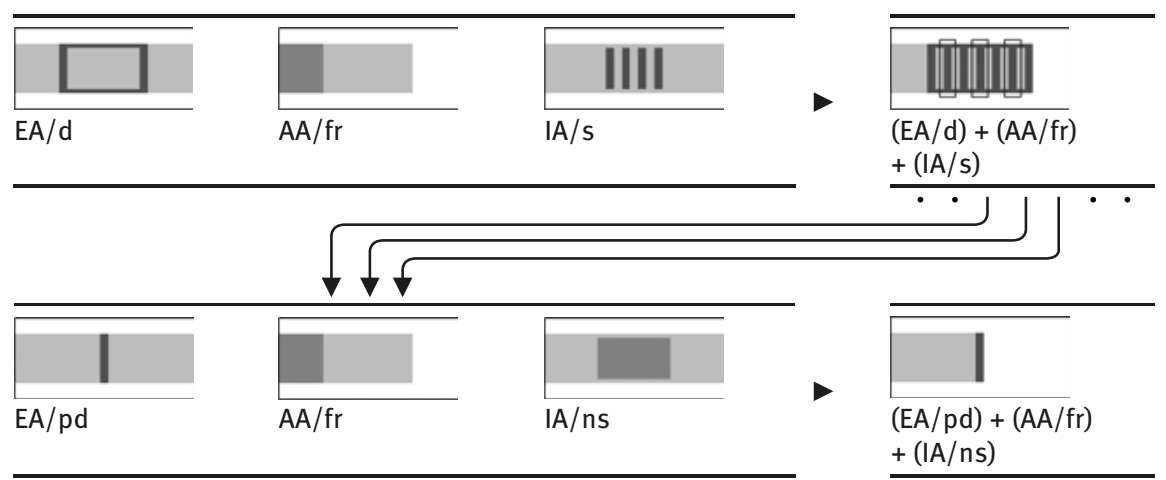

\subsubsection{Delimitation Schema 6/10, 10, 10, ... : [((EA/d) + (AA/ir) + (IA/s)) >} $((E A / p d)+(A A / i r)+(I A / n s)),((E A / p d)+(A A / i r)+(I A / n s)),((E A / p d)+$ $(A A / i r)+(I A / n s)), \ldots]$

(37) Sp. Durante tres años le estuve [Perf. Sim.] enviando cartas. [estar + Ger.] 'For three years I have been sending him letters.'

(38) Cat. Els passatgers van [Pret. Perf. Per.] estar desembarcant tot el dia. [estar + Ger.] 'The passengers have been disembarking from the ship all day long.'

The states of affairs in examples (37) and (38) represent the following combination of aspectual basic conceptualisations:

First level:

a) externally delimited (EA/d)

b) with initial adjacency relevance (AA/ir)

c) internally subdivided (IA/s)

Second level:

a') externally punctually delimited (EA/pd)

b') with initial adjacency relevance (AA/ir)

c') not internally subdivided (IA/ns)

a") $\ldots$ 
In (37) and (38), on the first level of the combination of aspectual basic conceptualisations, a) both the starting point $t_{x}$ and the endpoint $t_{y}$ of the respective entire states of affairs - i.e., both the beginning and the end of my three-year-long sending of letters (considered continuously in its progression) in (37) and the passengers' disembarking from the ship in (38) - are focussed. In other words, the entire states of affairs are presented as completed and have b) initial adjacency relevance (because both my sending of letters and the passengers' disembarking from the ship determine the beginning of their respective subsequent adjacencies: when the three years have passed, all the letters sent are on their way or have already arrived, and when all passengers have disembarked from the ship, they are all ashore). Finally, c) substantially different moments $t_{x 1}, t_{x 2}, \ldots t_{x n}$ can be perceived in the sending of the letters (as well as the disembarking from the ship), in which (different) letters have been sent (and (different) passengers have disembarked from the ship).

Here, too, it is precisely this realisation of internal aspectuality of the entire state of affairs, that is the prerequisite for further perspectivisation within the situation frame. Several - but each one separately $-t_{\mathrm{x} 1}, t_{\mathrm{x} 2}, \ldots t_{\mathrm{xn}}$ in the entire states of affairs are further focussed (and this permits a dynamic representation of the state of affairs); each of these moments represents a temporal boundary around which a subframe is formed within the entire situation frame (so that there are as many subframes as there are $t_{\mathrm{x} 1}, t_{\mathrm{x} 2}, \ldots t_{\mathrm{xn}}$ ), each corresponding to the following delimitation schema: a') external punctual aspectuality (EA/pd), b') initial adjacency relevance (AA/ir), and c') no subdivision of their internal aspectuality (IA/ns). Each $t_{x 1}, t_{x 2}, \ldots t_{x n}$ in the sending of letters is focussed together with its coinciding boundaries, since each time a moment that is individually isolated and considered completed is focussed (thus, there are different $\delta t_{x 1}, \delta t_{x 2}, \ldots \delta t_{x n}$, in all of which I have sent a letter); each of the moments in which I have sent a letter determines the beginning of the subsequent moment of the letter being on its way and is therefore no longer with me (in $t_{x 1}$ more letters have been sent than in $t_{x 1-1}$ ); each $\delta t_{x 1}, \delta t_{x 2}, \ldots \delta t_{x n}$ in which a letter was sent cannot logically be internally subdivided. Example (38) can be analysed similarly.

The aspectual contents described are conveyed in examples (37) and (38) by a verbal periphrasis of the type STARE + gerund with the auxiliary verb in the Pretérito Indefinido and Pretèrit Perfet Perifràstic, respectively. This construction interacts with the verbs 'my sending of letters' and 'the passengers leaving the ship' (and their first and possibly other arguments) and with, respectively, the adverbials durante tres años and tot el dia, which intensify the representation of the duration of the iterated states of affairs. Also important in (37) is the 
presence of an (indefinite) plural marking on cartas, which also reinforces the idea of iteration and duration.

Table (12) illustrates this delimitation schema $(6 / 10,10,10, \ldots)$ :

Tab. 12: $D S 6 / 10,10,10, \ldots$ : [((EA/d) + (AA/ir $)+(I A / s))>((E A / p d)+(A A /$ ir $)+(I A / n s)),((E A / p d)+$ $(A A / i r)+(I A / n s)),((E A / p d)+(A A / i r)+(I A / n s)), \ldots .$.

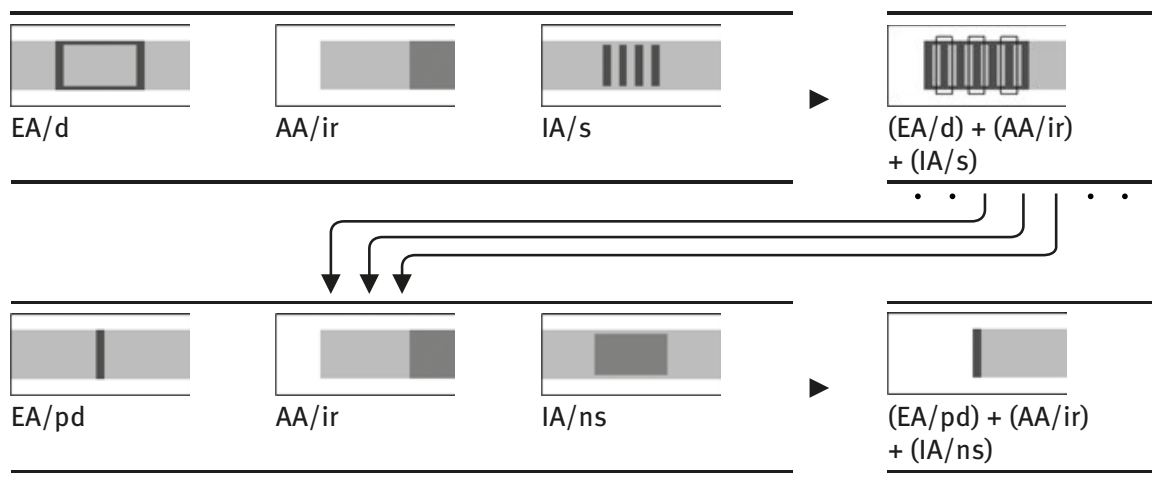

6.2.2.12 Delimitation Schema 7/11, 11, 11, ... : [((EA/d) + (AA/tr) + (IA/s)) > $((E A / p d)+(A A / t r)+(I A / n s)),((E A / p d)+(A A / t r)+(I A / n s)),((E A / p d)+$ $(\mathrm{AA} / \mathrm{tr})+(\mathrm{IA} / \mathrm{ns})), \ldots]$

(39) Sp. Durante semanas Juan estuvo [Perf. Sim.] obsesionándose buscándola. [estar + Ger.]

'For weeks Juan has been obsessed with looking for her.'

(40) Cat. Em vaig estar [Pret. Perf. Per.] enamorant d'en Daniel durant tot l'hivern. [estar + Ger.]

'I have been falling in love with Daniel throughout the whole winter.'

The states of affairs in examples (39) and (40) represent the following combination of aspectual basic conceptualisations (for reasons of space only one $t_{\mathrm{x} 1}$ of the sublevel is shown here by way of example):

First level:

a) externally delimited (EA/d)

b) with initial and final (transformative) adjacency relevance (AA/tr)

c) internally subdivided (IA/s) 
Second level:

a') externally punctually delimited (EA/pd)

b') with initial and final (transformative) adjacency relevance (AA/tr)

c') not internally subdivided (IA/ns)

a') $\ldots$

In (39) and (40), on the first level of the combination of aspectual basic conceptualisations, a) both the starting point $t_{x}$ and the endpoint $t_{y}$ of the respective entire states of affairs - i.e., both the beginning and the end of Juan's becoming obsessed (continuously observed in its progression during the weeks in which he looked for her) in (39) or my falling in love with Daniel throughout the winter in (40) - are focussed. In other words, the respective states of affairs are presented as completed and b) with initial and final (thus transformative) relevance to their adjacencies, because both Juan's becoming obsessed and my falling in love with Daniel determine the beginning and the end of their subsequent and previous adjacencies: when Juan becomes obsessed, he is obsessed after becoming obsessed and is no longer what he was before he became obsessed, namely healthy; when I fall in love, I am in love after falling in love and am no longer not in love. Finally, c) in Juan's becoming obsessed (as well as in my falling in love), substantially different moments $t_{x 1}, t_{x 2}, \ldots t_{x n}$ can be perceived, in which Juan became obsessed (and I was falling in love with Daniel).

Here, too, it is precisely this realisation of internal aspectuality of the entire states of affairs that is the prerequisite for further perspectivisation within the situation frame. Several - but each one separately $-t_{x 1}, t_{x 2}, \ldots t_{x n}$ in the entire states of affairs are further focussed (and it is this that gives the states of affairs their dynamic representation); each of these moments represents a temporal boundary around which a subframe is formed within the whole situation frame (so that there are as many subframes as $t_{x 1}, t_{x 2}, \ldots t_{x n}$ ), each of which has the following delimitation schema: a') external punctual aspectuality (EA/pd), b') transformative adjacency relevance (AA/tr) and c') no internal subdivision of the aspectuality (IA/ns). Each $t_{x 1}, t_{x 2}, \ldots t_{x n}$ of Juan becoming obsessed for weeks is focussed together with its coinciding boundaries, since each time a moment that is individually isolated and is considered completed is focussed (thus, there are different $\delta t_{x 1}, \delta t_{x 2}, \ldots \delta t_{x n}$ in which Juan respectively gets (a little more) obsessed); each of the moments in which Juan has become a little more obsessed determines the end of the previous and the beginning of the subsequent moment of becoming obsessed (in $t_{x 1-1}$ Juan is a 
little less obsessed than in $t_{x 1}$ and in every $t_{x 1+1}$ he has become a little more obsessed); therefore, each $\delta \mathrm{t}_{\mathrm{x} 1}, \delta \mathrm{t}_{\mathrm{x} 2}, \ldots \delta \mathrm{t}_{\mathrm{xn}}$ in which Juan became obsessed (more precisely, in which he was about to become a little more obsessed) cannot logically be internally subdivided. A similar analysis can be carried out for (40).

The aspectual contents described are expressed in examples (39) and (40) by a verbal periphrasis of the type STARE + gerund with the auxiliary verb in the Pretérito Indefinido and Pretèrit Perfet Perifràstic, respectively, - which is a special feature of the Ibero-Romance construction of this type (see §6.3.3). This construction interacts with the verbs 'becoming obsessed' and 'falling in love with' (and their respective first and possibly further arguments) and with the adverbials durante semanas and durant tot l'hivern, respectively, which intensify the representation of duration of the ongoing iterated state of affairs.

Table (13) illustrates this delimitation schema $(7 / 11,11,11, \ldots)$ :

Tab. 13: Delimitation Schema 7/11, 11, 11, . . : $[((E A / d)+(A A / t r)+(I A / s))>((E A / p d)+(A A / \operatorname{tr})+$ $(I A / n s)),((E A / p d)+(A A / t r)+(I A / n s)),((E A / p d)+(A A / t r)+(I A / n s)), \ldots]$.

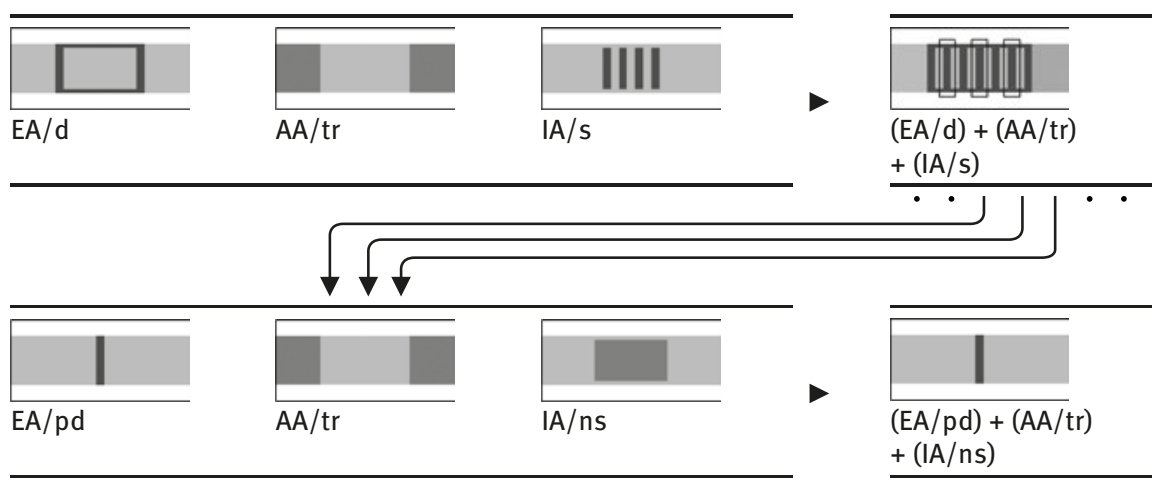

\section{3 (Aspectual) periphrastic verbal constructions}

Presentation of the second level of the system, where verbal periphrases are particularly frequent, has shown that, according to the model presented here, these constructions, which display different degrees of grammaticality or 
lexicality, also have their own place in the aspectual system of the Romance languages. In order to illustrate the significance of this, I will make a digression to look at the way verbal periphrases are generally dealt with in Romance linguistics.

The main question to be dealt with here concerns the nature of periphrastic constructions in general and aspectual verbal periphrases in particular and how they can be defined in terms of their affiliation to the lexicon or grammar. A critical examination of some traditional definitions and interpretations of verbal periphrases will also be undertaken. Special attention will be paid to the constructions examined above under DS 2/8-2/11 (§§6.2.2.1-6.2.2.4), i.e., those which express states of affairs with an aspectuality that is not externally delimited (EA/nd) and is internally subdivided (IA/s) by highlighting and further focussing on the progression of one of the constitutive moments $t_{x 1}, t_{x 2}, \ldots t_{x n}$, which are traditionally called "progressive". ${ }^{13}$ Verbal periphrases, such as the Italian construction stare + gerund, the French être en train de + infinitive, the Spanish estar + gerund and the Catalan estar + gerund will be given particular attention. To this end, their contexts and conditions of use will be analysed from a synchronic perspective, while from a diachronic perspective their degree of grammaticalisation will be discussed and their semantic paths briefly reconstructed.

\subsubsection{The relevance of the phenomenon and problems of definition}

La notion de 'périphrase verbale', traditionnelle en linguistique romane, est aussi traditionnellement mal définie. (Laca 2004a, 87)

The notion of 'verbal periphrasis', a traditional term in Romance linguistics, is also traditionally badly defined.

This short quote from Laca emphasises two important, closely-related issues: the "classical" status of verbal periphrases in the Romance linguistics tradition and the difficulty of defining the phenomenon. This section will deal with both questions in more detail.

Typical of the Romance languages is the possibility of formally expressing temporal, aspectual, modal and diathetic contents through verbal periphrastic constructions, i.e., multi-part combinations of verbs that have

13 For a characterisation of the different types of the so-called progressive see in particular §6.3.3. 
partially or completely developed into auxiliary verbs with so-called full or main verbs. ${ }^{14}$ The following types of verbal periphrases can be distinguished according to their conceptual content, i.e., the functional domain of which they are the (grammatical) categorial expression: a) temporal verbal periphrases: constructions that serve for the (more or less) grammaticalised location of states of affairs in time (as is achieved morphologically by the grammatical category tense and individual tense forms, or lexically by elements such as temporal adverbs). Examples are: Fr. aller + infinitive (as a future marker), It. avere/essere + participle, Sp. haber + participle and Cat. anar + infinitive (as past markers); b) aspectual verbal periphrases that express content referring to the temporal structure particular to the state of affairs (as realised morphologically by the grammatical category aspect and, in the Romance languages, individual forms of the past tenses, or lexically by elements such as aspectual adverbs). Examples are: Fr. être en train de + infinitive, It. venire + gerund, Sp. ir + gerund and Cat. acabar de + infinitive, as well as, of course, all forms of Lat. HABERE/ESSE + participle, if they are used in opposition to forms of the imperfect and are not understood only as temporal-deictic, i.e., temporal markers; c) diathetic verbal periphrases, which serve to express the semantic roles in the sentence. Examples of this are the passive constructions that in the Romance languages use ESSE + participle (this was expressed synthetically in Latin); d) modal verbal periphrases expressing the speaker's attitude towards the state of affairs (just as mode does grammatically and modal adverbs do lexically). Examples are: Fr. savoir + infinitive, It. avere $d a+$ infinitive, Sp. tener que + infinitive and Cat. caldre + infinitive.

The ubiquity and the special role of verbal periphrases has been recognised practically from the beginning of Romance studies and the comparative linguistic and literary study of the languages that emerged from Vulgar Latin. These constructions represent - especially as regards their analyticity - not least an important typological distinction between the Romance languages and the synthetic Latin language. ${ }^{15}$

It is therefore not surprising that such an important phenomenon has also become a traditional subject of Romance research. Examples of Romance verbal

14 Of course, these exist alongside other synthetic morphological variants in the verbal grammar, such as forms of the traditional tenses and modes.

15 The Romance tendency towards analyticity compared with the Latin tendency towards syntheticity is found not only, of course, in the verbal domain. On periphrasticity, analyticity and syntheticity (also in their relationship to each other) see Haspelmath (2000) and Schwegler (1990). 
periphrases had already appeared in Diez's first Romance grammar, ${ }^{16}$ and in recent years investigation of them has substantially increased in Romance linguistics. Semasiological and onomasiological inventories (according to individual languages or functional domains) have been complied, the contents and contexts of use of various individual verbal periphrases have been analysed, diachronic examinations of their genesis have been carried out and the relevant grammaticalisation paths reconstructed. ${ }^{17}$ We now therefore have a systematic and theoretically exacting - as well as comparative - exploration of Romance verbal periphrases to hand - a truly classic subject.

This research tradition is usually considered to have officially begun in the 1960s, particularly with the publication of Coseriu's Das romanische Verbalsystem (1976). ${ }^{18}$ In this book, Coseriu, on the one hand, provides a general explanation of Romance verbal periphrases within his general temporalaspectual verbal system, and on the other hand, deals in particular with aspectual periphrastic constructions. For he emphasises the overall - and typically - Romance character of the aspectual categories expressed with periphrases, recognises their internal connection(s) and presents them in a coherent functional system. ${ }^{19}$ The originality of this system, but also its advantages and disadvantages in terms of a general aspectual theory, have already been discussed in $\$ 1.3 .3$, although it should be briefly mentioned here that what constitute genuine aspectual categories (which are expressed by periphrases) in his system are those of Schau ('view') and Phase ('stage'). Schau refers to the category that includes consideration of the action as a whole or in its unfolding (see Coseriu 1966, 41 and 1976, 99): the speaker can view the verbal action in various ways, such as overall (i.e., as a whole), partially (in extracts), between two points of its unfolding (from a certain viewpoint), etc. Phase, on the other hand, is the category that expresses the relationship between the moment of observation and the degree of unfolding (i.e., the progression) of the verbal process under consideration.

16 See Diez (1836-44), and on Diez see Dietrich (1973, 66ff.).

17 See, among others, Bertinetto (1995a, 1995b, 1998a, 1998b and 2001), Böckle (1979 and 1984), Coseriu (1976), Dietrich (1973, 1985 and 1996), Gavarró/Laca (2002), Fernández de Castro (1999), Gómez Torrego (1988), Gougenheim (1929), Haspelmath (2000), Laca (1995, 1998, 2002b, 2004a and 2004b), Mitko (1999 and 2000), Pusch (2003a and 2003b), Roca Pons (1958), Olbertz (1998), Schlieben-Lange (1971), Squartini (1990 and 1998) and Werner (1980).

18 Lyer's writings on the topic (1934, esp. 129-211) and Wandruszka's (1969, esp. 333-349 and 355-361) ought also to be mentioned.

19 See also, in this context, Dietrich (1973) and Schlieben-Lange (1971). 
Coseriu's interpretation is mentioned here not only for the above-mentioned historical reason, but also because it underlies much of the later Romance research, such as that of Schlieben-Lange (1971) and Dietrich (1973), who apply and develop this approach in further detail in their studies of, respectively, the Occitan and Catalan verbal systems and Romance periphrastic verbal aspect. ${ }^{20}$

Classic topics are, of course, subject to recurrent discussion and usually also theoretical controversy. In the case of verbal periphrases, these emerge at the most fundamental level, i.e., the description of the subject matter itself, because there is no consensus among linguists on a definition or a classification of verbal periphrases. The problems lie on several levels. If a verbal periphrasis is considered as a whole, as a complex - i.e., multi-part - syntactic construction representing a semantic unit, it is necessary to clarify, for example, the nature of the semantic relationships between its parts and the relationships of the parts to the overall construction, and how the overall meaning of the construction emerges from its parts. Furthermore, it is also important to be clear about its status, for example, the greater or lesser degree of grammaticality or lexicality of the periphrasis in question and its components. When considering periphrases in relation to their individual parts, further problems must be addressed concerning both the auxiliary verb and the second element of the construction (usually a nonfinite verbal form, such as an infinitive, a gerund or a participle in the Romance languages). ${ }^{21}$

Some important aspects of the discussions that take place in this research area will be examined here, although I do not claim that this examination will be exhaustive, which would certainly go beyond the scope of this study and in any case other relevant works are already available (see footnote 17 in this chapter). ${ }^{22}$

20 The seemingly non-chronological order should not confuse here: Das romanische Verbalsystem, published in 1976, came out of lectures given in Tübingen in 1968/69, the first versions of which had already been given by Coseriu in Bonn in 1962 and in Tübingen in 1963. See also Coseriu's 1966 and 1968 publications. Some of the more recent studies in Romance linguistics, such as Laca's (see, e.g., 1995, 2002a and 2004a), also refer to Coseriu. An entire comparative Spanish-German grammar is based on his interpretation of the Romance verbal system, i.e., Cartagena/Gauger (1989).

21 There are, however, examples - albeit rare - of verbal periphrases whose second element contains a finite verb, namely of the type tomo y me voy or cojo y escribo in Spanish (e.g., in Cualquier día cojo y escribo un programa que vaya bien), or prendo/piglio e me ne vado in Italian (e.g., Se continui a tormentarmi così, prendo e me ne vado); see, in this context, Coseriu (1966 and 1976, 127).

22 Brief mention should be made of Haspelmath's approach (2000, see in particular 654f.), which has its origins in typological and universal research and which distinguishes between 
I shall introduce the issues dealt with in this section with Coseriu's definition:

Eine 'Periphrase' ist nämlich im eigentlichen Sinn ein sprachliches materiell mehrgliedriges Zeichen, das eine einheitliche, eingliedrige Bedeutung hat, d.h. ein gegliedertes 'Signifiant', dem aber ein einfaches 'Signifié' entspricht. (Coseriu 1976, 119)

In its main sense, a 'periphrasis' is a material multi-part linguistic sign with a uniform, onepart meaning, i.e., it is an articulated 'signifiant' that corresponds with a simple 'signifié'.

According to Coseriu, all periphrases have in common the characteristic semantic integration of their constitutive parts; they are practically the opposite of a compound word. He distinguishes two main forms of periphrasis, (a) lexical and (b) grammatical. The "lexical periphrases" (a) - such as It. tavola calda ('restaurant' or 'lunch menu') or Fr. belle-sœur ('sister-in-law') - exhibit, according to Coseriu, loss of the original meaning of both parts of the periphrasis and the emergence of a new meaning, which cannot be directly derived from the individual constitutive parts (i.e., it has a non-compositional meaning). A tavola calda (literally 'warm table') is neither a table nor something warm; a belle-sœur (literally 'beautiful sister') is not a sister as such and is not necessarily beautiful. On the other hand, in the "grammatical periphrases" (b) (such as Fr. J'ai parlé, Sp. voy a comer, Cat. vaig partir and It. stiamo facendo) the original lexical meaning of one of the constituents is lost (the verbs avoir, ir, anar and stare now serve as auxiliary verbs and no longer mean, respectively, 'to have' (in the sense of 'to possess'), 'to go', 'to go' and 'to stand') while the original lexical meaning of the other constitutive part is preserved (respectively, the verbs 'to speak' (in the participle form), 'to eat' (infinitive), 'to drive' (infinitive) and 'to do' (gerund).

The question has rightly been asked several times ${ }^{23}$ of how to subsume under Coseriu's definition of grammatical periphrases those aspectual constructions

\footnotetext{
"suppletive" and "categorial” verbal periphrases. According to Haspelmath, suppletive periphrases serve as fillers of - primarily synchronically understood - gaps in the syntheticinflectional paradigm (cf. in Latin the modal periphrasis future participle + esse functioning as the future subjunctive). Categorial periphrases, on the other hand, play a more central role in the grammar of a language, since they assume completely the expression of languageparticular grammatical categories.

23 See Squartini's strong objections (1990, 123f.) and the less forceful ones from SchliebenLange (1971) and Dietrich (1973). The latter offers the following definition and problematisation: “'Periphrasis' (and therefore also 'compound', 'circumscription', 'analytical form', 'periphrastic construction', etc.) is generally understood to be a combination of at least two autonomous linguistic units which form a unit in a certain way. It is usually assumed that the elements thus assembled are not on the same level in terms of content, but rather that one or
} 
which native speakers in general intuitively recognise as aspectual verbal periphrases and which also prove to be such in conventional semantic or syntactic tests (see, for example, Gómez Torrego 1988, 127ff.), such as Fr. commencer à parler 'to start talking', Sp. acabar de trabajar 'to have just stopped working', It. continuare a giocare 'to continue playing', Cat. començar a menjar 'to start eating'. On the one hand, these are genuine periphrases, i.e., single-predicate units, as shown in examples (41a-f) and (42a-f), which illustrate the difference between a multi-part predicate unit and several predicate units:

(41a) Sp. Antonio salió corriendo de su despacho.

'Antonio ran out of his office.'

(42a) It. Maria cominciò la lezione parlando di Cesare.

'Maria began the lesson by talking about Cesare.'

Sentences such as (41a) and (42a), which each contain two independent predicate units (respectively, salió and corriendo, and cominciò and parlando), can be easily converted into the following sentences $(41 b-c)$ and $(42 b-c)$ without any syntactic or semantic difficulty:

(41b) Sp. Antonio salió de su despacho y corrió.

'Antonio left his office and ran.'

(41c) Sp. Cuando Antonio salió de su despacho, corría.

'When Antonio left his office, he was running.'

(42b) It. Maria cominciò la lezione e parlò di Cesare.

'Maria began the lesson and talked about Cesare.'

(42c) It. Quando Maria cominciò la lezione, parlava di Cesare.

'When Maria began the lesson, she talked about Cesare.'

In contrast, sentences such as (41d) and (42d), which each contain a multi-part, semantically-related predicate unit, are not semantically equivalent to - hence cannot be paraphrased by - sentences (41e-f) and (42e-f), respectively:

more is subordinate to the other. Non-uniformity, however, consists in assessing the nature and degree of inseparability of these connections, especially in their paradigmatic assignment to other, unassembled linguistic units, in their syntactic use, and, in particular, with regard to their corresponding content, i.e., their semantic configuration.” (Dietrich 1973, 21f., orig. Ger.). 
(41d) Sp. En aquel momento, salió diciendo que era la mujer de su vida.

'At that moment, he came out with it saying she was the woman of his life.'

(41e) Sp. $\neq$ En aquel momento, salió y dijo que era la mujer de su vida. ${ }^{24}$

'At that moment, he came out and said she was the woman of his life.'

(41f) Sp. $\neq$ Cuando salió, dijo que era la mujer de su vida.

'When he came out, he said she was the woman of his life.'

(42d) It. Cominciò a raccontare a tutti che voleva andare a vivere a Londra. 'He started telling everyone he wanted to live in London.'

(42e) It. $\neq$ Cominciò e raccontò a tutti che voleva andare a vivere a Londra. 'He started and told everyone he wanted to live in London.'

(42f) It. $\neq$ Quando cominciò, raccontò a tutti che voleva andare a vivere a Londra.

'When he started, he told everyone he wanted to live in London.'

On the other hand, it cannot be said of constructions such as those in (41d) and (42d) that one of the elements has definitively lost its lexical meaning, for salir and cominciare as auxiliary verbs still display the semantic lexical features found in the full verbs (such as MOVEMENT (to leave) and INGRESSIVENESS (to begin)). However, definitive loss is certainly an essential part of the definition of grammatical periphrasis according to Coseriu (for a more precise explanation of such cases and their classification in the model presented here, see §5.2.2 and §6.2.2). ${ }^{25}$ In this we can see an important, unsolved problem that has led to a more precise definition being frequently adopted in research:

Verbalperiphrasen [sind] eine Verbindung von zwei (oder, in Ausnahmefällen, mehr) Verbalformen, die eine einzige und semantisch einheitliche (nicht-kompositionelle)

24 The not equal sign indicates that sentences (41e and f) and (42e and f) are not the semantic equivalents of, respectively, sentences (41d) and (42d) and not that they are ungrammatical.

25 A definition which reflects the opposite position is given by Olbertz (1998, 32ff.), according to whom multi-part verbal units with auxiliary verbs used exclusively as auxiliary verbs (i.e., which no longer appear also autonomously as full verbs, as lexical units, such as haber/haver in Spanish and Catalan) may not be referred to as verbal periphrases. This would exclude some important analytical constructions (of temporal function) from the category. 
Prädikationseinheit bilden und deren Auxiliarelement bei sehr stark abgeschwächtem semantischen Gehalt als Träger der flexiv markierten Verbalkategorien dient, während ein zweites nicht finites Verbalelement, das also (in den romanischen Sprachen) als Infinitiv, Gerund bzw. Partizip vorliegen kann, die semantische Hauptinformation der Prädikationseinheit beisteuert. (Pusch/Wesch 2003b, 2f.)

Verbal periphrases [are] a combination of two (or, in exceptional cases, more) verbal forms which form a single and semantically uniform (non-compositional) predicate unit and whose auxiliary element serves as a carrier of the inflectionally-marked verbal categories with greatly weakened semantic content, while a second non-finite verbal element, which may therefore appear (in the Romance languages) in the infinitive, gerund or participle, carries the main semantic information of the predicate unit.

However, this definition, too, shows how much the main problem with any attempt at definition lies in the way in which the so-called "loss of meaning" ("desemanticisation" or "semantic bleaching") of one verbal unit of the construction is perceived; in other words, in the way the transformation of a full verb into an auxiliary verb is conceived.

To address this problem, it is necessary to establish parameters to determine the position of a given element on the continuum between analyticity and syntheticity and to measure the stage of grammaticalisation of an auxiliary verb. According to Heine (1993, 54ff.), the linguistic shifts that constitute grammaticalisation form the following four chains or continuums, along which salient stages can be identified: ${ }^{26}$

- desemanticisation: the auxiliary verb loses its original lexical meaning;

- decategorisation: the auxiliary verb loses its morphosyntactic status as a verb;

- cliticisation: the auxiliary verb loses its status as an autonomous word;

- phonological erosion.

However, for several reasons it is difficult to come up with an exact definition of the stages of grammaticalisation from a full verb to an auxiliary verb, and hence also a definition of verbal periphrases. On the one hand, we may ask

26 "Once these schemas are pressed into service for the expression of grammatical concepts, this is likely to trigger a number of linguistic shifts. Some of these shifts will now be looked at in more detail. Each of them can be viewed as constituting a distinct continuum or chain; for the sake of descriptive convenience, however, I will attempt to define a few salient stages or focal points along them. Four chains, each relating to a different aspect of linguistic behavior, will be distinguished referring, respectively, to the semantic (desemanticization), morphosyntactic (decategorialization), morphophonological (cliticization), and phonetic shifts (erosion) concerned.” (Heine 1993, 54). 
whether, in fact, it is always possible to determine at what exact point a (former full) verb begins to take on the characteristics of an auxiliary (i.e., when it becomes more grammatical and less lexical) and when this process is completed, i.e., the point when the lexical-semantic (and syntactic) autonomy of the finite element of a multi-part verbal expression is so weakened that the overall expression may be referred to as periphrastic. ${ }^{27}$ On the other hand, it seems also doubtful whether all of Heine's parameters have the same continual character. Concerning semanticity, is it really possible to detect in all the transformations from a full verb to an auxiliary verb a gradual loss of the lexical meaning of the full verb, or are there examples in which this is not the case and for which other explanations are more appropriate ${ }^{28}$

In order to arrive at a flexible but also satisfactory and comprehensive definition of verbal periphrases from the perspective chosen here, two important specifications need to be added to the overall discussion, one of a more general nature and one more specifically linked to verbal periphrases: a) rather than on stages, the focus should be on parameters, so that grammaticalisation can be reconstructed as a multifactorial process (see also Ch. Lehmann 1995 and 2002); b) it is not the degree of grammaticalisation of an auxiliary verb in a verbal periphrasis that determines the status of a verbal periphrasis as such:

Le perifrasi non sono tutte uguali, non godono tutte allo stesso modo di una certa proprietà, ma si dispongono lungo una scala di perifrasticità con livelli diversi di integrazione. Si va da casi in cui l'integrazione semantica e la desemantizzazione del Hilfsverb sono molto evidenti, a casi in cui Hilfsverb e Hauptverb si mostrano molto più indipendenti. (Squartini 1990, 124)

Periphrases are not all the same, they do not all possess a given property in the same way, rather they lie along a periphrastic scale with different degrees of integration. They range from cases where the semantic integration and the desemanticisation of the Hilfsverb is very evident to cases where the Hilfsverb and Hauptverb are much more independent.

Regardless of the degree of auxiliarisation of one of the parts of the periphrasis, i.e., regardless of how much of the lexical meaning is retained in the auxiliary verb, ${ }^{29}$ or of how strongly grammaticalised it is, or even whether it exists only

27 In this context, see especially Squartini (1998) and Pusch/Wesch (2003b).

28 See Detges' (1999 and 2001) objections to the thesis of desemanticisation (or semantic bleaching). Detges analyses certain cognitive and pragmatic determinants of the grammaticalisation of tense markers in the Romance languages (e.g., aller + infinitive) and shows, in particular, various cases that are not attributable to either metaphor or bleaching, but rather to metonymy (see in particular Detges 1999).

29 Hopper (1991, 22) uses the term "persistence". 
as an auxiliary verb, ${ }^{30}$ all constructions that meet the above criteria to a certain degree are to be defined as periphrases.

\title{
6.3.2 A flexible definition
}

The term verbal periphrasis used in this work is based on the definition given above, which is widely used in research (see the quote from Pusch/Wesch 2003b, 2-3 above), but, on the one hand, it is generalised, and, on the other, it is specified by combining it with the definitional criterion of "scalar periphrasticity” introduced by Squartini (1990 and 1998):

\begin{abstract}
From a synchronic perspective, verbal periphrasis is to be understood as a semantically coherent construction that has the function of a predicate unit and formally consists of two (or more) verbal forms. One of them appears in finite form, performs the function of an auxiliary verb and provides the grammatical and - indirectly proportionally to its degree of auxiliarisation - also a part of the lexical information of the entire construction. The other, which usually ${ }^{31}$ appears in a non-finite form (especially in the infinitive, participle and gerund in the Romance languages), functions as the main verb of the entire construction and contributes directly proportionally to the degree of auxiliarisation of the first element of the periphrasis a more or less large part of the lexical information of the predicate unit.
\end{abstract}

Definition 1: Verbal periphrases

Of course, even if a flexible definition such as Squartini's scalar notion of periphrasticity (1998) is adopted, it is still not easy to determine the degree of grammaticality that an aspectual verbal periphrasis has reached or the extent of the lexical meaning it retains. However, this statement no longer seems relevant, as the scalar notion of periphrasticity is, by definition, not required to provide a classification of precisely delimited - i.e., discrete - units in terms of degree of grammaticality. This definition, therefore, makes it possible to classify together synchronously all constructions that are perceived as aspectual verbal

30 This would allow us to also categorise constructions such as those with haber/haver in Spanish and Catalan as verbal periphrases (see footnote 25 in this chapter).

31 A problematic aspect of the common definition of periphrasis (see, among others, Gómez Torrego 1988) is the prerequisite that these multi-part expressions must consist of an inflected and at least one uninflected form. However, it is well-known - both from general language typological research and comparative Romance studies - that serially coordinated constructions with several inflected verbal elements can also have periphrastic status (in this case, an auxiliary can usually be clearly identified as such); see Pusch (2003b) and Pusch/Wesch (2003b). 
periphrases, i.e., both highly grammaticalised and weakly grammaticalised constructions, as presented in the following Romance examples:

(43) It. Leo sta [Pres.] guardando un episodio di Shaun the Sheep. [stare + Ger.] 'Leo is watching an episode of Shaun the Sheep.'

(44) It. Julia va [Pres.] raccontando storie bizzarre da tre settimane. [andare + Ger.] 'Julia has been going around telling odd stories for three weeks.'

(45) It. Leo finisce [Pres.] di mangiare la pasta. [ [ finire di + Inf.] 'Leo is finishing eating his pasta.'

(46) Fr. Julie est [Prés.] en train de préparer le repas. [être en train de + Inf.] 'Julie is preparing the meal.'

(47) Fr. Julie vient [Prés.] de chanter. [venir de + Inf.] 'Julie has just sung.'

(48) Fr. Marie-Rose se met [Prés.] à chanter. [se mettre à + Inf.] 'Marie-Rose is starting to sing.'

(49) Sp. Clara está [Pres.] hablando de los hombres de su vida. [estar + Ger.] 'Clara is talking about the men in her life.'

(50) Sp. Juan anda [Pres.] pensando en cómo arreglar el problema. [andar + Ger.] 'Juan is thinking about how to solve the problem.'

(51) Sp. Termino [Pres.] de trabajar a las tres. [terminar de + Inf.] 'I finish working at three o'clock.'

(52) Cat. M'estic [Pres.] menjant una galeta. [estar + Ger.] 'I'm eating a biscuit.'

(53) Cat. Acabo [Pres.] de parlar amb el president de la república italiana. [acabar de + Inf.] 'I have just spoken with the President of the Italian Republic.'

(54) Cat. El pacient ara tot just comença [Pres.] a tastar aliment sòlid. [començar a + Inf.] 'The patient is just beginning to eat solid food.' 
All the two-part constructions in (43)-(54) are perceived by native speakers as belonging together syntactically and semantically as predicate units. However, periphrases such as It. stare + gerund (43), Fr. être en train de + infinitive (46), Sp. estar + gerund (49) and Cat. estar + gerund (52) have a greater degree of grammaticality (and are therefore closer to inflectionally-marked forms of an aspectual nature) than periphrases of the type It. finire di + infinitive (45), Fr. se mettre $\grave{a}+$ infinitive (48), Sp. terminar de + infinitive (51) and Cat. començar $a+$ infinitive $(54),{ }^{32}$ for the lexical meaning of the first verbal element ${ }^{33}$ in the constructions in (43), (49) and (52) is very weakened (it has nothing to do with 'to exist' or 'to remain' and consequently these meanings do not merge with the overall meaning of the construction), so that they contribute almost exclusively grammatical information and hardly any lexical semantic information to the predicate unit as a whole. The main lexical semantic information is provided by the second element in the construction, respectively, 'to watch', 'to talk' and 'to eat'. In contrast, the first element in the constructions in (45), (48), (51) and (54) contributes a certain degree of lexical meaning to that of the predicate unit as a whole: given the overall meaning of the periphrases, we can see that the meaning of 'to finish' is retained in the last stages of eating in (45), that of 'to begin' in the first stages of eating in (54). The fact that the first element in the constructions is to a certain degree still an auxiliary verb with a grammatical function and is not a main (or full) verb seems evident, if, for example, the construction in (45) is compared with example (55), where finire is clearly in its function as a main verb (with a distinctly lexical meaning, which is 'to spend' here, that is 'to finish' his money): ${ }^{34}$

(55) It. Ogni volta che va in pasticceria Leo finisce [Pres.] tutti i soldini messi da parte mangiando tortine al cioccolato.

'Every time he goes to the bakery Leo spends all his saved money eating chocolate cakes.'

32 The periphrastic constructions in examples (45), (48), (51) and (54) are at an intermediate stage on the grammaticalisation scale, where se mettre $\grave{a}+$ infinitive has a higher degree of grammaticality than the other three periphrases.

33 In the case of French, it is rather a so-called prepositional periphrasis.

34 For this purpose, the test used in $§ 6.3 .1$ can also be applied here: while Ogni volta che va in pasticceria Leo finisce tutti i soldini messi da parte mangiando tortine al cioccolato could be easily paraphrased by Ogni volta che va in pasticceria Leo finisce tutti i soldini e mangia tortine al cioccolato or Quando Leo va in pasticceria mangia tortine al cioccolato e finisce tutti $i$ soldini messi da parte, the sentences $\neq$ Leo finisce e mangia la pasta and $\neq Q$ uando Leo finisce mangia la pasta cannot be regarded as paraphrases of Leo finisce di mangiare la pasta. 


\subsubsection{STARE + gerund - a semasiological parenthesis}

The more highly grammaticalised Romance aspectual verbal periphrases of the type STARE + gerund will now be dealt with in more detail. However, an important issue from a semasiological perspective - i.e., with regard to the form in question and its function in different contexts - must first be clarified in order to arrive at the various aspectual meanings expressed in each case. Consider the following examples:

(56) It. Mi scusi, sto [Pres.] telefonando da lontano e devo riattaccare. [stare + Ger.] 'I'm sorry, I'm calling from far away and I have to hang up.'

(57) It. Ho perso le chiavi per la terza volta in un'ora: è segno che sto [Pres.] impazzendo. [stare + Ger.]

'I have lost my keys for the third time in an hour: it's a sign that I'm going crazy.'

(58) Sp. Julia estaba [Imp.] escribiendo una carta cuando Leo entró en su habitación. [estar + Ger.]

'Julia was writing a letter when Leo came into her room.'

(59) Sp. ¡No sabes lo que estoy [Pres.] soportando con esta mujer! [estar + Ger.] 'You don't know what I'm going through with this woman!'

Although the same analytical forms are used in (56) and (57) and in (58) and (59), i.e., they contain the same formal type of verbal periphrasis, they do not have the same aspectual content. One of the typical uses of Romance periphrases of the type STARE + gerund is to express aspectual contents that can be called "progressive-focalised" after Bertinetto (1995a), and these are exemplified in (56), (57) and (58). ${ }^{35}$ This type of aspectual content - or, in the

35 Bertinetto (1995a) distinguishes between two types of progressive and compares them in detail: the first type is called Progressif Focalisé (Prog. Foc.), the second Progressif Duratif (Prog. Dur.). While the Prog. Foc. refers to a single moment of focus, which is particularly emphasised and considered, and which "simply indicates a moment in the unfolding of the event, while the actual duration of the event remains undetermined" (Bertinetto 1995a, 39, orig. Fr.), the Prog. Dur. determines the aspectual value of the state of affairs in relation to an interval (a longer interval, which thus represents duration) (see also Bertinetto 1986 in general on the progressive). It is interesting to compare this with Coseriu's interpretation of the STARE + gerund periphrasis. In a case like sto facendo (a construction that, according to Bertinetto, expresses a Prog. Foc.), which expresses both a kontinuative Phase ('continuous stage') and a 
terminology used here, this combination of aspectual basic conceptualisations can be described in summary form as follows (for a more precise classification of these cases in the model developed here see §6.2.2):

- The state of affairs is presented as externally non-delimited (EA/nd) and is therefore considered open with regard to its (initial and) final delimitation (and therefore overall as uncompleted). In (56), when the telephone call started and when it will end is not stated; likewise in (58) there is no information as to when Julia started writing the letter and when she will end it.

- The state of affairs is internally subdivided (IA/s) and therefore comprises several points in time $t_{\mathrm{x} 1}, \mathrm{t}_{\mathrm{x} 2}, \ldots \mathrm{t}_{\mathrm{xn}}$, but is considered in its unfolding from a certain point in time $t_{x}$, i.e., a certain $t_{x}$ (with regard to the internal aspectual subdivision of the situation frame) is focussed. The ongoing telephone conversation in (56) and the writing of the letter in (58) are considered from a specifically chosen moment of, respectively, telephoning $t_{x 1}$ and writing $t_{x 2}$.

However, periphrases of the type STARE + gerund ${ }^{36}$ are polysemous, or rather polyfunctional linguistic forms, that can therefore express several aspectual contents. Cases can also be found in which verbal periphrases of this type express a progressive-durative content (see Bertinetto 1995a). In (57) and (59), for example, the following aspectual structuring of the state of affairs can be observed:

- The state of affairs - as in (56) and (58) - is presented as open with regard to its (beginning and) end, so it is considered as not externally delimited (EA/ nd) and therefore not completed. When my going crazy in (57) or my going through with this woman in (59) began and will end are not indicated.

- The state of affairs - as in (56) and (58) - is presented as internally subdivided (IA/s). However, in (57) and (59) it is not considered from a certain, focussed point of time $t_{x}$, but as a continuing process. This means that no specific moment within the situation frame is highlighted, but rather that all the individual $\mathrm{t}_{\mathrm{x} 1}, \mathrm{t}_{\mathrm{x} 2}, \ldots \mathrm{t}_{\mathrm{xn}}$ of the internal aspectuality of this state of affairs (except, of course, the initial and final delimitation of the state of affairs itself) are focussed. In (57), the form sto impazzendo expresses a

\footnotetext{
partialisierende Schau ('partialising view'), Coseriu (1976) speaks of syncretism between Phase and Schau: periphrases, which mainly represent a partialisierende Schau, can take on further meaning, namely that which represents the degree of the process. Sto facendo focusses (even though it expresses a kontinuative Phase) a fixed (temporal) point from which the process that continues developing (in this precise moment) is observed.

36 What is meant here, of course, is the respective realisations of this type in Italian and Spanish, but a similar statement could also apply to Catalan.
} 
graduality that is observed not in a certain moment of craziness, but in various moments of this craziness (hence the aforementioned durativity), in which, moreover, the craziness gradually increases over several points in time (for further details see §6.2.2.8, where the role AA plays here is described); similarly, in (59) several moments $t_{x 1}, t_{x 2}, \ldots t_{x n}$ of my going through with this woman, i.e., a period of time, are foregrounded in the state of affairs.

Cases like (57) and (59), however, are in the minority in Italian, as is shown in more detail below. Their use is highly restricted to certain aspectual contexts, which are found in clearly lower frequencies than those in (56) (externally nondelimited (EA/nd), internally subdivided (IA/s) and with a focus on one of the $t_{x}$ of the internal aspectuality). This highlights one of the most important differences between the various Romance languages regarding the use of this type of periphrasis, because in Spanish and Catalan - as will be shown in the following section - this so-called durative use is highly frequent.

\subsubsection{STARE + gerund - contexts of use}

In contemporary Spanish and Catalan, the possibilities of expressing morphologically different types or realisations of external aspectuality (referred to in Chapter 4 as (EA/d) and (EA/nd)) through periphrases of the type STARE + gerund - which is, by the way, also formally identical - are very similar. This is illustrated by the possible and impossible variants in the comparative examples $(60 a-d)$ and $(61 a-d)$ :

(60a) Sp. Leo está [Pres.] comiendo con Julia.

'Leo is eating with Julia.'

(60b) Sp. Leo ha estado [Perf. Com.] comiendo con Julia esta tarde. 'Leo has been eating with Julia this afternoon.'

(60c) Sp. Leo estaba [Imp.] comiendo con Julia, cuando Juan salió de su casa. 'Leo was eating with Julia, when Juan left his house.'

(60d) Sp. Leo estuvo [Perf. Sim.] comiendo con Julia toda la tarde. 'Leo was eating with Julia all afternoon.'

(61a) Cat. El Leo está [Pres.] menjant amb la Júlia. 'Leo is eating with Julia.' 
(61b) Cat. El Leo avui ha menjat [Pret. Indef.] amb la Júlia. 'Leo ate with Julia today.'

(61c) Cat. El Leo estava [Imp.] menjant amb la Júlia, quand van trucar a la porta. 'Leo was eating with Julia, when someone knocked at the door.'

(61d) Cat. El Leo estiguà [Pret. Perf. Sim.]/va estar [Pret. Perf. Per.] menjant amb la Júlia durant dos dies.

'Leo was eating with Julia for two days.'

The use of the Sp./Cat. periphrasis estar + gerund in states of affairs with external aspectuality of the type non-delimited (EA/nd) is unproblematic. In (60a and c), and in (61a and c), in which the auxiliary verb appears respectively in each pair in the present and imperfect tense, neither the initial nor the final moment of Leo's and Julia's eating is focussed; the pluriphasic state of affairs is represented in its progression - and from a particular $t_{x}$ in this progression. However, the construction can also appear in states of affairs with external aspectuality of the type delimited (EA/d), as in examples (60b and d) and in (61b and d) (see also the analyses in §§6.2.2.9-6.2.2.12). Here, the initial and the final moment of Leo's and Julia's eating are focussed, so the state of affairs is represented as completed, i.e., as delimited within a particular period of time: Leo and Julia ate together for a limited time, i.e., until the present moment of speaking in (60b), a whole afternoon in (60d) and for two days in (61d). This is the case even though the individual moments of the progression of the pluriphasic state of affairs within this delimited period of time are further focussed (i.e., all and every single one, as shown above for (57) and (59)), so that within the given external boundaries of the states of affairs the internal constitutive moments are represented as being in progress: in all the examples all the single $t_{x 1}, t_{x 2}, \ldots t_{x n}$ of Leo's and Julia's eating together are further focussed.

The auxiliary verb, moreover, carries morphological markers of an analytical nature (the Pretérito Perfecto Compuesto and the Pretèrit Indefinit Indicatiu in (60b) and (61b), respectively) and a synthetic nature (the Pretérito Indefinido and the Pretèrit Perfet Simple in (60d) and (61d), respectively). In both languages, estar + gerund can have either a progressive-durative function (this is the case, e.g., in combination with morphological markers on the auxiliary verb which express EA/d, as in (60b and d) and (61b and d), though not exclusively), or a progressive-focalised function (as in (60a and c) and (61a and c)), so the periphrasis is not just specified for one of the aspectual meanings. Examples (62)-(64), which illustrate the progressive-durative use, further confirm this: 
(62) Sp. Yo salgo de aquí a las seis y media de la mañana y me estoy trabajando hasta las doce, la una de la mañana.

'I leave here at 6:30 in the morning and I'm working until twelve, one o'clock in the morning.'

(example and translation taken from Squartini 1998, 77)

(63) Sp. Estuvo escribiendo hasta después del alba.

'He was writing until after dawn.'

(example and translation taken from Squartini 1998, 38)

(64) Sp. No me mire así, no piense que durante todo este tiempo me he estado burlando de su inocencia y de su voluntad de saber.

'Don't look at me in that way. Don't think that for all this time I have been mocking her innocence and her desire to know.'

(example and translation taken from Squartini 1998, 39)

The aspectual possibilities of these periphrases are interpreted differently by Laca (1995), who insists on the exclusive imperfective nature of the construction, which, therefore, even in combination with perfective tenses, continues to convey an imperfective aspectual meaning (or in the terminology used here, $\mathrm{EA} / \mathrm{nd})$ :

Cette particularité combinatoire [avec les temps perfectifs sds] ne contredit cependant en rien le caractère aspectuel imperfectif de la périphrase. En effet, on s'accorde à considérer comme imperfective toute forme verbale qui exclut la visualisation de la 'borne droite' d'une situation. [...] Les analogies constatées [entre l'imparfait et estar + Gérondif sds] constituent des indices à mon avis très clairs en faveur de la nature aspectuelle imperfective de cette périphrase, qui est maintenue même dans sa combinaison avec les temps perfectifs. (Laca 1995, 496-498)

However, this particular type of combination [with the perfective tenses sds] does not contradict in any way the imperfective aspectual nature of the periphrasis. Indeed, we agree to consider any verbal form where the 'right boundary' of the situation is not visible as imperfective. [...] The analogies observed [between the imperfect and estar + gerund sds] are, in my opinion, very clear indications of the imperfective aspectual nature of this periphrasis, which is maintained even when it is combined with perfective tenses.

Laca makes a comparison of imperfect and telic verbs to show the analogy between the imperfect and the aforementioned verbal periphrasis, and of the behaviour of the periphrasis in combination with the imperfect and with telic verbs to prove the thesis advocated above. One problematic aspect, 
however, is that (non-)telicity and (im-)perfectivity are thus mixed (see §2.5 on the objection to mixing aspectual-grammatical and actional categories voiced by advocates of bidimensional approaches). If these categories are not identical by definition, it may also not be sufficient to show the nontelicity of a verb (or the so-called "suspension of the telos" in a state of affairs) to prove the imperfectivity of a state of affairs (or even a construction per se). ${ }^{37}$

However, the theoretical direction associated with the bidimensionalist tradition - see Gómez Torrego (1988), for example - also offers an interpretation of the aspectual contents of this periphrasis, which provides for the possibility that STARE + gerund has no particular aspectual nature, but can express various aspectual meanings:

[...] hemos puesto ejemplos con el auxiliar en presente o pretérito imperfecto, formas muy apropiadas para la descripción por su carácter imperfectivo, en consonancia, también, con el valor imperfectivo del gerundio. Si el auxiliar apareciera en pretéritos indefinidos o pretéritos perfectos compuestos, entonces se conjuntan el valor imperfectivo del gerundio con el perfectivo del auxiliar. De esta forma, se nos ofrece una imagen o idea durativa que se da por acabada en un momento determinado: Estuve estudiando toda la noche. (Gómez Torrego 1988, 141, my underlying, sds)

[...] we have given examples with the auxiliary in the presente or preterito imperfecto that are highly appropriate forms for describing its imperfective nature, in accordance, also, with the imperfective value of the gerund. If the auxiliary appears in the preteritos indefinidos or pretéritos perfectos compuestos, then the imperfective value of the gerund is combined with the perfective value of the auxiliary. In this way, we are offered a durative image or idea that is considered to be finished at a given time: I was studying all night.

The Ibero-Romance use of STARE + gerund, which can also express external aspectuality of the type delimited (EA/d), differs significantly from use of the same formal means in other (including Romance) languages, which do not have the same means to express this particular combination of aspectual building blocks. Contemporary Italian is clearly different from Spanish and

37 The tests used by Laca $(1995,497)$ are a little problematic. She compares the following examples: (a) \#Es va morir, però a la fin no es va morir; (b) Es moria, però a la fin no es va morir; (c) \#Ahir vaig corregir els exercicis, però no vaig acabar de corregir-los; (d) Ahir vaig estar corregint els exercicis, però no vaig acabar de corregir-los, although the forms in (c) and (d) are not exactly comparable to those in (a) and (b). For a precise comparison, the following forms should be cited: (e) \#Ahir vaig corregir els exercicis, però no vaig corregir-los; (f) \#Ahir vaig estar corregint els exercicis, però no vaig corregir-los. In this case, it can be seen that there is no analogy between (b) and (f) that would justify the syllogism in the interpretation of them. 
Catalan in its use of the periphrasis STARE + gerund. ${ }^{38}$ In terms of the restrictions of use and compatibility, it is more similar to the French periphrasis être en train de + infinitive (although this construction has a completely different formal origin). ${ }^{39}$

In fact, contemporary Italian and French progressive constructions can only be combined with a) synthetic tenses that have b) non-delimited external aspectuality (EA/nd) and c) are specialised for the so-called "focalised progressivity". This is clearly shown in the possible and impossible variants of the comparative examples $(65 a-d)$ and $(66 a-d)$ :

(65a) It. Leo sta [Pres.] mangiando con Julia. (EA/nd)

'Leo is eating with Julia.'

(65b) It. *Leo è stato [Perf. Com.] mangiando con Julia.

'Leo has been eating with Julia.'

(65c) It. Leo stava [Imp.] mangiando con Julia. (EA/nd)

'Leo was eating with Julia.'

(65d) It. ^Leo stette [Perf. Sem.] mangiando con Julia.

'Leo was eating with Julia.'

(66a) Fr. Léo est [Prés.] en train de manger avec Julie. (EA/nd)

'Leo is eating with Julie.'

(66b) Fr. *Léo a été [Pass. Com.] en train de manger avec Julie.

'Leo has been eating with Julie.'

38 More recent literature on the conditions of use and characteristics of this periphrasis in Italian includes, among others, Brianti (1992 and 2000), Streb (2002), Natale (2009) and Dessì Schmid (2011b). For the classic literature on the subject, see below.

39 The prepositional periphrasis être en train de + infinitive is the most recent of the French aspectual progressive (copulative) periphrases. At the beginning of its grammaticalisation in the 17th and 18th centuries it was used as a modal periphrasis expressing the subject's intention (mood) to do something, see Gougenheim $(1929,63)$; it became common as a progressive aspectual periphrasis around the middle of the 19th century, although, of course, examples of its use with this function can also be found earlier. For general information on the French periphrasis être en train de + infinitive, see, among others, Gougenheim (1929), Laca (2004a), Mitko (1999), Pusch (2003a), Squartini (1998) and Werner (1980). 
(66c) Fr. Léo était [Imp.] en train de manger avec Julie. (EA/nd)

'Leo was eating with Julie.'

(66d) Fr. *Léo fut [Pass. Sim.] en train de manger avec Julie.

'Leo was eating with Julie.'

In other words, it is impossible for Italian and French to express states of affairs with external aspectuality of the type delimited (EA/d) with the verbal periphrasis stare + gerund or être en train de + infinitive. Furthermore, in these languages - as mentioned in $§ 6.3 .3$ - their use with a progressive-durative function is rare.

A diachronic examination of this construction in Italian that follows the path of its grammaticalisation can help us understand the reasons for its restrictions and aspectual specialisations.

\subsubsection{STARE + gerund in Italian - the grammaticalisation path}

So far, the phenomenon of verbal periphrasis has mainly been described and defined synchronically, but now we ask what path does the grammaticalisation of the first element of the construction follow? What happens when aspectual periphrastic constructions emerge?

From a diachronic perspective, verbal periphrases are the outcome of grammaticalisation processes, i.e., the result of a change from independent lexical units to more or less grammatical units (see what was said in $§ 6.3 .1$ regarding auxiliary verbs). ${ }^{40}$ Aspectual verbal periphrases in particular would then, of course, also have to be understood as the outcome of grammaticalisation processes, namely, as the result of a change from a lexically expressed verb meaning or verb meaning component to another, but somehow cognitively connected, grammatically expressed aspectual verb meaning (component). From this perspective and on the basis of results from grammaticalisation research in general in recent years, lexicon and grammar can only be considered as two ends of a continuum (see §2.4.2 for more details). We cannot, therefore, help but assume that concepts such as periphrasticity and auxiliarity are also scalar, in agreement with Squartini (1990 and 1998), which has already become clear from the above analysis of the phenomenon from a synchronic

40 On grammaticalisation research in general see, among others, Ch. Lehmann (1995), Hopper/Traugott (2003) and Detges/Waltereit (2002); on the grammaticalisation of auxiliaries see Heine (1993); on the issue of grammaticalisation in general see Chapters 2 and 3 here. 
perspective. If we are looking for indications of grammaticalisation, they can be found in their frequency of use, because:

Textual frequency is often considered prima facie evidence of degree of grammaticalization. (Hopper/Traugott 2003, 113) ${ }^{41}$

Consistent with Hopper and Traugott's claim, ${ }^{42}$ an indirect indication of the grammaticalisation of the Italian stare + gerund in its so-called progressivefocalised use can certainly be found in the huge increase in its frequency in both literary and newspaper language since the last century (see Durante 1981 as well as Squartini 1990 and 1998, Bertinetto 1996 and Del Pietro 1995). ${ }^{43}$

Different opinions can be found on the stage of grammaticalisation reached by the progressive periphrasis in Italian ranging between two extremes. On the one hand, Marchand (1955) denies that it has any grammaticality and banishes it to the level of stylistics, while on the other hand, Blücher (1973 and 1974) equates it with the developmental stage of the English continuous form. The majority of more recent research on the progressive (Bertinetto 1986 and 1995b) holds that It. stare + gerund cannot simply be attributed a stylistic function, but rather a grammatical ${ }^{44}$ one, albeit not the same one it has taken on in English.

Sprachen unterscheiden sich hauptsächlich in dem, was sie ausdrücken müssen, und nicht so sehr in dem, was sie ausdrücken können. (Jakobson 1981 [1959], 195)

Languages differ mainly in what they must express and not so much in what they can express.

41 In this context, see also Heine/Claudi/Hünnemeyer (1991) and Bybee/Perkins/Pagliuca (1994).

42 In this context, see also Squartini $(1998,87)$ : "When stare becomes a specialized marker of progressive aspect it strengthens its position in the verb system, becoming more grammaticalized, and therefore increases its frequency with respect to the other gerundial periphrases.”

43 This is not the place to discuss the reasons for this increase, but it should be noted that Durante's (1981) thesis that it was due to the influence of English on Italian seems unlikely. It is more likely to be due to the gradual spread of a spoken national language than to English influence. See also Squartini's (1998, 86-87) analysis of oral and written corpora, which points to a far more frequent occurrence of stare + gerund in the oral language.

44 On the basis of Heine's criteria (1993), which can be used to measure the grammaticalisation stages of an auxiliary verb (see §6.3.1), it can be said that the progressive periphrasis is grammaticalised to a quite high degree in Italian, because not only has the first stage of desemanticisation been reached, i.e., loss of the lexical meaning of stare, but also the second, since there is a clear sign of at least partial decategorisation in its incompatibility with morphemes that (normally) express external aspectuality of the type delimited, i.e., its morphological paradigm has shrunk to the imperfective forms. 
If we consider this famous phrase of Jakobson's, we find something important that speaks against Blücher's position: the obligatoriness of the continuous form in English has no equivalent in Italian - nor in Spanish, Catalan or French.

However, as the theoretical emphasis here was placed rather on the semantic development, it is the grammaticalisation path of It. stare + gerund that I mainly wish to investigate. For this purpose, the following examples from older language stages of Italian need to be analysed in more detail:

(67) It. Le notti e le dia sta [Pres.] plorando. (Elegia giudeo-italiana, 12th-13th c., from Durante 1981, 180) 'He is crying night and day.'

(68) It. Pigliava al far del giorno alcun riposo/sempre sognando stava [Imp.] in quel desire. (Boiardo, Orlando Innamorato, 15th c., from Dietrich 1985, 204)

'At break of day he took some rest/still dreaming he was in that desire.’

(69) It. E mentre che lui stava [Imp.] riguardando,/quello altro campion con voce altiera/gli disse. (Boiardo, Orlando Innamorato, 15th c.)

'And while he was looking, the other hero in a haughty voice said to him.'

(example and translation taken from Squartini 1998, 85)

(70) It. Sono stato [Perf. Com.] un poco pensando meco. (Aretino, Talanta, 16th c., from Durante 1981, 180)

'I have been thinking a little bit by myself.'

(71) It. Dopo queste e altre simili parole, il conte Attilio uscì, per andare a caccia; e don Rodrigo stette [Perf. Sem.] aspettando con ansietà il ritorno del Griso. (Manzoni, I promessi sposi, 1840-42, from Squartini 1990, 193) 'After these and other similar words, Count Attilio went out to hunt; and Don Rodrigo was waiting anxiously for the return of Griso.'

In Old Italian and until the 19th century, stare + gerund was compatible both with forms that express aspectuality of the type externally non-delimited (EA/nd) (in (69) with the auxiliary verb in the Imperfetto) and with forms that express aspectuality of the type externally delimited (EA/d) (as can be clearly seen in (70) and (71), where the auxiliary verb is in the Passato Prossimo and Passato 
Remoto, respectively). Stare + gerund was also found - evenly distributed - in both progressive-focalised (as in (69)) and progressive-durative use (as in (67) and (68)). ${ }^{45}$

If we compare the use of this construction in this language stage with its use in contemporary Italian, we can note the following changes:

- a significant increase in the use of the periphrasis in its progressivefocalised meaning and a decrease in its durative use;

- a reduction in its morphological combinatorics, in particular a reduction in its compatibility with morphemes, expressing aspectuality of the type externally delimited $(\mathrm{EA} / \mathrm{d}) .^{46}$

The semantic grammaticalisation path of the Italian progressive periphrasis as could be claimed with Squartini $(1998,73 \mathrm{ff}$.) - is one that has led from LOCATIVITY via DURATIVITY to IMPERFECTIVE PROGRESSIVITY. ${ }^{47}$ It thus proceeds entirely in the sense of the - albeit not absolutely universal, but at least crosslinguistic - processes described by Bybee/Dahl (1989) and Bybee/Perkins/ Pagliuca (1994):

\section{LOCATIVITY > DURATIVITY > IMPERFECTIVE PROGRESSIVITY}

Grammaticalisation path of stare + gerund in Italian I.

More precisely, Squartini's (1998) detailed study of the aspectual meaning components of the verbs that participate in periphrastic constructions shows that this process of grammaticalisation from LOCATIVITY (via DURATIVITY) to IMPERFECTIVE PROGRESSIVITY mirrors the development of an originally "actional” - Squartini's terminology must be used here - to an aspectual-grammatically driven form. The earlier durative use of the Italian periphrasis stare + gerund was only possible with non-telic Aktionsarten verbs (according to Vendler's classification of actional classes (1957), these are “activities”, see \$1.2.4), although it could have both imperfective and perfective aspect. Today's progressive periphrasis is compatible

45 Concerning stare + gerund in Old Italian, see also Ferreri (1983) and Heinemann (2003). 46 See, among others, Durante (1981), Bertinetto (1986) and Squartini (1990, 1998). This reduction, however, applies to both the indicative and subjunctive modes, as shown in the following examples, in which stava expresses only externally delimited aspectuality in the indicative and stesse only in the subjunctive: Gli chiesi se stava ancora lavorando a Roma or Non sapevo se stesse lavorando alla sua tesi o se avesse terminato.

47 See Bertinetto (1995a) for a presentation of the typology of the diachronic development of progressive constructions and actional constraints (verb types allowed in progressive constructions). 
with almost all Aktionsarten, but can only have imperfective aspect. In a further grammaticalisation step towards progressivity, stare + gerund was also used in so-called telic contexts (especially with "accomplishments" and "achievements" in Vendler’s sense). In Squartini’s bidimensional approach (see §2.4), the use of progressive periphrases in combination with telic verbs is a means of indicating suspension of the endpoint to be reached. According to Squartini, this becomes evident in examples such as (72), which may be analysed as follows: the endpoint of the state of affairs conveyed by the verb stem of scrivere in combination with the argument una lettera, i.e., the finishing of the letter, is cancelled or blocked by the insertion of stava finendo and therefore not reached. ${ }^{48}$ In the very moment (emphasised by giusto) when Julia called, Francesca was writing the letter which thus was not finished: ${ }^{49}$

(72) It. Francesca stava [Imp.] giusto finendo di scrivere una lettera, quando ha telefonato Julia. [stare + Ger.]

'Francesca was just finishing writing a letter when Julia called.'

Therefore, Schema (1) ought to be specified for Italian as in Schema (2) (following Squartini 1998, 73ff.):

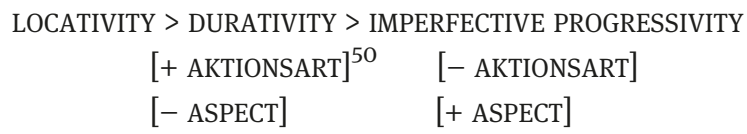

Schema 2: Grammaticalisation path of stare + gerund in Italian II.

48 This analysis naturally presupposes that the verb is considered irrespective of the concrete state of affairs in which it appears, i.e., irrespective of its combination with the other elements in the sentence in question and the meaning it thereby assumes there.

49 Sasse (1991) describes these as typical grammaticalisation paths of aspectual-grammatical markers. Squartini's (1990) and Bertinetto's (1996) data show accomplishments increasing in parallel with an increase in use of the periphrasis to express the progressive. It has already been mentioned (see footnote 39) that the French verbal periphrasis être en train de + infinitive has a different origin to that of the corresponding periphrasis in Italian, and its grammaticalisation path is, of course, likewise different: "[...] even though the French construction ends up performing the function of progressive marker, just like the Italian stare periphrasis, it has a different history. Its progressive meaning has a different origin, deriving from the modal sense of intention and volition, and does not pass through a durative stage. [...] The French form, which is created with different semantic tools, has a completely different path of grammaticalization [...].” (Squartini 1998, 127).

50 Squartini speaks of "actionality" for what is commonly referred to as Aktionsart. 
So far, our discussion of aspectual verbal periphrases has implied a general aspectual content common to all verbal periphrases. Now, however, we can see that in Squartini's analysis - where this is also implied - this commonality is again split into aspect and Aktionsart. We are therefore dealing again with the well-known problem of the semantic subdivision of the aspectual domain, which is, however, particularly problematic in phenomena such as verbal periphrases, as will be shown in more detail in the following section.

\subsection{4 "Aspectual-grammatical" and "actional" verbal periphrases?}

On the one hand, Squartini emphasises that it is indeed the progressive that is particularly useful for showing how the relationship between Aktionsart and aspect can be interpreted as a diachronic process. It is, in his view, precisely this emergence of aspect from Aktionsart that makes it possible to recognise the semantic similarity of the two categories, since they derive from the same "cognitive mould":

\footnotetext{
It [the progressive sds] is rather to be conceived as an aspectual form, which derives diachronically (at least in some languages) from a construction constrained to a given actional value. From this point of view, even if aspect and actionality have to be considered as independent notions, a diachronic relationship between the two can be assumed, so that aspect emerges from actionality, or, put another way, aspect derives from the grammaticalization of actionality. This is why a semantic similarity between aspect and actionality can be recognized, [...] for aspect emerges from the same cognitive mould as actionality. (Squartini 1998, 17f.)
}

On the other hand, he insists on maintaining the distinction between aspect and Aktionsart, which should not be confounded on the synchronic level. Yet, it seems more reasonable to deal with the problem not by distinguishing diachrony and synchrony, but rather by distinguishing onomasiological and semasiological procedures.

Insisting on the categorial distinction, Squartini agrees with the two classic objections against unidimensional approaches (see also §2.5). The first is that the differences connected with language levels and with conceptual and categorial subdivisions are levelled out. In other words, he is mainly concerned with positioning himself against the customary identification of the subcategories aspect and Aktionsart; for example, against equating imperfectivity with durativity and perfectivity with telicity. This is a confusion which, in his opinion, does not allow for the type of subtle investigation of the developments and states of phenomena that he undertakes in his work. The second objection 
concerns the unsuitability of these approaches for highly detailed investigation and analysis of concrete linguistic phenomena.

However, insisting on the distinction between aspect and Aktionsart entails once again some major difficulties.

First of all, it is not easy to identify a cognitive, categorial source with contents common to both on the diachronic level and at the same time to insist on a semantic - i.e., not only formal, morphological - categorial distinction on the synchronic level, as synchronic polyfunctionality is only a kind of snapshot of functional change in diachrony. ${ }^{51}$ What, then, is the common ground on the basis of which - and this seems to be a particularly big problem - we can call all aspectual periphrases - from the highest to the lowest degree of periphrasticity - aspectual, if this common semantic basis is missing in synchrony? How are we to assign examples such as those discussed at the beginning, i.e., the low-grammaticalised or actional- (Aktionsart-) driven periphrases such as It. cominciare a parlare, Fr. se mettre à chanter, Sp. andar pensando, Cat. acabar de parlar? Are they to be conceived as Aktionsart or aspect? Should we rather talk about actional periphrases? And if so, when do they become genuine aspectual-grammatical ${ }^{52}$ periphrases? Finally, we can also ask why, with regard to elements in transition, we should operate with discrete semantic categories, especially when we can clearly identify their cognitive - semantic - unity, even if this consists only in a common origin (the "same cognitive mould" mentioned above)?

With regard to the first criticism of unidimensionality, the following needs to be repeated: ${ }^{53}$ if we posit the existence of two categories which are also semantically different and are expressed on two different linguistic levels (grammar and lexicon), it is theoretically less consistent and can lead to confusions of various kinds if we then define subcategories such as imperfective and perfective on the one hand and stative, durative, telic, etc. on the other and subsequently identify these subcategories with each other again, for example, the imperfective with the durative or the perfective with the telic. It goes without saying that these subcategories of the aspectual domain are, by definition, conceived differently and therefore cannot simply be identified with each other. But it is equally clear that the similarities, the semantic affinities which, on the one hand, relate telicity to perfectivity, and, on the other hand, atelicity to imperfectivity, are already intuitively

51 See the relationship between polysemy and semantic change in the lexicon.

52 Here, I use the term "aspectual-grammatical” (Ger. aspektuell) - and not "aspectual” (Ger. aspektual) as is usual in the conception of this model - since this passage refers to the traditionally understood category of aspect (as opposed to that of Aktionsart, cf. "actional" above). 53 In this context, see also Chapters 2 and 3. 
obvious. But is it really necessary - and this question needs to be repeated here to assume at first the existence of two categories, only to have to then reunite them?

It is perfectly legitimate and practical to adhere to such distinctions when working semasiologically (both synchronically and diachronically), but when working onomasiologically and acknowledging that we are dealing with the same "cognitive mould" in aspect and Aktionsart, we must also acknowledge the reality of a category that encompasses both of these on a universal, conceptual level, i.e., that of aspectuality. From this perspective, to continue to insist on the semantic difference between aspect and Aktionsart proves problematic: on a more general level, both express the internal temporal structuring of a state of affairs, both are aspectuality, and this fact cannot, it seems, be simply banished to the diachronic level. Rather, it is the reason why - synchronically and diachronically - it is possible to assume this "commonality" in aspect and Aktionsart, and it is also the reason why it is possible for a diachronic shift of aspectual information between lexicon and grammar to take place. ${ }^{54}$ We can therefore repeat what has already been emphasised for aspectual verbal periphrases: it is only the means by which Aktionsart and aspect express this information that are different - lexicon or grammar - and these represent variable entities along a continuum.

\subsection{Verbal periphrases - a last interim conclusion}

In view of the quantity, variety and relevance of periphrastic constructions, which, in addition to inflectional past tense markings, express aspectual content especially in the Romance verbal system, it would seem difficult to refuse verbal periphrases an autonomous place of their own in this verbal system.

In the approach described here, the distinction between aspect and Aktionsart at the semantic level is overridden in a superordinate, conceptual universal content category, as is the distinction between so-called "aspectualgrammatical" and "actional verbal periphrases". The common denominator that connects all verbal periphrases is their semantics: all aspectual verbal periphrases express (together with other elements in the situation frame, of course) a particular realisation of a single content category, a particular combination of aspectual basic conceptualisations. The question, which is difficult to answer in the traditional semasiological view of aspectual categories, as to

54 For a different interpretation of the reasons for this shift, see Squartini (1998). 
which aspectual categories they can be assigned - whether they are aspect or Aktionsart - is simply no longer relevant: they are merely aspectuality.

I have shown that, contrary to one of the most serious objections to unidimensional models for the interpretation and description of aspectual information, the model developed here is able to describe and explain in detail the subtleties of the most varied phenomena that express aspectual information in states of affairs - especially the more complex phenomena, such as the verbal periphrases dealt with here as examples.

The possibilities of the model are not, however, limited to this. The particular advantages of this onomasiological treatment of verbal periphrases are, firstly, better comparability of formally different periphrases, for individual languages and crosslinguistically, and secondly, that these must no longer be represented as separate or hybrid linguistic means in the Romance verbal system, but as another equivalent possibility for the Romance language system to express aspectual contents. Through their integration into a general system of aspectuality based on cognitive principles, the verbal periphrases are thus finally treated as 'normal' forms in the Romance verbal paradigm and lose their special status as 'marked'. 


\section{Closing Remarks}

Without doubt, it is possible to speak of aspectuality in the Romance languages. This content category is so clearly discernible in the individual Romance language systems and the linguistic means used to express it are so numerous and varied that there can be no doubt about its relevance and centrality.

With this answer to the question which opened this book, and with some further words about its outcomes and the perspectives resulting from it I now close. On these last pages, I will summarise the main theses and the central results (an overview of the individual chapters can be found in the introduction) followed by a look forward to further possible expansions of the model developed here.

Some recurrent basic functions or categories in the languages of the world can be identified as crosslinguistic or even universal; they express very general spatial and temporal structurings through which humans organise what they perceive the world to be by means of their cognitive abilities. These are therefore conceptual content categories, which are then expressed in the individual languages by the most diverse linguistic means - lexical and grammatical morphemes as well as more complex syntactic units. If we want to compare languages, we have to look for such categories as will allow this and that can therefore serve as a tertium comparationis.

It is precisely in this sense - and hence from an onomasiological perspective - that aspectuality has been defined in this book as a universal semantic category through which speakers linguistically structure the way a state of affairs develops and is distributed in time. The distinction between aspect and Aktionsart as subcomponents within aspectuality has been overridden, because it then proves impossible to continue to insist on a semantic difference between aspect and Aktionsart. On a more general, cognitive level, both categories express the internal temporal structuring of states of affairs, both are aspectuality. With this defence of the semantic homogeneity of the aspectual domain, this work positions itself within aspectological research among the unidimensional approaches.

Aspectuality is seen here as a complex, interactional category, with complexity essentially played out on two levels. On the one hand, we have the level of the onomasiological foundation of the category as such, and, on the other, that of the diverse interacting elements through which aspectuality is linguistically realised in describing states of affairs.

The approach taken in this book therefore differs in one important point from many studies on aspectual categories. For although there is certainly broad 
general consensus on the necessity of classifying verbs in context (a verb cannot be assigned to one or another verb class independently of its arguments), reference is rarely made to the influence of other elements in the sentence on the aspectual value, and even less frequently to the effect of extralinguistic and pragmatic factors. This is precisely what this study has paid particular attention to: the aspectual interpretation of a state of affairs results from a very complex interaction of several elements or subcomponents. Even the elements that do not directly convey aspectual information (such as negation or certain types of word order) interact with those that do so directly (such as verb lexemes, morphological aspectual markings and adverbial determiners) to influence the overall interpretation of the state of affairs. This interaction can mean mutually reinforcing or specifying, but also correcting or eliminating the wealth of information concerning the temporal structuring of the state of affairs.

Following the presentation of this comprehensive category of aspectuality, one of the main concerns of this work was to provide a unidimensional model for classifying and interpreting the aspectual contents of states of affairs, which could be applied crosslinguistically and efficiently in language comparison using a set of descriptive and analytical tools on a conceptual level, while also being able to provide detailed analyses of more specific phenomena in the individual languages.

Unlike other unidimensional models, the model was also intended to focus on the semantics and not on the syntax of the sentences used to describe the states of affairs. A frame-theoretical approach was chosen for this purpose and, consequently, states of affairs were conceived as situation frames.

The advantages of such a decision are various: first of all, frame theory provides a particular conception of the content category of aspectuality as a perceptual or conceptual gestalt, a form of human conceptual organisation of reality that solves many of the problems of the traditional conception.

Frame - defined as a structured, interrelated knowledge context, which can be generally conceptual or culture-specific in nature, by means of which humans approach different everyday situations - is a multidimensional notion with conceptual and social dimensions that allows for fruitful examination of certain forms of polysemy. A semantic explanation of linguistic structures that takes into account human encyclopaedic knowledge has the enormous advantage of being able to embrace the historical and socio-cultural factors of communication. Here, linguistic elements are not understood as a simple, direct expression of concepts, with which they would then also be directly equivalent, but rather as tools that trigger activation of certain areas of speakers' and hearers' knowledge of the world. In different contexts of use, different areas are activated to different degrees. This proves to be particularly useful when dealing 
with linguistic structurings of aspectual contents of entire states of affairs. The aspectuality frames discussed here are, therefore, to be classified on a very abstract level, because they represent whole classes of frames.

As frames consist of elements related to each other by contiguity, aspectuality has been defined here as consisting of elements that are related by a particular type of contiguity and which can each be focussed or perspectivised in a different way. In accordance with the onomasiological perspective adopted, the delimitation principle was chosen as the rule of description and classification of aspectual contents, based on the figure-ground principle and therefore on the basic cognitive association principle of contiguity.

On the basis of the delimitation principle, which is generally to be understood as the setting of initial, final and subdividing temporal boundaries in the temporal development of a state of affairs, aspectuality was subdivided into three dimensions or perspectives of observation, depending on what is highlighted or focussed within the situation frame. In the delimitation process, the elements participating in the process - the boundaries $t_{x}$ themselves, the previous and subsequent adjacencies of the set boundaries, and the interval surrounded by two set boundaries are thus focussed from three different perspectives: 1) the external aspectuality of a state of affairs or its absolute delimitation; 2) the adjacency-related aspectuality or the relevance of a state of affairs for its adjacencies; 3) the internal aspectuality or its further internal subdivision. Each of these dimensions is perceived as a figure in relation to the other two (as the associated ground), and each occurs in a limited number of realisations within the individual frame: the aspectual basic conceptualisations.

These can be combined with each other on the higher level of the whole state of affairs (and are necessarily combined in the currently-expressed state of affairs) and the overall aspectual meaning of a situation frame arises precisely from this combination. Hence, an inventory was also drawn up of the possible and impossible combination patterns of the aspectual basic conceptualisations, referred to here as delimitation schemas.

In more complex states of affairs, the temporal boundaries presented in the state of affairs can be further perspectivised. Starting from the combinations of basic conceptualisations, the model of aspectuality was developed and organised on two levels: on the first level, combinations of basic conceptualisations of less complex states of affairs are represented; on the second level, the constitutive moments $t_{x 1}, t_{x 2}, \ldots t_{x n}$ (presumed on the first level) of an internally subdivided state of affairs are further focussed - individually or severally -, i.e., highlighted within the situation frame and once again their surrounding aspectual delimitation is represented. On the second level, for example, complex temporal structurings of states of affairs such as the progressive are represented. 
By combining the limited number of realisations of the three perspectives of delimitation on the two levels of the model, it is indeed possible to present all aspectual contents of states of affairs in any language.

Application of the model to four Romance languages - Italian, French, Spanish and Catalan - was another central concern of the book. On the one hand, the efficiency of the model in describing aspectual contents can be tested by applying it to various individual languages; on the other hand, a detailed comparative study of aspectuality in the Romance languages, which is still absent from more recent research, can also be simultaneously presented. The application was carried out from an onomasiological perspective: beginning with the presentation of the various aspectual contents that result from different combinations of basic conceptualisations (the delimitation schemas), I examined the linguistic means by which these Romance languages express these contents, although I did not provide a comprehensive inventory of all the possible language-particular realisations.

To this end, I presented and commented in parallel examples from the four Romance languages, in which aspectuality is expressed through both lexical and grammatical means and which also mostly have different tenses. There were several reasons for this: initially, parallel treatment of examples from the four Romance languages served to show the variety of formal means available to them for expressing aspectual content, which made it possible to show both that different languages can have different means of expressing the same aspectual content, and that one and the same language has at its disposal several alternative possibilities. Presentation of these differences showed that there is not necessarily a correspondence between a particular realisation of aspectuality and a particular morphological marking or a particular type of predicate. In fact, it is not only the verb forms traditionally referred to as perfective that can express an externally delimited state of affairs, as this can also be expressed through other tense forms, such as the present, and also through lexical or lexical-syntactic forms, such as adverbial determiners or combinations of verb stems and special arguments. This also makes it clear that the model is not a mere translation of traditional categories into another terminology.

Analysis of both levels of the model through the Romance languages also makes it possible to address and overcome the classification problems associated with language forms that display different degrees of grammaticalisation or lexicalisation, such as aspectual verbal periphrases, and thus to integrate them into the Romance verbal system and free them from their hybrid position.

This unidimensionality-based and frame-oriented model, which comprises a compact group of elementary meanings or basic concepts (the basic conceptualisations) and which is ultimately also based on a single but comprehensive 
cognitive principle, has proven to be a suitable instrument for both the comparative language study of aspectual contents and for the description of aspectuality in individual languages. In the latter case, therefore, separate investigation from a semasiological perspective is not an absolute necessity.

At this stage of the work, the following seem obvious topics for further study:

On a more general level, the model - one of whose particular strengths may lie in its application in typological studies - should be tested in other, typologically different, languages. For example, investigation should be carried out on the possible combinations of aspectual basic conceptualisations that are actually expressed in various languages and the means they use to express them. The validity of the constraints presented here should also be further verified so that the universality of the model can also rest on a broader empirical basis.

As far as application of the model to the Romance languages is concerned, some of the synchronic analyses of single phenomena in individual languages carried out here could be deepened with further data or, more specifically, the focus of the study could be shifted from language comparison to individual languages. In this way, a complete and detailed picture of aspectuality in a given Romance language could be obtained, something that has rarely been attempted so far from an onomasiological perspective. The model may also be applied to other individual Romance language phenomena in diachrony (such as the change in use of so-called aspect oppositions from Old to Modern French or from Old to Modern Italian).

Further applications of the model in specific areas of linguistics, such as translation theory and language teaching could prove particularly fruitful. For example, a classic problem, such as the lack of a German equivalent to Romance aspectuality marked on the verb by inflection, could be approached from a different perspective. For with this model's descriptive tools it is no longer necessary to postulate for each language an aspectual category (the one here is particularly efficient), which then possesses its own organisational principles and subcategories (which are not entirely comparable with other categories). Describing aspectual contents by means of basic conceptualisations can also serve as the basis for developing a language teaching model, especially one for comparing languages that express aspectual content and its combinations in very different ways. 



\section{Abbreviations}

\section{Languages}

$\begin{array}{ll}\text { Cat. } & \text { Catalan } \\ \text { Eng. } & \text { English } \\ \text { Fr. } & \text { French } \\ \text { Ger. } & \text { German } \\ \text { It. } & \text { Italian } \\ \text { Lat. } & \text { Latin } \\ \text { OFr. } & \text { Old French } \\ \text { Olt. } & \text { Old Italian } \\ \text { Sp. } & \text { Spanish }\end{array}$

\section{Verbal Forms}

\section{Catalan}

$\begin{array}{ll}\text { [Pres.] } & \text { Present Indicatiu } \\ \text { [Imp.] } & \text { Pretèrit Imperfet Indicatiu } \\ \text { [Pret. Perf. Sim.] } & \text { Pretèrit Perfet Simple Indicatiu } \\ \text { [Pret. Perf. Per.] } & \text { Pretèrit Perfet Perifràstic Indicatiu } \\ \text { [Pret. Indef.] } & \text { Pretèrit Indefinit Indicatiu } \\ \text { [Fut.] } & \text { Futur Simple Indicatiu }\end{array}$

\section{English}

$\begin{array}{ll}\text { [Sim. Pres.] } & \text { Simple Present } \\ \text { [Pres. Prog.] } & \text { Present Progressive } \\ \text { [Sim. Past] } & \text { Simple Past } \\ \text { [Past Prog.] } & \text { Past Progressive }\end{array}$

\section{French}

$\begin{array}{ll}\text { [Prés.] } & \text { Présent Indicatif } \\ \text { [Imp.] } & \text { Imparfait Indicatif } \\ \text { [Pass. Sim.] } & \text { Passé Simple Indicatif } \\ \text { [Pass. Com.] } & \text { Passé Composé Indicatif } \\ \text { [Fut.] } & \text { Futur Simple Indicatif } \\ \text { [Prés. Imp.] } & \text { Présent Impératif } \\ \text { [Prés. Subj.] } & \text { Présent Subjonctif }\end{array}$

Ә Open Access. () 2019 Sarah Dessì Schmid, published by De Gruyter. (cc) BY-NC-ND This work is licensed under a Creative Commons Attribution-NonCommercial-NoDerivatives 4.0 International License. 


\section{German}

$\begin{array}{ll}\text { [Präs.] } & \text { Präsens Indikativ } \\ \text { [Prät.] } & \text { Präteritum Indikativ } \\ \text { [Perf.] } & \text { Perfekt Indikativ } \\ \text { [Fut.] } & \text { Futur Indikativ } \\ \text { [Präs. Imp.] } & \text { Präsens Imperativ } \\ \text { [Präs. Konj.] } & \text { Präsens Konjunktiv } \\ \text { [Inf.] } & \text { Infinitiv } \\ \text { [Ger.] } & \text { Gerundium }\end{array}$

\section{Italian}

[Pres.] Presente Indicativo

[Imp.] Imperfetto Indicativo

[Perf. Sem.] Perfetto Semplice Indicativo

[Perf. Com.] Perfetto Composto Indicativo

[Fut.] Futuro Semplice Indicativo

[Pres. Imp.] Presente Imperativo

[Pres. Cong.] Presente Congiuntivo

\section{Spanish}

$\begin{array}{ll}\text { [Pres.] } & \text { Presente Indicativo } \\ \text { [Imp.] } & \text { Imperfecto Indicativo } \\ \text { [Perf. Sim.] } & \text { Perfecto Simple Indicativo } \\ \text { [Perf. Com.] } & \text { Perfecto Compuesto Indicativo } \\ \text { [Fut.] } & \text { Futuro Simple Indicativo } \\ \text { [Pres. Imp.] } & \text { Presente Imperativo } \\ \text { [Pres. Subj.] } & \text { Presente Subjuntivo }\end{array}$

\section{Traditional Labels for Aspectual Oppositions}
[v. abit.] valore abituale ${ }^{1}$
[v. prog.] valore progressivo
[v. cont.] valore continuativo
[v. comp.] valore compiuto
[v. aor.] valore aoristico
[Prog. Foc.] Progressif focalisé ${ }^{2}$
[Prog. Dur.] Progressif duratif

1 These forms are indicated in Italian, as they refer to Bertinetto (1986).

2 These forms are indicated in French, as they refer to Bertinetto (1995a). 


\title{
Abbreviations of Aspectuality Terms and Aspectual Basic Conceptualisations
}

\author{
SA state of affairs \\ SF situation frame \\ DS delimitation schema \\ EA external aspectuality \\ AA adjacency-related aspectuality \\ IA internal aspectuality \\ EA/d externally delimited SA \\ $E A / p d \quad$ externally punctually delimited $S A$ \\ $\mathrm{EA} / \mathrm{nd}$ externally not delimited SA \\ $\mathrm{AA} / \mathrm{fr} \quad \mathrm{SA}$ with final adjacency relevance \\ AA/ir SA with initial adjacency relevance \\ AA/tr SA with final and initial (transformative) relevance \\ AA/nr SA without adjacency relevance \\ $\mathrm{IA} / \mathrm{s} \quad$ internally subdivided $\mathrm{SA}$ \\ $\mathrm{IA} / \mathrm{ns} \quad$ internally non-subdivided SA \\ NEA impossibility of external aspectuality \\ NAA impossibility of adjacency-related aspectuality \\ NIA impossibility of internal aspectuality
}





\section{References}

Abraham, Werner/Janssen, Theo (edd.), Tempus - Aspekt - Modus. Die lexikalischen und grammatischen Formen in den germanischen Sprachen, Tübingen, Niemeyer, 1989.

Agrell, Sigurd, Aspektänderung und Aktionsartbildung beim polnischen Zeitwort. Ein Beitrag zum Studium der indogermanischen Präverbia und ihrer Bedeutungsfunktionen, Lund, Ohlsson, 1908.

Aijmer, Karin, The Semantic Path from Modality to Aspect: "Be Able to" in a Cross-Linguistic Perspective, in: Hans Lindquist/Christian Mair (edd.), Corpus approaches to grammaticalization in English, Amsterdam, Benjamins, 2004, 57-78.

Alarcos Llorach, Emilio, Sobre la estructura del verbo español, Boletín de la Biblioteca Menéndez Pelayo 31 (1949), 108-139.

Alarcos Llorach, Emilio, Otra vez sobre el sistema verbal español, in: Rafael Lapesa (ed.), Homenaje a la memoria de Don Antonio Rodríguez Moñino, Madrid, Castalia, 1975, 9-26.

Alarcos Llorach, Emilio, Gramática de la lengua española, Madrid, Espasa (Real Academia Española, colección Nebrija y Bello), ${ }^{10} 1999$.

Alturo, Nuria, La semàntica verbal del català: la representació dels esdeveniments, doctoral thesis, Barcelona, Publicacions de la Universitat de Barcelona, 1997.

Alturo, Nuria, El papel de la anterioridad y de la perfectividad en la representación de estados y eventos, in: María José Serrano (ed.), Estudios de variación sintática, Madrid, Iberoamericana, 1999, 143-172.

Alturo, Nuria, Les activitats no són accions (situacions $i$ tipus de text en anglès $i$ català), Caplletra, Revista internacional de Filología 30 (2001), 111-134.

Ambrosini, Riccardo, L'uso dei tempi storici nell'italiano antico, L'Italia dialettale 29/1 (1960/61), 13-124.

Ambrosini, Riccardo, Sulla sintassi del verbo nella prosa toscana del Dugento - ovvero - Tempo e aspetto nell'italiano antico, Lingua e Stile 35/4 (2000), 547-571.

Anderson, Stephen R., On the formal description of inflection, CLS 13 (1977), 15-44.

Anderson, Stephen R., Where's Morphology?, Linguistic Inquiry 13 (1982), 571-612.

Anderson, Stephen R., Morphological Theory, in: Frederick J. Newmeyer (ed.), Linguistics: The Cambridge survey, vol. 1: Linguistic Theory: Foundations, Cambridge, Cambridge University Press, 1988, 146-191.

Anscombre, Jean-Claude, Imparfait et passé composé: des forts en thème/propos, L'information grammaticale 55 (1992), 43-53.

Anscombre, Jean-Claude, L'imparfait d'atténuation: quand parler à l'imparfait, c'est faire, Langue française 142 (2004), 75-99.

Anstatt, Tanja, "Zeit". Motivierungen und Strukturen der Bedeutungen von Zeitbezeichnungen in slawischen und anderen Sprachen, München, Sagner, 1996.

Anstatt, Tanja, Aspekt, Argumente und Verbklassen im Russischen, unpublished Habilitation thesis, Universität Tübingen, 2003.

Aschenberg, Heidi, On remplace les mauvaises têtes? Zum Kontextbegriff in der Sprachwissenschaft, unpublished manuscript, 2008.

Asnes, Maria, Incompatibility between Telicity and Homogeneity in French, in: Bart Hollebrandse/Angeliek van Hout/Co Vet (edd.), Crosslinguistic Views on Tense, Aspect and Modality, Amsterdam, Rodopi, 2005, 93-102.

¿ Open Access. (C) 2019 Sarah Dessì Schmid, published by De Gruyter. (cc)BY-NC-ND This work is licensed under a Creative Commons Attribution-NonCommercial-NoDerivatives 4.0 International License. https://doi.org/10.1515/9783110562088-010 
Auwera van der, Johan/Gast, Volker, Categories and Prototypes, in: Jae Jung Song (ed.), The Oxford Handbook of Linguistic Typology, Oxford, Oxford University Press, 2011, 166-189. Bach, Emmon, The Algebra of Events, Linguistics and Philosophy 9/1 (1986), 5-16.

Bache, Carl, Aspect and Aktionsart: towards a semantic distinction, Linguistics 18 (1982), 57-72.

Bache, Carl, The Study of Aspect, Tense and Action: Towards a Theory of the Semantics of Grammatical Categories, Frankfurt a. M. et al., Peter Lang, 1995 (=1995a).

Bache, Carl, Another look at the distinction between aspect and action, in: Pier Marco Bertinetto et al. (edd.), Temporal Reference, Aspect and Actionality, vol. 2: Typological Perspectives, Torino, Rosenberg \& Sellier, 1995, 65-78 (= 1995b).

Bache, Carl/Basbøll, Hans/Lindberg, Carl-Erik, Tense, Aspect and Action. Empirical and Theoretical Contributions to Language Typology, Berlin/New York, De Gruyter, 1994.

Badia i Margarit, Antoni M., Gramàtica de la llengua catalana. Descriptiva, normativa, diatòpica, diastràtica, Barcelona, Proa, 1994.

Barsalou, Lawrence W., Frames, Concepts and conceptual Fields, in: Adrienne Lehrer (ed.), Frames, fields and contrasts: new essays in semantic and lexical organization, Hillsdale, NJ, Erlbaum, 1992, 21-64.

Bates, Elizabeth/MacWhinney, Brian, Functionalist approaches to grammar, in: Lila R. Gleitman/Eric Wanner (edd.), Language Acquisition: The State of the Art, Cambridge, Cambridge University Press, 1982.

Bazzanella, Carla, "Modal" uses of the Italian Indicativo Imperfetto in a pragmatic perspective, Journal of Pragmatics 14/3 (1990), 439-457.

Beck, Gabriele, Verb, Satz, Zeit: zur temporalen Struktur der Verben im Französischen, Tübingen, Niemeyer, 1987.

Beck-Busse, Gabriele, Per una rilettura di "Verbs and Times" di Zeno Vendler, Studi italiani di linguistica teorica e applicata 24/1 (1995), 43-58.

Becker, Martin, From temporal to modal: divergent fates of the Latin synthetic pluperfect in Spanish and Portuguese, in: Ulrich Detges/Richard Waltereit (edd.), The Paradox of Grammatical Change. Perspectives from Romance, Amsterdam/Philadelphia, Benjamins, 2008, 147-179.

Becker, Martin, Welten in Sprache. Zur Entwicklung der Kategorie "Modus" in romanischen Sprachen, Berlin/Boston, De Gruyter, 2014.

Bello, Andrés, Análisis ideológica de los tiempos de la conjugación castellana, in: Obras Completas: Estudios gramaticales, Caracas, Ministerio de Educación, 1951 (1841), 1-67.

Bello, Andrés, Gramática de la lengua castellana destinada al uso de los americanos, ed. Ramón Trujillo, Santa Cruz de Tenerife, Instituto universitario de Lingüística Andrés Bello, 1981 (1847).

Benveniste, Émile, Les relations de temps dans le verbe français, Bulletin de la Société de Linguistique de Paris 54 (1959), 69-82 (repr. 1966 in: Problèmes de linguistique générale, 1966, 237-250).

Berlin, Brent/Kay, Paul, Basic Color Terms: Their Universality and Evolution, Berkeley, University Press, 1969.

Berrettoni, Pierangiolo, La metafora aspettuale, Studi e Saggi Linguistici 12 (1972), 250-259.

Berrettoni, Pierangiolo, Aspetto verbale e viaggi temporali: sul contenuto semantico dell'aspetto progressivo, Studi e Saggi Linguistici 22 (1982), 49-118.

Berthonneau, Anne-Marie/Kleiber, Georges, Pour une nouvelle approche de l'imparfait: l'imparfait, un temps anaphorique méronanique, Langages 112 (1993), 55-73. 
Berthonneau, Anne-Marie/Kleiber, Georges, Un imparfait de plus... et le train déraillait, in: Sylvie Mellet/Marcel Vuillaume (edd.), Modes de repérages temporels, Amsterdam, Rodopi, 2003, 1-24.

Bertinetto, Pier Marco, Nuovamente sull'imperfetto narrativo, Lingua Nostra 41 (1980), 83-89.

Bertinetto, Pier Marco, Il carattere del processo ("Aktionsart") in italiano: proposte sintatticamente motivate. Per una tipologia del lessico verbale, in: Massimo Moneglia (ed.), Tempo verbale: Strutture quantificate in forma logica. Atti del Seminario, Accademia della Crusca 13-14 dicembre 1979, Firenze, Accademia della Crusca, 1981.

Bertinetto, Pier Marco, Tempo, aspetto e azione nel verbo italiano. Il sistema dell'indicativo, Firenze, Accademia della Crusca, 1986.

Bertinetto, Pier Marco, Avverbi pseudodeittici e restrizioni sui tempi verbali in italiano, in: Nicoletta Maraschio et al. (edd.), Tra Rinascimento e strutture attuali (Atti del Primo Convegno della Società Internazionale di Linguistica e Filologia Italiana, Siena, 28-31 marzo 1989), Torino, Rosenberg \& Sellier, 1991, 289-304.

Bertinetto, Pier Marco, Le strutture tempo-aspettuali dell'italiano e dell'inglese a confronto, in: Antonia G. Mocciaro/Giulio Soravia (edd.), L'Europa linguistica: contatti, contrasti, e affinità di lingue, Roma, Bulzoni, 1992, 49-68 (=1992a).

Bertinetto, Pier Marco, Metafore tempo-aspettuali, Linguistica 32 (1992), 89-110 (=1992b).

Bertinetto, Pier Marco, Temporal reference, Aspect and Actionality: Their neutralizations and interactions, mostly exemplified in Italian, in: Carl Bache/Hans Basbøll/Carl-Erik Lindberg (edd.), Tense, Aspect and Action. Empirical and Theoretical Contributions to Language Typology, Berlin/New York, Mouton de Gruyter, 1994, 113-137.

Bertinetto, Pier Marco, Vers une typologie du progressif dans les langues d'Europe, Modèles Linguistiques 16/2 (1995), 37-61 (= 1995a).

Bertinetto, Pier Marco, Le perifrasi abituali in italiano ed in inglese, Studi Orientali e Linguistici 6 (1995/96) (1995), 117-133 (= 1995b).

Bertinetto, Pier Marco, Le perifrasi progressiva e continua nella narrativa dell'Otto e Novecento, in: Lucio Lugnani/Mario Santagata/Alfredo Stussi (edd.), Studi offerti a Luigi Blasucci dai colleghi e dagli allievi pisani, Lucca, Pacini Fazzi, 1996, 77-100.

Bertinetto, Pier Marco, Il dominio tempo-aspettuale. Demarcazioni, intersezioni, contrasti (con la collaborazione di Denis Delfitto), Torino, Rosenberg \& Sellier, 1997.

Bertinetto, Pier Marco, Sui connotati azionali ed aspettuali della perifrasi continua ("andare / venire + gerundio"), in: Giuliano Bernini/Pierluigi Cuzzolin/Piera Molinelli (edd.), Ars linguistica. Studi offerti da colleghi ed allievi a Paolo Ramat in occasione del suo $60^{\circ}$ compleanno, Roma, Bulzoni, 1998, 109-128 (= 1998a).

Bertinetto, Pier Marco, Verso una definizione della perifrasi "continua" ("andare / venire + gerundio"), in: Luciano Agostiniani et al. (edd.), do-ra-qe pe-re: Studi in memoria di Adriana Quattordio Moreschini, Pisa, Giardini, 1998, 87-101 (= 1998b).

Bertinetto, Pier Marco, Il sintagma verbale, in: Lorenzo Renzi/Giampaolo Salvi/Anna Cardinaletti (edd.), Grande grammatica italiana di consultazione, vol. 2, Bologna, II Mulino, ${ }^{2} 2001,11-317$.

Bertinetto, Pier Marco/Bianchi, Valentina/Higginbotham, James/Squartini, Mario (edd.), Temporal Reference, Aspect and Actionality, vol. 1: Semantic and Syntactic Perspectives, Torino, Rosenberg \& Sellier, 1995.

Bertinetto, Pier Marco/Bianchi, Valentina/Dahl, Östen/Squartini, Mario (edd.), Temporal Reference, Aspect and Actionality, vol. 2: Typological Perspectives, Torino, Rosenberg \& Sellier, 1995. 
Bertinetto, Pier Marco/Delfitto, Denis, L'espressione della progressività-continuità: un confronto tripolare (italiano, inglese e spagnolo), in: Paola Benincà et al. (edd.), Italiano e dialetti nel tempo. Studi di grammatica per Giulio C. Lepschy, Roma, Bulzoni, 1996, 45-66.

Bertinetto, Pier Marco/Lenci, Alessandro, Habituality, Pluractionality, and Imperfectivity, in: Robert Binnick (ed.), The Oxford Handbook of Tense and Aspect, Oxford, Oxford University Press, 2012, 852-880.

Bickel, Balthasar, Aspect, Mood, and Time in Belhare: Studies in the Semantics-Pragmatics Interface of a Himalayan Language, Zürich, Universität Zürich, 1996.

Bickel, Balthasar, Aspectual scope and the difference between logical and semantic representation, Lingua 102 (1997), 115-131.

Bickel, Balthasar, Unlogischer Aspekt: Zur Bedeutungsstruktur von Aspekt und Aktionsart, besonders im Belharischen, in: Walter Breu (ed.), Probleme der Interaktion von Lexik und Aspekt (ILA), Tübingen, Niemeyer, 2000, 1-20.

Bickel, Balthasar, Grammatical Relations Typology, in: Jae Jung Song (ed.), The Oxford Handbook of Linguistic Typology, Oxford, Oxford University Press, 2011, 399-444.

Bickerton, Derek, Language and human behaviour, London, UCL Press, 1996.

Binnick, Robert I., Time and the Verb. A Guide to Tense and Aspect, Oxford, Oxford University Press, 1991.

Binnick, Robert I., The Project on Annotated Bibliography of Contemporary Research in Tense, Grammatical Aspect, Aktionsart, and Related Areas - Bibliographic Entries, Toronto, University of Toronto Scarborough, 2006.

Binnick, Robert I. (ed.), The Oxford Handbook of Tense and Aspect, Oxford, Oxford University Press, 2012.

Blank, Andreas, Prinzipien des lexikalischen Bedeutungswandels am Beispiel der romanischen Sprachen, Tübingen, Niemeyer, 1997.

Blank, Andreas, Einführung in die lexikalische Semantik für Romanisten, Tübingen, Niemeyer, 2001.

Blank, Andreas/Koch, Peter (edd.), Historical Semantics and Cognition, Berlin/New York, Mouton de Gruyter, 1999.

Blücher, Kolbjørn, Considerazioni sui costrutti del tipo "stare cantando", "andare cantando", "venire cantando", Revue Romane 8/1-2 (1973), 13-20.

Blücher, Kolbjørn, Studio sulle forme "ho cantata", "cantai", "centavo", "stavo cantando". Struttura, funzione e uso nel sistema verbale del italiano moderno, Bergen/Oslo/Tromsø, Universitetsforlaget, 1974.

Blumenthal, Peter, Vergangenheitstempora, Textstrukturierung und Zeitverständnis in der französischen Sprachgeschichte, Wiesbaden, Steiner, 1986.

Böckle, Klaus, Zur aspektuellen Verbalperiphrase im Französischen, Portugiesischen und Italienischen, in: Richard Baum/Franz Josef Hausmann/Irene Monreal-Wickert (edd.), Sprache in Unterricht und Forschung: Schwerpunkt Romanistik, Tübingen, Narr, 1979, 195-216.

Böckle, Klaus, Zum Konjunktiv im Portugiesischen. Kritik älterer Theorien und Versuch eines neuen Ansatzes am Beispiel der Konstruktion mit "dai que", in: Jürgen Schmidt-Radefeldt (ed.), Portugiesische Sprachwissenschaft, Tübingen, Narr, 1983 (= 1983a).

Böckle, Klaus, Eine diachronische Untersuchung zum Verhältnis von "por" und "para" in der Iberoromania: Kritik und Ergänzungen, Zeitschrift für romanische Philologie 99 (1983), 69-83 (= 1983b). 
Böckle, Klaus, Para uma análise semântica do emprego dos modos nas orações ilativas iniciadas por "daí que" e semelhantes correlativos em português contemporâneo, in: José G. Herculano de Carvalho/Jürgen Schmidt-Radefeldt (edd.), Estudos de linguística portuguesa, Coimbra, Coimbra Editora, 1984.

Bondarko, Aleksandr V., Diskussii I obsuždenija, Voprosy jazykoznanija 2 (1967), 18-31.

Bondarko, Aleksandr V., Teorija funkcional'noj grammatiki, vol. 1: Vvedenie. Aspektual'nost'. Vremennaja lokalizovannost', Taksis, Leningrad, 1987.

Bonfante, Giuliano, L'aspetto verbale del tipo italiano: “(io) sto facendo”, “(io) sto insegnando", Archivio Glottologico Italiano 68 (1983), 50.

Bonomi, Andrea/Zucchi, Alessandro, Tempo e linguaggio. Introduzione alla semantica del tempo e dell'aspetto verbale, Milano, Mondadori, 2001.

Boogaart, Ronny, Towards a theory of discourse aspectuality, in: Pier Marco Bertinetto et al. (edd.), Temporal Reference, Aspect and Actionality, vol. 1: Semantic and Syntactic Perspectives, Torino, Rosenberg \& Sellier, 1995, 221-236.

Booij, Geert, Construction Morphology, Oxford, Oxford University Press, 2010.

Borillo, Andrée/Vetters, Carl/Vuillaume, Marcel (edd.), Regards sur l'aspect, Amsterdam, Rodopi, 1997.

Borillo, Andrée/Vetters, Carl/Vuillaume, Marcel (edd.), Variations sur la référence verbale, Amsterdam, Rodopi, 1998.

Bosque, Ignacio (ed.), Tiempo y aspecto en español, Madrid, Cátedra, 1990 (= 1990a).

Bosque, Ignacio (ed.), Sobre el Aspecto en los adjetivos y en los participios, in: id. (ed.), Tiempo y aspecto en español, Madrid, Cátedra, 1990, 177-214, (= 1990b).

Bosque, Ignacio/Demonte, Violeta (edd.), Gramática descriptiva de la lengua española, 3 vol., Madrid, RAE-Espasa Calpe, 1999.

Breu, Walter, Zur Rolle der Lexik in der Aspektologie, Die Welt der Slaven 29 (1984), 123-148.

Breu, Walter, Handlungsgrenzen als Grundlage der Verbklassifikation, in: Werner Lehfeldt (ed.), Slavistische Linguistik, München, Sagner, 1985, 9-34.

Breu, Walter, Interactions between lexical, temporal and aspectual meanings, Studies in Language 18 (1994), 23-44.

Breu, Walter (ed.), Probleme der Interaktion von Lexik und Aspekt (ILA), Tübingen, Niemeyer, 2000.

Brianti, Giovanna, Périphrases aspectuelles de l'italien. Le cas de "andare", "venire" et "stare" + gérondif, Bern, Peter Lang, 1992.

Brianti, Giovanna, Diacronia delle perifrasi aspettuali dell'italiano. Il caso di "stare" + gerundio, "andare" e "venire" + gerundio, Lingua Nostra 61/1-2 (2000), 35-53.

Brinton, Laurel J./Traugott, Elizabeth C., Lexicalization and language change, Cambridge, Cambridge University Press, 2005.

Brucart, Josep M./Rigau, Gemma, Els temps verbals en español i en català: sistemàtica i terminologia, Articles de didàctica de la llengua i de la literatura 12 (1997), 81-100.

Brugmann, Karl, Griechische Grammatik. Lautlehre, Stammbildungs- und Flexionslehre und Syntax, München, C. H. Beck'sche Verlagsbuchhandlung, ${ }^{3} 1900$ (1885).

Bühler, Karl, Sprachtheorie: die Darstellungsfunktion der Sprache, Jena, Fischer, 1934.

Bull, William E., Modern Spanish Verb-Form Frequencies, Hispania 30 (1947), 451-466.

Bull, William E., Time, Tense and the Verb: a Study in Theoretical and Applied Linguistics, with particular Attention to Spanish, Berkeley/Los Angeles, University of California Press, 1960.

Bull, William E./Farley, Rodger, Exploratory Study of the Nature of Actions and the Functions of Verbs in Spanish, Hispania 32 (1949), 64-73. 
Bustos Gisbert, José M., La temporalidad en español: Análisis intencional, Linguística Española Actual 17/2 (1995), 143-166.

Bybee, Joan L., Morphology: a Study of the Relation between Meaning and Form, Amsterdam/ Philadelphia, Benjamins, 1985.

Bybee, Joan L./Dahl, Östen, The creation of tense and aspect systems in the languages of the world, Studies in Language 13/1 (1989), 51-103.

Bybee, Joan L./Perkins, Revere D./Pagliuca, William, The evolution of grammar: tense, aspect and modality in the languages of the world, Chicago/London, The University of Chicago Press, 1994.

Cano Aguilar, Rafael, El español a través de los tiempos, Madrid, Arco Libros, 1988.

Carlson, Greg N., Reference to Kinds in English, Ph.D. Diss., University of California, 1977.

Carlson, Greg N., Generics, Habituals and Iteratives, in: The Encyclopedia of Language and Linguistics, Oxford, Elsevier, 2005.

Carlson, Greg N., Habitual and Generic Aspect, in: Robert Binnick (ed.), The Oxford Handbook of Tense and Aspect, Oxford, Oxford University Press, 2012, 828-851.

Carlson, Greg N./Pelletier, Francis J. (edd.), The Generic Book, Chicago, University of Chicago Press, 1995.

Cartagena, Nelson, Acerca de las categorías de tiempo y aspecto en el sistema verbal español, Revista de la Sociedad Española de Lingüística 8 (1978), 373-391.

Cartagena, Nelson, Das Tempussystem der spanischen Gegenwartssprache, in: Rolf Thieroff/ Joachim Ballweg (edd.), Tense Systems in European Languages, Tübingen, Niemeyer, 1994, 173-190.

Cartagena, Nelson/Gauger, Hans-Martin, Vergleichende Grammatik Spanisch-Deutsch, 2 vol., Mannheim, Duden, 1989.

Cassirer, Ernst, Philosophie der symbolischen Formen, Erster Teil: Die Sprache, in: Gesammelte Werke. Hamburger Ausgabe, vol. 11, edd. Birgit Recki/Claus Rosenkranz, Hamburg, Meiner, 2001 (1923).

Cassirer, Ernst, Die Sprache und der Aufbau der Gegenstandswelt, in: Aufsätze und kleine Schriften (1932-1935), in: Gesammelte Werke. Hamburger Ausgabe, vol. 18, edd. Birgit Recki/Ralf Becker, Hamburg, Meiner, 2004 (1932), 111-116.

Caudal, Patrick, Degree Scales and Aspect, in: Bart Hollebrandse/Angeliek van Hout/Co Vet (edd.), Crosslinguistic Views on Tense, Aspect and Modality, Amsterdam, Rodopi, 2005, 103-118.

Chomsky, Noam, Syntactic Structures, Den Haag, Mouton, 1957.

Chomsky, Noam, Aspects of the Theory of Syntax, Cambridge, Mass., MIT Press, 1965.

Chomsky, Noam, Principle and Parameters in Syntactic Theory, in: Norbert Hornstein/David Lightfoot (edd.), Explanation in Linguistics, London, Longman, 1981, 32-75.

Chomsky, Noam, A Minimalist Program for Linguistic Theory, in: Kenneth Hale/Samuel J. Keyser (edd.), The View from Building 20, Cambridge, Mass., MIT Press, 1993, 1-52.

Chomsky, Noam, Bare Phrase Structure, in: Gert Webelhut (ed.), Government and Binding Theory and the Minimalist Programme, Oxford, Blackwell, 1995, 383-440.

Cohen, David, L'aspect verbal, Paris, Presses Universitaires de France, 1989.

Colón, Germà, El perfet perifràstic català "va + infinitiu”, in: Germà Colón (ed.), La llengua catalana en els seus textos, vol. 2, Barcelona, Curial, 1978, 119-130.

Comrie, Bernard, Aspect, Cambridge, Cambridge University Press, 1976. 
Comrie, Bernard, On Reichenbach's Approach to Tense, in: Roberta A. Endrik/Carrie S. Masek/ Mary F. Miller (edd.), Papers from the Seventeenth Regional Meeting of the Chicago Linguistic Society, Chicago, Chicago Linguistic Society, 1981, 24-30.

Comrie, Bernard, Tense, Cambridge, Cambridge University Press, 1985.

Comrie, Bernard, Conditionals: A Typology, in: Elizabeth C. Traugott et al. (edd.), On Conditionals, Cambridge, Cambridge University Press, 1986, 77-99.

Comrie, Bernard, Towards a General Theory of Tense, in: Balachandran Lakshmi Bai/Aditi Mukherjee (edd.), Tense and Aspect in Indian Languages, Hyderabad, Centre of Advanced Study in Linguistics (Osmania University)/Booklinks Corporation, 1993, 1-18.

Confais, Jean-Paul, Temps, mode, aspect: Les approches des morphèmes verbaux et leurs problèmes à l'exemple du français et de l'allemand, Toulouse, Presses Universitaires de Mirail, 1990.

Corblin, Francis/Swart, Henriëtte de (edd.), Handbook of French Semantics, Stanford, CSLI, 2004.

Coseriu, Eugenio, Tomo y me voy, Vox Romanica 25 (1966), 13-55.

Coseriu, Eugenio, El aspecto verbal perifrástico en griego antiguo, in: Actas del III Congreso Español de Estudios Clásicos, III, Coloquio de estudios estructurales sobre las lenguas clásicas, Madrid, Sociedad española de estudios clásicos, 1968, 93-116.

Coseriu, Eugenio, Über die Leistung und Grenzen der Kontrastiven Grammatik, in: Hugo Moser (ed.), Probleme der Kontrastiven Grammatik, Düsseldorf, Schwann, 1970, 9-31.

Coseriu, Eugenio, Der periphrastische Verbalaspekt im Altgriechischen, Glotta 53 (1975), 1-25.

Coseriu, Eugenio, Das romanische Verbalsystem, ed. Hansbert Bertsch, Tübingen, Narr, 1976.

Coseriu, Eugenio, Inhaltliche Wortbildungslehre (am Beispiel des Typs “coupe-papier"), in: Herbert E. Brekle/Dieter Kastovsky (edd.), Perspektiven der Wortbildungsforschung, Bonn, Bouvier Verlag Herbert Grundmann, 1977, 48-61.

Coseriu, Eugenio, Textlinguistik. Eine Einführung, ed. Jörn Albrecht, Tübingen, Narr, ${ }^{2} 1981$.

Coseriu, Eugenio, Verbalaspekt oder Verbalaspekte? Einige theoretische und methodische Fragen, in: Eugenio Coseriu, Formen und Funktionen. Studien zur Grammatik, ed. Uwe Petersen, Tübingen, Niemeyer, 1987, 119-132 [fr. version: Aspect verbal ou aspects verbaux? Quelques questions de théorie et de méthode, in: Jean David/Robert Martin (edd.), La notion d'aspect (Actes du Colloque organisé par le Centre d'Analyse Syntaxique de l'Université de Metz, 18.-20.05.1978), Paris, Klincksieck, 1980, 13-25].

Criado de Val, Manuel, La imagen del tiempo: verbo y relatividad, Madrid, Istmo, 1992.

Cristofaro, Sonia, Language Universals and Linguistic Knowledge, in: Jae Jung Song (ed.), The Oxford Handbook of Linguistic Typology, Oxford, Oxford University Press, 2011, 227-249.

Croft, William, Syntactic Categories and Grammatical Relations: The Cognitive Organization of Information, Chicago, University of Chicago Press, 1991.

Croft, William, The role of domains in the interpretation of metaphors and metonymies, Cognitive Linguistics 4 (1993), 335-370.

Croft, William, Explaining Language Change. An Evolutionary Approach, Harlow, Longman, 2000.

Croft, William, Radical construction grammar: syntactic theory in typological perspective, Oxford, Oxford University Press, 2001.

Croft, William, On explaining metonymy: Comment on Peirsman and Geeraerts "Metonymy as a prototypical category", Cognitive Linguistics 17/3 (2006), 317-326.

Croft, William, Verbs: Aspect and Causal Structure, Oxford, Oxford University Press, 2012. 
Croft, William/Cruse, Alan D., Cognitive Linguistics, Cambridge, Cambridge University Press, 2004.

Curtius, Georg, Die Bildung der Tempora und Modi im Griechischen und Lateinischen sprachvergleichend dargestellt, vol. 1: Sprachvergleichende Beiträge zur griechischen und lateinischen Grammatik, Berlin, Besser, 1846.

Dahl, Östen, On the definition of the telic-atelic (bounded-nonbounded) distinction, in: Philip J. Tedeschi/Annie Zaenen (edd.), Tense and Aspect, New York et al., Academic Press, 1981, 79-90.

Dahl, Östen, Tense and Aspect Systems, Oxford, Blackwell, 1985.

Dahl, Östen, Synchronic and Diachronic Generalizations about Tense-Aspect Systems, in: LarsGunnar Larsson (ed.), Proceedings of the Second Scandinavian Symposium on Aspectology, Uppsala, Almqvist \& Wiksell, 1989, 9-12.

Dahl, Östen, Tense and aspect in the languages of Europe, Berlin/New York, Mouton de Gruyter, 2000.

Dahl, Östen, Languages without tense and aspect, in: Karen H. Ebert/Fernando Zúñiga (edd.), Aktionsart and Aspectotemporality in Non-European Languages, Zürich, Seminar für Allgemeine Sprachwissenschaft, 2001, 159-173.

Dauses, August, Das Imperfekt in den romanischen Sprachen. Seine Bedeutung im Verhältnis zum Perfekt, Wiesbaden, Steiner, 1981.

Declerck, Renaat, Aspect and the Bounded/Unbounded Distinction, Linguistics 17 (1979), 761-794.

Declerck, Renaat, Boundedness and the Structure of Situations, Leuvense Bijdragen 78 (1989), 275-308.

Declerck, Renaat, The Relation between Temporal and Modal Uses of Indicative Verb Forms, in: Bart Hollebrandse/Angeliek van Hout/Co Vet (edd.), Crosslinguistic Views on Tense, Aspect and Modality, Amsterdam, Rodopi, 2005, 215-227.

Delfitto, Denis/Bertinetto, Pier Marco, A Case Study in the Interaction of Aspect and Actionality: the Imperfect in Italian, in: Pier Marco Bertinetto et al. (edd.), Temporal Reference, Aspect and Actionality, vol. 1: Semantic and Syntactic Perspectives, Torino, Rosenberg \& Sellier, 1995, 125-142.

Del Pietro, Sara, Le perifrasi aspettuali nell'italiano parlato, doctoral thesis, Universität Zürich, 1995.

De Mauro, Tullio, In principio c'era la parola?, Bologna, Il Mulino, 2009.

De Miguel, Elena, El aspecto en la sintaxis del español: perfectividad e impersonalidad, Madrid, Ediciones de la Universidad Autónoma de Madrid, 1992.

De Miguel, Elena, El aspecto léxico, in: Ignacio Bosque/Violeta Demonte (edd.), Gramática descriptiva de la lengua española, vol. 2, Madrid, Espasa, 1999, 2977-3060.

Demonte, Violeta, Temporal and Aspectual Constraints on Predicative Aps, in: Hector Campos/ Fernando Martínez-Gil (edd.), Current Studies in Spanish Linguistics, Washington D.C., Georgetown University Press, 1991, 165-200.

Depraetere, Ilse, On the necessity of distinguishing between (un)boundedness and (a)telicity, Linguistics and Philosophy 18 (1995), 1-19.

Dessì Schmid, Sarah, Ernst Cassirer und Benedetto Croce, die Wiederentdeckung des Geistes. Ein Vergleich ihrer Sprachtheorien, Tübingen/Basel, Francke, 2005.

Dessì Schmid, Sarah, Modal Uses of the Italian imperfetto and the Spanish imperfecto: A Comparison, in: Martin Becker/Eva-Maria Remberger (edd.), Modality and Mood in 
Romance: Modal Interpretation, Mood Selection, and Mood Alternation, Tübingen, Niemeyer/De Gruyter, 2010, 39-66.

Dessì Schmid, Sarah, Inquietudine terminologica e categoriale: per un approccio onomasiologico al sistema aspettuale dell'italiano, in: Gerhard Bernhard/Maria Selig (edd.), Akten des Marburger Italianistentags 2008, Bern et al., Peter Lang, 2011 (= 2011a).

Dessì Schmid, Sarah, Progressive periphrastische Konstruktionen: Skizze einer Neuinterpretation am Beispiel des Italienischen, in: Sarah Dessì Schmid et al. (edd.), Rahmen des Sprechens - Beiträge zu Valenztheorie, Varietätenlinguistik, Kreolistik, Kognitiver und Historischer Semantik. Peter Koch zum 60. Geburtstag, Tübingen, Narr, 2011 (= 2011b).

Dessì Schmid, Sarah, Perifrasi modali in italiano, La lingua italiana 8 (2012), 149-164.

Detges, Ulrich, Wie entsteht Grammatik? Kognitive und pragmatische Determinanten der Grammatikalisierung von Tempusmarkern, in: Jürgen Lang/Ingrid Neumann-Holzschuh (edd.), Reanalyse und Grammatikalisierung in den romanischen Sprachen, Tübingen, Niemeyer, 1999, 31-52.

Detges, Ulrich, Time and Truth: the Grammaticalization of Resultatives and Perfects within a Theory of Subjectification, Studies in Language 24 (2000), 345-377 (= 2000a).

Detges, Ulrich, Two types of restructuring in French Creoles. A cognitive approach to the genesis of tense markers, in: Ingrid Neumann-Holzschuh/Edgar W. Schneider (edd.), Degrees of Restructuring in Creole Languages, Amsterdam/Philadelphia, Benjamins, 2000, 135-162 (= 2000b).

Detges, Ulrich, Grammatikalisierung. Eine kognitiv-pragmatische Theorie dargestellt am Beispiel romanischer und anderer Sprachen, unpublished Habilitation thesis, Universität Tübingen, 2001.

Detges, Ulrich, How Cognitive is Grammaticalization? The History of the Catalan Perfet Perifrastic, in: Olga Fischer/Muriel Norde/Harry Perridon (edd.), Up and Down the Cline: the Nature of Grammaticalization, Amsterdam, Benjamins, 2004, 211-227.

Detges, Ulrich/Waltereit, Richard, Grammaticalization vs. reanalysis: A semantic-pragmatic account of functional change in grammar, Zeitschrift für Sprachwissenschaft 21 (2002), 151-195.

Detges, Ulrich/Waltereit, Richard (edd.), The Paradox of Grammatical Change. Perspectives from Romance, Amsterdam/Philadelphia, Benjamins, 2008.

Dickey, Stephen M., Parameters of Slavic Aspect: a cognitive approach, Ph.D. Diss., Bloomington, Indiana University Press, 2000.

Dietrich, Wolf, Der periphrastische Verbalaspekt in den romanischen Sprachen, Tübingen, Niemeyer, 1973.

Dietrich, Wolf, Die Entwicklung der aspektuellen Verbalperiphrasen im Italienischen und Spanischen, Romanische Forschungen 97 (1985), 197-225.

Dietrich, Wolf, Gemeinromanische Tendenzen III. Verbalperiphrasen, in: Günter Holtus/ Michael Metzeltin/Christian Schmitt (edd.), Lexikon der Romanistischen Linguistik, vol. 2, Tübingen, Niemeyer, 1996, 223-235.

Dietrich, Wolf, Sprachvergleichende Überlegungen zum verbalen Aspekt. Universales und Einzelsprachliches, in: Thomas Bruns/Henrieke Stahl (edd.), Sprache - Literatur - Kultur: Studien zur slawischen Philologie und Geistesgeschichte. Festschrift für Gerhard Ressel zum 60. Geburtstag, Frankfurt a. M. et al., Peter Lang, 2005, 145-160.

Diez, Friedrich Ch., Grammatik der romanischen Sprachen, 3 vol., Bonn, Weber, 1836-1844.

Dirven, René, Functionalism in linguistics, Amsterdam, Benjamins, 1987. 
Dirven, René/Goossens, Louis/Putseys, Yvan/Voralt, Emma (edd.), The Scene of Linguistic Action and its Perspectivisation by SPEAK, TALK, SAY and TELL, Amsterdam, Benjamins, 1982.

Dirven, René/Pörings, Ralf (edd.), Metaphor and metonymy in comparison and contrast, Berlin/New York, Mouton de Gruyter, 2002.

Dirven, René/Verspoor, Marjolijn (edd.), Cognitive exploration of language and linguistics, 2. rev. ed., Amsterdam, Benjamins, 2004.

Dowty, David R., Studies in the Logic of Verb Aspect and Time Reference in English, doctoral thesis, Department of Linguistics, University of Austin (Texas), 1972.

Dowty, David R., Towards a Semantic Analysis of Verb Aspect and the English Imperfective Progressive, Linguistics and Philosophy 1 (1977), 45-77.

Dowty, David R., Word Meaning and Montague Grammar. The Semantics of Verbs and Times in Generative Semantics and in Montague's PTQ, Dordrecht, D. Reidel Publishing Company, 1979.

Dowty, David R., The Effects of Aspectual Class on the Temporal Structure of Discourse: Semantics or Pragmatics?, Linguistics and Philosophy 9 (1986), 37-61.

Durante, Marcello, Dal latino all'italiano moderno. Saggio di storia linguistica e culturale, Bologna, Zanichelli, 1981.

Eberenz, Rolf, Tempus und Textkonstitution im Spanischen, Tübingen, Narr, 1981.

Eggs, Ekkehard, Vergangenheitstempora im Spanischen und Französischen, in: Christian Schmitt (ed.), Grammatikographie der Romanischen Sprachen: Akten der Gleichnamigen Sektion des Bamberger Romanistentages [Sektion zum Thema Grammatikographie der Romanischen Sprachen] (23.-29.9.1991), Bonn, Romanistischer Verlag, 1993, 97-134.

Ehrich, Veronika, Hier und jetzt: Studien zur lokalen und temporalen Deixis im Deutschen, Tübingen, Niemeyer, 1992.

Evans, Vyvyan/Green, Melanie, Cognitive Linguistics. An Introduction, Edinburgh, Edinburgh University Press, 2006.

Fauconnier, Gilles, Espaces mentaux. Aspects de la construction du sens dans les langues naturelles, Paris, Minuit, 1984.

Fauconnier, Gilles, Mappings in Thought and Language, Cambridge, Cambridge University Press, 1999.

Fauconnier, Gilles/Turner, Mark, Blending as a Central Process of Grammar, in: Adele E. Goldberg (ed.), Conceptual Structure, Discourse and Language, Stanford, Stanford University Press, 1996, 113-130.

Fauconnier, Gilles/Turner, Mark, The Way we Think. Conceptual Blending and the Mind's Hidden Complexities, New York, Basic Books, 2002.

Fernández de Castro, Felix, Las perífrasis verbales en el español actual, Madrid, Gredos, 1999.

Fernández Ramírez, Salvador, Gramática española, vol. 4: El verbo y la oración, Madrid, Arco Libros, 1986.

Ferreri, Silvana, The Evolving Gerund, Journal of Italian Linguistics 8/2 (1983), 25-66.

Ferretti, Francesco, The social mind, in: Massimo Marraffa/Mario de Caro/Francesco Ferretti (edd.), Cartographies of the Mind: Philosophy and Psychology in Intersection, Dordrecht, Kluwer, 2006.

Fillmore, Charles J., An Alternative to Checklist Theories of Meaning, in: Proceedings of the 1st Annual Meeting of the Berkeley Linguistic Society, Berkeley, Berkeley Linguistic Society, 1975, 123-131.

Fillmore, Charles J., Scenes-and-Frames-Semantics, in: Antonio Zampolli (ed.), Linguistic Structures Processing, Amsterdam, Benjamins, 1977, 55-81. 
Fillmore, Charles J., Frame semantics, in: Linguistic Society of Korea (ed.), Linguistics in the Morning Calm, Seoul, Hanshin Publishing, 1982, 111-137.

Fillmore, Charles J., Frames and the Semantic of Understanding, Quaderni di semantica 6 (1985), 222-254.

Fillmore, Charles J./Kay, Paul, Construction Grammar Lecture, Stanford, LSA Summer Institute, 1987.

Fillmore, Charles J./Kay, Paul/O'Connor, Mary Catherine, Regularity and idiomaticity in grammatical constructions: the case of let alone, Language 64 (1988), 501-538.

Fischer, Kerstin/Stefanowitsch, Anatol, Konstruktionsgrammatik I. Von der Anwendung zur Theorie, Tübingen, Stauffenburg, 2006.

Fitzek, Herbert/Salber, Wilhelm, Gestaltpsychologie: Geschichte und Praxis, Darmstadt, Wissenschaftliche Buchgesellschaft, 1996.

Fleischman, Suzanne, Temporal Distance: A basic linguistic metaphor, Studies in Language 13 (1989), 1-50.

Fleischman, Suzanne, Imperfective and Irrealis, in: Joan Bybee/Suzanne Fleischmann (edd.), Modality in Grammar and Discourse, Amsterdam/Philadelphia, Benjamins, 1995, 519-551 (=1995a).

Fleischman, Suzanne, La place de la grammaire dans la structuration des événements dans le récit: Le cas des "achievements", Modèles Linguistiques 16/2 (1995), 123-143 (= 1995b).

Fodor, Jerry A., The Language of Thought, New York, Crowell, 1975.

Fuchs, Catherine/Léonard, Anne-Marie, Vers une théorie des aspects: Les systèmes du français et de l'anglais, Paris, Mouton/École des Hautes Études en Sciences Sociales, 1979.

Gamillscheg, Ernst, Das sogenannte "Imparfait historique" ("imparfait de rupture"), in: Horst Heintze/Erwin Silzer (edd.), Im Dienste der Sprache: Festschrift für Victor Klemperer zum 75. Geburtstag am 9. Oktober 1956, Halle (Saale), Niemeyer, 1958, 271-275.

García Fernández, Luis, El aspecto gramatical en la conjugación, Madrid, Arco Libros, 1998.

García Fernández, Luis, Los complementos adverbiales temporales: la subordinación temporal, in: Ignacio Bosque/Violeta Demonte (edd.), Gramática descriptiva de la lengua española, Madrid, RAE-Espasa Calpe, 1999, 3129-3208.

García Fernández, Luis, El pretérito imperfecto: repaso histórico y bibliográfico, in: Luis García Fernández/Bruno Camus Bergareche (edd.), El pretérito imperfecto, Madrid, Gredos, 2004, 13-95.

García Fernández, Luis/Camus Bergareche, Bruno (edd.), El pretérito imperfecto, Madrid, Gredos, 2004.

Gautier, Laurent/Haberkorn, Didier (edd.), Aspekt und Aktionsarten im heutigen Deutsch, Tübingen, Stauffenburg, 2004.

Gavarrò, Anna/Laca, Brenda, Les perífrasis temporals, aspectuals i modals, in: Joan Solà et al. (edd.), Gramàtica del català contemporani, vol. 3, Barcelona, Empúries, 2002, 2663-2726.

Geeraerts, Dirk (ed.), Cognitive Linguistics. Basic Readings, Berlin/New York, Mouton de Gruyter, 2006.

Geeraerts, Dirk/Cuyckens, Hubert (edd.), The Oxford Handbook of Cognitive Linguistics, Oxford, Oxford University Press, 2007.

Giorgi, Alessandra/Pianesi, Fabio, Tense and Aspect: From Semantics To Morphosyntax, New York, Oxford University Press, 1997.

Giorgi, Alessandra/Pianesi, Fabio, Romance “Aspectual” Periphrases: Eventuality Modification versus "Syntactic" Aspect, in: Jacqueline Guéron/Jacqueline Lecarme (edd.), The Syntax of Time, Cambridge, Mass., MIT Press, 2004, 425-440. 
Gladrow, Wolfgang (ed.), Russisch im Spiegel des Deutschen. Eine Einführung in den russischdeutschen und deutsch-russischen Sprachvergleich, Frankfurt a. M. et al., Peter Lang, 1998.

Goldberg, Adele E., Constructions: A Construction Grammar Approach to Argument Structure, Chicago, Chicago University Press, 1995.

Goldberg, Adele E., Constructions at Work. The Nature of Generalization in Language, Oxford, Oxford University Press, 2006.

Goldberg, Adele E., Universal Grammar? Or prerequisites for natural language?, Behavioral and Brain Sciences 31/5 (2008), $522 \mathrm{f}$.

Gómez Torrego, Leonardo, Perífrasis Verbales. Sintaxis, semántica y estilística, Madrid, Arco Libros, 1988.

Gougenheim, Georges, Etude sur les périphrases verbales de la langue française, Paris, Les Belles Lettres, 1929.

Greenberg, Joseph H., A quantitative approach to the morphological typology of language, International Journal of American Linguistics 26 (1954), 178-194.

Grevisse, Maurice/Goosse, André, Le bon usage. Grammaire française, Paris, Duculot, ${ }^{14} 2008$.

Gruber, Andrea, Aspekt und Aktionsart im Russischen und Italienischen. Zur Problematik einzelsprachlicher und kontrastiver Begriffsbestimmung, Innsbruck, Institut für Sprachwissenschaft, 2000.

Guillaume, Gustave, Temps et Verbe: théorie des aspects, des modes et des temps, Paris, Champion (repr. 1965 with L'architectonique du temps dans les langues classiques), 1929.

Gumperz, John J./Levinson, Stephen C. (edd.), Rethinking linguistic relativity, Cambridge, Cambridge University Press, 1996.

Gutiérrez-Rexach, Javier (ed.), From Words to Discourse: Trends in Spanish Semantics and Pragmatics, Oxford, Elsevier, 2002.

Haan, Ferdinand de, Typology of Tense, Aspect, and Modality Systems, in: Jae Jung Song (edd.), The Oxford Handbook of Linguistic Typology, Oxford, Oxford University Press, 2011, 445-464.

Halliday, Michael A. K., An Introduction to functional grammar, London, Arnold, 1985.

Halliday, Michael A. K./Matthiessen, Christian M. I. M. (edd.), Construing experience through meaning: a language-based approach to cognition, London, Cassell, 1999.

Handke, Jürgen, The Structure of the Lexicon. Human versus Machine, Berlin/New York, Mouton de Gruyter, 1995.

Harris, Alice C./Campbell, Lyle, Historical syntax in cross-linguistic perspective, Cambridge, Cambridge University Press, 1995.

Haspelmath, Martin, From Space to Time: Temporal Adverbials in the World's Languages, München, Lincom Europa, 1997.

Haspelmath, Martin, Does grammaticalization need reanalysis?, Studies in Language 22 (1998), 315-351.

Haspelmath, Martin, Periphrasis, in: Geert Booij/Christian Lehmann/Joachim Mugdan (edd.), Morphologie. Morphology. Ein internationales Handbuch zur Flexion und Wortbildung. An international handbook on inflection and word-formation, Berlin/New York, De Gruyter, 2000, 654-664.

Haspelmath, Martin, Understanding Morphology, London, Arnold, 2002.

Haspelmath, Martin, Pre-established categories don't exist: Consequences for language description and typology, Linguistic Typology 11 (2007), 119-132.

Haspelmath, Martin/Dryer, Matthew S./Gil, David (edd.), The World Atlas of Language Structures, Oxford, Oxford University Press, 2005. 
Haug, Dag T. T., Aristotle's kinesis/energeia-test and the semantics of the Greek perfect, Linguistics 42/2 (2004), 387-418.

Hauser, Marc D./Chomsky, Noam/Fitch, W. Tecumseh, The Faculty of Language: What is it, who has it, and how did it evolve?, Science 298 (2002), 1569-1579.

Hay, Jennifer/Kennedy, Christopher/Levin, Beth, Scalar Structure Underlies Telicity in "Degree Achievements", in: Tanya Matthews/Devon Strolovitch (edd.), Proceedings of SALT 9, CLC Publications, Ithaca, NY, 1999, 127-144.

Heger, Klaus, Die Bezeichnung temporal-deiktischer Begriffskategorien im französischen und spanischen Konjugationssystem, Tübingen, Niemeyer, 1963.

Heim, Irene, The Semantics of Definite and Indefinite Noun Phrases, Ph.D. Diss., Amherst, University of Massachusetts, 1982.

Heim, Irene, File Change Semantics and the Familiarity Theory of Definiteness, in: Rainer Bäuerle/Christoph Schwarze/Arnim von Stechow (edd.), Meaning, Use and Interpretation of Language, Berlin, De Gruyter, 1983, 121-143 (= 1983a).

Heim, Irene, On the Projection Problem for Presuppositions, in: Michael Barlow et al. (edd.), Proceedings of the Second Annual West Coast Conference on Formal Linguistics, Stanford University, 1983, 114-125 (= 1983b).

Heine, Bernd, Auxiliaries: cognitive forces and grammaticalization, New York/Oxford, Oxford University Press, 1993.

Heine, Bernd/Claudi, Ulrike/Hünnemeyer, Friederike, Grammaticalization: a conceptual framework, Chicago, University of Chicago Press, 1991.

Heinemann, Sabine, "Stare"-Periphrasen im Altitalienischen, in: Claus Pusch/Andreas Wesch (edd.), Verbalperiphrasen in den (ibero-)romanischen Sprachen, Hamburg, Buske, 2003, 161-178.

Herrmann, Theo, Ganzheitspsychologie und Gestalttheorie, in: Heinrich Balmer (ed.), Die Psychologie des 20. Jahrhunderts, vol. 1: Die Europäische Tradition. Tendenzen, Schulen, Entwicklungslinien, Zürich, Kindler, 1976, 573-685.

Herweg, Michael, Zeitaspekte. Die Bedeutung von Tempus, Aspekt und temporalen Konjunktionen, Wiesbaden, Deutscher Universitätsverlag, 1990.

Hess-Lüttich, Ernest W. B./Schlieben-Lange, Brigitte (edd.), Signs and Time. Zeit und Zeichen, Tübingen, Narr, 1998.

Hewson, John, The Cognitive System of the French Verb, Amsterdam, Benjamins, 1997.

Hewson, John/Bubenik, Vit (edd.), Tense and Aspect in European Languages: Theory, Typology, Diachrony, Amsterdam, Benjamins, 1997.

Holenstein, Elmar, Phänomenologie der Assoziation: zu Struktur und Funktion eines Grundprinzips der passiven Genesis bei E. Husserl, Den Haag, Nijhoff, 1972.

Hollebrandse, Bart/Hout, Angeliek van, On the Acquisition of the Aspects in Italian, in: Ji-Yung Kim/Adam Werle (edd.), The Proceedings of SULA: the Semantics of Underrepresented Languages in the Americas, Amherst, Glsa, 2001, 111-120.

Hollebrandse, Bart/Hout, Angeliek van/Vet, Co (edd.), Crosslinguistic Views on Tense, Aspect and Modality, Amsterdam, Rodopi, 2005.

Holt, Jens von, Etudes d'aspect, Aarhus, Universitetsforlaget, 1943.

Hopper, Paul J., Some observations on the typology of focus and aspect in narrative language, Studies in Language 3/1 (1979), 37-64.

Hopper, Paul J., Tense-Aspect: Between Semantics and Pragmatics, Amsterdam, Benjamins, 1982 (= 1982a).

Hopper, Paul J., Studies in transitivity, New York, Academic Press, 1982 (= 1982b). 
Hopper, Paul J., On some principles of grammaticalization, in: Elizabeth C. Traugott/Bernd Heine (edd.), Approaches to grammaticalization, Amsterdam/Philadelphia, Benjamins, 1991, 17-35.

Hopper, Paul J./Thompson, Sandra A., Transitivity in grammar and discourse, Language 56 (1980), 251-299.

Hopper, Paul J./Traugott, Elizabeth C., Grammaticalization, Cambridge, Cambridge University Press, ${ }^{2} 2003$.

Hout, Angeliek van/Hollebrandse, Bart, On the Acquisition of the Aspects in Italian, in: University of Massachusetts Occasional Papers in Linguistics, 2001, 111-120.

Humboldt, Wilhelm von, Gesammelte Schriften, ed. Albert Leitzmann, 17 vol., Berlin, Behr (reprint Berlin, De Gruyter), 1903-1936.

Husserl, Edmund, Ideen zu einer reinen Phänomenologie und phänomenologischen Philosophie: allgemeine Einführung in die reine Phänomenologie, Tübingen, Niemeyer, ${ }^{5} 1993\left({ }^{2} 1922\right)$.

Husserl, Edmund, Cartesianische Meditationen: eine Einleitung in die Phänomenologie, ed. Elisabeth Ströker, Hamburg, Meiner, ${ }^{3} 1995$ (1929).

Imbs, Paul, L'emploi des temps verbaux en français moderne: Essai de grammaire descriptive, Paris, Klincksieck, 1960.

Isačenko, Alexander V., Die russische Sprache der Gegenwart, vol. 1: Formenlehre, Halle, Niemeyer, 1962.

Jackendoff, Ray S., Semantics and Cognition, Cambridge, Mass., MIT Press, 1983.

Jackendoff, Ray S., Semantic Structures, Cambridge, Mass., MIT Press, 1991 (= 1991a).

Jackendoff, Ray S., Parts and Boundaries, Cognition 41 (1991), 9-45 (= 1991b).

Jackendoff, Ray S., Foundation of Language. Brain, Meaning, Grammar, Evolution, New York et al., Oxford University Press, 2002.

Jacobsohn, Hermann, Aspektfragen, Indogermanische Forschungen 51 (1933), 292-318.

Jakobson, Roman, Two Aspects of Language and two Types of Aphasic Disturbances, in: Roman Jakobson/Morris Halle (edd.), Fundamentals of Language, Den Haag, Mouton, 1971 (1956), 67-96.

Jakobson, Roman, Linguistische Aspekte der Übersetzung, in: Wolfram Wilss (ed.), Übersetzungswissenschaft, Darmstadt, Wissenschaftliche Buchgesellschaft, 1981 (1959), 189-198.

Janssen, Theo/Redeker, Gisela (edd.), Cognitive Linguistics: Foundations, Scope, and Methodology, Berlin/New York, De Gruyter, 1999.

Jespersen, Otto, The Philosophy of Grammar, London, Allen \& Unwin, 1924.

Kabakčiev, Krasimir, Aspect in English. A “Common-Sense” View of the Interplay between Verbal and Nominal Referents, Dordrecht, Kluwer, 2000.

Kamp, Hans, A Theory of Truth and Semantic Representation, in: Jeroen Groenendijk/Theo Janssen/Martin J. B. Stokhof (edd.), Formal Methods in the Study of Language, Amsterdam, Mathematical Centre, 1981, 277-322 (= 1981a).

Kamp, Hans, Événements, représentations discursives et référence temporelle, Langages 64 (1981), 39-64 (= 1981b).

Kamp, Hans, The Perfect and Other Tenses in French and English, in: id. (ed.), Tense and Aspect in English and French, Edinburgh, Centre for Cognitive Science-University of Edinburgh, 1991, 41-64.

Kamp, Hans/Reyle, Uwe, From Discourse to Logic, Dordrecht, Kluwer, 1993. 
Kamp, Hans/Rohrer, Christian, Tense in Texts, in: Rainer Bäuerle/Christoph Schwarze/Arnim von Stechow (edd.), Meaning, Use, and Interpretation of Language, Berlin, De Gruyter, 1983, 250-269.

Kay, Paul/Fillmore, Charles J., Grammatical constructions and linguistic generalizations: the What's $X$ doing $Y$ ? construction, Language 75 (1999), 1-33.

Kenny, Anthony, Action, Emotion and Will, London/New York, Routledge/Kegan Paul, 1963.

King, Larry D., The semantic structure of Spanish: meaning and grammatical form, Amsterdam, Benjamins, 1992.

Kiparsky, Paul, Tense and Mood in Indo-European Syntax, Foundations of Language 4 (1968), 30-57.

Kleiber, Georges, Entre les deux mon cœur balance ou l'imparfait entre aspect et anaphore, Langue française 138 (2003), 8-18.

Klein, Wolfgang, Der Ausdruck der Temporalität im ungesteuerten Spracherwerb, in: Gisa Rauh (ed.), Essays on Deixis, Tübingen, Narr, 1983, 149-168.

Klein, Wolfgang, Time in language, London/New York, Routledge, 1994.

Klein, Wolfgang, A Time-Relational Analysis of Russian Aspect, Language 71/4 (1995), 669-695.

Klein, Wolfgang, An Analysis of the German Perfekt, Language 76/2 (2000), 358-382.

Klum, Arne, Verbe et adverbe. Étude sur le système verbal indicatif et sur le système de certains adverbes de temps à la lumière des relations verbo-adverbiales dans la prose du français contemporain, Stockholm, Almqvist \& Wiksell, 1961.

Klump, Andre, Trajectoires du changement linguistique. Zum Phänomen der Grammatikalisierung im Französischen, Stuttgart, Ibidem, 2007.

Koch, Peter, Gedanken zur Metapher - und zu ihrer Alltäglichkeit, in: Annette Sabban/ Christian Schmitt (edd.), Sprachlicher Alltag. Linguistik - Rhetorik Literaturwissenschaft. Festschrift für W.-D. Stempel, Tübingen, Niemeyer, 1994, 201-225.

Koch, Peter, Der Beitrag der Prototypentheorie zur Historischen Semantik: eine kritische Bestandsaufnahme, Romanistisches Jahrbuch 46 (1995), 27-46.

Koch, Peter, Le prototype entre signifié, désigné et référent, in: Hiltrud Dupuiy-Engelhardt (ed.), Questions de méthode et de délimitation en sémantique lexicale, Reims, Presses Universitaires de Reims, 1996, 113-135 (=1996a).

Koch, Peter, La sémantique du prototype: sémasiologie ou onomasiologie?, Zeitschrift für französische Sprache und Literatur 106 (1996), 223-240 (= 1996b).

Koch, Peter, Diskurstraditionen: zu ihrem sprachtheoretischen Status und ihrer Dynamik, in: Barbara Frank/Thomas Haye/Doris Tophinke (edd.), Gattungen mittelalterlicher Schriftlichkeit, Tübingen, Narr, 1997, 43-79.

Koch, Peter, Frame and Contiguity: On the Cognitive Bases of Metonymy and Certain Types of Word Formation, in: Günter Radden/Klaus-Uwe Panther (edd.), Metonymy in Language and Thought, Amsterdam/Philadelphia, Benjamins, 1999, 139-167 (= 1999a).

Koch, Peter, TREE and FRUIT. A cognitive-onomasiological approach, Studi italiani di linguistica teorica e applicata 28/2 (1999), 331-347 (=1999b).

Koch, Peter, Cognitive aspects of semantics change and polysemy: The semantic space HAVE/ $B E$, in: Andreas Blank/Peter Koch (edd.), Historical Semantics and Cognition, Berlin/ New York, De Gruyter, 1999, 279-305 (=1999c).

Koch, Peter, Metonymy. Unity in diversity, Journal of Historical Pragmatics 2/2 (2001), 201-244 (= 2001a). 
Koch, Peter, Lexical typology from a cognitive and linguistic point of view, in: Martin Haspelmath et al. (edd.), Language Typology and Language Universals/Sprachtypologie und sprachliche Universalien/La typologie des langues et les universaux linguistiques. An International Handbook/Ein internationales Handbuch/Manuel international, vol. 2, Berlin/New York, De Gruyter, 2001, 1142-1178 (= 2001b).

Koch, Peter, Qu'est-ce que le cognitif?, in: Peter Blumenthal/Jean-Emmanuel Tyvaert (edd.), La cognition dans les temps, Tübingen, Niemeyer, 2003, 85-100.

Koch, Peter, Metonymy between pragmatics, reference, and diachrony, metaphorik.de 7 (2004), 6-54.

Koch, Peter, Aspects cognitifs d'une typologie lexicale synchronique. Les hiérarchies conceptuelles en français et dans d'autres langues, Langue française 145 (2005), 11-33.

Koch, Peter, Assoziation - Zeichen - Schrift, in: Daniel Jacob/Thomas Krefeld (edd.), Sprachgeschichte und Geschichte der Sprachwissenschaft, Tübingen, Narr, 2007, 11-52.

Koch, Peter, Höflichkeit und Metonymie, in: Dorothee Kimmich/Wolfgang Matzat (edd.), Der gepflegte Umgang. Interkulturelle Aspekte der Höflichkeit in Literatur und Sprache, Bielefeld, Transcript, 2008, 143-184.

Koch, Peter, The pervasiveness of contiguity and metonymy in semantic change, in: Kathryn Allan/Justyna A. Robinson (edd.), Current Methods in Historical Semantics, Berlin/Boston, De Gruyter, 2012, 259-311.

Koch, Peter/Oesterreicher, Wulf, Gesprochene Sprache in der Romania: Französisch, Italienisch, Spanisch, Tübingen, Niemeyer, 1990.

Köhler, Wolfgang, Gestalt Psychology: an Introduction to New Concepts in modern Psychology, New York, Liveright, 1947.

Konerding, Klaus-Peter, Frames und lexikalisches Bedeutungswissen. Untersuchungen zur linguistischen Grundlegung einer Frametheorie und zu ihrer Anwendung in der Lexikographie, Tübingen, Niemeyer, 1993.

Krifka, Manfred, Nominalreferenz und Zeitkonstitution. Zur Semantik von Massentermen, Pluraltermen und Aspektklassen, München, Fink, 1989 (= 1989a).

Krifka, Manfred, Nominalreferenz, Zeitkonstruktion, Aspekt, Aktionsart: Eine semantische Erklärung ihrer Interaktion, in: Werner Abraham/Theo Janssen (edd.), Tempus - Aspekt Modus. Die lexikalischen und grammatischen Formen in den germanischen Sprachen, Tübingen, Niemeyer, 1989, 227-258 (= 1989b).

Krifka, Manfred, The Origins of Telicity, in: Susan Rothstein (ed.), Events and Grammar, Dordrecht, Reidel, 1998, 197-235.

Laca, Brenda, Une question d'aspect: à propos des périphrases progressives en catalán, in: Estudis de lingüística i filologia oferts a Antoni Badia i Margarit, Barcelona, Publicacions de l'Abadia de Montserrat, 1995, 495-509.

Laca, Brenda, Aspect - Périphrase - Grammaticalisation. A propos du "Progressif" dans les langues ibéro-romanes, in: Wolfgang Dahmen et al. (edd.), Neuere Beschreibungsmethoden der Syntax romanischer Sprachen, Tübingen, Narr, 1998, 207-226.

Laca, Brenda, Temps et aspect. De la morphologie à l'interprétation, Saint-Denis, Presses Universitaires de Vincennes, 2002 (= 2002a).

Laca, Brenda, Spanish "Aspectual" Periphrases: Ordering Constraints and the Distinction Between Situation and Viewpoint Aspect, in: Javier Gutiérrez-Rexach (ed.), From Words to Discourse: Trends in Spanish Semantics and Pragmatics, Oxford, Elsevier, 2002, 61-93 (= 2002b). 
Laca, Brenda, Les catégories aspectuelles à expression périphrastique: une interprétation des apparentes "lacunes" du français, Langue Française 141 (2004), 85-98 (= 2004a).

Laca, Brenda, Romance "Aspectual" Periphrases: Eventuality Modification versus "Syntactic" Aspect, in: Jacqueline Guéron/Jacqueline Lecarme (edd.), The Syntax of Time, Cambridge, Mass., MIT Press, 2004, 425-440 (= 2004b).

Lagae, Véronique/Carlier, Anne (edd.), Temps et aspect, Amsterdam, Rodopi, 2002.

Lakoff, George, Women, Fire, and Dangerous Things: What Categories Reveal about the Mind, Chicago, University of Chicago Press, 1987.

Lakoff, George/Johnson, Mark, Metaphors We Live By, Chicago, University of Chicago Press, 1980.

Lakoff, George/Johnson, Mark, Philosophy in the Flesh: the Embodied Mind and its Challenge to Western Thought, New York, Basic Book, 1999.

Lang, Jürgen/Neumann-Holzschuh, Ingrid (edd.), Reanalyse und Grammatikalisierung in den romanischen Sprachen, Tübingen, Niemeyer, 1999.

Langacker, Ronald W., Foundations of Cognitive Grammar, vol. 1: Theoretical Prerequisites, Stanford, Stanford University Press, 1987.

Langacker, Ronald W., Concept, Image, and Symbol. The Cognitive Basis of Grammar, Berlin, Mouton de Gruyter, 1990.

Langacker, Ronald W., Foundations of Cognitive Grammar, vol. 2: Descriptive Application, Stanford, Stanford University Press, 1991.

Langacker, Ronald W., Grammar and Conceptualization, Berlin/New York, Mouton de Gruyter, 1999.

Langacker, Ronald W., On the continuous debate about discreteness, Cognitive Linguistics 17/1 (2006), 107-151.

Lasch, Alexander/Ziem, Alexander, Konstruktionsgrammatik III. Aktuelle Fragen und Lösungsansätze, Tübingen, Stauffenburg, 2011.

Lathrop, Thomas A., Curso de gramática histórica española, Barcelona, Ariel, 2002.

Laurent, Richard S., Past Participles from Latin to Romance, Berkeley, University of California Press, 1999.

Lee, David, Cognitive Linguistics. An Introduction, Oxford, Oxford University Press, 2001.

Lehmann, Christian, Thoughts on Grammaticalization, München, Lincom Europa, 1995.

Lehmann, Christian, New Reflections on Grammaticalization, in: Ilse Wischer/Gabriele Diewald (edd.), New reflections on grammaticalization, Amsterdam/Philadelphia, Benjamins, 2002, 1-18.

Lehmann, Volkmar, Satzsemantische oder verarbeitungssemantische Aspektbeschreibung, in: Renate Rathmayr (edd.), Slavistische Linguistik 1985, 1986, 147-173.

Lehmann, Volkmar, Grammatische Zeitkonzepte und ihre Erklärung, Kognitionswissenschaft 2 (1992), 156-170.

Lehmann, Volkmar, Die russischen Aspekte als gestufte Kategorie. Ein Beispiel für die Bedeutung der Kognitiven Linguistik in der slavistischen Sprachwissenschaft, Die Welt der Slaven 38 (1993), 265-297.

Lehmann, Volkmar, Der Aspekt. Wie lexikalische Kategorien grammatische Funktionen motivieren, in: Peter Kosta/Elke Mann (edd.), Slavistische Linguistik 1996, 1997, 137-154.

Lehmann, Volkmar, Der russische Aspekt, in: Helmut Jachnow (ed.), Handbuch der sprachwissenschaftlichen Russistik und ihrer Grenzdisziplinen, Wiesbaden, Harrassowitz, 1999, 214-242.

Leiss, Elisabeth, Die Verbalkategorien des Deutschen, Berlin, De Gruyter, 1992. 
Leiss, Elisabeth, Artikel und Aspekt. Die grammatischen Muster von Definitheit, Berlin/ New York, De Gruyter, 2000.

Lo Cascio, Vincenzo, On the Relation Between Tense and Aspect in Romance and Other Languages, in: Pier Marco Bertinetto et al. (edd.), Temporal Reference, Aspect and Actionality, vol. 1: Semantic and Syntactic Perspectives, Torino, Rosenberg \& Sellier, 1995, 273-291.

Lo Cascio, Vincenzo/Vet, Co (edd.), Temporal structure in Sentence and Discourse, Dordrecht, Foris, 1986.

Lucy, John A., Language diversity and thought: a reformulation of the linguistic relativity hypothesis, Cambridge, Cambridge University Press, 1992.

Lucy, John A., Grammatical categories and cognition: a case study of the linguistic relativity hypothesis, Cambridge, Cambridge University Press, 1996.

Lucy, John A., Linguistic relativity, Annual review of anthropology 26 (1997), 291-312.

Lyer, Stanislav, Syntaxe du gérondif et du participe présent dans les langues romanes, Paris, Droz, 1934.

Lyons, Christopher, Voice, Aspect, and Arbitrary Arguments, in: John C. Smith/Martin Maiden (edd.), Linguistic theory and the Romance Languages, Amsterdam, Benjamins, 1995, 77-114.

Lyons, John, Semantics, 2 vol., Cambridge, Cambridge University Press, 1977.

Maienborn, Claudia, Die logische Form von Kopula-Sätzen, Berlin, Akademie Verlag, 2003.

Marchand, Hans, On a Question of Aspect: a Comparison between the Progressive Form in English and that in Italian and Spanish, Studia Linguistica 9 (1955), 45-52.

Marchello-Nizia, Christiane, Grammaticalisation et changement linguistique, Bruxelles, De Boeck-Duculot, 2006.

Marcos Marín, Francisco, Curso de gramática española, Madrid, Cincel, 1980.

Marzo, Daniela, Polysemie als Verfahren lexikalischer Motivation: Theorie und Empirie am Beispiel von Metonymie und Metapher im Französischen und Italienischen, Tübingen, Narr, 2013.

Maslov, Jurij S., Vid i leksičeskoe značenie glagola v sovremennom russkom literaturnom jazyke, in: Očerki po aspektologii, Leningrad, 1984 (1948), 48-65.

Maslov, Jurij S., Zur Entstehungsgeschichte des slavischen Verbalaspekts, Zeitschrift für Slavistik 4 (1959), 560-568.

Maslov, Jurij S., Universal'nye semantiesčkie komponenty $v$ soderžanii grammatičeskoj kategorii soveršennogo/nesoveršennogo vida, Sovetskoe slvjanovedenie 4 (1973), 73-83.

Maslov, Jurij S., Zur Semantik der Perfektivitätsopposition, Wiener Slavistisches Jahrbuch 20 (1974), 107-122.

Maslov, Jurij S., An outline of Contrastive Aspectology, in: id. (ed.), Contrastive Studies in Verbal Aspect, Heidelberg, Gross, 1985 (1978), 1-44.

Maslov, Jurij S., Contrastive Studies in Verbal Aspect, Heidelberg, Gross, 1985.

Matthews, Peter H., Morphology, Cambridge, Cambridge University Press, 1974.

Matthiessen, Christian, Lexicogrammatical Cartography: English Systems, Tokyo, International Language Science Publishers, 1995.

Mellet, Sylvie, Temps, mode, aspect: De l'unité des catégories verbales, L'information grammaticale 38 (1988), 16-18.

Metzger, Wolfgang, Gestalt-Psychologie: ausgewählte Werke aus den Jahren 1950-1982, ed. Michael Stadler, Frankfurt a. M., Kramer, 1986. 
Meunier, Annie, Une construction complexe No-humain être Adj de V0-inf. W caractéristique de certains adjectifs à sujet humain, Langages 133 (1999), 12-44.

Meyer-Lübke, Wilhelm, Grammatik der romanischen Sprachen, 4 vol., Leipzig, Fues, Reisland, $1890 \mathrm{ff}$.

Michaelis, Susanna, Temps et aspect en créole seychellois: valeurs et interférences, Hamburg, Buske, 1993.

Mihatsch, Wiltrud, Kognitive Grundlagen lexikalischer Hierarchien untersucht am Beispiel des Französischen und Spanischen, Tübingen, Niemeyer, 2006.

Minsky, Marvin, A Framework for Representing Knowledge, in: Patrick H. Winston (ed.), The Psychology of Computer Vision, New York, Mc Grow-Hill, 1975, 211-277.

Mitko, Julia, Zur Herausbildung einer formalen Aspektopposition auf der temporalen Nullstufe: "être en train de" + Infinitiv als teilgrammatikalisierte Verlaufsform des Gegenwartsfranzösischen, in: Jürgen Lang/Ingrid Neumann-Holzschuh (edd.), Reanalyse und Grammatikalisierung in den romanischen Sprachen, Tübingen, Niemeyer, 1999, 75-95.

Mitko, Julia, Aspekt im Französischen. Eine semantisch-funktionelle Analyse, Tübingen, Narr, 2000.

Montague, Richard, Formal Philosophy. Selected Papers of Richard Montague, ed. Richmond H. Thomason, New Haven/London, Yale University Press, 1974.

Moravcsik, Edith A., Explaining Language Universals, in: Jae Jung Song (ed.), The Oxford Handbook of Linguistic Typology, Oxford, Oxford University Press, 2011, 69-89.

Mourelatos, Alexander P. D., Events, Processes and States, Linguistics and Philosophy 2/3 (1978), 415-434.

Natale, Silvia, Gebrauchsdeterminanten der progressiven Verbalperiphrase "stare" + gerundio, Tübingen, Narr, 2009.

Niemeier, Susanne/Dirven, René (edd.), Evidence for linguistic relativity, Amsterdam, Benjamins, 2000.

Olbertz, Hella, Verbal Periphrases in a Functional Grammar of Spanish, Berlin/New York, Mouton de Gruyter, 1998.

Oshima, David Y., Between Being Wise and Acting Wise: A Hidden Condition in Some Constructions with Propensity Adjectives, Journal of Linguistics 45 (2009), 363-393.

Pagliuca, William (ed.), Perspectives on grammaticalization, Amsterdam/Philadelphia, Benjamins, 1994.

Palmer, Frank R., Mood and Modality, Cambridge, Cambridge University Press, ${ }^{2} 2001$.

Peirsman, Yves/Geeraerts, Dirk, Metonymy as a prototypical category, Cognitive Linguistics 17/3 (2006), 269-316 (= 2006a).

Peirsman, Yves/Geeraerts, Dirk, Don't let metonymy be misunderstood: An answer to Croft, Cognitive Linguistics 17/3 (2006), 327-335 (= 2006b).

Penny, Ralph, Variation and Change in Spanish, Cambridge, Cambridge University Press, 2000.

Penny, Ralph, Gramática histórica del español, Barcelona, Ariel, 2001.

Perea, Maria-Pilar, Flexió verbal regular, in: Joan Solà et al., Gramàtica del català contemporani, 3 vol., Barcelona, Empúries, 2002, 583-646.

Pérez Saldanya, Manuel, Les categories flexives del temps i l'aspecte: una aproximació sintàctica, semàntica i morfologica, in: Amadeu Viana (ed.), Sintaxi: Teoria i Perspectives, Lleida, Pagès Editors, 1993, 197-214.

Pérez Saldanya, Manuel, Del "perfet" a l'“indefinite" (i viceversa): el nom dels temps verbals $i$ altres problemes terminològics relacionats amb les categories gramaticals del verb, in: 
Jaume Macià Guilà/Joan Solà (edd.), La terminologia lingüística en l'ensenyament secundari: propostes pràctiques, Barcelona, Graó, 2000, 91-119.

Pérez Saldanya, Manuel, Las relacions temporals i aspectuals, in: Joan Solà/Maria-Rosa Lloret/Joan Mascaró/Manuel Pérez Saldanya (edd.), Gramàtica del català contemporani, vol. 2, Barcelona, Empúries, 2002, 2567-2662.

Pérez Saldanya, Manuel, Los tiempos verbales: dificultades teóricas y terminológicas, in: Luis García Fernández/Bruno Camus Bergareche (edd.), El pretérito imperfecto, Madrid, Gredos, 2004, 194-228.

Pinker, Steven, The Language Instinct. How the Mind Creates Language, New York, William Morrow, 1994.

Pinker, Steven/Jackendoff, Ray S., The Faculty of Language: What's special about it?, Cognition 95/2 (2005), 201-236.

Piva, Cristina, L'aspetto verbale: una categoría controversa, in: Federico Albano Leoni/Rosaria Pigliaco (edd.), La grammatica: aspetti teorici e didattici, Roma, Bulzoni, 1979, 479-498.

Pollak, Wolfgang, Studien zum Verbalaspekt im Französischen, Wien, Rohrer, 1960.

Pollak, Wolfgang, Studien zum Verbalaspekt: mit besonderer Berücksichtigung des Französischen, Bern/New York, Peter Lang, 1988.

Pusch, Claus, La grammaticalisation de l'aspectualité. Remarques sur les périphrases à valeur progressive en français, Verbum. Revue de Linguistique 25/4 (2003), 495-508 (= 2003a).

Pusch, Claus, Aspectuality and Focality - Reflections on Semantics-Pragmatics Relations and Isomorphism in Romance Progressive Periphrases, in: Claus Pusch/Andreas Wesch (edd.), Verbalperiphrasen in den (ibero-)romanischen Sprachen, Hamburg, Buske, 2003, 179-192 (= 2003b).

Pusch, Claus/Wesch, Andreas (edd.), Verbalperiphrasen in den (ibero-)romanischen Sprachen, Hamburg, Buske, 2003 (= 2003a).

Pusch, Claus/Wesch, Andreas, Verbalperiphrasen zwischen Grammatik, Lexikon und Pragmatik. Zu den Beiträgen dieses Bandes, in: idd. (edd.), Verbalperiphrasen in den (ibero-)romanischen Sprachen, Hamburg, Buske, 2003, 1-10 (= 2003b).

Pustejovsky, James, The Geometry of Events, in: Carol Tenny (ed.), Studies in Generative Approaches to Aspect. Lexicon Project Working Papers 24, Cambridge, Mass., MIT Press, 1988, 19-39.

Pustejovsky, James, The Syntax of Event Structures, in: Beth Levin/Steven Pinker (edd.), Lexical and Conceptual Structure, Oxford, Blackwell, 1991, 47-81.

Pustejovsky, James, The Generative Lexicon, Cambridge, Mass., MIT Press, 1995.

Pütz, Martin/Verspoor, Marjolyn H. (edd.), Explorations in linguistic relativity, Amsterdam, Benjamins, 2000.

Quer, Josep, Subordinació i mode, in: Joan Solà et al. (edd.), Gramàtica del català contemporani, vol. 3, Barcelona, Empúries, 2002, 2799-2866.

Radden, Günter/Panther, Klaus-Uwe (edd.), Metonymy in Language and Thought, Amsterdam/ Philadelphia, Benjamins, 1999.

Raible, Wolfgang, Zur Einleitung, in: Wolfgang Raible/Helmut Stimm (edd.), Zur Semantik des Französischen, Wiesbaden, Steiner, 1983, 1-24.

Real Academia Española (RAE), Nueva grámatica de la lengua Española. Morfología, Syntaxis, Madrid, Asociación de Academias de la lengua española, 2009.

Reichenbach, Hans, Elements of Symbolic Logic, New York/London, Free Press/CollierMacMillian, 1947.

Reiff, Karl P., Grammaire raisonnée de la langue russe, 2 vol., Petersburg, 1829. 
Renzi, Lorenzo/Salvi, Giampaolo/Cardinaletti, Anna, Grande grammatica italiana di consultazione, 3 vol., Bologna, Il Mulino, ${ }^{2} 2001$.

Ridruejo, Emilio, Modo y modalidad. El modo en las subordinadas sustantivas, in: Ignacio Bosque/Violeta Demonte (edd.), Gramática descriptiva de la lengua española, vol. 2, Madrid, RAE-Espasa, 1999, 3209-3251.

Riegel, Martin/Pellat, Jean-Christophe/Rioul, René, Grammaire méthodique du français, Paris, Presses Universitaires de France, ${ }^{3} 2004$.

Roca Pons, José, Estudios Sobre Perífrasis Verbales del Español, Madrid, C.S.I.C., 1958.

Rojo, Guillermo, Temporalidad y aspecto en el verbo español, Linguística Española Actual 10, 1988, 195-216.

Rojo, Guillermo, Relaciones entre temporalidad y aspecto en el verbo español, in: Ignacio Bosque (ed.), Tiempo y aspecto en español, Madrid, Cátedra, 1990, 17-43.

Rojo, Guillermo/Veiga, Alexandre, El tiempo verbal. Los tiempos simples, in: Ignacio Bosque/ Violeta Demonte (edd.), Gramática descriptiva de la lengua española, vol. 2, Madrid, RAEEspasa, 1999, 2867-2934.

Rosch, Eleanor, Natural Categories, Cognitive Psychology 4 (1973), 328-350.

Rosch, Eleanor, Human Categorization, in: Neil Warren (ed.), Advances in Cross-Cultural Psychology, vol. 1, London, Acadamic Press, 1977, 3-49.

Rosch, Eleanor, Principles of Categorization, in: Eleanor Rosch/Barbara B. Lloyd (edd.), Cognition and Categorization, Hillsdale, NJ, Erlbaum, 1978, 27-48.

Rosch, Eleanor/Gray, Wayne D./Johnson, David M./Boyes-Braem, Penny, Basic objects in natural categories, Cognitive Psychology 8 (1976), 382-439.

Rosch, Eleanor/Mervis, Carolyn B., Family Resemblances, Cognitive Psychology 7 (1975), 573-605.

Rubin, Edgar, Visuell wahrgenommene Figuren. Studien in psychologischer Analyse, København, Gyldendalske Boghandel, 1921.

Sasse, Hans-Jürgen, Aspect and Aktionsart: A reconciliation, in: Carl Vetters/Willy Vandeweghe (edd.), Perspectives on Aspect and Aktionsart (Belgian Journal of Linguistics 6), 1991, 31-45.

Sasse, Hans-Jürgen, Aspektsemantik und Lexikonorganisation: Beobachtungen zum Cayuga (Nordirokesisch), Köln, Institut für Sprachwissenschaft, Universität zu Köln, 1997.

Sasse, Hans-Jürgen, Aspektsemantik und Lexikonorganisation im Cayuga, in: Walter Breu (ed.), Probleme der Interaktion von Lexik und Aspekt (ILA), Tübingen, Niemeyer, 2000, 193-246.

Sasse, Hans-Jürgen, Recent activity in the theory of aspect: Accomplishments, achievements, or just non-progressive state?, Linguistic Typology 6 (2002), 199-271.

Scalise, Sergio, Generative Morphology, Dordrecht, Foris, 1984.

Scalise, Sergio, Inflection and Derivation, Linguistics 26 (1988), 561-582.

Schank, Roger C./Abelson, Robert P., Scripts, plans, goals and understanding: an inquiry into human knowledge structures, Hillsdale, NJ, Erlbaum, 1977.

Schlieben-Lange, Brigitte, Okzitanische und katalanische Verbprobleme. Ein Beitrag zur funktionellen synchronischen Untersuchung des Verbalsystems der beiden Sprachen (Tempus und Aspekt), Tübingen, Niemeyer, 1971.

Schogt, Henry G., Le système verbal du français, Den Haag, Mouton, 1968.

Schøsler, Lene, Did "Aktionsart" ever "Compensate" Verbal Aspect in Old and Middle French?, in: Henk Aertsen/Robert J. Jeffers (edd.), Historical Linguistics 1989, Amsterdam, Benjamins, 1993, 429-448.

Schøsler, Lene, From Latin to Modern French: Actualization and Markedness, in: Henning Andersen (ed.), Actualization. Linguistic Change in Progress (Papers from a workshop held 
at the 14th International Conference on Historical Linguistics, Vancouver, B.C., 14 August 1999), Amsterdam/Philadelphia, Benjamins, 2001, 169-185.

Schumacher, Helmut (ed.), Verben in Feldern: Valenzwörterbuch zur Syntax und Semantik deutscher Verben, Berlin et al., De Gruyter, 1986.

Schwall, Ulrike, Aspektualität. Eine semantisch-funktionelle Kategorie, Tübingen, Narr, 1991. Schwarze, Christoph, Grammatik der italienischen Sprache, Tübingen, Niemeyer, 1988.

Schwarze, Christoph, Gli avverbi in "-mente" e la separazione tra derivazione e flessione, in: Maria Grossmann/Anna Thornton (edd.), La formazione delle parole, Roma, Bulzoni, 2005, 487-494.

Schwarze, Christoph, Grammatica della lingua italiana, Roma, Carocci, 2010.

Schwegler, Armin, Analyticity and Syntheticity: a Diachronic Perspective with special reference to Romance languages, Berkeley, California, 1990.

Serianni, Luca, Grammatica italiana: italiano comune e lingua letteraria, Torino, UTET, ${ }^{2} 1991$. Siskind, Jeffrey M., Visual Event Perception, in: Katsushi Ikeuchi/Manuela Velosa (edd.), Symbolic Visual Learning, Oxford, Oxford University Press, 1997, 225-263.

Siskind, Jeffrey M., Grounding the Lexical Semantics of Verbs in Visual Perception using Force Dynamics and Event Logic, Journal of Artificial Intelligence Research 15 (2001), 31-90.

Slobin, Dan, The crosslinguistic study of language acquisition, Hillsdale, NJ, Erlbaum, 1985. Smith, Carlota, The parameter of Aspect, Dordrecht, Kluwer, 1991.

Söll, Ludwig, Imparfait und Passé simple, Die Neueren Sprachen 14 (1965), 411-425, 461-472.

Sokol, Monica, Das Zusammenspiel der Verbalkategorien und die französischen Futura, Tübingen, Niemeyer, 1999.

Solà, Joan et al., Gramàtica del català contemporani, 3 vol., Barcelona, Empúries, 2002.

Song, Jae Jung (edd.), The Oxford Handbook of Linguistic Typology, Oxford, Oxford University Press, 2011.

Squartini, Mario, Contributo per la caratterizzazione aspettuale delle perifrasi italiane "andare" + gerundio, "stare" + gerundio, "venire" + gerundio. Uno studio diacronico, Studi e saggi linguistici 30 (1990) (supplemento a L'Italia dialettale, 80), 117-212.

Squartini, Mario, Verbal Periphrases in Romance. Aspect, Actionality and Grammaticalization, Berlin/New York, Mouton de Gruyter, 1998.

Squartini, Mario, The Internal Structure of Evidentiality in Romance, Studies in Language 25 (2001), 297-334.

Squartini, Mario, Sequence of Tenses in Old Italian (Comrie vs. Declerck), Folia Linguistica 37 (2003), 319-345.

Squartini, Mario, La compatibilidad aspectual de los predicados estativos intrínsecamente delimitados, in: Luis García Fernández/Bruno Camus Bergareche (edd.), El pretérito imperfecto, Madrid, Gredos, 2004, 317-345.

Squartini, Mario, /l verbo, in: Giampaolo Salvi/Lorenzo Renzi (edd.), Grammatica dell'italiano antico, http://ludens.elte.hu/ gps/konyv/indice.html (21.07.2005), 2005.

Stassen, Leon, The Problem of Cross-linguistic Identification, in: Jae Jung Song (ed.), The Oxford Handbook of Linguistic Typology, Oxford, Oxford University Press, 2011, 90-99.

Stechow, Arnim von, Syntax und Semantik, in: Arnim von Stechow/Dieter Wunderlich (edd.), Semantik. Ein internationales Handbuch der zeitgenössischen Forschung (Handbücher zur Sprach- und Kommunikationswissenschaft 6), Berlin et al., De Gruyter, 1991.

Stefanowitsch, Anatol/Fischer, Kerstin, Konstruktionsgrammatik II. Von der Konstruktion zur Grammatik, Tübingen, Stauffenburg, 2008. 
Stein, Achim, Semantische Repräsentation italienischer Verben. Automatische

Disambiguierung mit Konzepthierarchien, Tübingen, Niemeyer, 2005.

Streb, Michael, Die aspektuelle Verbalperiphrase ("stare"/“estar" + Gerundium) im Italienischen und Spanischen. Methodische Überlegungen zur Grammatikalisierung, Erlangen/Jena, Palm \& Enke, 2002.

Stussi, Alfredo, Imperfetto e passato remoto nella prosa volgare del Quattrocento, L'Italia Dialettale 24/1 (1960/61), 125-133.

Swart, Henriëtte de, Aspect shift and coercion, Natural Language and Linguistic Theory 16 (1998), 347-385.

Swart, Henriëtte de, Tense, Aspect and Coercion in a Cross-Linguistic Perspective, in: Miriam Butt/Tracy H. King (edd.), Proceedings of the Berkeley Formal Grammar Conference, University of California, Berkeley, Stanford, Calif., CSLI Publications, 2000.

Sweetser, Eve, From Etymology to Pragmatics. Metaphorical and Cultural Aspects of Semantic Structure, Cambridge, Cambridge University Press, 1990.

Sweetser, Eve, Compositionality and blending: semantic composition in a cognitively realistic framework, in: Theo Janssen/Gisela Redeker (edd.), Cognitive Linguistics: Foundations, Scope, and Methodology, Berlin/New York, De Gruyter, 1999, 129-162.

Swiggers, Pierre, Time and Tense: The Case of the French Verb, Studies in Language 8 (1984), 415-438.

Talmy, Leonard, Lexicalisation patterns: Semantic structure in lexical forms, in: Timothy Shopen (ed.), Language Typology and Syntactic Description, vol. 3: Grammatical Categories and the Lexicon, Cambridge, Cambridge University Press, 1985, 57-149.

Talmy, Leonard, The windowing of attention in language, in: Masayoshi Shibatani M./Sandra A. Thompson (edd.), Grammatical Constructions. Their Form and Meaning, Oxford, Clarendon, 1996, 235-287.

Talmy, Leonard, Toward a cognitive semantics, vol. 1: Concept structuring systems, vol. 2: Typology and process in concept structuring, Cambridge, Mass., MIT Press, 2000.

Talmy, Leonard, Cognitive Semantics: An overview, in: Claudia Maienborn/Klaus von Heusinger/Paul Portner (edd.), Semantics: an international handbook of natural language meaning, Berlin, Mouton de Gruyter, 2011, 622-642.

Taylor, John R., Linguistic Categorization. Prototypes in Linguistic Theory, Oxford, Clarendon, ${ }^{2} 1995,235-287$.

Taylor, John R., Cognitive Grammar, Oxford, Oxford University Press, 2002.

Tedeschi, Philip J./Zaenen, Annie, Tense and Aspect, New York et al., Academic Press, 1981.

Tekavčić, Pavao, Grammatica storica dell'italiano, 3 vol., Bologna, Il Mulino, 1972/74.

Tenny, Carol L., The aspectual interface hypothesis, Cambridge, Mass., Center for Cognitive Science, 1989.

Tenny, Carol L., Aspectual roles and the syntax-semantics interface, Dordrecht, Kluwer, 1994.

Tenny, Carol L., Events as grammatical objects: the converging perspectives of lexical semantics and syntax, Stanford, Calif., CSLI, 2000.

Thieroff, Rolf, Inherent Verb Categories and Categorizations in European Languages, in: Rolf Thieroff/Joachim Ballweg (edd.), Tense Systems in European Languages, vol. 1, Tübingen, Niemeyer, 1994, 3-45.

Thieroff, Rolf/Ballweg, Joachim (edd.), Tense Systems in European Languages, 2 vol., Tübingen, Niemeyer, 1994-1995.

Timberlake, Alan, The temporal schemata of Russian predicates, in: Michael S. Flier/Richard E. Brecht (edd.), Issues in Russian Morphosyntax, Columbus, Ohio, 1985, 35-57. 
Tió Casacuberta, Jaume, Das Tempussystem im Katalanischen und im Deutschen:

Beschreibung und Vergleich, Frankfurt a. M., Peter Lang, 1983.

Tomasello, Michael, Language is not an Instinct, Cognitive Development 10 (1995), 131-156.

Tomasello, Michael, Cognitive Linguistics, in: William Bechtel (ed.), A Companion to Cognitive Science, Oxford, Blackwell, 1998.

Tomasello, Michael, The cultural Origins of Human Cognition, Cambridge, Mass., Harvard University Press, 1999.

Tomasello, Michael, Constructing a Language: A Usage-Based Theory of Language Acquisition, Cambridge Mass., Harvard University Press, 2003.

Trabant, Jürgen, Artikulationen: historische Anthropologie der Sprache, Frankfurt a. M., Suhrkamp, 1998.

Traugott, Elizabeth C. et al. (edd.), On Conditionals, Cambridge, Cambridge University Press, 1986.

Traugott, Elizabeth C./Heine, Bernd (edd.), Approaches to grammaticalization, Amsterdam/ Philadelphia, Benjamins, 1991.

Traugott, Elizabeth C./Dasher, Richard B., Regularity in semantic change, Cambridge, Cambridge University Press, 2002.

Trips, Carola, Lexical semantics and diachronic morphology: the development of "-hood", "-dom" and "-ship" in the history of English, Tübingen, Niemeyer, 2009.

Ullmann, Stephen, Semantics. An Introduction to the Science of Meaning, Oxford, Blackwell, 1962.

Ungerer, Friedrich/Schmid, Hans-Jörg, An introduction to cognitive linguistics, London, Longman, 1997.

Vater, Heinz, Einführung in die Zeit-Linguistik, Hürth-Efferen, Gabel, 1994.

Veiga, Alexandre, Compound Tenses and Verbal System Structure: a Functional Approach From Modern Spanish, in: Elisabeth Feldbusch/Reiner Pogarell/Cornelia Wela (edd.), Neue Fragen der Linguistik: Akten des 25. Linguistischen Kolloquiums, Paderborn 1990, vol. 1: Bestand und Entwicklung, Tübingen, Niemeyer, 1991, 243-251.

Veiga, Alexandre, La no independencia funcional del aspecto en el sistema verbal español, Español Actual 57 (1992), 65-80.

Veiga, Alexandre, La forma verbal "cantaba" y la estructura modo-temporal del sistema verbal español, in: Luis García Fernández/Bruno Camus Bergareche (edd.), El pretérito imperfecto, Madrid, Gredos, 2004, 96-193.

Vendler, Zeno, Verbs and Times, Philosophical Review 66 (1957), 143-160.

Vendler, Zeno, Verbs and Times, cap. 4, in: id. (ed.), Linguistics in Philosophy, New York, Cornell University Press, 1967, 97-121.

Verkuyl, Henk J., On the Compositional Nature of the Aspects, Dordrecht, Reidel, 1972.

Verkuyl, Henk J., A Theory of Aspectuality. The Interaction between Temporal and Atemporal Structure, Cambridge, Cambridge University Press, 1993.

Verkuyl, Henk J. et al., Tense and Aspect in Sentences, in: Francis Corblin/Henriëtte de Swart (edd.), Handbook of French Semantics, Stanford, CSLI, 2004, 233-270.

Vet, Co, Temps, aspects, et adverbes de temps en français contemporain: essai de sémantique formelle, Genève, Droz, 1980.

Vet, Co, La notion de "monde possible" et le système temporel et aspectuel du français, Langages 64 (1981), 109-124.

Vet, Co, Predication, Aspect, and Negation, in: Michael Fortescue/Peter Harder/Lars Kristoffersen (edd.), Layered Structure and Reference in a Functional Perspective: Papers 
from the Functional Grammar Conference in Copenhagen 1990, Amsterdam, Benjamins, 1992, 57-71.

Vet, Co/Vetters, Carl (edd.), Tense and Aspect in Discourse, Berlin/New York, Mouton de Gruyter, 1994.

Vetters, Carl, Temps et deixis, in: id. (ed.), Le temps, de la phrase au texte: Sens \& structure, Lille, Presses Universitaires de Lille, 1993, 85-115 (= 1993a).

Vetters, Carl, Passé simple et l'imparfait: un couple mal assorti, Langue française 100 (1993), 14-30 (= 1993b).

Vetters, Carl, L'opposition passé simple-imparfait: une question d'aspect ou de structuration textuelle?, Ann Arbor Michigan, UMI International, 1995 (=1995a).

Vetters, Carl, Temps, aspect et narration, Amsterdam, Rodopi, 1995 (=1995b).

Waltereit, Richard, Metonymie und Grammatik. Kontiguitätsphänomene in der französischen Satzsemantik, Tübingen, Niemeyer, 1998.

Wandruszka, Mario, Sprachen. Vergleichbar und unvergleichlich, München, Piper, 1969.

Wandruszka, Ulrich, Frasi subordinate al congiuntivo, in: Lorenzo Renzi/Giampaolo Salvi/ Anna Cardinaletti (edd.), Grande grammatica italiana di consultazione, vol. 2, Bologna, Il Mulino, 2001, 415-481.

Weinrich, Harald, Tempus: Besprochene und erzählte Welt, München, Beck, 1964.

Werner, Edeltraud, Die Verbalperiphrase im Mittelfranzösischen. Eine semantisch-syntaktische Analyse, Frankfurt a. M. et al., Peter Lang, 1980.

Wertheimer, Max, Drei Abhandlungen zur Gestalttheorie, Erlangen, Philosophische Akademie, 1925.

Wildgen, Wolfgang, Kognitive Grammatik: klassische Paradigmen und neue Perspektiven, Berlin et al., De Gruyter, 2008.

Wittgenstein, Ludwig, Tractatus logico-philosophicus. Tagebücher 1914-1916. Philosophische Untersuchungen, in: Werkausgabe, vol. 1, ed. Joachim Schulte, Frankfurt a. M., Suhrkamp, ${ }^{2} 1995$.

Wunderlich, Dieter, An Investigation of Lexical Composition: The Case of German "be"-verbs, Linguistics 25 (1987), 283-331. 



\section{Author Index}

Agrell, Sigurd 20, 37

Anstatt, Tanja 20, 21, 57, 89

Bertinetto, Pier Marco 1, 2, 5, 11, 13, 14, 19, $20,25,26,27,28,29,30,31,34,36$, 43, 46, 50, 51, 57, 59, 60, 84, 111, 120, 174, 184, 205, 215, 216, 223, 225 , 226, 238

Blank, Andreas 4, 73, 74, 75, 78, 80, 81, 83,88

Blücher, Kolbjørn 223, 224

Böckle, Klaus 42, 205

Bondarko, Aleksandr V. 39, 40

Bühler, Karl 16

Bybee, Joan 2, 53, 57, 65, 82, 84, 87, 223, 225

Carlson, Greg N. 23, 111, 124

Cassirer, Ernst 5, 66, 67, 68

Chomsky, Noam 66

Comrie, Bernard 2, 11, 16, 17, 29, 31, 46, 108

Coseriu, Eugenio 5, 26, 33, 34, 35, 37, 50, 53, 71, 84, 95, 187, 205, 206, 207, 209, 215, 216

Croft, William 2, 4, 51, 67, 73, 74, 75, 77, 80, $88,96,104,114$

Dahl, Östen 2, 53, 58, 65, 82, 84, 87, 225

De Mauro, Tullio 65

De Miguel, Elena 2, 6, 33, 41, 45, 46, 47, $49,51,88$

Depraetere, Ilse 50, 113, 114

Detges, Ulrich 35, 53, 74, 84, 211, 222

Dietrich, Wolf 205, 206, 207, 208, 224

Dowty, David R. 21, 91, 114, 155, 158

Durante, Marcello 223, 224, 225

Ehrich, Veronika 50, 60, 85

Fillmore, Charles J. 4, 67, 72, 78, 80, 96

Gómez Torrego, Leonardo 205, 208, 212, 220

Grevisse, Maurice 13, 14, 41
Haspelmath, Martin 27, 40, 53, 54, 57, 82 , 84, 204, 205, 206, 207

Heger, Klaus 16, 40, 70

Heine, Bernd 92, 210, 211, 222, 223

Holenstein, Elmar 75, 76

Holt, Jens von 16

Hopper, Paul J. 2, 53, 82, 84, 211, 222, 223

Humboldt, Wilhelm von 5, 66

Husserl, Edmund 75, 76

Isačenko, Alexander 21, 40

Jackendoff, Ray S. 2, 66

Jakobson, Roman 104, 223, 224

Klein, Wolfgang 11, 12, 43, 56

Koch, Peter 4, 69, 70, 71, 73, 74, 75, 76, 77, $78,80,81,82,88,104,105$

Krifka, Manfred 2, 59, 91, 113, 114

Laca, Brenda 51, 187, 203, 205, 206, 219 , 220, 221

Langacker, Ronald W. 2, 53, 67, 68, 72, 73, $75,100,104$

Lee, David 78, 80, 95, 96

Lehmann, Christian 53, 84, 211, 222

Lehmann, Volkmar 20, 21, 40, 89

Maienborn, Claudia 24

Marchand, Hans 223

Maslov, Jurij S. 21, 25, 39, 46, 51

Minsky, Marvin 4, 72

Olbertz, Hella 205, 209

Pérez Saldanya, Manuel 25, 37, 51, 84

Pinker, Steven 66, 70

Pollak, Wolfgang 20, 80

Pusch, Claus 187, 205, 210, 211, 212, 221

Raible, Wolfgang 40, 75, 82, 83

Reichenbach, Hans 11, 12, 27, 108

Reiff, Karl P. 20, 80

Ә Open Access. (C) 2019 Sarah Dessì Schmid, published by De Gruyter. (cc) BY-NC-ND This work is licensed under a Creative Commons Attribution-NonCommercial-NoDerivatives 4.0 International License. https://doi.org/10.1515/9783110562088-011 
Rojo, Guillermo 1, 5, 13, 14, 26, 31, 32, 33, 46

Rosch, Eleanor 72

Sasse, Hans-Jürgen 2, 3, 9, 26, 42, 50, 51, $62,82,91,106,226$

Scalise, Sergio 54, 57

Schlieben-Lange, Brigitte 205, 206, 207

Schwarze, Christoph 42, 44, 71

Serianni, Luca 41

Smith, Carlota 2, 6, 25, 48, 49, 50, 51, 57, $60,82,85,87,110,118$

Squartini, Mario 3, 50, 51, 54, 62, 92, 205 , 207, 211, 212, 219, 221, 222, 223, 224, 225, 226, 227, 229

Talmy, Leonard 5, 67, 75, 78, 79, 80, 82, 84, $85,87,104,106$
Tomasello, Michael 65, 66, 68, 96

Trabant, Jürgen 70

Traugott, Elizabeth C. 53, 84, 222, 223

Veiga, Alexandre 1, 5, 13, 14, 26, 31, 32, 33, 46

Vendler, Zeno 2, 21, 22, 24, 25, 30, 52, 87, $89,113,152,225,226$

Verkuyl, Henk J. 2, 21, 25, 51, 53, 89, 91, 94, 113

Waltereit, Richard 53, 66, 73, 74, 83, 84, 105, 222

Weinrich, Harald 1, 11, 33

Wildgen, Wolfgang 96, 100, 101

Wittgenstein, Ludwig 5, 75, 76 